\author{
UNIVERSIDADE DE SÃO PAULO \\ ESCOLA DE ENGENHARIA DE SÃO CARLOS \\ DEPARTAMENTO DE HIDRÁULICA E SANEAMENTO
}

JOÃO PAULO GUARDABAXO SIQUEIRA

\title{
MÉTODOS DE PARTIÇÃO DE REDE DE ABASTECIMENTO DE ÁGUA: UM ESTUDO DE CASO EM PEDERNEIRAS/SP
}

VERSÃO CORRIGIDA 

JOÃO PAULO GUARDABAXO SIQUEIRA

\section{MÉTODOS DE PARTIÇÃO DE REDE DE ABASTECIMENTO DE ÁGUA: UM ESTUDO DE CASO EM PEDERNEIRAS/SP}

Dissertação apresentada à Escola de Engenharia de São Carlos, da Universidade de São Paulo, como parte dos requisitos para obtenção do título de Mestre em Ciências: Engenharia Hidráulica e Saneamento.

Orientador: Prof. Tit. Edson Wendland

VERSÃO CORRIGIDA

São Carlos

2019 
AUTORIZO A REPRODUÇÃO TOTAL OU PARCIAL DESTE TRABALHO, POR QUALQUER MEIO CONVENCIONAL OU ELETRONNICO, PARA FINS DE ESTUDO E PESQUISA, DESDE QUE CITADA A FONTE.

Ficha catalográfica elaborada pela Biblioteca Prof. Dr. Sérgio Rodrigues Fontes da EESC/USP com os dados inseridos pelo(a) autor(a).

Guardabaxo-Siqueira, João Paulo

G618m Métodos de partição de rede de abastecimento de água: um estudo de caso em Pederneiras/SP / João Paulo Guardabaxo-Siqueira; orientador Edson Wendland. São Carlos, 2019 .

Dissertação (Mestrado) - Programa de Pós-Graduação em Engenharia Hidráulica e Saneamento e Área de Concentração em Hidráulica e Saneamento -- Escola de Engenharia de São Carlos da Universidade de São Paulo, 2019 .

1. Gerenciamento de Redes de Distribuição de Água. 2. Índice de Modularidade. 3. Partição de Grafos. 4. Partição Multiníveis. I. Título.

Eduardo Graziosi Silva - CRB - 8/8907 


\section{FOLHA DE JULGAMENTO}

Candidato: Engenheiro JOÃO PAULO GUARDABAXO SIQUEIRA.

Título da dissertação: "Métodos de partição de rede de abastecimento de água: um estudo de caso em Pederneiras/SP".

Data da defesa: 17/05/2019.

\section{Comissão Julgadora:}

Prof. Titular Edson Cezar Wendland

\section{(Orientador)}

(Escola de Engenharia de São Carlos/EESC)

Prof. Dr. Edevar Luyvizotto Júnior

(Universidade Estadual de Campinas/UNICAMP)

Profa. Dra. Cali Laguna Achon

(Universidade Federal de São Carlos/UFSCar)
Resultado:

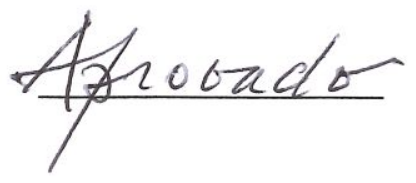

aprorado

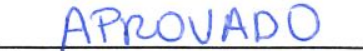

Coordenador do Programa de Pós-Graduação em Engenharia Hidráulica e Saneamento:

Prof. Dr. Eduardo Mario Mendiondo

Presidente da Comissão de Pós-Graduação:

Prof. Titular Murilo Araujo Romero 



\section{AGRADECIMENTOS}

Agradeço a Deus, a verdadeira fonte de Sabedoria, e à Virgem Maria, Sua Santíssima Mãe, por fortificar meus estudos, conduzir o seu curso e aperfeiçoar o seu fim.

Aos meus pais Jupiaci Donizeti Siqueira e Silvia de Lourdes Guardabaxo Siqueira, por todo o suporte familiar, emocional e financeiro que me proporcionaram e pelo encorajamento dos sonhos de um jovem estudante.

Aos meus irmãos, Diego Augusto Guardabaxo Siqueira e Maria Fernanda Guardabaxo Siqueira, por terem suportado a ausência física de um irmão e alegrado meus finais de semana.

Aos meus avós Diva, Paulo e Vicente, que intercederam do céu por meus intentos e às minhas avós Cida e Dirce, que sempre me apoiaram.

À minha namorada Isabela, que sempre soube me auxiliar nos momentos de desesperança, me fazendo mais feliz a cada dia ao seu lado e sendo sempre minha grande incentivadora.

Ao Prof. Dr. Edson Wendland, por todos os ensinamentos que me proporcionaram um grande amadurecimento pessoal e profissional.

Aos colegas do Laboratório de Hidráulica Computacional, Alan, Alice, Ana, Bergamo, Camila, Davi, David, Dimaghi, Érick, Gabriel, Hélio, Jamil, Jaque, Jean, Juliana, Kalyl, Lazarini, Livia, Nathy e Suave, agradeço a todos pelo grande conhecimento técnico adquirido, pelos cafés após o almoço e pelas grandes amizades que fiz.

Aos professores Fernanda, Maria, Porto e Schulz, que juntamente com o prof. Edson me inspiraram a adentrar o mundo da ciência e muito me ensinaram pessoal e profissionalmente.

Aos professores das disciplinas que cursei, por toda a preocupação quanto ao ensino e ao exemplo como docentes.

À SABESP, em especial ao Marlon da SABESP-Pederneiras e Wesley Arradi da SABESP-São Manuel, pela grande disposição e auxílio contínuo a minha pesquisa.

Aos colegas de apartamento Bixo, Clay, Edione, Lazarini e Renan, além das agregadas Ana Laura, Aninha e Rosângela, pelos vários momentos de felicidade e alegria que passamos juntos.

À todos os amigos que fiz durante meus longos anos em São Carlos, especialmente Allara, Balde, Cartaxo, Érica, Fit, Kino, Giu Loira, Giu Japa, Guti, Jin, Júlia, Magna, Massa, Pedrozo, Picos, Vivian e todos os integrantes da SEC, SACivil e Econ, por todo incentivo e inspiração que me proporcionaram e ainda proporcionam. 
À secretaria de pós-graduação do Departamento de Hidráulica e Saneamento da Escola de Engenharia de São Carlos, pela organização e preocupação com os alunos.

À CAPES pelo suporte financeiro à pesquisa.

Ao Programa de Pós-Graduação do Departamento de Hidráulica e Saneamento da Escola de Engenharia de São Carlos e à USP, pela excelência no ensino e no desenvolvimento da ciência. 


\section{RESUMO}

GUARDABAXO-SIQUEIRA, J. P. (2019). Métodos de partição de rede de abastecimento de água: um estudo de caso em Pederneiras/SP. São Carlos, 2019, 181 p. Dissertação Mestrado - Escola de Engenharia de São Carlos, Universidade de São Paulo.

Com o crescimento urbanístico e, consequentemente, das redes de abastecimento de água, o gerenciamento dessas redes torna-se cada vez mais necessário. Existem muitas formas de se realizar esse gerenciamento, sendo a mais eficaz a realização da partição da rede, dividindo-a em partes menores, chamadas de distritos, e consequentemente mais simples de serem compreendidas. Este trabalho tem por objetivo sistematizar os passos necessários para a realização de partição de uma rede de abastecimento de água, o que consistiu na construção do modelo hidráulico; na realização de um plano de amostragem; na realização da campanha de medição; na calibração do modelo; na partição da rede através de dois diferentes métodos advindo da partição de grafos: um baseado em índice de modularidade (ModulMax) e outro em partição multinível (METIS); na comparação e seleção da melhor partição através de um método proposto, que leva em consideração métricas amplamente utilizadas na literatura; e na análise dos resultados. Essa sistematização foi aplicada na rede de abastecimento de água da cidade de Pederneiras/SP, comparando os resultados das duas metodologias de partição de redes através de cinco métricas: número de tubulações que interligam diferentes distritos; número de conexões do distrito mais conectado; índice de balanço do comprimento; índice de balanço da demanda; e índice de modularidade. Os resultados apontam que para esse estudo de caso a divisão da rede em 30 partes, através do método ModulMax, é a mais adequada, gerando uma economia estimada de $8,2 \%$ de água para abastecimento. A sistematização apresentada neste estudo foi bem-sucedida para a rede de Pederneiras e pode ser considerada para a aplicação em outras redes a fim de melhorar o gerenciamento.

Palavras chave: Gerenciamento de Redes de Distribuição de Água; Índice de Modularidade; Partição de Grafos; Partição Multinível. 



\begin{abstract}
GUARDABAXO-SIQUEIRA, J. P. (2019). Partitioning methods of water supply network: a case study in Pederneiras / SP. São Carlos, 2019, 181 p. Master Dissertation - São Carlos School of Engineering, University of São Paulo.

The urban growth implicates in an augment of the water supply networks. Consequently, the good management of these networks becomes more necessary. There are many ways to perform this management and the most efficient seems to be the network partitioning. This approach simplifies the network dividing it into smaller parts called districts. The objective of this study is to systematize all the necessary steps for the water supply network partitioning. The steps of the systematization pursued the following sequence: hydraulic model construction; sampling design implementation; measurement campaign; calibration of the hydraulic model; network partitioning through two different approachs from the graphs partition (one based on modularity index, the ModulMax, and another on multilevel partitioning, METIS). After that, the study proposed a method for the comparison and selection of the best partition. This proposed method used metrics widely applied in Literature. The systematization was applied in the water supply network of Pederneiras city (São Paulo - Brazil). The results of the network partitioning were compared through five metrics: number of pipelines connecting different districts; number of connections in the most connected district; length balance index; demand balance index; and modularity index. For this case study, the results indicated that the network partitioning in 30 parts through the ModulMax method was the best one, generating an estimated saving of $8.2 \%$ of supply water. The systematization presented in this study was well succeeded in Pederneiras' water network supply and can be considered applicable for other networks in order to improve the management.
\end{abstract}

Keywords: Graph partition; Modularity Index; Multilevel partitioning; Water network supply management. 



\section{LISTA DE FIGURAS}

Figura 1 - Exemplo de divisão de um conjunto de soluções no espaço objetivo f1 e f2 em frentes Pareto utilizadas no método NSGA II

Figura 2 - Organograma do capítulo de Material e Métodos ........................................ 58

Figura 3 - Área urbana de Pederneiras (SP) e Estado de São Paulo............................ 59

Figura 4 - Rede de abastecimento de Pederneiras com diâmetros das tubulações e destaque do Setor Lacta 61

Figura 5 - Localização das VRP's e da zona alta - Setor Lacta

Figura 6 - Esquema do modelo hidráulico de Pederneiras no WaterGEMS. As cores representam as cotas topográficas

Figura 7 - Esquema topográfico do modelo Hidráulico do Setor Lacta visualizado no software WaterGEMS

Figura 8 - Curva de consumo adimensional utilizada no modelo preliminar - 24 horas

Figura 9 - Fluxograma do processo de calibração utilizado

Figura 10 - Processo realizado para a seleção da melhor partição da rede. C.I. Conjunto Inicial; C.R. Conjunto Restrito; C.F.P. Conjunto da Frente Pareto; C.C.I. Conjunto Compromisso Ideal; C.C.N. Conjunto Compromisso NADIR; C.S. Conjunto Selecionado. . 85

Figura 11 - Curva Pareto do plano de amostragem 87

Figura 12 - Localização dos pontos definidos no plano de amostragem (pontos verdes) e da instalação dos medidores de carga de pressão (pontos vermelhos) 90

Figura 13 - Local de instalação do data logger P2 para a campanha de medição do Setor Lacta 91

Figura 14 - Local de instalação do data logger P5 para a campanha de medição do Setor Lacta.

Figura 15 - Local de instalação do data logger P6 para a campanha de medição do Setor Lacta. 92

Figura 16 - Instalação do medidor de vazão na saída do reservatório Lacta 92

Figura 17 - Dados de carga de pressão dinâmica(mca) coletados durante a campanha de medição.

Figura 18 - Dados de vazão com intervalos de leitura de 1 minuto, coletados na saída do reservatório que abastece o setor Lacta durante a campanha de medição, com uma curva de média móvel utilizando um período de 60 medições. 
Figura 19 - Localização da tubulação encontrada na rede após verificação da modelagem preliminar.

Figura 20 - Nova configuração do Setor Lacta

Figura 21 - Dados médios horários dos pontos de carga de pressão medidos e da vazão de saída do reservatório que abastece o Setor Lacta. .98

Figura 22 - Nível de água no reservatório que abastece o setor Lacta 99

Figura 23 - Relação entre as cargas de pressões observadas e simuladas antes do processo de calibração

Figura 24 - Relação entre as cargas de pressões observadas e simuladas após o processo de calibração

Figura 25 - Erro absoluto entre as cargas de pressões observadas e simuladas após a calibração do Setor Lacta 104

Figura 26 - Erro relativo entre as cargas de pressões observadas e simuladas após a calibração do Setor Lacta 104

Figura 27 - Validação do modelo hidráulico do Setor Lacta - pressões observadas (pontos) e simuladas (linha) do ponto P1 106

Figura 28 - Comparação entre as pressões observadas e simuladas durante todo o período de validação

Figura 29 - Curvas adimensionais de consumo para todos os dias usados na validação da calibração do Setor Lacta 107

Figura 30 - Curva adimensional típica de consumo nos dias da semana - Setor Lacta 108

Figura 31 - Modelo hidráulico final de Pederneiras com as indicações dos setores da rede de abastecimento da cidade

Figura 32 - Índice de Modularidade das partições geradas pelos métodos ModulMax e METIS

Figura 33 - Número de tubulações entre distritos das partições geradas pelos métodos ModulMax e METIS

Figura 34 - Número de conexões do distrito mais conectado das partições geradas pelos métodos ModulMax e METIS

Figura 35 - Índice de balanço da demanda das partições geradas pelos métodos ModulMax e METIS 
Figura 36 - Índice de balanço do comprimento das partições geradas pelos métodos ModulMax e METIS

Figura 37 - Comparação das métricas dos métodos ModulMax e METIS para partições de 5, 10, 20, 30, 40, 50, 75 e 100 distritos. Todas as métricas foram normalizadas de 0 a 1 , sendo 1 o máximo valor obtido para uma partição e 0 o menor.

Figura 38 - Comprimento da tubulação do distrito mais extenso e limite imposto na seção 4.4.1

Figura 39 - Número de conexões do distrito mais conectado e limite imposto pela seção 4.4.1

Figura 40 - Demanda média máxima e limite imposto pela seção 4.4.1 117

Figura 41 - Gráficos de frequência e correlação das cinco métricas normalizadas de todas as soluções contidas no Conjunto Pareto, utilizadas para a seleção da melhor partição 119

Figura 42 - Partição da Rede de Abastecimento de Água de Perderneiras em 18 distritos, utilizando o método METIS

Figura 43 - Conjunto de soluções em cada etapa do processo realizado para a seleção da melhor partição da rede.

Figura 44 - Partição da Rede de Abastecimento de Água de Perderneiras em 30 distritos, utilizando o método ModulMax.

Figura 45 -Indicação das 42 tubulações que ligam diferentes distritos da rede de abastecimento de água de Pederneiras. 126

Figura 46 -Visualização dos distritos de uma parte da rede de abastecimento de água no município de Pederneiras antes (a) e depois (b) de realizar-se a partição. As cores significam o agrupamento por distrito, o que facilita a análise da rede por partes.

Figura 47 - Distribuição de pressões no modelo hidráulico de Pederneiras às 4:00 h antes da partição proposta e inclusão de válvulas 128

Figura 48 - Distribuição das pressões no modelo hidráulica de Pederneiras às 4:00h após a partição proposta e inclusão de válvulas

Figura 49 - Validação do modelo hidráulico do Setor Lacta - pressões observadas (pontos) e simuladas (linha) do ponto P1

Figura 50 - Validação do modelo hidráulico do Setor Lacta - pressões observadas (pontos) e simuladas (linha) do ponto P2 145 
Figura 51 - Validação do modelo hidráulico do Setor Lacta - pressões observadas (pontos) e simuladas (linha) do ponto P3

Figura 52 - Validação do modelo hidráulico do Setor Lacta - pressões observadas (pontos) e simuladas (linha) do ponto P4 146

Figura 53 - Validação do modelo hidráulico do Setor Lacta - pressões observadas (pontos) e simuladas (linha) do ponto P5

Figura 54 - Validação do modelo hidráulico do Setor Lacta - pressões observadas (pontos) e simuladas (linha) do ponto P6

Figura 55 - Validação do modelo hidráulico do Setor Lacta - pressões observadas (pontos) e simuladas (linha) do ponto P9 148

Figura 56 - Vazões referentes ao consumo total e ao vazamento durante todo o período de validação da calibração do setor Lacta 148

Figura 57 - Porcentagem do consumo total relativo a vazamentos durante todo o período de validação da calibração do setor Lacta

Figura 58 - Soluções pertencentes ao Conjunto Restrito e ao Conjunto Pareto, com indicação de suas métricas e suas métricas normalizadas

Figura 59 - Partição da rede de abastecimento de água de Pederneiras em 5 distritos, através do método METIS.

Figura 60Partição da rede de abastecimento de água de Pederneiras em 5 distritos, através do método ModulMax 161

Figura 61 - Partição da rede de abastecimento de água de Pederneiras em 10 distritos, através do método METIS. 162

Figura 62 - Partição da rede de abastecimento de água de Pederneiras em 10 distritos, através do método ModulMax

Figura 63 - Partição da rede de abastecimento de água de Pederneiras em 20 distritos, através do método METIS 164

Figura 64 - Partição da rede de abastecimento de água de Pederneiras em 20 distritos, através do método ModulMax 165

Figura 65 - Partição da rede de abastecimento de água de Pederneiras em 30 distritos, através do método METIS 166

Figura 66 - Partição da rede de abastecimento de água de Pederneiras em 30 distritos, através do método ModulMax 167 
Figura 67 - Partição da rede de abastecimento de água de Pederneiras em 40 distritos, através do método METIS

Figura 68 - Partição da rede de abastecimento de água de Pederneiras em 40 distritos, através do método ModulMax

Figura 69 - Partição da rede de abastecimento de água de Pederneiras em 50 distritos, através do método METIS 170

Figura 70 - Partição da rede de abastecimento de água de Pederneiras em 50 distritos, através do método ModulMax

Figura 71 - Partição da rede de abastecimento de água de Pederneiras em 18 distritos, através do método METIS

Figura 72 - Partição da rede de abastecimento de água de Pederneiras em 19 distritos, através do método METIS 173

Figura 73 - Partição da rede de abastecimento de água de Pederneiras em 45 distritos, através do método METIS 174

Figura 74 - Partição da rede de abastecimento de água de Pederneiras em 31 distritos, através do método ModulMax

Figura 75 - Partição da rede de abastecimento de água de Pederneiras em 36 distritos, através do método ModulMax 176

Figura 76 - Partição da rede de abastecimento de água de Pederneiras em 38 distritos, através do método ModulMax 177

Figura 77 - Partição da rede de abastecimento de água de Pederneiras em 44 distritos, através do método ModulMax

Figura 78 - Pressões na rede de abastecimento de água de Pederneiras às 13:00h após a partição proposta e inclusão de VRP's.

Figura 79 - Pressões na rede de abastecimento de água de Pederneiras às 13:00h antes da partição proposta e inclusão de VRP's. 



\section{LISTA DE TABELAS}

Tabela 1 - Número de sensores sugeridos pelo Water Research Centre 40

Tabela 2 - Número de sensores sugerido pelo American Engineering Computer Application Committee

Tabela 3 - Vantagens e desvantagens de métodos de partição de redes analisados na revisão bibliográfica. 55

Tabela 4 - Quantificação das características físicas da rede - Pederneiras 60

Tabela 5 - Quantificação das características físicas da rede - Setor Lacta. 62

Tabela 6 - Informações técnicas do transdutor de pressão e datalogger Metrolog NA100.

Tabela 7 - Métricas utilizadas para a comparação das partições 82

Tabela 8 - Pontos Ideal e NADIR de cada métrica utilizada para a seleção multicritério da melhor partição. 83

Tabela 9 - Sensibilidade dos planos de amostragem da curva Pareto e o ganho de sensibilidade e entropia pela inclusão de um sensor 88

Tabela 10 - Características das tubulações fictícias utilizadas para calibrar as perdas de carga localizadas dos acessórios da rede 100

Tabela 11 - Valor iniciais das variáveis do modelo a serem calibradas 100

Tabela 12 - Resultados das iterações do processo de calibração do setor Lacta......... 101

Tabela 13 - Métricas calculadas para o modelo antes e após o processo de calibração 101

Tabela 14 - Métricas calculadas para o modelo para o período de calibração e validação 106

Tabela 15 - Informações dos setores da rede de abastecimento de água de Pederneiras 110

Tabela 16 - Métricas da partição inicial da rede de abastecimento de água de Pederneiras 110

Tabela 17 - Soluções com menor distância euclidiana da origem dos gráficos que relacionam as métricas duas a duas. Na diagonal da tabela, estão as soluções que possuem o menor valor da métrica

Tabela 18 - Indicadores da partição da rede de abastecimento de água de Pederneiras em 30 distritos através do método ModulMax 
Tabela 19 - Indicação dos status de todas as tubulações que ligam os distritos, indicando também em quais distritos foram incluídas VRP's. A cor da segunda coluna se refere às cores

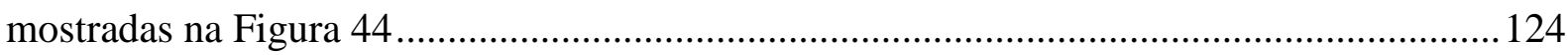

Tabela 20 - Resultados das partições dos métodos ModulMax e METIS, com os valores das métricas utilizadas para avaliar as soluções encontradas. 151 


\section{LISTA DE ABREVIATURAS E SIGLAS}

ACO - Ant Colony Optimization

CCI - Conjunto Compromisso Ideal

$\mathrm{CCN}$ - Conjunto Compromisso NADIR

CDTB - Community Detection Toolbox

CFP - Conjunto da Frente Pareto

$\mathrm{CI}$ - Conjunto Inicial

CR - Conjunto Restrito

CS - Conjunto Selecionado

ECAC - American Engineering Computer Application Committee

EESC - Escola de Engenharia de São Carlos

HGP - Hybrid Graph Partitioning

IWA: Associação Internacional de Água

MAS - Multi Agent Simulation

MOGA - Multiobjective Genetic Algorithm

NBR: Norma Brasileira

NSGA - Non-dominated Sorting Genetic Algorithm

NSGA II - Non-dominated Sorting Genetic Algorithm II

PVC - Policloreto de Vinila

SABESP - Companhia de Saneamento Básico do Estado de São Paulo

SHS - Departamento de Engenharia Hidráulica e Saneamento

SNIS -- Sistema Nacional de Informações sobre Saneamento

SP - Estado de São Paulo

SPEA - Stregh Pareto Evolutinary Algorithm

SWANP - Smart Water Network Partitioning

USP - Universidade de São Paulo

VEGA - Vector Evaluated Genetic Algorithm

VRP - Válvula Redutora de Pressão

WRC - Water Research Centre

WSC - Water Spectral Clusters 



\section{LISTA DE SÍMBOLOS}

$\widetilde{E A}-$ erro absoluto mediano

$\overline{E A}$ - Erro Absoluto médio

$\widetilde{E R}$ - erro relativo mediano

$\overline{E R}$ - Erro relativo médio

A - matriz de adjacência de um grafo

C - Coeficiente de rugosidade de Hazen-Williams

$\mathrm{c}$ - coeficiente de vazamento

CA - Critério de avaliação

$\mathrm{C}_{\mathrm{ED}}$ - Condutância das tubulações entre distritos

D - Diâmetro da tubulação

Dh - Diâmetro Hidráulico

f - fator de atrito de Darcy-Weisbach

Fcc - p-distância entre o ponto ideal e o ponto correspondente aos critérios de avaliação

Fnadir - p-distância entre o ponto NADIR e o ponto correspondente aos critérios de avaliação

FO - Função Objetivo

$\mathrm{g}$ - gravidade

$\mathrm{g}_{\mathrm{v}}$ - ganho de Kernighan-Lin

H - Carga hidráulica

$\mathrm{I}_{\mathrm{B}}$ - Índice de balanço

$\mathrm{I}_{\mathrm{B}}{ }^{\mathrm{C}}$ - Índice de balanço do comprimento

$\mathrm{I}_{\mathrm{B}}{ }^{\mathrm{D}}$ - índice de balando da demanda

Ideal - Ponto ideal

IQ - Índice de modularidade

$\mathrm{K}$ - Coeficiente de perda localizada

L - Comprimento de tubulação

$\mathrm{L}_{\mathrm{e}}$ - comprimento da tubulação fictícia

$\mathrm{m}$ - número de arestas de um grafo

$\mathrm{M}_{\text {con }}$ - Matriz de sensibilidade quanto ao consumo

$M_{\text {dem }}$ - Matriz de sensibilidade quanto à demanda

$\mathrm{M}_{\text {rug }}$ - Matriz de sensibilidade quanto à rugosidade

MSE - Erro médio quadrático

$\mathrm{M}_{\mathrm{vaz}}$ - Matriz de sensibilidade quanto ao vazamento 
NADIR - Ponto NADIR

$\mathrm{N}_{\mathrm{FEC}}$ - Número de tubulações ligando distritos

$\mathrm{N}_{1}$ - Número de tubulações na rede de abastecimento de água

$\mathrm{N}_{\mathrm{n}}$ - Número de nós na rede de abastecimento de água

$\mathrm{N}_{\mathrm{P}}$ - Número de conexões do distrito mais conectado

$\mathrm{p}$ - carga de pressão nodal

Pr - Pressão hidrostática

$\mathrm{Q}$ - demanda nodal

q - vazão na tubulação

$\mathrm{R}_{\mathrm{ED}}$ - Resistência hidráulica das tubulações entre distritos

Rey - Número de Reynolds

RICE - Recorrência da tubulação entre distritos

$\mathrm{v}$ - velocidade do fluido

$\mathrm{W}-$ pesos

$\mathrm{X}$ - Conjunto de variáveis de decisão

$\mathrm{z}$ - carga de posição

$\alpha$ - expoente de vazamento

$\gamma-$ peso específico do fluído

$\delta$ - delta de Kronecker

$\Delta H$ - Perda de Carga

$\Delta \mathrm{IQ}$ - variação do índice de modularidade

$\varepsilon$ - rugosidade absoluta da tubulação

$\mu$ - viscosidade dinâmica do fluído

$\rho$ - massa específica do fluído 


\section{SUMÁRIO}

1. INTRODUÇÃ

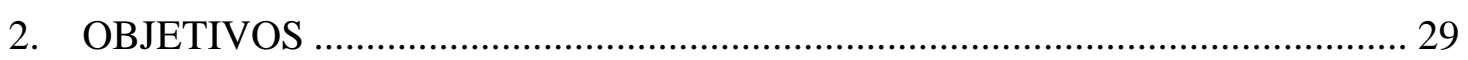

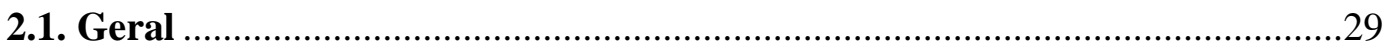

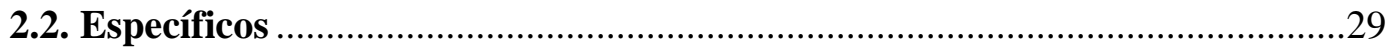

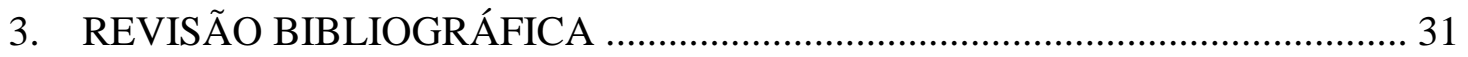

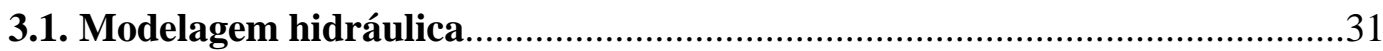

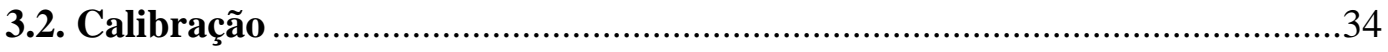

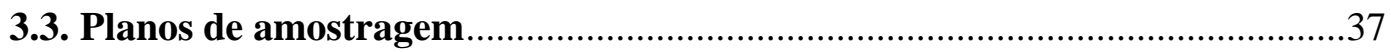

3.3.1. Quantidade de pontos de monitoramento …............................................39

3.4. Técnicas de otimização multiobjetivo de algoritmos evolucionários .............41

3.5. Partição de redes de abastecimento de água ................................................45

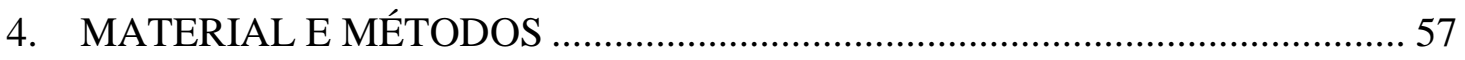

4.1. Caracterização do estudo de caso: Pederneiras - SP .....................................59

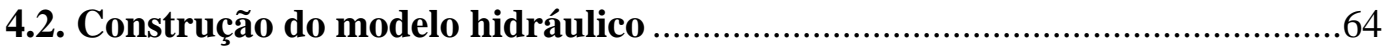

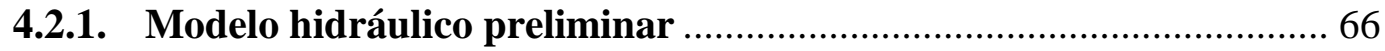

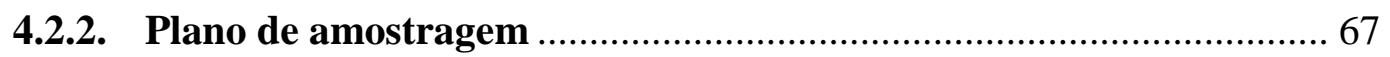

4.2.3. Campanha de medição ............................................................. 73

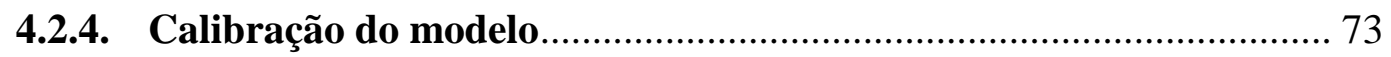

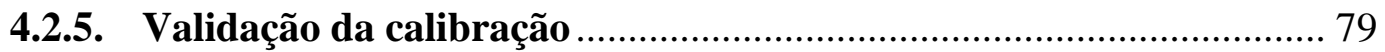

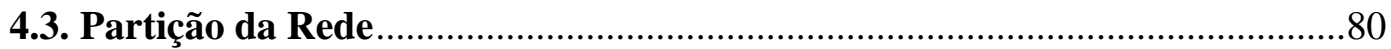

4.3.1. Características topológicas da rede de abastecimento de água......... 80

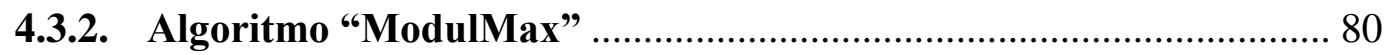

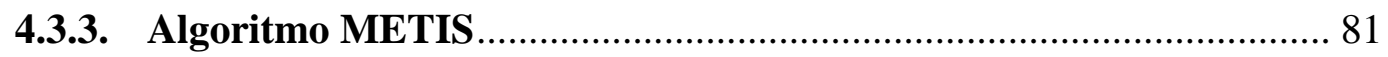

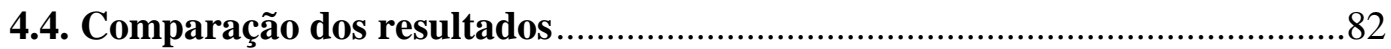


4.5. Determinação do status das tubulações.

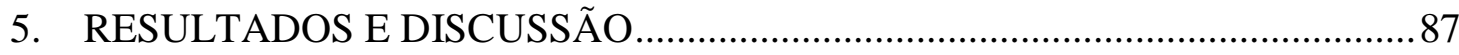

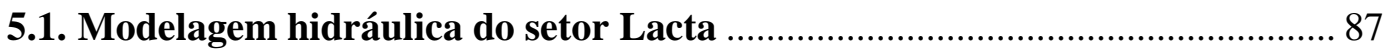

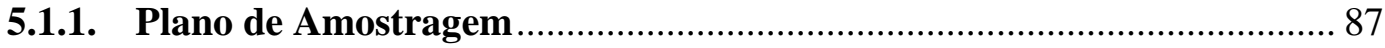

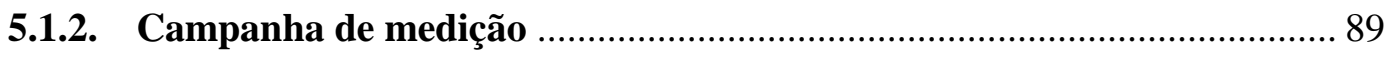

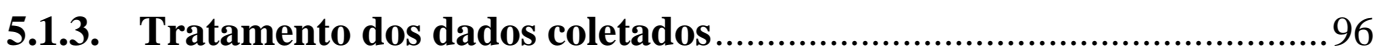

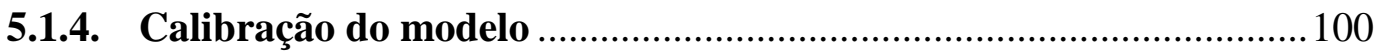

5.2. Construção do modelo hidráulico final de Pederneiras ……....................... 108

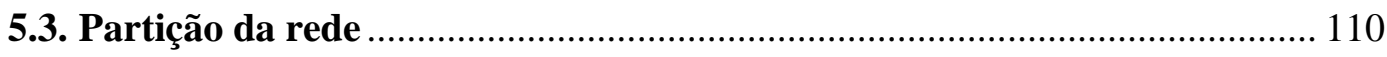

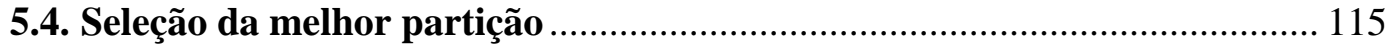

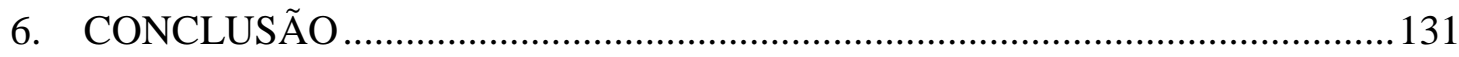

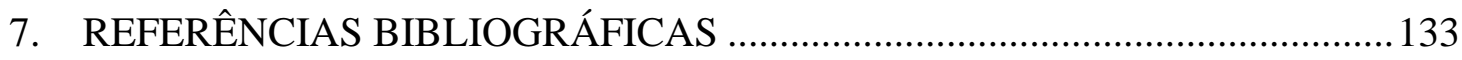




\section{INTRODUÇÃO}

No Brasil, o alto crescimento populacional urbano das últimas décadas trouxe, de maneira geral, uma expansão desordenada nos municípios (BILAC; ALVES, 2015). Esse crescimento fez com que as redes de abastecimento de água que atendem aos municípios crescessem também de forma desordenada. Criaram-se, então, sistemas grandes e mal gerenciados, os quais contribuem para os altos índices de perdas de água. O levantamento realizado pelo Sistema Nacional de Informações sobre Saneamento (SNIS) mostrou que, em 2017, 38,3 \% da água tratada foi perdida na rede de distribuição no Brasil (BRASIL, 2019). Uma das metas definidas pelo Plano Nacional de Saneamento Básico (BRASIL, 2013) estipula que o índice de perda de água na distribuição deva cair gradativamente até chegar a $31 \%$ em 2033.

O controle efetivo de perdas pode ser feito por meio de quatro atividades complementares (LAMBERT; HIRNER, 2000): através do gerenciamento de pressão, buscando minimizar as altas pressões no sistema; pelo controle ativo de vazamentos; pela velocidade e qualidade dos reparos; e por meio do gerenciamento da infraestrutura, substituindo trechos da rede como forma de prevenção. Ainda segundo Lambert e Hirner (2000), dessas quatro atividades, o gerenciamento de pressão é o mais difícil de se obter, pois é necessário que se tenha um bom conhecimento sobre a infraestrutura e funcionamento do sistema de abastecimento.

A divisão da rede de abastecimento de água em distritos pitométricos isoláveis é considerada uma maneira eficiente de melhorar o gerenciamento e reduzir as perdas de água (FARLEY, 2001). Assim, a divisão da rede em distritos pitométricos, chamada neste trabalho de partição da rede, é um processo necessário e extremamente útil para as companhias de abastecimento de água.

A NBR 12218 (2017) estabelece que os sistemas de abastecimento de água sejam divididos em distritos pitométricos e que sejam alimentados pelo menor número de tubulações possível. Também, que esses distritos contenham uma extensão de tubulação máxima de 25 km, que não seja necessário fechar mais do que 20 válvulas para isolá-lo dos demais e que o número de economias por distrito seja inferior a 5000. Essa divisão, no entanto, não é simples, uma vez que depende do tamanho da rede e das informações topológicas e hidráulicas da mesma.

Atualmente, a maioria das partições de rede é feita manualmente, observando apenas características topológicas da rede. No entanto, muitos estudos estão sendo feitos para tornar 
este processo mais eficiente através da automatização da partição (DI NARDO et al., 2018). Diante do exposto, o presente trabalho é uma avaliação sobre os passos fundamentais para a setorização de um sistema de abastecimento de água, que parte desde a aquisição de dados físicos da rede, passando pelo processo de calibração do modelo hidráulico construído e chegando à proposição da partição da rede em distritos gerenciáveis. Para o desenvolvimento do projeto foi selecionada a rede de abastecimento de água do município de Pederneiras/SP como estudo de caso. 


\section{OBJETIVOS}

\subsection{Geral}

Sistematizar o procedimento necessário para a realização de uma partição automatizada de redes de abastecimento de água e comparar duas diferentes técnicas utilizando métodos computacionais para a definição dos distritos, propondo uma metodologia para selecionar uma das soluções encontradas.

\subsection{Específicos}

- Coletar os dados necessários para a realização do processo de calibração do modelo hidráulico da rede de abastecimento de água de um setor de Pederneiras/SP.

- Modelar e calibrar computacionalmente a rede de abastecimento de água do município de Pederneiras/SP para permitir a utilização do algoritmo de partição de rede.

- Particionar a rede supracitada utilizando os métodos de Newman (NEWMAN, 2004) e METIS (KARYPIS; KUMAR, 2013), ambos advindos da teoria de grafos.

- Comparar os resultados de partição através de métricas propostas na Literatura.

- Propor uma metodologia para selecionar uma das soluções encontradas. 


\section{REVISÃO BIBLIOGRÁFICA}

\subsection{Modelagem hidráulica}

Modelos hidráulicos são amplamente utilizados para análise, projeto, operação e manutenção de redes de abastecimento de água (SAVIC; KAPELAN; JONKERGOUW, 2009). Esses modelos têm a função de simular o comportamento hidráulico para a determinação de cargas hidráulicas em nós e vazões em tubulações de uma rede. As equações que governam esses modelos são as equações de conservação de massa e de energia (KAPELAN; SAVIC; WALTERS, 2005a):

$$
\begin{gathered}
\sum_{m=1}^{N i} q_{m}-Q_{d, i}=0 \quad\left(i=1, \ldots, N_{n}\right) \\
H_{k, m}-H_{k, j}-\Delta H_{k}=0 \quad\left(k=1, \ldots, N_{l}\right)
\end{gathered}
$$

sendo $q_{m}$, as vazões desconhecidas de todos os $N_{i}$ tubos conectados no nó $i\left(\mathrm{~m}^{3} / \mathrm{s}\right) ; Q_{d, i}$, a demanda conhecida no nó $i\left(\mathrm{~m}^{3} / \mathrm{s}\right) ; H_{k, m}$, a carga hidráulica desconhecida do nó a montante do tubo $\mathrm{j}(\mathrm{m}) ; H_{k, j}$, a carga hidráulica desconhecida do nó a jusante do tubo $\mathrm{j}(\mathrm{m}) ; \Delta H_{k}$, a diferença entre a perda de carga total do tubo $k$ e a energia fornecida pela bomba no trecho $(\mathrm{m}) ; N_{l}$, o número de tubos da rede; e $N_{n}$, o número de nós da rede.

A carga de hidráulica em um nó pode ser calculada através de equação ( 3 ):

$$
H_{i}= \pm \frac{p r}{\gamma}+z \pm \frac{v^{2}}{2 g}
$$

sendo $H_{i}$ a carga hidráulica no nó i $(\mathrm{m}) ; p r$ a pressão hidrostática no ponto i $(\mathrm{Pa}) ; \gamma$ é o peso específico do fluído, no caso, água $\left(\mathrm{N} / \mathrm{m}^{3}\right)$; z é a carga de posição $(\mathrm{m})$; v é a velocidade do fluído $(\mathrm{m} / \mathrm{s}) ;$ g é a gravidade $\left(\mathrm{m} / \mathrm{s}^{2}\right) ; \mathrm{pr} / \gamma$ é a carga de pressão $(\mathrm{m}) ; \mathrm{v}^{2} / 2 \mathrm{~g}$ é a carga cinética $(\mathrm{m})$.

Pelo modelo descrito acima, percebe-se que as demandas e as pressões são incluídas somente nos nós da rede, enquanto as perdas de carga e as vazões são características pertencentes somente às tubulações.

A perda de carga, $\Delta \mathrm{H}$, pode ser calculada de diversas formas. As mais usuais em redes de abastecimento de água, e utilizadas neste trabalho, são as equações de Hazen-Williams e a de Darcy-Weisbach (também chamada de fórmula universal da perda de carga). A equação de Hazen-Willians é uma fórmula empírica cuja expressão é (PORTO, 2006): 


$$
\Delta H=10,65 * L * \frac{q^{1,85}}{C^{1,85} * D^{4,87}}
$$

sendo L o comprimento da tubulação $(\mathrm{m})$; Q a vazão na tubulação $\left(\mathrm{m}^{3} / \mathrm{s}\right)$; D o diâmetro da tubulação (m); e C o coeficiente de rugosidade, dependente da natureza e do estado das paredes da tubulação $\left(\mathrm{m}^{0,367} / \mathrm{s}\right)$.

A fórmula universal de perda de carga, por sua vez, pode ser expressa como (PORTO, 2006):

$$
\Delta H=f * \frac{L}{D} * \frac{v^{2}}{2 g}
$$

sendo L o comprimento da tubulação (m); D diâmetro da tubulação (m); V a velocidade do fluido $(\mathrm{m} / \mathrm{s})$; g a gravidade $\left(\mathrm{m} / \mathrm{s}^{2}\right)$; f o fator de atrito (adimensional).

O fator de atrito f é calculado em função do Número de Reynolds do escoamento, da rugosidade absoluta ( $\mathrm{mm}$ ) e do diâmetro da tubulação (m). O número de Reynolds é um número adimensional utilizado para classificar o escoamento de um fluido sobre uma superfície, e é calculado como (REYNOLDS, 1883):

$$
\operatorname{Rey}=\frac{\rho * v * D h}{\mu}
$$

sendo Rey o número de Reynolds; $\rho$ a massa específica do fluido $\left(\mathrm{kg} / \mathrm{m}^{3}\right)$; Dh o diâmetro hidráulico da tubulação $(\mathrm{m}) ; \mu$ a viscosidade dinâmica do fluido ( $\left.\mathrm{Pa}^{*} \mathrm{~s}\right)$.

Existem muitas formas de se estimar o valor do fator de atrito, sendo a mais geral a equação proposta por Swamee (1993):

$$
f=\left\{\left(\frac{64}{\text { Rey }}\right)^{8}+9,5 *\left[\ln \left(\frac{\varepsilon}{3,7 * D}+\frac{5,74}{R e y^{0,9}}\right)-\left(\frac{2500}{\text { Rey }}\right)^{6}\right]^{-16}\right\}^{0,125}
$$

sendo f o fator de atrito (adimensional); Rey o Número de Reynolds (adimensional); $\varepsilon$ a rugosidade absoluta da tubulação (m); D o diâmetro da tubulação (m).

Devido à não linearidade da equação ( 2 ) (uma vez que o cálculo da perda de carga não é linear), esses problemas são resolvidos diretamente somente em casos específicos. Na maioria dos casos, é necessário empregar um método de solução aproximada, como por exemplo: Gradiente Local, Newton-Raphson, Linearização, Minimização Numérica e Métodos Híbridos 
(FORMIGA; CHAUDHRY, 2008). Cada um desses métodos possui suas vantagens e desvantagens. Segundo Abraham e Stoianov (2015), o método mais utilizado atualmente é o método do Gradiente (TODINI; PILATI, 1988), o qual se baseia na junção dos métodos de Minimização Numérica e de Newton-Raphson. Esse método é usado na maior parte dos programas de simulação hidráulica disponíveis atualmente, como EPANET e WaterGEMS (REGO, 2007).

O método do Gradiente, assim como todos outros métodos, tem suas limitações. A principal desvantagem desse método é que ele supõe que todas as cargas hidráulicas são positivas, ou seja, que todas as demandas são abastecidas (TANYIMBOH; TAHAR; TEMPLEMAN, 2003).

Existem modelos hidráulicos dirigidos pela demanda e dirigidos pela pressão. Aqueles dirigidos pela demanda supõem que as demandas dos nós da rede são conhecidas, assim como seu padrão de consumo. Nesse tipo de abordagem, as vazões e as cargas hidráulicas são as variáveis de saída do modelo. O programa de computador EPANET (ROSSMAN, 2000) faz uso do modelo dirigido pela demanda. Já na abordagem dos modelos dirigidos pela pressão, o consumo nodal da rede depende da carga de pressão dos nós. Esse tipo de modelo é mais interessante quando deseja-se simular um vazamento no modelo (SOARES, 2003).

Ainda que o EPANET utilize o modelo dirigido pela demanda, há como simular um vazamento nesse programa através da inclusão de um elemento chamado aspersor. Este elemento simula uma demanda no nó, que varia de acordo com a carga de pressão no ponto. A equação que define a demanda devido ao aspersor é:

$$
Q_{i}^{h}=c *\left(p_{i}^{h}\right)^{\alpha}
$$

sendo $Q^{h}{ }_{i}(L / s)$ a demanda no instante $h$ gerada no nó $i$ pela imposição deste aspersor; $c$ o coeficiente de vazamento $\left(L /\left(s^{*} m^{\alpha}\right)\right) ; p(m c a)$, a carga de pressão no nó $i$ no instante $h$; e $\alpha$, o expoente de vazamento.

Estudos experimentais realizados por Greyvenstein e Van Zyl (2007) concluem que o valor de $\alpha$ varia em função do material da tubulação e das características da fissura que gera o vazamento. Em tubulações de PVC, os valores dessa variável variam de 0,40 a 1,85. Jowitt e Xu (1990) e Vairavamoorthy e Lumbers (1998) sugerem $\alpha=1,18$ para redes de abastecimento de água. 
Em outro estudo, Germanopoulos (1985) define que o coeficiente de vazamento $c$ pode variar consideravelmente em função das características da rede, como material, comprimento, diâmetro e idade das tubulações. A ordem de grandeza desse parâmetro, porém, é cerca de $c=$ $1 * 10^{-4} L /\left(s * m^{\alpha}\right)$, quando o dado de entrada da carga de pressão é dado em m.c.a. e o consumo é dado em L/s. No entanto, os mais diversos valores são utilizados na Literatura (GAMBOA MEDINA, 2017).

\subsection{Calibração}

Modelos hidráulicos são amplamente utilizados para o gerenciamento de redes de distribuição de água (HUTTON et al., 2014). Devido à existência de incertezas nos parâmetros do modelo, geralmente existe uma diferença entre a resposta do modelo hidráulico e o comportamento real da rede. Portanto, esses modelos devem ser calibrados antes de serem utilizados (ORMSBEE, L. AND WOOD, 1986; SAVIC; KAPELAN; JONKERGOUW, 2009; SHAMIR; HOWARD, 1968; WALSKI, 1983, 1986).

O processo de calibração tem por objetivo determinar vários parâmetros de entrada que, quando incluídos no modelo hidráulico, resultam em valores semelhantes entre os valores de pressões e vazões medidos em campo e os simulados (SHAMIR; HOWARD, 1968). Esse processo requer um longo trabalho de análise e experiência técnica, além de envolver um grande número de parâmetros do modelo (rugosidade da tubulação, coeficiente de perda de carga localizada, demanda nodal, cota de água no reservatório, características da bomba, entre outros) utilizando poucos dados observados para comparação (GAO, 2017).

Gao (2017) classifica os métodos de calibração em quatro categorias: métodos de tentativa e erro; métodos de simulação ou explícitos; métodos de otimização ou implícitos; e métodos utilizando a abordagem de mínimos quadrados ponderados.

Os métodos de tentativa e erro (BHAVE, 1988; RAHAL et al., 1980) calibram os parâmetros através de muitas tentativas até que o modelador fique satisfeito com os resultados. Embora o método consuma muito tempo e dependa fortemente da experiência dos modeladores e de um bom conhecimento prévio da rede, esta abordagem pode guiar a modelagem para bons resultados.

Os métodos de simulação ou explícitos (ORMSBEE e WOOD, 1986) estimam os parâmetros a serem calibrados resolvendo equações hidráulicas não lineares. Esses métodos requerem um número de dados medidos igual ao de parâmetros desconhecidos. 
Os métodos de otimização ou implícitos (ALVISI; FRANCHINI, 2010; KAPELAN; SAVIC; WALTERS, 2007; KOPPEL; VASSILJEV, 2009; LANSEY et al., 2001; SOARES et al., 2003) utilizam algoritmos de otimização, como: Método Simplex (NELDER; MEAD, 1965); Algoritmos Genéticos (GOLDBERG, 1989); Técnicas de Enxame (EBERHART; KENNEDY, 1995); Técnica de Colônia de Formigas (DORIGO; MANIEZZO; COLORNI, 1996); entre outros. Esses métodos são utilizados para resolver um problema indeterminado e são capazes de estimar os parâmetros a serem calibrados mesmo com um número de dados medidos menor que o número de incógnitas.

Os métodos de mínimos quadrados ponderados (DATTA; SRIDHARAN, 1994), por sua vez, utilizam a correlação entre os parâmetros iniciais, sendo estes calculados através da resolução de equações não lineares adicionais construídas usando medidas de carga de pressão e vazão. Esses métodos requerem que o número de dados medidos seja muito maior que o número de incógnitas a serem calibradas no sistema.

Nos últimos anos, uma atenção maior tem sido dada aos métodos implícitos (FIORINI MOROSINI et al., 2014), sendo que diferentes modelos e aplicações desse método foram propostos.

Righetto (2001) propôs um método de calibração para ajustar os coeficientes de rugosidade e os diâmetros das tubulações utilizando algoritmo genético como otimizador. Os resultados encontrados pelo autor foram satisfatórios, no entanto a rede utilizada para a calibração era composta por apenas 17 nós e 25 tubos.

Soares (2003) propôs a calibração de redes de abastecimento de água considerando vazamentos e demandas dirigidas pela pressão. Em seu trabalho, ele utilizou o método híbrido de dois passos para a calibração, que consiste em aplicar um algoritmo genético durante um número pré-definido de gerações, e depois utilizou o método Simplex (NELDER; MEAD, 1965) para o refinamento da solução. Esta abordagem tem como objetivo reduzir o tempo computacional e refinar os resultados obtidos.

Já Dini e Tabesh (2014) propuseram um algoritmo para calibrar coeficientes de rugosidade e o padrão de demanda de uma rede de abastecimento de água utilizando o método de Colônia de Formigas “Ant Colony Optimization - ACO”. A metodologia foi testada em uma rede teórica e em uma rede real. Segundo os autores, os resultados mostram que esta abordagem é capaz de calibrar as variáveis de decisão com alta precisão.

Martínez-Solano, Iglesias-Rey e Arce (2017) propuseram uma metodologia que calibra simultaneamente vazamentos, demanda e perda de carga. A metodologia é aplicada em modelos que possuem demanda dirigida pela vazão e demanda dirigida pela pressão simultaneamente, 
sendo a primeira parcela referente ao consumo e a segunda referente aos vazamentos da rede. Para simular os vazamentos, foi utilizada a abordagem proposta por Germanopoulos (1985). O processo de calibração foi dividido em três etapas:

a) Calcula-se o coeficiente de vazamento a fim de satisfazer o balanço hídrico do sistema.

b) Calcula-se a curva de demanda dos pontos.

c) Calibra-se o modelo para encontrar os coeficientes de rugosidade das tubulações.

Os autores utilizaram a metodologia para calibrar três distritos da rede de abastecimento de água de Guayaquil (Equador). Eles avaliaram que os resultados foram satisfatórios e que o processo de calibração mostrou-se rápido e eficiente.

Existem também alguns programas de simulação hidráulica que possuem um calibrador acoplado (WALSKI; WU; HARTELL, 2004). Dentre eles existe o Darwin Calibrator (WU et al., 2002), implementado no WaterGEMS. Esse calibrador utiliza algoritmos genéticos para determinar a rugosidade das tubulações, as demandas nodais e o status das válvulas (aberta ou fechada). A grande vantagem desse programa é a interface amigável. Como ele encontra-se acoplado a um programa de simulação hidráulica, seu uso torna-se mais simples e rápido.

Independentemente do método de otimização utilizado, a função objetivo do problema de otimização geralmente consiste em minimizar os desvios entre os valores de carga de pressão e vazão simulados e observados, segundo a equação ( 9 ) (ABE, 2014):

$$
\operatorname{Min} F O=\sum_{t=1}^{T}\left[\sum_{j=1}^{n_{t}^{P}} \frac{\left(p_{t, j}-p_{t, j}^{*}\right)^{2}}{\left(\sum_{i=1}^{n_{t}^{p}} \frac{p_{t, i}^{*}}{n_{t}^{p}}\right)^{2}}+\sum_{k=1}^{n_{t}^{Q}} \frac{\left(q_{t, k}-q\right)^{2}}{\left(\sum_{w=1}^{n_{t}^{q}} \frac{q_{t, w}^{*}}{n_{t}^{q}}\right)^{2}}\right]
$$

sendo T o número de padrões de sistema observados para o qual se dispõem de dados, $n_{t}^{p}$ e $n_{t}^{q}$ o número de observações feitas no padrão $\mathrm{t}$ para carga de pressão e vazão, respectivamente, $\mathrm{p}$ as cargas de pressão simuladas, $\mathrm{p}^{*}$ as cargas de pressão observadas, q as vazões simuladas e $\mathrm{q}^{*}$ as vazões observadas. O Darwin Calibrator, no entanto, utiliza a seguinte função objetivo para a calibração (APAYDIN, 2013):

$$
\operatorname{Min} F O=\frac{\sum_{j=1}^{n^{P}} w_{n h}\left(\frac{p_{j}-p_{j}^{*}}{p_{p p f}}\right)^{2}+\sum_{k=1}^{n^{Q}} w_{n f}\left(\frac{q_{k}-q_{k}^{*}}{q_{p p f}}\right)^{2}}{n^{P}+n^{Q}}
$$


sendo $p_{\text {ppf }}$ um fator de carga de pressão por ponto de aptidão, $q_{p p f} \mathrm{o}$ fator de vazão por ponto de aptidão, $w_{n h}$ e $w_{n f}$ os pesos associados às pressões e vazões, respectivamente. Os fatores de pressão e vazão são utilizados para adimensionalizar os erros quadráticos da carga de pressão e vazão, respectivamente, enquanto os pesos têm a função de aumentar a importância de um dos elementos na calibração. Por padrão, no Darwin Calibrator, $\mathrm{w}_{\mathrm{nh}} \mathrm{e} \mathrm{w}_{\mathrm{nf}}$ são iguais a 1 e ppf é igual a 0,30 m, enquanto qpp é igual a 0,63 L/s. Segundo WaterGEMS (2009), estes valores fornecem uma boa precisão para a calibração. Neste trabalho, o Darwin Calibrator foi utilizado para o processo de calibração, utilizando a equação ( 6 ) como função objetivo.

\subsection{Planos de amostragem}

Para a calibração de uma rede de abastecimento de água é necessário coletar dados de carga de pressão e vazão em alguns pontos estratégicos da rede (DE SCHAETZEN, 2000). A escolha dos locais para a medição desses dados, chamada de "Plano de Amostragem", é de suma importância para que a calibração ocorra de forma satisfatória (KAPELAN; SAVIC; WALTERS, 2005b).

Segundo Kapelan, Savic e Walters (2003) um plano de amostragem pode ter a função de determinar "(i) quais variáveis de estado devem ser observadas para calibração (carga de pressão, vazão, demanda nodal, etc); (ii) onde devem ser coletados esses dados; (iii) quando observá-los (duração e frequência); e (iv) sob quais condições (status de bombas ou válvulas, etc)". Usualmente as variáveis de estado observadas são carga de pressão e vazão, por serem mais simples de coletar. A duração e a frequência das observações dependem do aparelho utilizado e as condições do sistema devem ser conhecidas para a criação do modelo. Portanto, um plano de amostragem deve ter a função principal de estipular a localização das observações a serem realizadas.

Uma das primeiras sugestões sobre a localização destes aparelhos foi feita por Walski (1983). Foi sugerido que as observações de carga de pressão fossem feitas em pontos em que a demanda fosse mais alta, preferencialmente nas tubulações de maior diâmetro e longe dos reservatórios.

Yu e Powell (1994) formularam um problema de otimização multiobjetivo que busca minimizar os custos envolvidos e maximizar a estimativa da precisão dos dados coletados. $\mathrm{O}$ método utiliza uma análise da matriz de covariância das variáveis de estado e uma árvore de decisão foi desenvolvida para selecionar os melhores pontos para estimativa do estado da rede de distribuição de água. 
De Schaetzen, Walters e Savic (2000) compararam 3 diferentes técnicas de planos de amostragem para selecionar pontos de medição de carga de pressão visando calibrar coeficientes de rugosidade das tubulações. Os dois primeiros métodos utilizam o algoritmo do menor caminho. Em cada iteração, calcula-se a distância de todos os nós até o reservatório mais próximo. Em seguida, seleciona-se o nó que tenha a maior distância para ser um nó de monitoramento. No método 1, adiciona-se uma tubulação de comprimento nulo do nó monitorado até o reservatório mais próximo e realiza-se uma nova iteração. Já o método 2 anula o comprimento de todas as tubulações que pertencem ao caminho entre o nó monitorado e o reservatório mais próximo e então passa-se para a próxima iteração. O método 3 proposto nesse artigo identifica o melhor conjunto de pontos de monitoramento através da maximização da função de sensibilidade, da entropia de Shannon e utilizando algoritmo genético. A comparação entre os três métodos mostrou que todos eles são eficientes para auxiliar na escolha da localização dos pontos de monitoramento. O melhor resultado, no entanto, foi obtido através do terceiro método.

Kapelan, Savic e Walters (2003) propuseram uma abordagem que utiliza a otimização multiobjetivo como ferramenta para a seleção dos pontos do plano de amostragem. Os objetivos são maximizar a precisão do modelo através da minimização de incertezas relevantes e minimizar o custo total do plano. Os autores associaram os dois objetivos em um único e compararam as soluções dos problemas tratados como multiobjetivo e com objetivo único. Concluiu-se que a abordagem multiobjetivo apresenta resultados melhores por explicitar a precisão do modelo, além de possibilitar que mais de uma solução seja apresentada através da curva Pareto resultante.

Behzadian et al. (2008) utilizaram o algoritmo genético multiobjetivo NSGA-II (DEB et al., 2002) para identificar a curva Pareto, tendo como funções objetivo a maximização da precisão do modelo calibrado e a minimização do número de aparelhos utilizados na amostragem. São comparadas duas abordagens estocásticas e uma determinística. Na determinística, as soluções ótimas são identificadas com base nos valores estimados dos parâmetros de calibração. Já a abordagem estocástica é feita de duas maneiras diferentes, sendo uma utilizando uma simulação Monte Carlo e outra utilizando "Noisy Genetic Algorithm" (WU et al., 2006). Os autores chegam à conclusão de que as abordagens estocásticas chegam a melhores resultados que a determinística, especialmente em redes de abastecimento de água de grandes dimensões (algumas centenas de nós).

Fiorini-Morosini et al. (2014) utilizaram uma abordagem baseada em matriz de sensibilidade para selecionar os pontos mais sensíveis a uma alteração de rugosidade e 
demanda. Cada elemento dessas matrizes representa a variação da carga de pressão ou vazão, pela variação da demanda requerida no nó i ou do coeficiente de rugosidade do tubo j. Assim, cada elemento da matriz de sensibilidade para carga de pressão p p (nos nós) e vazão $q_{j}$ (nos tubos) é representado por:

$$
\partial p_{j, i}=\partial p_{i} / \partial \varepsilon_{j} \text { e } \partial q_{j, i}=\partial q_{i} / \partial \varepsilon_{j}
$$

para a matriz de variação do coeficiente de rugosidade $\varepsilon$ e

$$
\partial p_{j, i}=\partial p_{i} / \partial Q_{j} \text { e } \partial q_{j, i}=\partial q_{i} / \partial Q_{j}
$$

para a matriz de variação de demanda, sendo p, a carga de pressão no nó (m), Q a demanda requerida no nó $\left(\mathrm{m}^{3} / \mathrm{s}\right), \varepsilon$, o a rugosidade absoluta no tubo $(\mathrm{mm})$ e q, a vazão que passa no tubo $\left(\mathrm{m}^{3} / \mathrm{s}\right)$.

Com estas equações são construídas as matrizes de sensibilidade e selecionados os nós mais sensíveis. O método foi testado em uma rede fictícia e em uma rede real. Segundo os autores, a boa qualidade dos resultados mostrou que o método pode ser utilizado para a definição de um plano de amostragem com um baixo custo computacional.

Simone et al. (2017) propuseram a abordagem de teoria de redes complexas para estimar pontos de monitoramento de carga de pressão que melhor representassem um conjunto de pontos ao seu redor. Para isso, um problema de otimização multiobjetivo utilizando índice de modularidade foi utilizado. A estratégia consiste em otimizar a localização de pontos de monitoramento definindo áreas de carga de pressão que possuem características semelhantes.

O plano de amostragem tem por objetivo determinar a quantidade e localização dos pontos de medição que devem ser incluídos na campanha de medição de uma rede de abastecimento de água. Na maior parte dos métodos estudados, o número de pontos a serem monitorados é um dado de entrada do problema e, portanto, teria que ser definido à priori.

\subsubsection{Quantidade de pontos de monitoramento}

Os Estados Unidos e o Reino Unido possuem manuais que definem a quantidade mínima de aparelhos que deve ser utilizada para realizar uma calibração de uma rede de abastecimento de água (DE SCHAETZEN, 2000).

No Reino Unido, o Water Research Centre (WRC, 1989) estabelece o número de equipamentos de cada tipo para se realizar uma campanha de medição (Tabela 1). 
Tabela 1 - Número de sensores sugeridos pelo Water Research Centre

\begin{tabular}{l|c|c|c}
\hline \multirow{2}{*}{ Porte da Cidade } & \multicolumn{3}{|c}{ Número de Sensores } \\
\cline { 2 - 4 } & Carga de Pressão & Vazão & Nível de água \\
\hline $\begin{array}{l}\text { Cidade com menos de } \\
30.000 \text { habitantes }\end{array}$ & $20-40$ & $2-6$ & $2-4$ \\
\hline $\begin{array}{l}\text { Cidade com menos de } \\
300.000 \text { habitantes }\end{array}$ & $40-80$ & $5-15$ & $4-8$ \\
\hline $\begin{array}{l}\text { Cidade com mais de } \\
1.000 .000 \text { de habitantes }\end{array}$ & $60-120$ & $15-30$ & $10-20$ \\
\hline
\end{tabular}

Fonte: Adaptado de WRC (1989)

Entretanto, a maior parte das companhias do Reino Unido possui suas próprias recomendações baseadas na experiência dos modeladores para determinar o número de sensores utilizados. A densidade de pontos de monitoramento varia de um sensor de carga de pressão para cada 75 residências até um aparelho para cada 400 propriedades (DE SCHAETZEN, 2000).

Nos Estados Unidos, o órgão que sugere o número de pontos de monitoramento é o American Engineering Computer Application Committee (ECAC, 1999). A Tabela 2 apresenta as sugestões dessa instituição, que varia em função do nível de detalhamento desejado e do tamanho da rede. O órgão estabelece também o nível de detalhamento necessário de acordo com o tipo de trabalho a ser realizado na rede.

Tabela 2 - Número de sensores sugerido pelo American Engineering Computer Application Committee

\begin{tabular}{l|l|l}
\hline \multicolumn{1}{c|}{$\begin{array}{c}\text { Nível de Detalhamento } \\
\text { Desejado }\end{array}$} & \multicolumn{1}{c|}{$\begin{array}{c}\text { Sensor de Carga de } \\
\text { Pressão }\end{array}$} & \multicolumn{1}{c}{ Sensor de Vazão } \\
\hline $\begin{array}{l}\text { Planejamento a longo prazo } \\
\text { (baixo) }\end{array}$ & $2 \%$ dos nós & $1 \%$ das tubulações \\
\hline Projeto (moderado a alto) & 5 a $10 \%$ dos nós & $3 \%$ das tubulações \\
\hline Operação (baixo a alto) & 2 a $10 \%$ dos nós & $2 \%$ das tubulações \\
\hline Qualidade da água (alto) & $10 \%$ dos nós & $5 \%$ das tubulações \\
\hline
\end{tabular}

Fonte: Adaptado de ECAC (1999) 


\subsection{Técnicas de otimização multiobjetivo de algoritmos evolucionários}

Vários problemas de calibração ou de seleção dos pontos de monitoramento podem ser resolvidos utilizando técnicas de otimização multiobjetivo. Esses problemas têm como característica a busca pela maximização ou minimização de mais de uma função objetivo simultaneamente, respeitando algumas restrições preestabelecidas (CHEUNG, 2004).

Um problema de otimização multiobjetivo pode ser matematicamente formulado como (ZHOU et al., 2011):

$$
\operatorname{Minimizar} F(x)=\left(f_{1}(x), f_{2}(x), \ldots, f_{s}(x)\right)^{T}
$$

Sujeito a $x \in \Omega$,

sendo $\Omega$, o espaço de decisões e $x \in \Omega$, o vetor de decisão. $\mathrm{F}(\mathrm{x})$ contém as funções objetivo $f_{i}: \Omega \rightarrow R_{i}, i=1,2, \ldots, s$, em que R é o espaço dos objetivos.

Os objetivos de $\mathrm{F}(\mathrm{x})$ com frequência são conflitantes, portanto, uma ação que vise à melhora de uma função objetivo pode provocar a piora em outra. Logo, uma única solução que otimize todas as funções objetivo raramente existe.

Para contornar esse problema, deve-se procurar pelas soluções em que a alteração de seu vetor solução não consiga melhorar uma função objetivo sem piorar ao menos uma outra (PARETO, 1896). A esse conjunto de soluções dá-se o nome de "soluções ótimas Pareto" (STADLER, 1979).

O conceito de soluções ótimas Pareto, considerando um problema de minimização, pode ser definido como (DEB, 2001; MIETTINEN, 1999):

Definição 1. Um vetor $a=\left(a_{1}, a_{2}, \ldots, a_{s}\right)^{T}$ é dito dominado por outro vetor $b=$ $\left(b_{1}, b_{2}, \ldots, b_{s}\right)^{T}$, denotado por $a<b$, se $\forall i \in\{1,2, \ldots, s\}, a_{i} \geq b_{i}$ e $a \neq b$. Se, além disso, $\exists i \in\{1,2, \ldots, s\}, a_{i}=b_{i}$, é dito que a é dominado fracamente por $\mathrm{b}$, denotado por $a \preccurlyeq b$.

Definição 2. Uma solução factível $x^{*} \in \Omega$ é chamada de solução Pareto ótima se $\nexists y \in$ $\Omega$ tal que $F(y)>F\left(x^{*}\right)$. O conjunto de soluções ótima Pareto é chamado de Conjunto Pareto $(\mathrm{CP})$, matematicamente definido por:

$$
C P=\{x \in \Omega \mid \nexists y \in \Omega, F(y)>F(x)\}
$$


A imagem do conjunto Pareto é chamada de Frente de Pareto (FP):

$$
F P=\{F(x) \mid x \in C P\}
$$

Segundo Zhou et al. (2011) os algoritmos evolucionários são capazes de encontrar um conjunto de vetores soluções bastante próximos ao conjunto Pareto ótimo. Essa família de algoritmo de otimização vem sendo muito utilizada, possuindo mais de 10.500 publicações sobre o assunto até junho de 2017, segundo dados estatísticos baseados em um web site mantido pelo Prof. Dr. Carlos A. Coello Coello (COELLO COELLO, 2018).

Entre os algoritmos de otimização evolucionários tem-se uma vasta diversidade de metodologias, e dentre elas a mais utilizada é a de algoritmos genéticos. A primeira implementação de algoritmos genéticos visando a otimização multiobjetivo foi proposta por Schaffer (1985), através do método "Vector Evaluated Genetic Algorithm (VEGA)". Esse método divide o conjunto de vetores de soluções em subgrupos e cada grupo é avaliado segundo uma função objetivo.

Goldberg (1989) percebeu que o princípio de dominância teria um resultado melhor que o sugerido por Schaffer (1985) e sugeriu uma nova metodologia baseada no maior número de vetores de soluções não-dominadas e no conceito de nicho (niching), que dá preferência a conjuntos de soluções mais diversos.

Fonseca e Fleming (1993) propuseram uma metodologia chamada de "Multiobjective Genetic Algorithm (MOGA)", a qual foi a primeira a explicitamente apontar soluções não dominadas e simultaneamente manter a diversidade dessas soluções. Nessa metodologia, as soluções são classificadas de acordo com uma classificação, que é definida como:

$$
r_{i}=1+\eta_{i}
$$

sendo $r_{i}$ a classificação da solução i e $\eta_{i}$ o número de soluções que dominam fracamente o vetor de soluções i.

Desse modo, as soluções não dominadas recebem valor 1 (classificação 1) e as piores soluções recebem valores maiores. Os valores de aptidão são, então, atribuídos de acordo com as classificações e calcula-se também a avaliação compartilhada de cada solução. Essa avaliação compartilhada tem como objetivo garantir maior diversidade às soluções, dando uma aptidão melhor àquelas soluções que estão mais distantes das demais quando comparadas com as outras soluções de mesma classificação.

Srinivas e Deb (1995) propuseram uma nova metodologia semelhante ao MOGA, chamada de "Non-Dominated Sorting Genetic Algorithm (NSGA)". A diferença deste para o 
MOGA é quanto à maneira de classificar os vetores de solução não dominados e na maneira de se calcular a avaliação compartilhada. Neste algoritmo, as soluções são divididas em frentes e suas aptidões são ajustadas de acordo com as técnicas de compartilhamento (Sharing Fitness). A classificação é feita a cada frente de pareto e o ajuste de compartilhamento é feito em cada frente. Deste modo as soluções não dominadas possuem um valor de aptidão fictício maior e consequentemente têm uma probabilidade maior de passarem para a próxima geração.

Rudolph (1996) propôs o conceito de elitismo em algoritmos de otimização evolucionários multiobjetivos. Zitzler e Thiele (1998) sugeriram um algoritmo evolucionário multiobjetivo chamado "Strength Pareto Evolutionary Algorithm (SPEA)", que tem como característica central a inclusão do elitismo através da criação e manutenção de uma população externa que armazena um número fixo de soluções não dominadas encontradas. A cada geração, as novas soluções não-dominadas encontradas são comparadas com as soluções da população externa e apenas as soluções não-dominadas resultantes são armazenadas na população externa. Este algoritmo não apenas preserva as soluções não dominadas como também as utiliza para a criação de novas soluções. Uma técnica de agrupamento de soluções é aplicada para permitir uma maior diversidade entre as soluções preservadas na população interna.

Baseado no algoritmo NSGA e incluindo a técnica de elitismo, Deb et al. (2002) propuseram um método chamado de "Elitist Non-Dominated Sorting Genetic Algorithm (NSGA-II)”. Este algoritmo utiliza dois grupos de soluções diferentes simultaneamente, denominados população pai e população filha. Na primeira geração, constrói-se uma população inicial como nos algoritmos genéticos convencionais. Calcula-se, então, um valor de aptidão para cada solução. Este valor de aptidão varia de acordo com a frente em que a solução se encontra. As soluções não dominadas recebem o valor de aptidão igual a 1. O próximo passo é ignorar a existência das soluções tidas como não dominadas na etapa anterior e traçar uma nova frente pareto, fazendo com que as soluções pertencentes a essa nova frente recebam o valor de aptidão 2. Repetem-se os passos anteriores até que todas as soluções tenham um valor de aptidão. Na Figura 1 é dado um exemplo da criação dessas frentes para um problema de maximização das funções f1 e f2. 
Figura 1 - Exemplo de divisão de um conjunto de soluções no espaço objetivo f1 e f2 em frentes Pareto utilizadas no método NSGA II

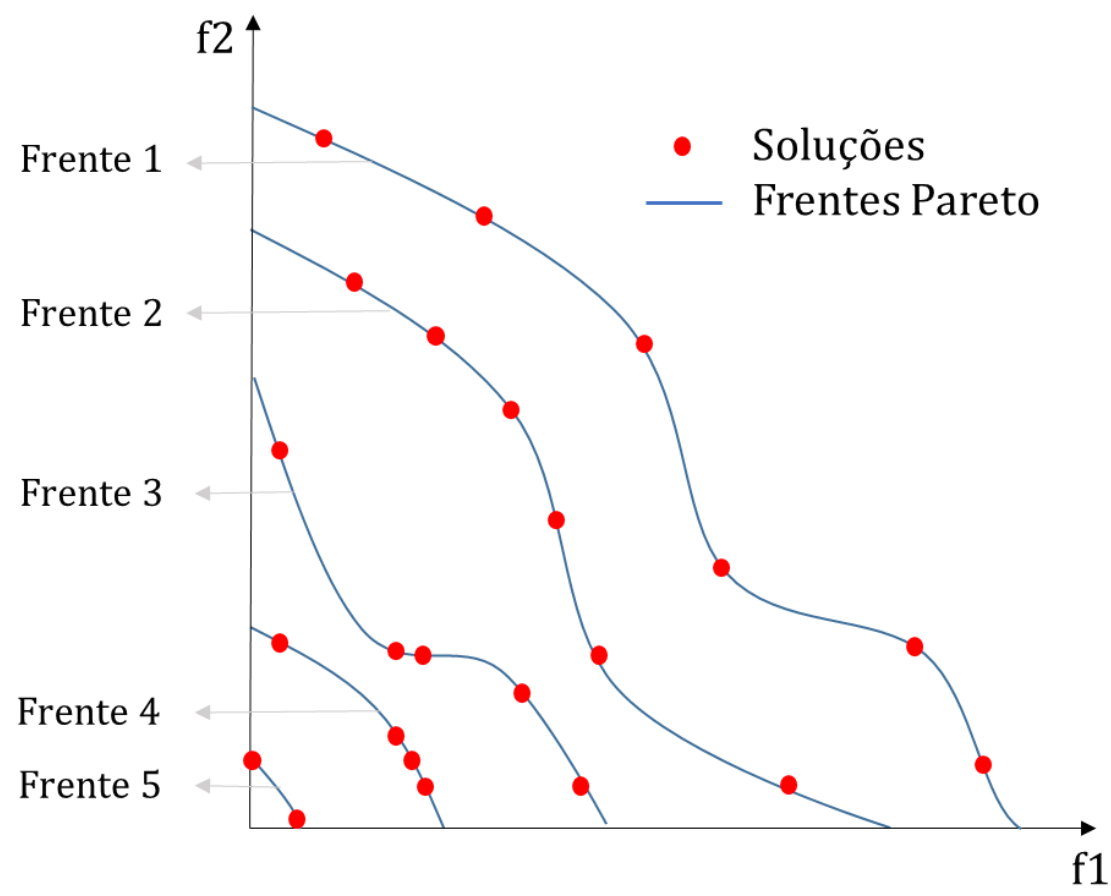

Fonte: Elaboração própria

Em seguida, aplica-se os operadores de seleção (torneio), recombinação e mutação, obtendo assim a população filha de mesma dimensão que a população pai. As duas populações são agrupadas em um único conjunto e este é ordenado de acordo com a frente à qual a solução pertence. Posteriormente, descarta-se metade das soluções deste conjunto, preservando as melhores soluções para a próxima geração. Se houver necessidade de escolher um subconjunto de soluções de uma mesma frente, um critério de compartilhamento (crowding distance) é utilizado, preservando as soluções mais espalhadas naquela frente.

Muitos outros algoritmos evolucionários foram propostos para a resolução de problemas de otimização multiobjetivos (COELLO COELLO; LECHUGA, 2002; CORNE; KNOWLES; OATES, 2000; KITA et al., 1996; KNOWLES; CORNE, 2000; OSYCZKA; KUNDU, 1996).

Reed et al. (2013) fizeram um estudo da utilização de otimizadores evolucionários multiobjetivos na área de recursos hídricos e sugerem que o NSGA-II é o algoritmo mais utilizado na área por resultar em boas soluções de forma eficiente. De fato, em muitas aplicações recentes, o otimizador escolhido foi o NSGA-II (GAMBOA-MEDINA; REIS, 2017; HAJEBI et al., 2014; MAKAREMI; HAGHIGHI; GHAFOURI, 2017; MUHAMMED et al., 2017). 


\subsection{Partição de redes de abastecimento de água}

Agrupamento é o processo de dividir um conjunto de elementos em grupos, de forma que cada elemento seja similar, segundo alguma característica, a todos os outros elementos que façam parte do mesmo grupo e que seja diferente, segundo essa mesma característica, dos elementos que não pertencem ao seu grupo (GÜNTER; BUNKE, 2003). Esse processo pode ser aplicado também para decompor uma rede de abastecimento de água em subsistemas menores e mais gerenciáveis (SALOMONS; SKULOVICH; OSTFELD, 2017). A esse processo dá-se o nome de partição de rede, onde cada subsistema da rede é chamado de distrito pitométrico ou, simplesmente, distrito. Se um distrito não possui nenhuma ligação com outro, este é chamado de distrito pitométrico isolado (DI NARDO; DI NATALE; SANTONASTASO, 2014).

Desde que a complexidade das redes de abastecimento de água aumentou, a técnica de partição de rede tornou-se essencial para que seja possível realizar um efetivo gerenciamento da rede, facilidade de manutenção e controle de vazamentos e de pressões (FARLEY, 2001). Muitos métodos foram propostos visando a otimização da partição de redes de abastecimento de água, sendo que a maioria segue uma abordagem com dois passos (ZHANG et al., 2017):

a) Encontrar a partição da rede baseado em características da mesma;

b) Minimização de ligações entre os distritos e mantendo o bom funcionamento da rede.

Segundo Di Nardo et al. (2013), tradicionalmente, o processo de partição de redes de abastecimento de água é feito por meio de sugestões empíricas e com abordagens de "tentativa e erro", como reportado em alguns estudos (LTD WATER INDUSTRY RESEARCH, 1999; WATER AUTHORITIES ASSOCIATION; CENTRE, 1985). No entanto, para redes de grande porte, a partição manual torna-se um processo complicado. Para solucionar este problema, algumas técnicas baseadas em diferentes abordagens (breadth and depth first search, abordagem espectral, partição multinível, estrutura de comunidade, entre outras) foram propostas. Todos esses métodos advêm da teoria de grafos. Algumas definições básicas e propriedades dessa teoria podem ser encontradas no item 4.3.1 e no artigo de revisão de Fortunato (2010).

Os métodos breadth first search (POHL, 1969) e depth first search (TARJAN, 1972) transformam a rede em um grafo e exploram o seu nível de conectividade para classificar os nós como fracamente ou fortemente conectados. A partir dessa classificação, a rede pode ser particionada. 
Tzatchkov, Alcocer-Yamanaka e Bourguett-Ortíz (2006) utilizaram estes métodos, juntamente com análises da idade da água e direção do fluxo de água para setorizar dois municípios do México. Perelman e Ostfeld (2011) criaram um algoritmo que identifica grupos fortemente ou fracamente conectados através dos métodos supracitados e de acordo com a direção do fluxo de água nas tubulações. Di Nardo et al. (2014) propuseram um método chamado de método de nível hierárquico comum. O algoritmo busca por subgrafos independentes considerando também a minimização da dissipação de energia da rede setorizada. O método foi aplicado na rede dos municípios de Parete (Itália) e Colorado (México).

Os métodos baseados na abordagem espectral, por sua vez, utilizam os autovetores de matrizes para particionar um grafo. Essa matriz pode ser a própria matriz de adjacência da rede ou outras matrizes derivadas desta. Esta metodologia consiste em transformar um conjunto inicial de objetos em um conjunto de pontos no espaço, cujas coordenadas são elementos do segundo menor autovetor, conhecido como vetor de Fiedler. Estes conjuntos de pontos são então agrupados através de técnicas tradicionais, como o agrupamento k-médio, por exemplo (MACQUEEN, 1967 apud FORTUNATO, 2010).

Herrera et al. (2010) propuseram um algoritmo de agrupamento semi-supervisionado. O algoritmo constrói a matriz de afinidade da rede e inclui os consumos nodais e diâmetros como pesos dos vértices e arestas, respectivamente. Matrizes de dissimilaridade são também construídas, utilizando diferentes restrições e informações. Essas matrizes são então transformadas em uma matriz de kernel (SCHÖLKOPF; SMOLA, 2002), que sintetiza todas as informações dadas. O método aplica então o algoritmo de agrupamento espectral, buscando a minimização de tubulações cortadas a fim de dividir a rede em um número pré estabelecido de distritos.

Han e Liu (2017) propuseram outra metodologia baseada em agrupamento espectral. Os autores afirmam que o objetivo principal de uma partição deve ser a minimização do número de tubulações fechadas, uma vez que esses fechamentos alteram significantemente as características hidráulicas da rede. Nesta metodologia, constrói-se uma matriz de adjacência ponderada de acordo com o fluxo hidráulico. Calcula-se então a matriz laplaciana normalizada e seus maiores autovetores (FORTUNATO, 2010). Com esta matriz, utiliza-se o método $k$-way combinado com um algoritmo genético para encontrar os melhores agrupamentos.

Já os métodos de partição multinível consistem em dividir os vértices em grupos de tamanhos pré definidos de maneira que o número de arestas entre os grupos seja mínimo (FORTUNATO, 2010; SELA PERELMAN et al., 2015). Na maioria dos casos, deseja-se 
dividir o grafo em grupos de mesmo tamanho. Dentre os métodos de partição multinível, o mais utilizado em redes de abastecimento de água é o proposto por Karypis e Kumar (1998a), chamado METIS. Esta abordagem utiliza um método $k$-way para minimizar o número de cortes de arestas, buscando manter o balanço dos grupos. O processo de partição consiste em três partes: agrupamento, partição e refinamento.

Na primeira parte, de agrupamento, o grafo inicial é sucessivamente transformado em grafos menores através de algum método, como o Random Matching (BUI; JONES, 1993), Heavy-edge Matching (KARYPIS; KUMAR, 1998b) e Modified Heavy-edge Matching (KARYPIS; KUMAR, 1995). Assim, o agrupamento gera um grafo menor que garante as seguintes proporiedades (HENDRICKSON; LELAND, 1995):

a) $\mathrm{O}$ corte de um particionamento no grafo reduzido é igual ao corte do mesmo particionamento do grafo original.

b) Um particionamento balanceado no grafo reduzido resulta em um particionamento também balanceado do grafo original.

Na segunda parte do método, o grafo reduzido é particionado em quantas partes forem desejadas. Nesta etapa podem ser utilizados os mais diversos algoritmos de particionamento de grafos, sendo o mais utilizado o algoritmo de Kerlinghan-Lin (KERNIGHAN; LIN, 1970). Como o grafo original foi reduzido, a etapa de partição permite a utilização de algoritmos computacionalmente mais lentos.

Com o grafo reduzido particionado, a última etapa da partição multinivel é realizada, desagrupando sucessivamente o grafo reduzido para os grafos intermediários obtidos na fase de agrupamento até que ele se torne o grafo original novamente. A cada passo do desagrupamento dos nós, um processo de refinamento pode ser realizado, visando a redução do número de arestas cortadas e o balanço dos grupos. Os métodos mais utilizados nessa etapa para o refinamento são o algoritmo de refinamento de Kerlingan-Lin (KERNIGHAN; LIN, 1970), algoritmo de Fiduccia-Mattheyses (FIDUCCIA; MATTHEYSES, 1982), o algoritmo simplificado de Kerlingan-Lin (KARYPIS; KUMAR, 1998a), entre outros.

Sempewo, Pathiarana e Vairavamoorthy (2009) utilizaram o programa METIS para aplicar o método de Partição Recursiva de Bisecção Multinível (MLRB) (KARYPIS; KUMAR, 1995), adotando como pesos o diâmetro, o comprimento das tubulações e a demanda dos nós. O método foi testado em uma pequena rede de 10 nós e depois aplicado em redes maiores. Os autores concluíram que o método foi satisfatório para particionar e melhor gerenciar a rede. Além disso, destacaram como qualidade do método a possibilidade de se criar grupos balanceados em função de algum peso (demanda, comprimento da tubulação, entre outros). 
Di Nardo et al. (2013) criaram um programa que particiona a rede utilizando MLRB e simularam o particionamento da rede do município de Villaricca, Itália. Os autores usaram diferentes combinações de pesos assossiados aos nós e arestas, e concluiram que o peso que resultou na melhor partição foi a dissipação de energia. Como validação da partição foram utilizados índices de desempenho de carga de pressão e resiliência (DI NARDO et al., 2015).

A abordagem de estrutura de comunidade, por sua vez, utiliza o índice de modularidade como indicador para quantificar a qualidade da partição de um grafo (NOVÁK; NEUMANN; MACAS, 2010). Este indicador foi proposto por Newman inicialmente com o objetivo de mensurar a qualidade de uma partição dada. Essa métrica é a fração do número de arestas que ligam dois vértices de um mesmo grupo menos o número esperado de ligações entre os dois vértices se estes fossem ligados aleatóriamente (NEWMAN, 2004):

$$
I Q=\frac{1}{2 m} \sum_{i j}\left[A_{i j}-\frac{k_{i} * k_{j}}{2 m}\right] \delta\left(c_{i}, c_{j}\right)
$$

sendo IQ o índice de modularidade; m o número de arestas do grafo; A a matriz de adjacência do grafo; $\mathrm{k}_{\mathrm{i}} \mathrm{o}$ grau do vértice $\mathrm{i}$, definido como o número de arestas ligadas ao vértice; e $\delta\left(\mathrm{c}_{\mathrm{i}}, \mathrm{c}_{\mathrm{j}}\right)$ é o delta de Kronecker $\left(\delta\left(\mathrm{c}_{\mathrm{i}}, \mathrm{c}_{\mathrm{j}}\right)=1\right.$, se $\mathrm{c}_{\mathrm{i}}$ for igual a $\mathrm{c}_{\mathrm{j}}, \delta\left(\mathrm{c}_{\mathrm{i}}, \mathrm{c}_{\mathrm{j}}\right)=0$ caso contrário); e $\mathrm{c}_{\mathrm{i}}$ é o grupo em que o vértice i pertence.

Este índice de modularidade pode ser entendido como uma medida de comparação entre o número de arestas intracomunidades em relação a uma rede aleatória com o mesmo número de vértices e arestas (SCHUETZ; CAFLISCH, 2008). Se o número de arestas intracomunidades for maior que a da rede aleatória, IQ < 0 . Se não existirem arestas que ligam diferentes comunidades, então IQ $=1$. Portanto, o índice de modularidade pode ser qualquer valor real menor ou igual a um (ZHU et al., 2008). De maneira geral, indíces maiores que 0,3 indicam que a rede possui uma boa partição.

As metodologias de estrutura de comunidade buscam, através de diferentes maneiras, encontrar uma partição que resulte em um alto índice de modularidade. Newman (2004) propôs um algoritmo guloso, ou "greedy algorithm" (algoritmos que seguem a heurística de resolver o problema fazendo uma escolha localmente ótima em cada iteração, com intenção de encontrar o ótimo global (BLACK, 2006)), para a maximização da modularidade, que foi revisado melhorando seu desempenho computacional por Clauset, Newman e Moore (2004). O algoritmo inicia assumindo que cada vértice é uma comunidade e calcula o ganho do índice de modularidade por agrupar todas as comunidades possíveis. $\mathrm{O}$ agrupamento que resultar em um 
maior ganho da modularidade é realizado e os ganhos de modularidade são então atualizados. O processo termina quando toda a rede for agrupada em uma única comunidade. A melhor partição é aquela que resultou no maior índice de modularidade. A alteração do índice de modularidade por agrupar uma comunidade i a uma comunidade $\mathrm{j}$ pode ser calculado de acordo com a equação ( 18 ):

$$
\Delta I Q\left(A, C_{c i, c j}\right)=I Q\left(A, C-c_{i}-c_{j}+c_{i} \cup c_{j}\right)-I Q(A, C)
$$

sendo $\Delta \mathrm{IQ}\left(\mathrm{A}, \mathrm{C}_{\mathrm{ci}, \mathrm{cj}}\right)$ a variação do índice de modularidade por agrupar a comunidade $\mathrm{c}_{\mathrm{i}} \mathrm{e} \mathrm{c}_{\mathrm{j}}$; e $\mathrm{IQ}(\mathrm{A}, \mathrm{C})$ o índice de modularidade da matriz de adjacência A particionada como C.

Utilizando essa metodologia para particionar redes de abastecimento de água, Diao, Zhou e Rauch (2013) utilizaram o algoritmo guloso de Newman (NEWMAN; GIRVAN, 2004) para dividir a rede utilizada no desafio "battle of the water-sensors network 2" (OSTFELD et al., 2008). O resultado foi comparado com o proposto por Grayman, Murray e Savic (2009), que realizou o mesmo processo de maneira iterativa e manual. Os autores concluem que os resultados das duas metodologias foram próximos e que, portanto, o algoritmo é capaz de encontrar uma boa solução para a partição de redes de abastecimento de água.

Giustolisi e Rridolfi (2014) propuseram uma metodologia baseada em um índice de modularidade modificado para atender melhor ao caso particular de redes de abastecimento de água. Para a segmentação da rede, um problema de otimização multiobjetivo foi formulado, levando em consideração a maximização do índice de modularidade modificado e a minimização do custo de se instalar válvulas na rede. Os autores aplicaram a metodologia para uma rede fictícia e concluíram que a utilização da métrica modificada traz benefícios para a partição da rede, uma vez que com esta abordagem é possível levar em consideração atributos das tubulações para realizar o agrupamento.

Ciaponi, Murari e Todeschini (2016) utilizaram o algoritmo proposto por Clauset, Newman e Moore (2004) juntamente com critérios práticos de projeto de partição de redes de abastecimento de água a fim de facilitar o gerenciamento de rede, visando a detecção de vazamentos, o controle de pressões, a facilidade monitoramento, entre outros fatores. Para isso, os autores primeiramente identificaram as tubulações tronco da rede e criaram subdivisões na rede. Dentro dessas subdivisões o algoritmo de Newman foi utilizado e a rede particionada. Os autores aplicaram a metodologia em uma rede real de Castelfranco Emilia (Modena, Itália), que foi previamente testada em outros processos de partição (ALVISI; FRANCHINI, 2014). Concluiu-se que a metodologia proposta apresentou resultados similares aos obtidos através de outros procedimentos. 
Zhang et al. (2017) fazem uma crítica às metodologias aplicadas a partição de rede, afirmando que a utilização dos dados de carga de pressão na rede não é adequada, pois os grafos não ponderados não levam este fator em consideração. Os autores afirmam também que dentre os métodos disponíveis, o mais adequado é o da modularidade de Girvan e Newman (2002). Porém, apontam que essa abordagem limita o tamanho mínimo da comunidade, o que pode ser ruim para a partição da rede. Outra crítica feita aos métodos de partição propostos é quanto ao uso de algoritmos evolucionários para a identificação de quais tubulações devem ficar fechadas ou não. Os autores afirmam que esses algoritmos não são eficientes para a resolução de problemas discretos com muitas variáveis de decisão, uma vez que o tempo de processamento pode ser longo. Foi proposta, então, uma nova abordagem, em que todos estes problemas são resolvidos. Nessa proposta, o grafo utilizado é ponderado de acordo com a carga de pressão da rede, e para superar a limitação do tamanho mínimo da comunidade, é usada uma metodologia baseada em modularidade estendida. Para encontrar as tubulações que devem ser fechadas é utilizado o otimizador BORG (REED et al., 2013), uma nova hiper-heurística que funciona melhor para problemas inteiros, segundo os autores.

Através da revisão bibliográfica descrita nessa seção, observou-se que muitas abordagens foram propostas para resolver o problema de partição de redes de abastecimento de água principalmente nos últimos anos. Atualmente, existe uma grande discussão sobre comparações de diferentes metodologias. Para realizar essas comparações, diversas métricas foram aplicadas, sendo as mais comuns:

\section{a) Número de tubulações ligando distritos (NFEC) (DI NARDO; DI NATALE; SANTONASTASO, 2014):}

Representa o número total de tubulações que ligam distritos. Busca-se minimizar esta métrica, pois assim a interferência causada pela partição na rede é minimizada.

b) Número de conexões do distrito mais conectado (NP) (SELA PERELMAN et al., 2015)

Representa o número máximo de tubulações que ligam um único distrito aos demais. Deseja-se minimizar esse índice. 
c) Condutância das tubulações entre distritos (CED) (DI NARDO et al., 2017)

É a soma das razões entre os diâmetros e os comprimentos de todas as tubulações que ligam diferentes distritos.

$$
C_{E D}=\sum_{i}^{N_{E D}} d_{i} / l_{i}
$$

sendo $d_{i}$ e $l_{i}$ o diâmetro e o comprimento da tubulação i, respectivamente.

d) Resistência hidráulica das tubulações entre distritos (RED) (DI NARDO et al., 2017) É a soma das razões entre os comprimentos e a quinta potência dos diâmetros de todas as tubulações que ligam diferentes distritos.

$$
R_{E D}=\sum_{i}^{N_{E D}} \frac{l_{i}}{d_{i}{ }^{5}}
$$

sendo $d_{i}$ e $l_{i}$ o diâmetro e o comprimento da tubulação i, respectivamente.

e) Índice de Balanço (Iв) (DI NARDO et al., 2013):

$$
I_{B}=\frac{\kappa * \max (n p)}{N_{n}}
$$

sendo $\mathrm{I}_{\mathrm{B}} \mathrm{O}$ índice de balanço, $\kappa$ o número de distritos criados pela partição, $\mathrm{N}_{\mathrm{n}} \mathrm{o}$ número de nós que existe na rede e max (np) é o número de nós do maior distrito da rede. Quanto menor o índice, melhor é considerada a partição. Este índice pode ser ponderado por qualquer característica da rede, como demanda ou comprimento, gerando assim o índice de balanço da demanda ou do comprimento, respectivamente.

f) Índices de Pressão (DI NARDO et al., 2015):

São utilizados o índice $\mathrm{H}_{\text {médio, }}$ que é igual à média das cargas hidráulicas de todos os nós da rede, $\mathrm{H}_{\min }$ e $\mathrm{H}_{\text {máx }}$, que representam a menor e a maior carga de pressão encontradas na rede, respectivamente. O desvio padrão das cargas hidráulicas, $\mathrm{H}_{\mathrm{dp}}$, também pode ser usado como métrica.

g) Índice de modularidade (IQ) (NEWMAN; GIRVAN, 2004)

Índice explicitado na equação ( 17 ). Deseja-se que esse índice seja maximizado.

h) Recorrência da tubulação entre distritos (RICE) (SELA PERELMAN et al., 2015) É o número de vezes que uma tubulação que conecta diferentes distritos aparece em diferentes níveis de partição. Por exemplo, se uma rede é dividida em 5, 10 e 20 distritos e uma dada tubulação aparece em todas as três partições como uma tubulação entre distritos, então seu RICE é igual a três. Quanto maior for a média dessa métrica, melhor é a partição. 
Com essas métricas, várias pesquisas puderam ser feitas visando a comparação de diferentes métodos de partição.

Di Nardo et al. (2013) desenvolveram um programa chamado Smart Water Network Partitioning (SWANP) (DI NARDO et al., 2014b), que utiliza o algoritmo de bissecção recursiva multinível (KARYPIS; KUMAR, 1998a) baseado na abordagem de partição multinível. Di Nardo et al. (2014c) compararam essa metodologia com outras três, sendo elas:

a) Multi Agent Simulation (MAS) (HAJEBI et al., 2013), que utiliza o algoritmo de agrupamento k-médio (HARTIGAN; WONG, 1979) seguido de um sistema de negociação multi agente para particionar a rede;

b) Hybrid Graph Partitioning (HGP) (FERRARI; BECCIU; OTHERS, 2012), o qual combina duas teorias de grafos, a Kernighan-Lin e a depth-first seach;

c) Water Spectral Clusters (WSC) (HERRERA et al., 2010), que utiliza a abordagem de agrupamento espectral.

Os índices de desempenho utilizados foram o número de válvulas necessárias, o número de medidores de vazão necessários e as pressões média, mínima e máxima após a partição. Os autores concluíram que o programa SWANP atingiu melhores resultados quando comparados com HGP e WSC em todas as métricas utilizadas. Já quando comparado ao MAS, o programa atinge melhores resultados somente em relação aos índices de carga de pressão. Os autores ainda criticaram a falta de informações contidas nos trabalhos que propuseram as metodologias utilizadas para comparação, o que dificulta a reprodução dos resultados, e recomendaram que as comparações fossem feitas em redes maiores.

Sela Perelman et al. (2015) compararam três algoritmos advindos da teoria de grafo, representando diferentes abordagens. Os algoritmos utilizados foram:

a) Agrupamento Global, que é um algoritmo tradicional da teoria de grafos que agrupa objetos de acordo com uma função de similaridade, que na metodologia em questão é representada pela distância euclidiana dos vértices (HASTIE; TIBSHIRANI; FRIEDMAN, 2009)

b) Estrutura de Comunidade, que utiliza o algoritmo guloso de Newman (NEWMAN, 2004), mesma metodologia utilizada por Diao, Zhou e Rauch (2013).

c) Partição Multinível, que aplica o algoritmo de bissecção recursiva multinível (KARYPIS; KUMAR, 1998a), mesmo método aplicado por (DI NARDO et al., 2013). 
Para avaliar o desempenho de cada metodologia, os autores utilizaram a visualização da matriz de adjacência ordenada de acordo com os seus grupos; o layout da rede agregada, transformando cada grupo em um único nó e deixando explicita as tubulações que ligam os diferentes grupos da rede; e um gráfico de radar para uma avaliação multicritérios. Os critérios utilizados foram: demanda do maior grupo, maior número de cortes para isolar um grupo, número de cortes total da partição, recorrência de tubulações entre grupos (o número de arestas que são cortas em partições de diferentes tamanhos) e o tempo de execução do programa.

Os autores aplicaram os métodos em duas redes reais, particionando-as em 5, 10, 15, 25, 35 e 50 grupos. Os autores concluíram que as abordagens de estrutura de comunidade e partição multinível resultam em partições melhores quando comparadas com a de agrupamento global, e ambas podem ser utilizadas para melhorar o gerenciamento de pressões e vazamentos de redes de abastecimento de água satisfatoriamente.

Di Nardo et al. (2017) compararam a abordagem multinível com a abordagem espectral utilizando três diferentes pesos nos dois métodos: sem peso; ponderada em função da razão entre o diâmetro e o comprimento da tubulação; e ponderada em função da razão entre o comprimento e a quinta potência do diâmetro da tubulação, chamado de resistência hidráulica. Para realizar a comparação foram usadas as seguintes métricas: número total de tubulações cortadas; índice de balanço (demanda do maior distrito dividido pela demanda média distritais); a soma da razão entre o diâmetro e o comprimento de todas as tubulações cortadas; e a soma das resistências hidráulicas $\left(1 / \mathrm{d}^{5}\right)$ das tubulações cortadas. A rede de abastecimento de água de Parete, Itália, foi utilizada para a realização das partições pelas duas metodologias. A rede foi dividida desde 2 até 10 distritos pelas duas metodologias.

Os autores concluíram que ambas as metodologias resultam em boas partições, sendo que a abordagem de partição multinível aponta soluções com melhor índice de balanço, mas apresenta mais tubulações cortadas.

Liu et al. (2018) apresentaram uma análise comparativa de três diferentes abordagens, incluindo: Estrutura de comunidade (CLAUSET; NEWMAN; MOORE, 2004), Partição Multinível (KARYPIS; KUMAR, 1998a) e o processo de Random Walk (PONS; LATAPY, 2005). Foram utilizados somente índices de avaliação relacionados a teoria de grafos. As metodologias dividiram a rede EXNET em 5, 10, 15, 20, 30 e 50 distritos, realizando um processo sem utilizar pesos e outro processo utilizando demanda como peso dos nós.

Os autores concluíram que: o método de estrutura de comunidade resulta em melhores índices de modularidade, uma vez que otimiza diretamente esse indicador; o método de partição 
multinível retorna partições com melhores índice de balanço; e que o processo de Random Walk apresenta piores resultados que as outras duas metodologias.

Através da revisão bibliográfica feita sobre métodos de partição de redes de abastecimento de água, percebe-se que não há um consenso sobre qual método produz melhores resultados. Dentre todas as abordagens comparadas, as de estrutura de comunidade e de partição multinível são as mais utilizadas.

A estrutura de comunidade, por otimizar diretamente o índice de modularidade, produz partições com um menor número de arestas entre distritos e, portanto, tende a apresentar menor custo de implantação. Já a partição multinível preza por produzir distritos de tamanhos homogêneos, o que é vantajoso no processo de partição de redes de abastecimento, pois facilita o gerenciamento da mesma.

As principais informações sobre os artigos que compararam diferentes métodos de partição de redes de abastecimento de água são mostradas na Tabela 3. 
Tabela 3 - Vantagens e desvantagens de métodos de partição de redes analisados na revisão bibliográfica.

\begin{tabular}{|c|c|c|c|c|}
\hline Referência & Rede & $\begin{array}{l}\text { Número de } \\
\text { distritos }\end{array}$ & Métricas & Abordagem \\
\hline \multirow{4}{*}{$\begin{array}{l}\text { DI NARDO et } \\
\text { al., } 2014 \mathrm{c}\end{array}$} & \multirow{4}{*}{$\begin{array}{l}\text { Cada método } \\
\text { utilizou uma } \\
\text { rede diferente }\end{array}$} & \multirow{4}{*}{$\begin{array}{l}\text { Cada método } \\
\text { utilizou um } \\
\text { número } \\
\text { diferente }\end{array}$} & \multirow{4}{*}{$\begin{array}{c}\text { Número de válvulas } \\
\text { necessárias; número de } \\
\text { medidores de vazão } \\
\text { necessários; índices de pressão } \\
\text { (f) }\end{array}$} & $\begin{array}{l}\text { Partição } \\
\text { Multinível }\end{array}$ \\
\hline & & & & Multi Agente \\
\hline & & & & Híbrida \\
\hline & & & & $\begin{array}{c}\text { Agrupamento } \\
\text { Espectral }\end{array}$ \\
\hline \multirow{3}{*}{$\begin{array}{c}\text { SELA } \\
\text { PERELMAN } \\
\text { et al., } 2015\end{array}$} & \multirow{3}{*}{$\begin{array}{c}\text { Dois diferentes } \\
\text { distritos do } \\
\text { Singapura }\end{array}$} & \multirow{3}{*}{$\begin{array}{c}5,10,15,25 \\
35,50\end{array}$} & \multirow{3}{*}{$\begin{array}{l}\text { Matriz de adjacência } \\
\text { reordenada; layout dos } \\
\text { distritos; gráfico de radar com } \\
\text { as seguintes métricas: } \\
\text { tamanho do maior distrito, } \\
\text { número máximo de tubulações } \\
\text { cortadas em um único distrito } \\
\text { (b), total de tubulações } \\
\text { cortadas (a), recorrência de } \\
\text { tubulações cortadas (h), tempo } \\
\text { de processamento }\end{array}$} & $\begin{array}{c}\text { Agrupamento } \\
\text { Global }\end{array}$ \\
\hline & & & & $\begin{array}{l}\text { Estrutura de } \\
\text { Comunidade }\end{array}$ \\
\hline & & & & $\begin{array}{l}\text { Partição } \\
\text { Multinível }\end{array}$ \\
\hline \multirow{2}{*}{$\begin{array}{l}\text { DI NARDO et } \\
\text { al., } 2017\end{array}$} & \multirow{2}{*}{ Parete, Itália } & \multirow{2}{*}{2 a 10} & \multirow{2}{*}{$\begin{array}{l}\text { Número total de tubos } \\
\text { cortados (a); índice de balanço } \\
\text { da demanda (e); condutância } \\
\text { das tubulações entre distritos } \\
\text { (c); Resistência hidráulica das } \\
\text { tubulações entre distritos (d) }\end{array}$} & $\begin{array}{l}\text { Partição } \\
\text { Multinível }\end{array}$ \\
\hline & & & & $\begin{array}{l}\text { Agrupamento } \\
\text { Espectral }\end{array}$ \\
\hline \multirow{3}{*}{$\begin{array}{l}\text { LIU et al., } \\
2018\end{array}$} & \multirow{3}{*}{ EXNET } & \multirow{3}{*}{$\begin{array}{c}5,10,15,20 \\
30 \text { e } 50\end{array}$} & \multirow{3}{*}{$\begin{array}{l}\text { Índice de modularidade (g); } \\
\text { condutância; densidade; } \\
\text { expansão; número total de } \\
\text { cortes (a); volume de } \\
\text { comunicação }\end{array}$} & $\begin{array}{l}\text { Estrutura de } \\
\text { Comunidade }\end{array}$ \\
\hline & & & & $\begin{array}{l}\text { Random } \\
\text { Walk }\end{array}$ \\
\hline & & & & $\begin{array}{l}\text { Partição } \\
\text { multinível }\end{array}$ \\
\hline
\end{tabular}

Os índices entre parênteses se referem às métricas explicitadas nesta seção.

Fonte: Elaboração do Autor 


\section{MATERIAL E MÉTODOS}

A seguir, uma breve apresentação da estrutura da metodologia é realizada. Na seção 4.1 os dados físicos da rede do município de Pederneiras são descritos. Na seção 4.2 os dados utilizados para a construção do modelo hidráulico preliminar são explicitados (4.2.1). A metodologia utilizada para o plano de amostragem é apresentada no subitem 4.2.2 e as informações sobre os aparelhos utilizados na campanha de medição, assim como o período em que foram coletados os dados, estão presentes na seção 4.2.3. Em 4.2.4 a metodologia utilizada para a calibração do modelo é mostrada, e na seção 4.2 .5 o processo utilizado para a validação da calibração é apresentado.

No item 4.3 as duas metodologias utilizadas para particionar a rede calibrada são expostas, sendo o algoritmo ModulMax explicitado no item 4.3.2 e o METIS em 4.3.3. Em 4.4 as métricas utilizadas para a comparação das partições são apontadas e a metodologia proposta para selecionar a melhor partição é descrita.

Por fim, na seção 4.5, o método empírico utilizado neste trabalho para definir o status que cada tubulação da rede deve apresentar (fechada, aberta sem VRP, aberta com VRP) após o processo de partição é explicitado. A Figura 2 apresenta um organograma dos passos realizados nesta pesquisa para particionar a rede de distribuição de água do município de Pederneiras/SP.

Nessa pesquisa, o programa de simulação hidráulica EPANET 2 (ROSSMAN, 2000), o Matlab (THE MATHWORKS INC., 2015) e o Python (VAN ROSSUM, 2007) foram utilizados para a implementação dos algoritmos. Para promover a interação entre o simulador hidráulico EPANET 2 e o Matlab (Versão R2015a) foi utilizada uma biblioteca de funções desenvolvida pelo centro de pesquisa KIOS, da Universidade do Chipre, chamada EPANET-MATLAB toolkit (ELIADES et al., 2016).

Outro programa de simulação hidráulica, chamado WaterGEMS (WATERGEMS, 2009), também foi utilizado em algumas etapas do projeto. A utilização deste programa é justificada pela melhor visualização e análise dos dados que ele possui, quando comparado com o EPANET 2.

Para a realização das partições, utilizou-se o programa METIS (KARYPIS; KUMAR, 2013), implementado em Python (versão 3.2) e um pacote de funções chamado Community Detection Toolbox (CDTB), desenvolvido por Athanasios Kehagias, implementado em Matlab (Versão R2015a), para o algoritmo ModulMax. 
Figura 2 - Organograma do capítulo de Material e Métodos

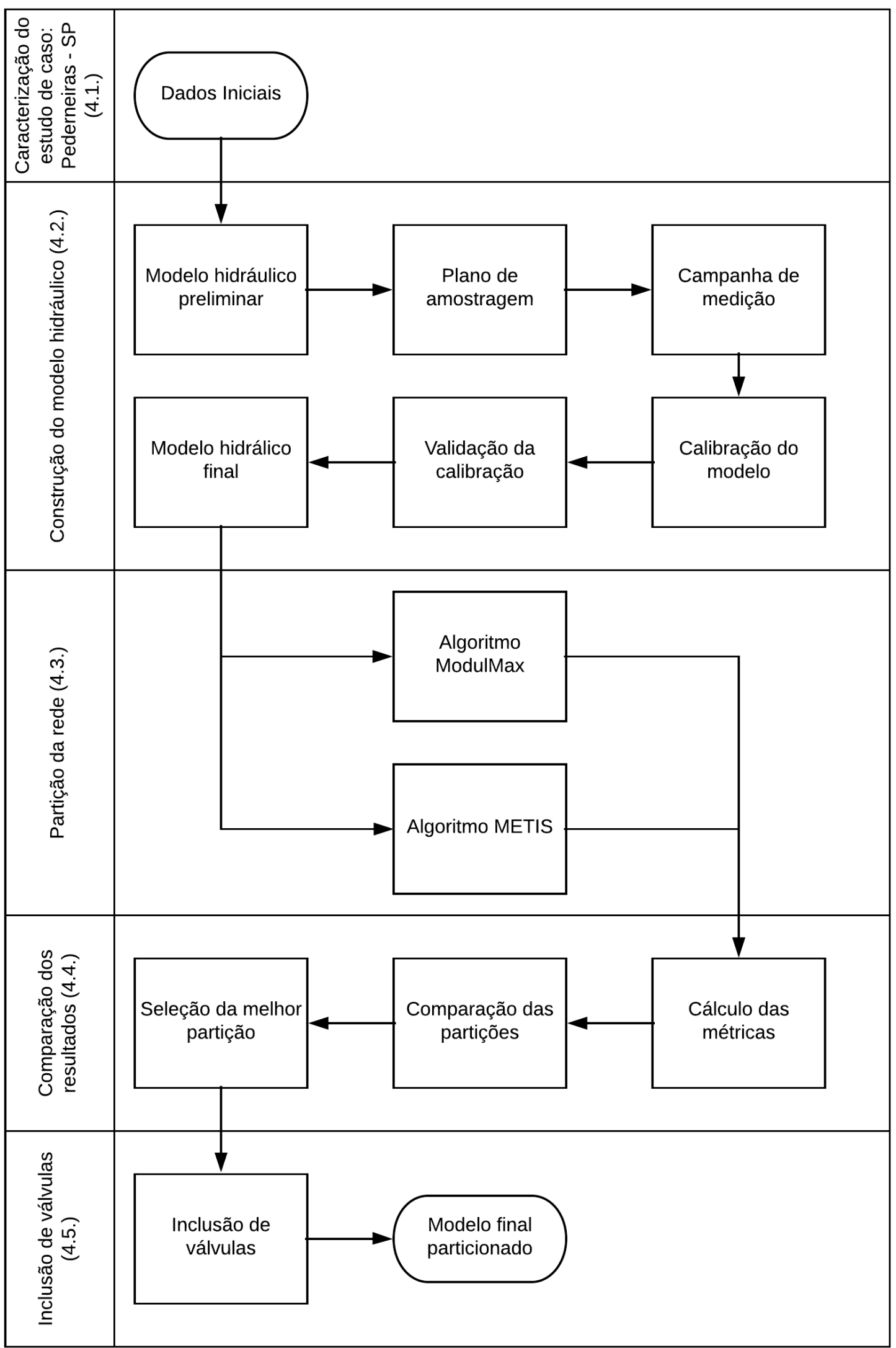

Fonte: Elaboração do autor 


\subsection{Caracterização do estudo de caso: Pederneiras - SP}

Pederneiras é um município localizado no Estado de São Paulo, a $320 \mathrm{~km}$ da capital paulista (Figura 3). Tem como limites geográficos as cidades de Arealva e Bariri ao norte; Boraceia, Bariri, Itapuí e Jaú a leste; Lençóis Paulista e Macatuba ao sul; e Agudos e Bauru a oeste. Este município possui uma área de $729 \mathrm{~km}^{2}$ e uma população estimada de 45.708 pessoas (IBGE, 2016).

Figura 3 - Área urbana de Pederneiras (SP) e Estado de São Paulo

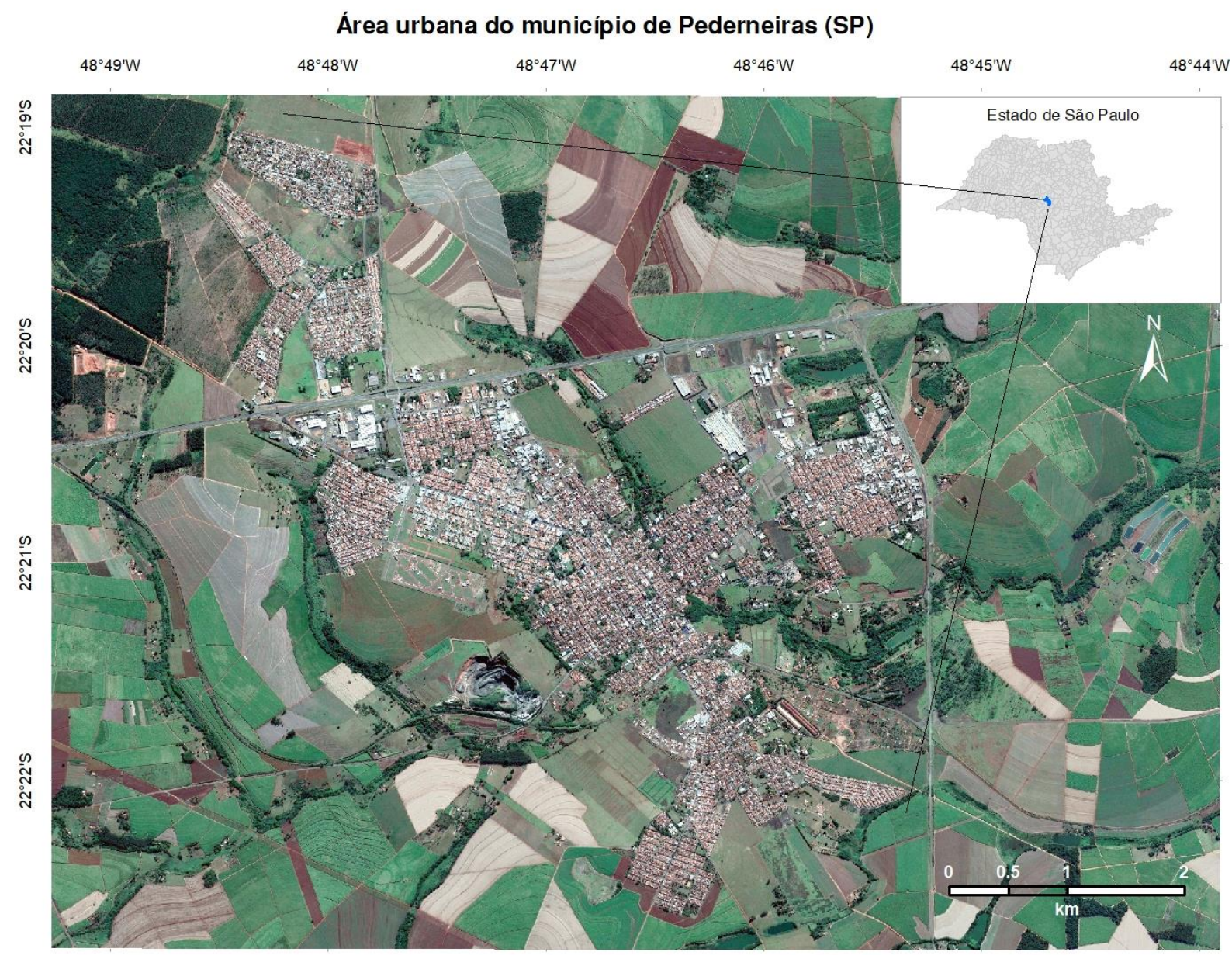

Fonte: Google Maps

Uma parceria firmada entre a SABESP - Pederneiras (Companhia de Saneamento Básico do Estado de São Paulo) e o Departamento de Engenharia Hidráulica e Saneamento (SHS), da EESC-USP permitiu que os dados disponíveis da rede do município fossem acessados. A planta da rede hidráulica do município, fornecida pela SABESP, é mostrada na Figura 4. Na Tabela 4 são listadas algumas características físicas da rede em questão. Todas as tubulações da rede de distribuição do município são de PVC. 
Tabela 4 - Quantificação das características físicas da rede - Pederneiras

\begin{tabular}{l|l}
\hline Elemento & Quantidade \\
\hline Tubulações & 2697 \\
\hline Válvulas Redutoras de Pressão & 2 \\
\hline Válvulas de Isolamento & 106 \\
\hline Reservatórios & 7 \\
\hline Sistemas de Bombeamento & 6 \\
\hline Comprimento de Tubulação $-50 \mathrm{~mm}$ & $160.566 \mathrm{~m}$ \\
\hline Comprimento de Tubulação $-75 \mathrm{~mm}$ & $15.068 \mathrm{~m}$ \\
\hline Comprimento de Tubulação $-100 \mathrm{~mm}$ & $14.562 \mathrm{~m}$ \\
\hline Comprimento de Tubulação $-125 \mathrm{~mm}$ & $700 \mathrm{~m}$ \\
\hline Comprimento de Tubulação $-150 \mathrm{~mm}$ & $10.889 \mathrm{~m}$ \\
\hline Comprimento de Tubulação $-200 \mathrm{~mm}$ & $5.680 \mathrm{~m}$ \\
\hline Comprimento de Tubulação $-250 \mathrm{~mm}$ & $307 \mathrm{~m}$ \\
\hline Comprimento de Tubulação - Total & $207.773 \mathrm{~m}$ \\
\hline
\end{tabular}

Fonte: Elaboração do autor 
Figura 4 - Rede de abastecimento de Pederneiras com diâmetros das tubulações e destaque do Setor Lacta

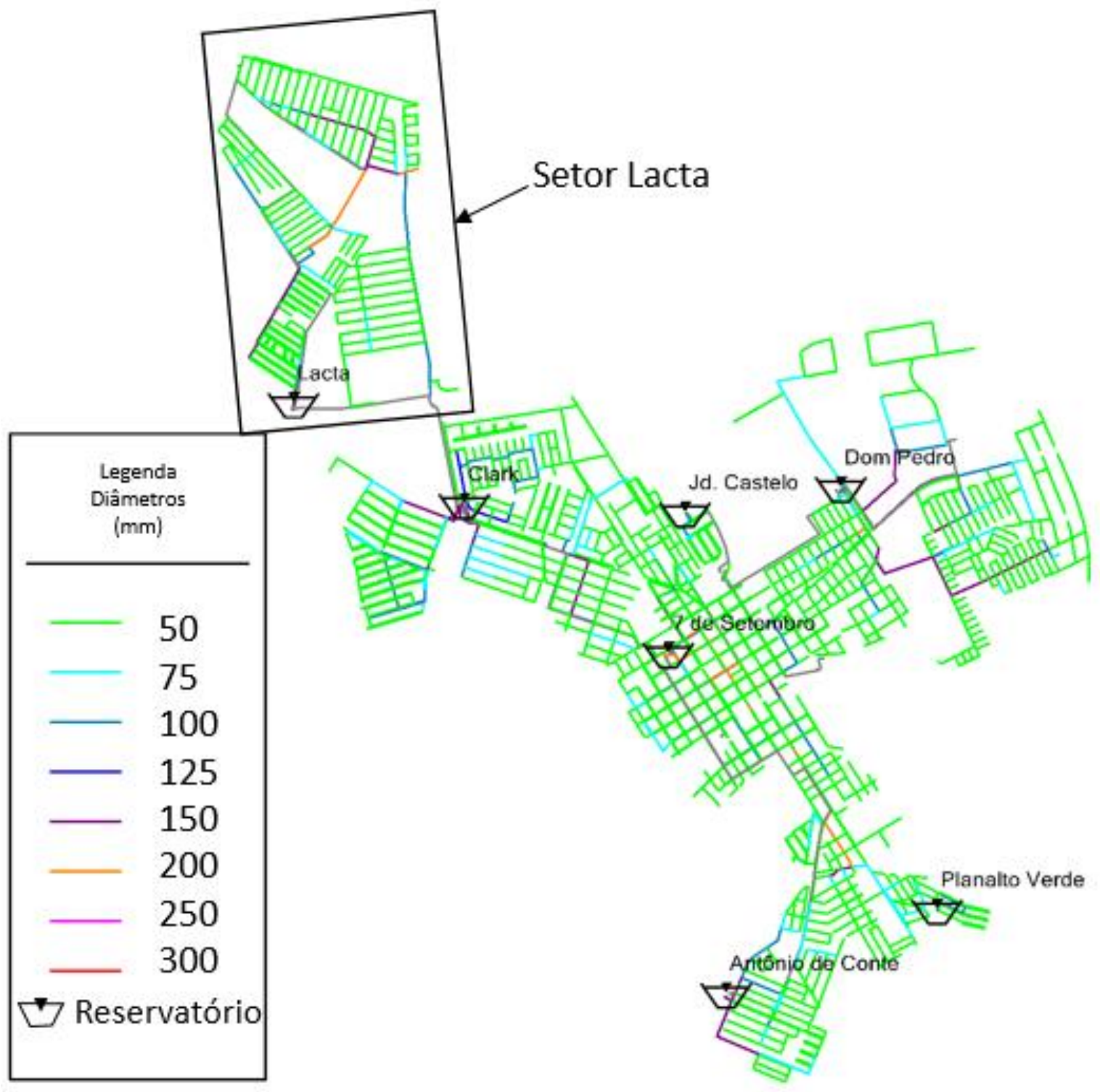

Fonte: Elaboração do autor

Essa rede é abastecida a partir de 7 centros de reservação (CR): Planalto Verde, Antônio de Conte, Dom Pedro, Sete de Setembro, Jardim Castelo, Clark e Lacta. Há também seis sistemas de bombeamento que pressurizam as áreas próximas aos reservatórios. O único setor de maior porte que é abastecido por um único reservatório é o setor Lacta.

O Setor Lacta possui mais de 3500 ligações e uma área de aproximadamente $2 \mathrm{~km}^{2}$, representando por volta de $18 \%$ de toda a rede do município. As características físicas do Setor Lacta são mostradas na Tabela 5. 
Tabela 5 - Quantificação das características físicas da rede - Setor Lacta

\begin{tabular}{l|l}
\hline Elemento & Quantidade \\
\hline Tubulações & 315 \\
\hline Válvulas Redutoras de Pressão & 2 \\
\hline Válvulas de Isolamento & 36 \\
\hline Reservatórios & 1 \\
\hline Sistemas de Bombeamento & 1 \\
\hline Comprimento de Tubulação $-50 \mathrm{~mm}$ & $27.442 \mathrm{~m}$ \\
\hline Comprimento de Tubulação $-75 \mathrm{~mm}$ & $2.273 \mathrm{~m}$ \\
\hline Comprimento de Tubulação $-100 \mathrm{~mm}$ & $2.950 \mathrm{~m}$ \\
\hline Comprimento de Tubulação $-150 \mathrm{~mm}$ & $2.153 \mathrm{~m}$ \\
\hline Comprimento de Tubulação $-200 \mathrm{~mm}$ & $1.647 \mathrm{~m}$ \\
\hline Comprimento de Tubulação - Total & $36.465 \mathrm{~m}$ \\
\hline
\end{tabular}

Fonte: Elaboração própria

O Setor Lacta possui uma pequena zona pressurizada por uma bomba nas tubulações próximas ao seu reservatório (zona alta). Essa zona é separada fisicamente do restante da rede, que é abastecida por gravidade. Além disso, existem duas válvulas redutoras de pressão (VRP) no sistema. As localizações das VRP's, bem como a zona alta, são mostradas na Figura 5. 
Figura 5 - Localização das VRP's e da zona alta - Setor Lacta

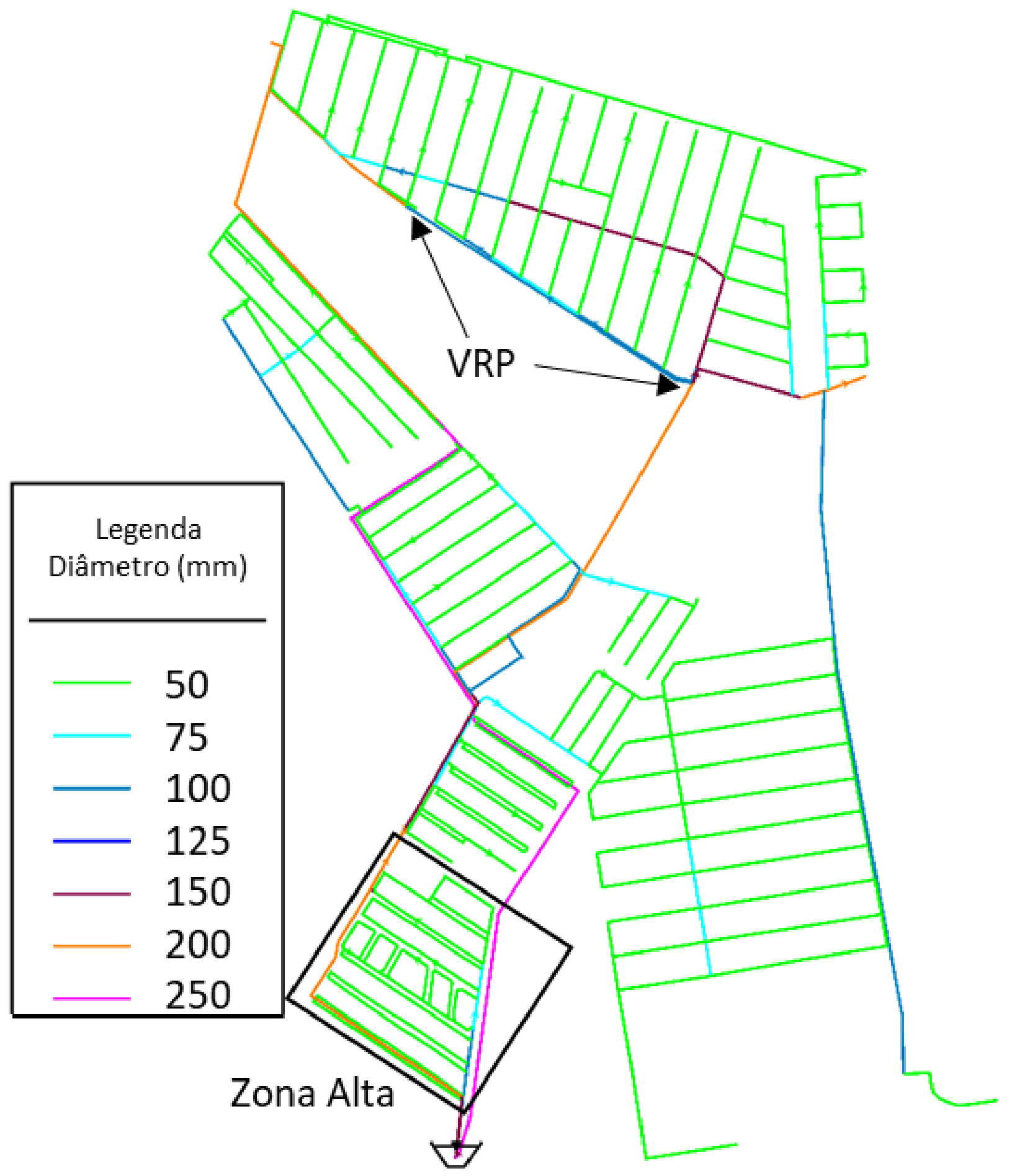

Fonte: Elaboração do autor 


\subsection{Construção do modelo hidráulico}

O presente trabalho teve como um dos objetivos específicos a construção do modelo hidráulico da rede de abastecimento de água do município de Pederneiras a ser utilizado para a partição da rede.

Utilizando WaterGEMS construiu-se um modelo hidráulico preliminar, que consistiu na importação dos dados do sistema de reservação e distribuição no software; no tratamento dos dados cadastrais de consumo para a inclusão de demanda nos nós e na inclusão de uma curva horária padrão para o consumo de água a partir dos dados fornecidos. Na Figura 6 pode-se observar o modelo preliminar resultante no software WaterGEMS em que as cores representam as cotas topográficas.

Figura 6 - Esquema do modelo hidráulico de Pederneiras no WaterGEMS. As cores representam as cotas topográficas

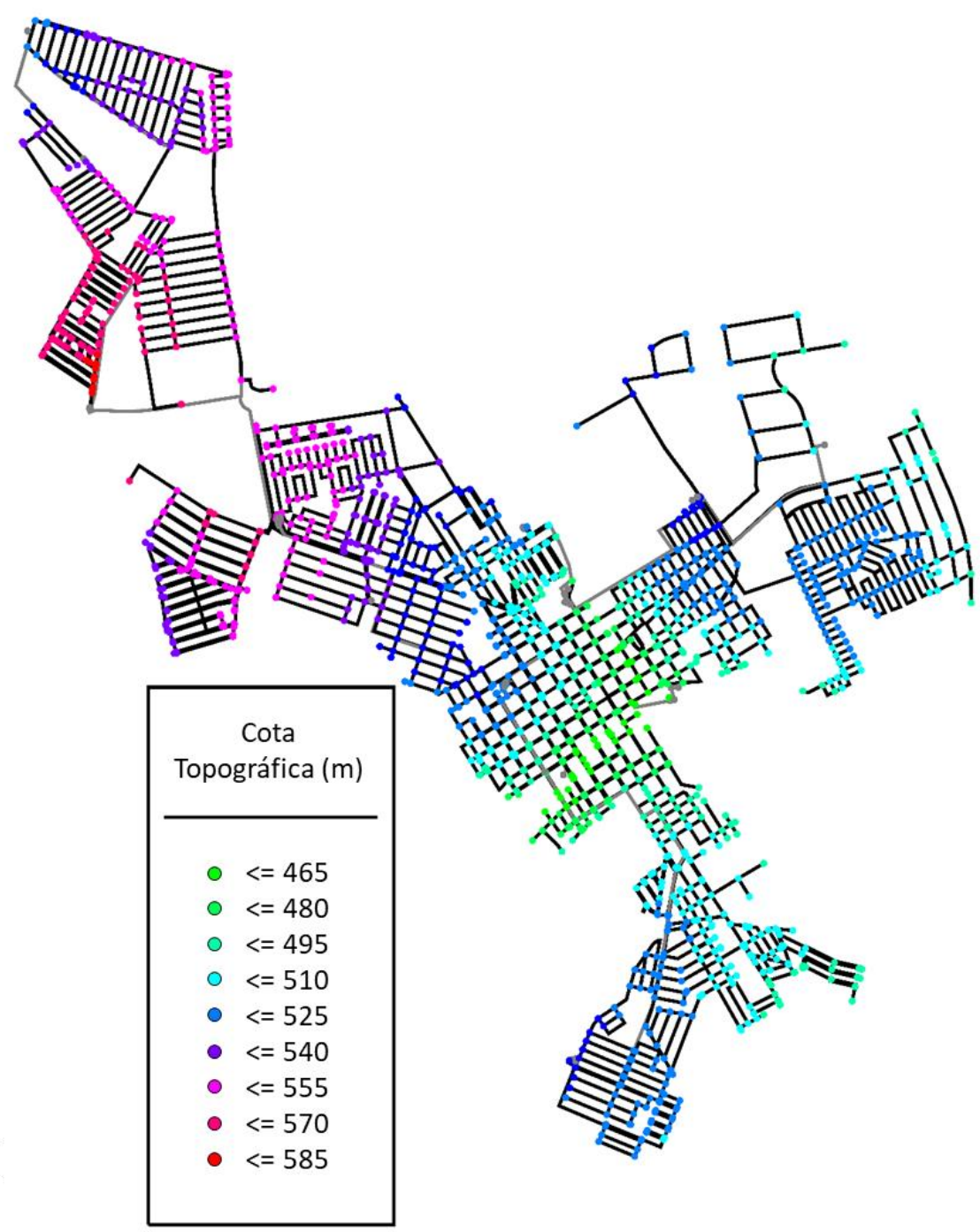

Fonte: Elaboração do autor 
Devido ao tamanho da área urbana do município, ao número de aparelhos medidores de vazão e carga de pressão disponíveis e ao curto tempo disponível para a pesquisa, decidiu-se realizar uma campanha de medição de pressões e vazões em apenas um distrito do município, calibrar apenas este distrito e estender os resultados da calibração para o restante da cidade. Sabe-se que essa metodologia não garantiu que o modelo hidráulico definitivo se comportasse de maneira semelhante à rede real. No entanto, o modelo gerado, mesmo com comportamento diferente da rede real, pode ser utilizado satisfatoriamente para a comparação dos resultados da partição da rede, que é o objetivo principal do projeto.

Assim, a campanha de medição foi realizada em apenas um distrito, chamado Setor Lacta. A escolha desse setor foi feita por ele ser teoricamente isolado fisicamente do restante da rede. Na Figura 7 pode-se observar o modelo hidráulico do Setor Lacta utilizado para a calibração. Os nós da rede são coloridos de acordo com sua cota de elevação.

\section{Figura 7 - Esquema topográfico do modelo Hidráulico do Setor Lacta visualizado no software} WaterGEMS

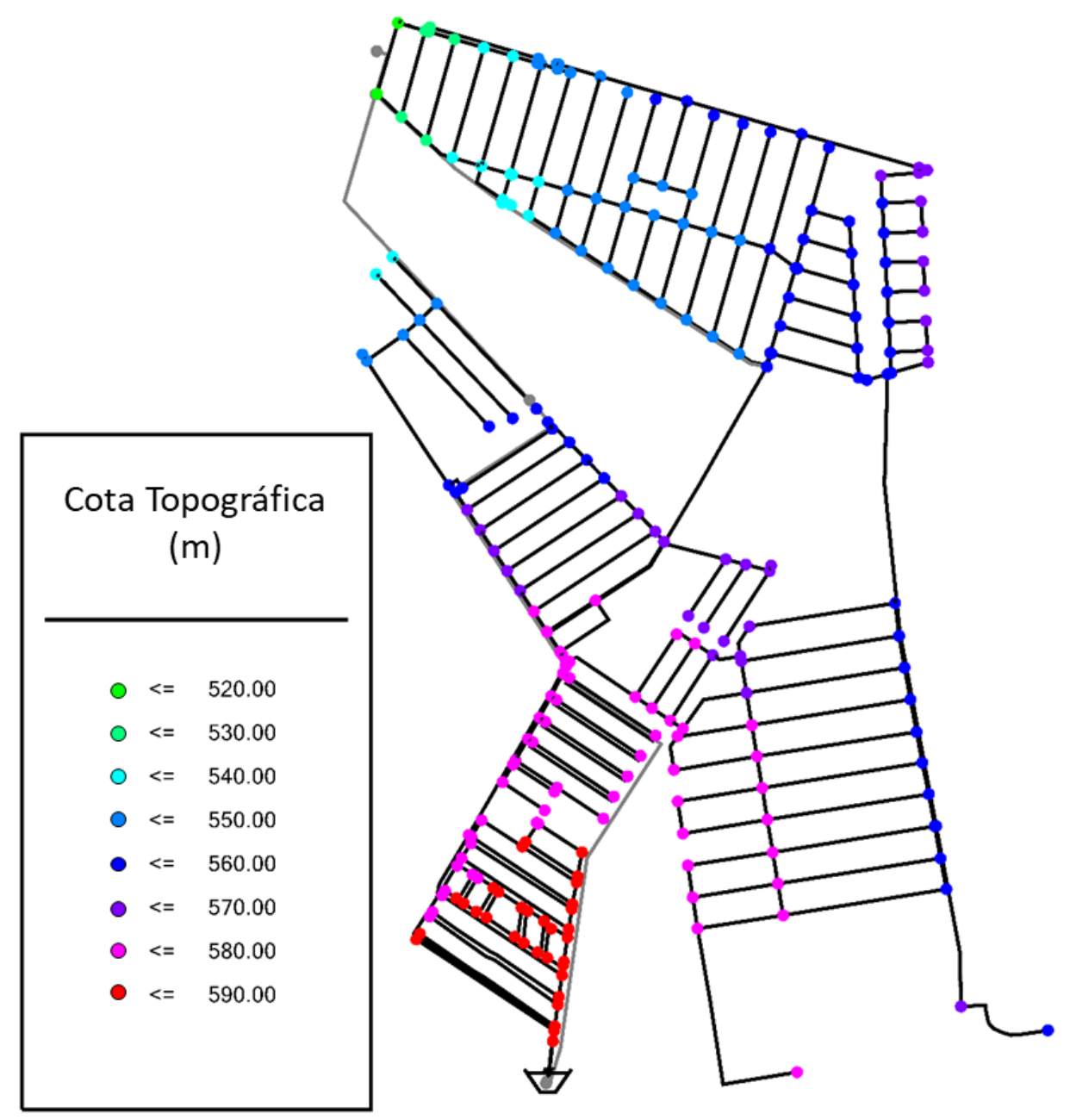

Fonte: Elaboração do autor 


\subsubsection{Modelo hidráulico preliminar}

Para o modelo hidráulico ser construído foi necessário informar alguns dados de entrada, como a duração da simulação, a rugosidade das tubulações, a demanda horária de cada nó, a curva que rege a cota de água nos reservatórios e o status dos elementos hidráulicos (bombas e válvulas), além das informações topográficas do modelo que já foram incluídas, como a cota topográfica dos elementos da rede, a curva das bombas e a localização dos elementos hidráulicos.

Para montar o modelo hidráulico preliminar, que foi utilizado para a realização do plano de amostragem, foram utilizados dados referentes ao mês de outubro de 2017. Para o cálculo da perda de carga foi utilizada a fórmula de Hazen-Willians, e o coeficiente de rugosidade utilizado para todas as tubulações foi $\mathrm{C}=130$.

A SABESP de Pederneiras forneceu os dados do consumo faturado do mês de outubro de 2017 de todas as áreas que compõem o Setor Lacta. Com estes dados foi possível incluir a demanda média mensal de cada nó através do método dos polígonos de Thiessen (BRASSEL; REIF, 1979).

A cota de água do reservatório que abastece o setor foi medida através de um transdutor de pressão. O nível médio horário desse reservatório foi calculado e incluído no modelo. A curva horária de consumo dos nós para 24 horas foi estimada de acordo com os valores encontrados na Literatura, utilizando-se a curva adimensional apresentada por Tsutiya (2004), a qual representa o consumo de água de uma quarta-feira do Setor de Itaim Paulista, localizado na cidade de São Paulo e com características predominantemente de área residencial (Figura 8). 
Figura 8 - Curva de consumo adimensional utilizada no modelo preliminar - 24 horas

Curva Adimensional utilizada no modelo preliminar

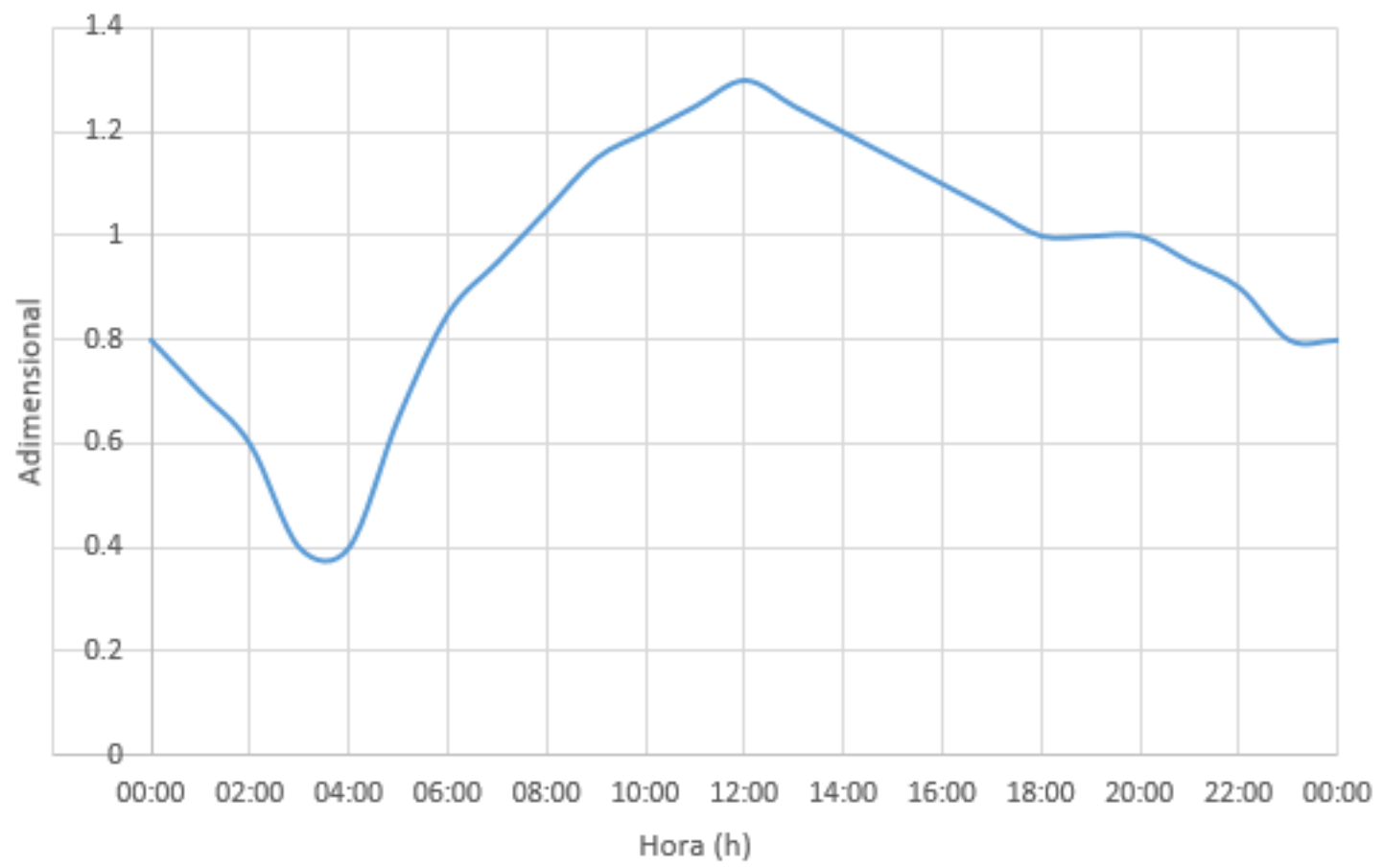

Fonte: Adaptado de Tsutiya (2004)

Além da curva de consumo, foi incluído um aspersor em cada nó do modelo com coeficiente de vazamento $c=3 * 10^{-4} l /\left(s * m^{1,18}\right)$ e um expoente de vazamento $\alpha$ igual a 1,18, que são valores utilizados amplamente na literatura (GAMBOA MEDINA, 2017; JOWITT; XU, 1990). Estes coeficientes resultaram em um vazamento correspondente a 15,9\% do consumo total da rede.

\subsubsection{Plano de amostragem}

Usualmente mede-se a vazão na saída dos reservatórios para a calibração. De fato, este é o ponto mais simples para se instalar o aparelho, além de permitir verificar o consumo total de água. Já a medição de carga de pressão pode ser feita em qualquer ponto da rede.

Para selecionar os pontos de coleta de carga pressão durante a campanha de medição foi utilizado um método que usa a entropia de Shannon e a matriz de sensibilidade, proposto por De Schaetzen, Walters e Savic (2000), com as adaptações para levar em consideração a sensibilidade dos pontos à rugosidade, à demanda e ao vazamento. A medida da sensibilidade de um nó foi feita através de 3 matrizes, sendo uma para rugosidade, outra para demanda e uma 
última para vazamento. Existem muitos métodos para o cálculo dos coeficientes da matriz de sensibilidade (KAPELAN; SAVIC; WALTERS, 2005b). Neste trabalho, foi utilizado o método das diferenças finitas.

Deste modo, sendo uma rede com $n$ nós e $m$ tubulações, os coeficientes da matriz de sensibilidade quanto à rugosidade, de dimensões $n \times m$, foram calculados através das equações abaixo:

$$
\begin{gathered}
M_{r u g}(i, j)=\left|\frac{\partial p_{i, h}}{\partial C_{j}}\right| \cong\left|\frac{p_{i, h}\left(C_{j}\right)-p_{i, h}\left(C_{j}^{\prime}\right)}{C_{j}-C_{j}^{\prime}}\right| \forall i \in[1, n], \forall j \in[1, m] \\
\left|\frac{\partial p_{i}}{\partial C_{j}}\right|=\sum_{h=1}^{24}\left|\frac{\partial p_{i, h}}{\partial C_{j}}\right|
\end{gathered}
$$

sendo $p_{i, h}\left(C_{j}\right)$ a carga de pressão simulada no ponto $i$ e no instante $h$ com o coeficiente de rugosidade no tubo $j$ igual a $C_{j}$; e $p_{i, h}\left(C^{\prime}{ }_{j}\right)$ a carga de pressão simulada no ponto $i$ e no instante $h$ com o coeficiente de rugosidade no tubo $j$ igual a $C{ }^{\prime} j$.

Neste estudo foi utilizada inicialmente uma rugosidade de Hazen-Williams de 130 para todas as tubulações e considerou-se $C^{\prime}{ }_{j}=C_{j}+1=131$ para todos os trechos.

Para a matriz relacionada à demanda, cada nó foi alterado em $0,001 \mathrm{~L} / \mathrm{s}$. Assim, o cálculo dos coeficientes da matriz de sensibilidade quanto à demanda foi feito da seguinte maneira:

$$
\begin{gathered}
M_{\text {dem }}(i, j)=\left|\frac{\partial p_{i, h}}{\partial D_{j}}\right| \cong\left|\frac{p_{i, h}\left(Q_{j}\right)-p_{i, h}\left(Q_{j}^{\prime}\right)}{Q_{j}-Q_{j}^{\prime}}\right| \forall i \in[1, n], \forall j \in[1, n] \\
\left|\frac{\partial p_{i}}{\partial Q_{j}}\right|=\sum_{h=1}^{24}\left|\frac{\partial p_{i, h}}{\partial Q_{j}}\right|
\end{gathered}
$$

sendo $p_{i, h}\left(Q_{j}\right)$ a carga de pressão simulada no ponto $i$ e no instante $h$ com demanda no nó $j$ igual a $Q_{j}$; e $p_{i, h}\left(Q_{j}^{\prime}\right)$ a carga de pressão simulada no ponto $i$ e no instante $h$ com demanda no nó $j$ igual a $Q^{\prime}{ }_{j}$.

Já a matriz relacionada ao vazamento alterou em $0,00001 \mathrm{~L} / \mathrm{s} . \mathrm{m}^{1,18}$ o coeficiente de vazamento do nó:

$$
M_{v a z}(i, j)=\left|\frac{\partial p_{i, h}}{\partial c_{j}}\right| \cong\left|\frac{p_{i, h}\left(c_{j}\right)-p_{i, h}\left(c_{j}^{\prime}\right)}{c_{j}-c_{j}^{\prime}}\right| \forall i \in[1, n], \forall j \in[1, n]
$$




$$
\left|\frac{\partial p_{i}}{\partial c_{j}}\right|=\sum_{h=1}^{24}\left|\frac{\partial p_{i, h}}{\partial c_{j}}\right|
$$

sendo $p_{i, h}\left(c_{j}\right)$ a carga de pressão simulada no ponto $i$ e no instante $h$ com coeficiente de vazão no nó $j$ igual a $c_{j}$; e $p_{i, h}\left(c^{\prime}{ }_{j}\right)$ a carga de pressão simulada no ponto $i$ e no instante $h$ com coeficiente de vazão no nó $j$ igual a $c$ ' ${ }_{j}$.

Nota-se que a dimensão das matrizes de sensibilidade quanto à demanda e ao vazamento é de $n \times n$, enquanto que a dimensão da matriz de sensibilidade quanto à rugosidade é de $n \times m$.

Assim, foram construídas três matrizes de sensibilidade, sendo $\mathrm{M}_{\text {rug }}$ a que se refere à alteração da rugosidade, $M_{\text {dem }}$ a que se refere à alteração de demanda e $M_{v a z}$ a que se refere à alteração do coeficiente de vazamento. $M_{\text {rug }}$ tem dimensões $n$ x m e o elemento $(i, j)$ desta matriz representa a sensibilidade da carga de pressão do nó i quanto à alteração de rugosidade da

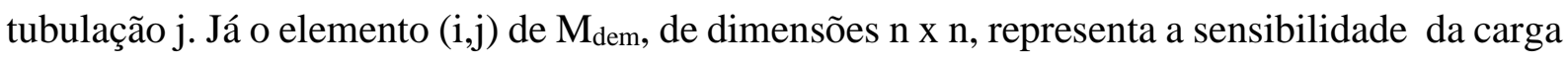
de pressão do nó i devido à alteração de demanda no nó j. O mesmo vale para $\mathrm{M}_{\mathrm{vaz}}$, mas a sensibilidade se refere à alteração do coeficiente de vazamento no nó j.

Após calcular as três matrizes de sensibilidade, essas foram normalizadas de forma que a soma de todos os elementos de uma das matrizes fosse igual a 1. Com essas três matrizes foi utilizado um algoritmo genético multiobjetivo baseado no NSGA-II (DEB et al., 2002) para selecionar os melhores conjuntos de pontos para monitoramento de carga de pressão. A seguir são mostradas as variáveis utilizadas para a construção do algoritmo otimizador do plano de amostragem.

\section{Variável de decisão $X_{k}$}

Um plano de amostragem $\mathrm{X}_{\mathrm{k}}$ é um conjunto discreto de $\mathrm{k}$ pontos de monitoramento, onde cada posição do vetor $\mathrm{X}_{\mathrm{k}}$ representa um nó da rede a ser monitorado. $\mathrm{O}$ número $\mathrm{k}$ de posições do vetor deve ser igual ao máximo de pontos de monitoramento simultâneos que se possa admitir no plano de amostragem. O número de posições nulas de um vetor indica a quantidade de pontos a serem desconsiderados no plano de monitoramento em relação à quantidade máxima admitida. Portanto, se em uma determinada rede deseja-se realizar um plano de amostragem que tenha no máximo 10 pontos de monitoramento, deve ser criado um vetor $\mathrm{X}$ com 10 casas. Caso um vetor $\mathrm{X}_{10}$ possua 3 posições nulas em sua composição, isto indica que o plano proposto utilizaria apenas 7 pontos de monitoramento. 
A aptidão de um plano de amostragem $X_{k}$ foi calculada através de duas funções objetivo, $f 1(x)$ e f2(x).

\section{Função Objetivo f1(X)}

A função objetivo f1(x) foi calculada tanto para a matriz de sensibilidade da pressão à rugosidade quanto para as matrizes sensibilidade à demanda e ao vazamento. Para facilitar o entendimento, explica-se primeiramente a metodologia aplicada para o cálculo de f1(x) relativo à matriz de sensibilidade quanto à rugosidade. Esta metodologia é exposta por De Schaetzen (2000). Para incluir a parcela de f1(X) devido às matrizes de demanda e vazamento foi utilizada a mesma metodologia, com a única diferença de utilizar uma matriz que é o resultado da média, elemento a elemento, das matrizes de sensibilidade relativas à demanda e ao vazamento, ao invés de utilizar a matriz de sensibilidade quanto à rugosidade.

\section{Função Objetivo f1(X) relativa à rugosidade}

A função objetivo $\mathrm{f} 1(\mathrm{X})$ relativa à rugosidade, chamada de $\mathrm{f} \mathrm{r}^{\mathrm{rug}}(\mathrm{X})$ foi subdividida em duas partes, sendo a primeira responsável por indicar a sensibilidade do conjunto de pontos $\mathrm{X}_{\mathrm{k}}$ na rede e a segunda por indicar a entropia do conjunto escolhido. Dessa maneira, a primeira parte da função $\mathrm{f} 1(\mathrm{X})$ será definida por $\mathrm{f} 1_{\mathrm{A}}{ }^{\mathrm{rug}}(\mathrm{X})$ :

$$
\begin{gathered}
f 1_{A}^{r u g}(X)=\sum_{j=1}^{m}(a j), \\
\text { sendo } a j=\max _{i \in X_{k}} M_{r u g}(i, j) \forall j \in[1, m]
\end{gathered}
$$

Os conjuntos $\mathrm{X}_{\mathrm{k}}$ que apresentarem os maiores valores de $\mathrm{f} 1_{\mathrm{A}}{ }^{\mathrm{rug}}(\mathrm{X})$ foram preferíveis, pois estes seriam mais sensíveis à alteração de rugosidade. O limite superior de $\mathrm{f} 1_{\mathrm{A}}{ }^{\mathrm{rug}}(\mathrm{X})$, chamado de $\mathrm{f} 1_{\mathrm{A}}{ }^{\text {rug,max }}(\mathrm{X})$ foi calculado como sendo a soma dos maiores valores de sensibilidade de cada nó, ou seja:

$$
\begin{gathered}
f 1_{A}^{\text {rug,max }}(X)=\sum_{j=1}^{m}\left(a j^{\text {max }}\right), \\
\text { sendo } a j^{\max }=\max _{i \in[1, n]} M_{r u g}(i, j) \forall j \in[1, m]
\end{gathered}
$$

$\mathrm{f} 1_{\mathrm{A}}{ }^{\text {rug,max }}(\mathrm{X})$ será igual a $\mathrm{f} 1_{\mathrm{A}}{ }^{\text {rug }}(\mathrm{X})$ na hipótese de se incluir um ponto de monitoramento em cada nó da rede, ou seja, $\mathrm{X}_{\mathrm{k}}=[1, \mathrm{n}]$. 
O limite inferior de $\mathrm{f} 1_{\mathrm{A}}{ }^{\text {rug }}(\mathrm{X})$, por sua vez, foi admitido como zero. Portanto $\mathrm{f} 1_{\mathrm{A}}{ }^{\text {rug,min }}(\mathrm{X})$ $=0$.

A segunda parte de $\mathrm{f} 1^{\text {rug }}(\mathrm{X})$, chamada de $\mathrm{f} 1_{\mathrm{B}}{ }^{\mathrm{rug}}(\mathrm{X})$, mede a entropia do conjunto através da seguinte equação:

$$
\begin{gathered}
f 1_{B}^{r u g}(X)=-\sum_{j=1}^{m} \omega_{j} * \ln \omega_{j}, \\
\text { sendo } \omega_{j}=\frac{a_{j}}{\sum_{j=1}^{m} a_{j}} \forall j \in[1, m]
\end{gathered}
$$

Esta segunda parte de $\mathrm{f} 1(\mathrm{X})$ valoriza os conjuntos de planos de amostragem que possuem pontos de monitoramento com distribuição mais uniforme quanto à sensibilidade das tubulações à rugosidade. $\mathrm{O}$ limite superior de $\mathrm{f} 1_{\mathrm{B}}{ }^{\text {rug }}(\mathrm{X})$, chamado de $\mathrm{f} 1_{\mathrm{B}}{ }^{\mathrm{rug}, \mathrm{max}}(\mathrm{X})$, foi admitido como sendo igual a $\ln (\mathrm{m})$. Este é um valor hipotético, que na maioria dos casos é impossível de se obter. Já o limite inferior, $\mathrm{F} 1_{\mathrm{B}}{ }^{\text {rug,min }}(\mathrm{X})$, foi admitido como sendo igual a zero. Também é desejado que esse valor seja maximizado.

Combinando as duas partes da função através da abordagem de programação por compromisso, tem-se:

$$
f 1^{\text {rug }}(X)=\sqrt{\left(\frac{f 1_{A}^{\text {rug }}(X)-f 1_{A}^{\text {rug,max }}(X)}{f 1_{A}^{\text {rug,min }}(X)-f 1_{A}^{\text {rug,max }}(X)}\right)^{2}+\left(\frac{f 1_{B}^{\text {rug }}(X)-f 1_{B}^{\text {rug,max }}(X)}{f 1_{B}^{\text {rug,min }}(X)-f 1_{B}^{\text {rug,max }}(X)}\right)^{2}}
$$

\section{Função Objetivo f1 $(\mathrm{X})$ relativa à demanda e ao vazamento}

A metodologia utilizada para o cálculo de $\mathrm{f} 1(\mathrm{X})$ relativa à demanda e ao vazamento, chamada de $f 1^{\text {con }}(\mathrm{X})$, foi a mesma que a mostrada acima, utilizando, porém, uma matriz diferente. Sendo $\mathbf{M}_{\mathrm{dem}}$ a matriz normalizada de sensibilidade relativa à demanda e $\mathbf{M}_{\mathrm{vaz}}$ a matriz normalizada de sensibilidade relativa ao vazamento, a matriz de dimensões $n \times n$ utilizada nesta etapa, chamada de $\mathrm{M}_{\mathrm{con}}$, foi calculada como:

$$
M_{c o n}=\frac{M_{d e m}+M_{v a z}}{2}
$$

Este cálculo foi feito para dar um peso proporcional à alteração de rugosidade e ao consumo nodal no cálculo de $\mathrm{f} 1(\mathrm{X})$, uma vez que ambas as matrizes relativas à demanda e vazamento foram calculadas através da alteração do consumo nodal da rede.

As equações utilizadas para o cálculo de $\mathrm{f} 1^{\mathrm{con}}(\mathrm{X})$ foram: 


$$
\begin{aligned}
& f 1_{A}^{c o n}(X)=\sum_{j=1}^{n}(b j) \\
& \text { sendo } b j=\max _{i \in X_{k}} M_{c o n}(i, j) \forall j \in[1, n] \\
& f 1_{A}^{\text {con,max }}(X)=\sum_{j=1}^{n}\left(b j^{\max }\right) \\
& \text { sendo } b j^{\text {max }}=\max _{i \in[1, n]} M_{c o n}(i, j) \forall j \in[1, n] \\
& f 1_{B}^{\text {con }}(X)=-\sum_{j=1}^{n} \varpi_{j} * \ln \varpi_{j} \\
& \text { sendo } \varpi_{j}=\frac{b_{j}}{\sum_{j=1}^{n} b_{j}} \forall j \in[1, n] \\
& f 1_{B}^{\text {con,max }}(X)=\ln n \\
& f 1^{\text {con }}(X)=\sqrt{\left(\frac{f 1_{A}^{\text {con }}(X)-f 1_{A}^{\text {con,max }}(X)}{f 1_{A}^{\text {con,min }}(X)-f 1_{A}^{\text {con, max }}(X)}\right)^{2}+\left(\frac{f 1_{B}^{\text {con }}(X)-f 1_{B}^{\text {con,max }}(X)}{f 1_{B}^{\text {con,min }}(X)-f 1_{B}^{\text {con,max }}(X)}\right)^{2}}
\end{aligned}
$$

Calculadas ambas as partes de $\mathrm{f1}(\mathrm{X})$, foi possível encontrar o valor desta função objetivo:

$$
f 1(X)=f 1^{\text {rug }}(X)+f 1^{\text {con }}(X)
$$

\section{Função Objetivo f2(X)}

A função objetivo $\mathrm{f} 2(\mathrm{X})$ busca minimizar a quantidade de pontos de monitoramento utilizados no plano de amostragem. Como o valor nulo em uma posição do vetor X indica a não utilização de um ponto de monitoramento, tem-se:

$$
f 2(X)=k-l
$$

sendo $k$ o número de posições do vetor $X$ e $l$ o número de posições deste mesmo vetor que possuírem o valor nulo. 
A partir da metodologia descrita acima e utilizando o Matlab foi construído um algoritmo que retorna a curva pareto do problema com as funções objetivo f1 e f2. Para o cálculo das matrizes de sensibilidade foi utilizada uma biblioteca de funções elaborada pelo centro de pesquisa KIOS, da Universidade do Chipre, que utiliza o Epanet2 como simulador hidráulico.

\subsubsection{Campanha de medição}

Para este trabalho, foram instalados 9 transdutores de pressão com dataloggers, sendo um cedido pela SABESP-Pederneiras e os outros oito pertencentes à Escola de Engenharia de São Carlos, em residências situadas próximas aos nós selecionados pelo plano de amostragem. Também foi utilizado um medidor de vazão, pertencente à SABESP, que mediu a vazão da saída do reservatório que abastece o Setor.

Na Tabela 6 são apresentadas as especificações técnicas dos transdutores de pressão e armazenador de dados que foram utilizados.

Tabela 6 - Informações técnicas do transdutor de pressão e datalogger Metrolog NA-100

\begin{tabular}{l|l}
\hline Marca & Metrolog NA-100 \\
\hline Faixa de operação & 0 a 100 metros de coluna de água \\
\hline Precisão & 0,1 metros \\
\hline Temperatura de operação & 1 a $40{ }^{\circ} \mathrm{C}$ \\
\hline Duração da Bateria & $\begin{array}{l}\text { Típica } 3 \text { anos para intervalos de gravação de } \\
1 \text { minuto }\end{array}$ \\
\hline Precisão do Relógio & Máx. erro de 100 segundos por mês \\
\hline Memória de armazenamento & $32 \mathrm{kB}$ \\
\hline
\end{tabular}

Fonte: Adaptado de Technolog (1998)

Os transdutores de pressão mediram as pressões em intervalos de 15 minutos e o medidor de vazão armazenou os dados da vazão de saída do reservatório em intervalos de 1 minuto. A campanha foi realizada entre os dias 21/02/2018 e 26/02/2018, resultando em 6 dias de monitoramento.

\subsubsection{Calibração do modelo}

Coletados os dados de vazão e carga de pressão disponíveis, pretendeu-se calibrar o Setor Lacta. Para a realização da calibração foi utilizada a metodologia proposta por Martínez- 
Solano, Iglesias-Rey e Arce (2017) e o Darwin Calibrator, do WaterGEMS (WU et al., 2008), como calibrador.

Após um estudo mais aprofundado sobre as características da rede, percebeu-se que, como os diâmetros que a compõe são em sua maioria iguais a $50 \mathrm{~mm}$, a rede seria melhor representada por um modelo que utilizasse a fórmula universal para o cálculo da perda de carga, ao invés de utilizar Hazen-Willians, como ocorreu no processo de seleção de pontos de monitoramento. Portanto, para o processo de calibração e de posterior partição de rede, a fórmula universal foi utilizada. Percebeu-se também que a rugosidade de todas as tubulações era baixa, uma vez que o material de todas era o PVC, e que a variação desta rugosidade não trazia uma alteração significativa nas pressões. Portanto, decidiu-se que a calibração da rugosidade absoluta não seria feita, e ao invés dela, seria feita a calibração dos coeficientes de perda de carga localizada nos pontos de maior relevância.

Para a calibração da perda de carga localizada dos acessórios da rede, foi utilizada uma tubulação fictícia em regime de escoamento hidraulicamente rugoso (número de Reynolds elevado), em que o fator de atrito (f) é preponderantemente influenciado pela rugosidade absoluta da tubulação (PORTO, 2006). Deste modo, estimando o comprimento da tubulação fictícia e igualando seu diâmetro com o diâmetro da peça que causa a perda de carga, foi possível calibrar a perda de carga localizada através do ajuste da rugosidade absoluta dessa tubulação fictícia. A conversão da perda de carga distribuída do tubo fictício em coeficiente de perda localizada foi feita através da equação:

$$
K=\frac{L_{e} * f}{D}
$$

sendo K o coeficiente da perda de carga localizada; $\mathrm{L}_{\mathrm{e}} \mathrm{o}$ comprimento da tubulação fictícia (m); f o fator de atrito; e D o diâmetro da tubulação fictícia, igual ao diâmetro do acessório que causa a perda de carga localizada.

Nesta etapa, pretendeu-se calibrar os coeficientes de perda de carga localizada (K), a curva de demanda horária e os coeficientes de vazamento. Os resultados obtidos foram expandidos para toda a rede de abastecimento de água do município. Sabe-se que o comportamento de consumo e vazamento não é o mesmo em toda a cidade, no entanto, esta extensão resultou em um modelo da rede com características mais próximas dos valores reais, que foi a intenção desta etapa da pesquisa. A não verossimilhança do modelo definitivo com a rede real em nada afetou a comparação dos resultados de partição de rede através de métricas, que foi o objetivo central do projeto. 
Para o processo de calibração, foi suposto que:

(i) O consumo efetivo de água, ou seja, a demanda, foi considerado independente da carga de pressão na rede. Como a maior parte das residências do município de Pederneiras possui caixa d'água, essa foi uma consideração plausível. Foi assumido que o consumo nodal também fosse conhecido e igual ao consumo do mês de outubro de 2017.

(ii) $\mathrm{O}$ volume de água que abastece todo o setor fosse conhecido, incluindo a variação temporal.

(iii) $\mathrm{O}$ volume de água que não faz parte do consumo efetivo fosse considerado como vazamento e portanto, o valor de sua vazão depende da carga de pressão no nó.

(iv) A rede tem a mesma característica de consumo e, portanto, uma única curva de consumo pode representar a variação de consumo de todos os nós da rede.

Dessa maneira, foi calibrado o coeficiente de vazamento da rede de abastecimento de água, a curva padrão da demanda diária dos nós e os coeficientes de perda de carga localizada em peças onde essa perda foi relevante.

São apresentadas a seguir as equações utilizadas por essa metodologia. No problema em questão, o volume de água abastecido e consumido pela rede era conhecido, no entanto a variação temporal do consumo era uma incógnita. O balanço hídrico pode ser escrito da seguinte forma:

$$
q_{s}(t)=\sum_{i=1}^{N n} w_{D, i}{ }^{t} * Q_{D B, i}+Q_{V}(t)
$$

sendo $q_{s}(t)$ a vazão de água que abastece o setor no instante $t ; Q_{V}(t)$ a vazão de água não consumida efetivamente pelo setor no tempo $t ; Q_{D B, i}$ a demanda de base (média) do nó $i$, e $N_{n} \mathrm{O}$ número de nós do modelo. A abordagem mais simples para modelar vazamentos é admitir que a demanda relativa ao vazamento é função da carga de pressão no nó em que ele está localizado:

$$
Q_{V, i}(t)=c_{E, i} * p_{i}(t)^{\alpha}
$$

sendo $p_{i}(t)$ é a carga de pressão (m) no nó $i$ no tempo $t, \alpha$ é o expoente de vazamento e $c_{E, i}$ é o coeficiente de vazamento do nó $i$. Portanto, a equação pode ser reescrita como:

$$
q_{s}(t)=\sum_{i=1}^{N n} w_{D, i}{ }^{t} * Q_{D B, i}+\sum_{i=1}^{N n} c_{E, i} * p_{i}(t)^{\alpha}
$$


Admitindo que a simulação seja dividida em $T$ intervalos de medições, o número de incógnitas seria igual a $N_{n} *(1+T)$. Portanto, foi necessário que se obtivesse o mesmo número de equações para que o sistema pudesse ser resolvido. A equação ( 49 ) pode ser contada $T$ vezes, uma para cada instante de simulação. Além disso, a média dos valores que compõem o padrão de demanda deve ser igual a 1 , somando assim $T+1$ equações. Admitindo que todos os nós tenham o mesmo padrão de demanda e o mesmo coeficiente de vazamento (c) o problema foi reduzido a $T+1$ incógnitas, sendo assim um sistema determinado. Neste estudo foi assumido que o expoente de vazamento de toda a rede é igual a 1,18, um valor usualmente utilizado na literatura (GAMBOA MEDINA, 2017).

$$
q_{s}(t)=w_{D}{ }^{t} * \sum_{i=1}^{N n} Q_{D B, i}+c_{E} \sum_{i=1}^{N n} p_{i}(t)^{1,18}
$$

Há uma relação entre o padrão de demanda, o coeficiente de vazamento e a carga de pressão em cada nó, explicitada na equação ( 49 ). As cargas de pressão foram calculadas através do EPANET, considerando o padrão de demanda e o coeficiente de vazamento fixos. Esse problema se tornou então iterativo, sendo que a cada passo deve ser estimado o coeficiente de vazamento, depois a curva padrão e por último o coeficiente de perda de carga localizada. Estimados todos esses parâmetros, uma nova iteração deve ser realizada até que algum critério de parada seja atingido.

\section{Coeficiente de Vazamento (c)}

Para a estimativa do coeficiente de vazamento, foi utilizada a equação ( 50 ) assumindo que a curva padrão de demanda é conhecida e igual à curva da vazão que abastece o sistema. Com esta hipótese, foi possível calcular as cargas hidráulicas do sistema e estimar a média de vazamentos. Incluindo o coeficiente de vazamento no modelo, as pressões nos pontos foram alteradas, o que alterou também a segunda parcela da equação ( 50 ). Assim, o procedimento foi repetido, encontrando um novo valor para o coeficiente de vazamento. Repetiu-se estes cálculos até que a diferença do coeficiente de vazamento encontrada entre duas iterações consecutivas não alterou a quinta casa decimal deste fator.

\section{Curva Padrão de Demanda (wD)}

Com o valor do coeficiente de vazamento calculado, o valor de cada multiplicador do padrão de demanda pode ser calculado a partir da equação ( 51 ):

$$
w_{D}^{t}=\frac{q_{s}(t)-c \sum_{i=1}^{N n} p_{i}(t)^{1,18}}{\sum_{i=1}^{N n} Q_{D B, i}}
$$


Novamente, com a alteração do multiplicador da demanda, as pressões nos nós foram alteradas. Assim, esse processo foi repetido e os multiplicadores recalculados, até que a máxima diferença absoluta entre a vazão medida e a calculada fosse menor que $0,10 \mathrm{~m}^{3} / \mathrm{h}$.

\section{Coeficiente de perda de carga localizada $(\mathrm{K})$}

Com o valor para o coeficiente de vazamento e a curva padrão de demanda, o ajuste do coeficiente de perda de carga localizada pode ser estimado através de um problema de otimização visando a minimização do desvio entre os dados de carga de pressão e vazão observados em campo através da campanha de medição e os dados simulados. Como descrito anteriormente, foi criada uma tubulação fictícia no local de cada acessório a ser calibrado e a variável de decisão foi a rugosidade absoluta desta tubulação. Para este ajuste, foi utilizado o Darwin Calibrator, ferramenta inclusa no programa WaterGEMS cuja função objetivo utilizada é a mostrada na equação ( 10 ), com $p_{p p f}=0,30 \mathrm{~m}, \mathrm{q}_{\mathrm{ppf}}=0,61 \mathrm{l} / \mathrm{s}, \mathrm{w}_{\mathrm{nh}} \mathrm{e} \mathrm{w}_{\mathrm{nf}}$ iguais a 1.

Com os três passos realizados, verificou-se se o coeficiente de vazamento foi modificado de uma iteração para outra, utilizando dois algarismos significativos. A calibração foi terminada quando este valor não se modificou. Na Figura 9 é apresentado o fluxograma do processo de calibração. 
Figura 9 - Fluxograma do processo de calibração utilizado

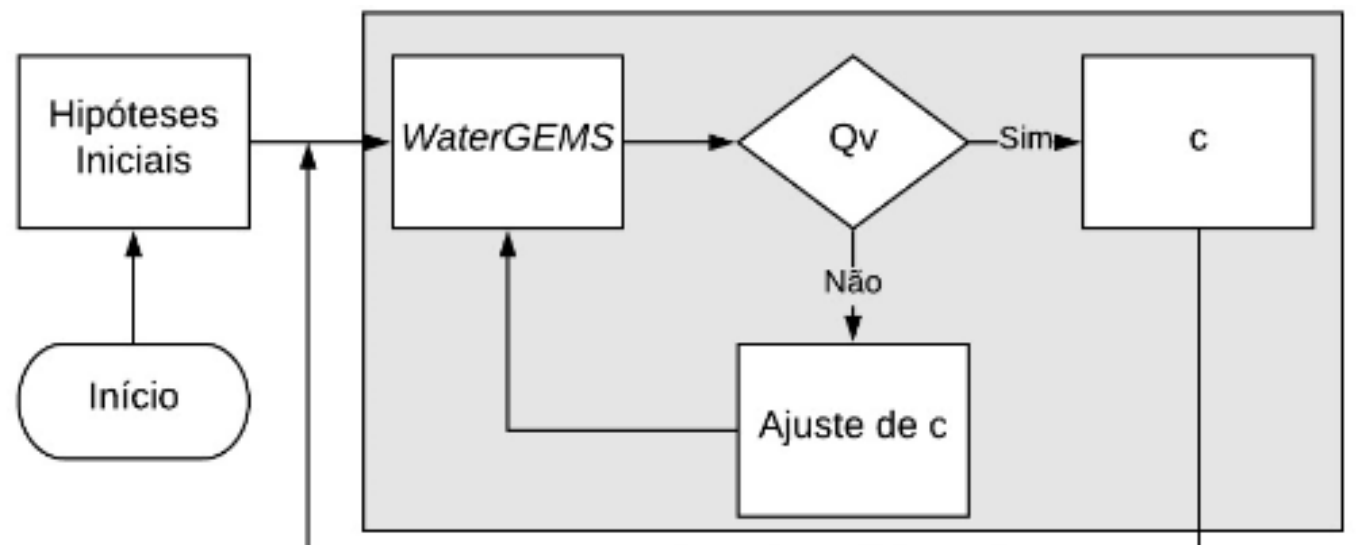

Passo 1. Ajuste do coeficiente de vazamento

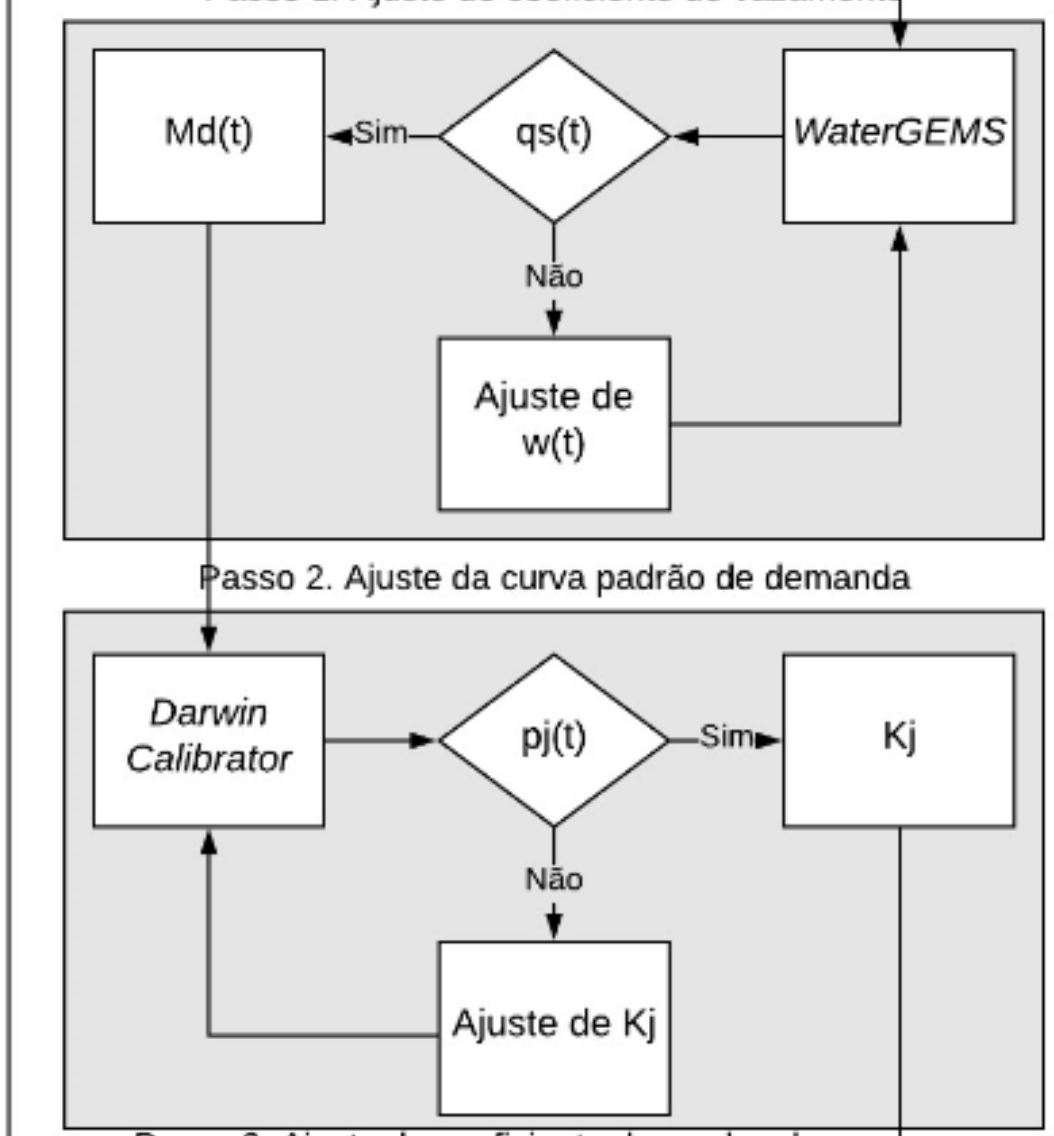

Passo 3. Ajuste do coeficiente de perdas de carga
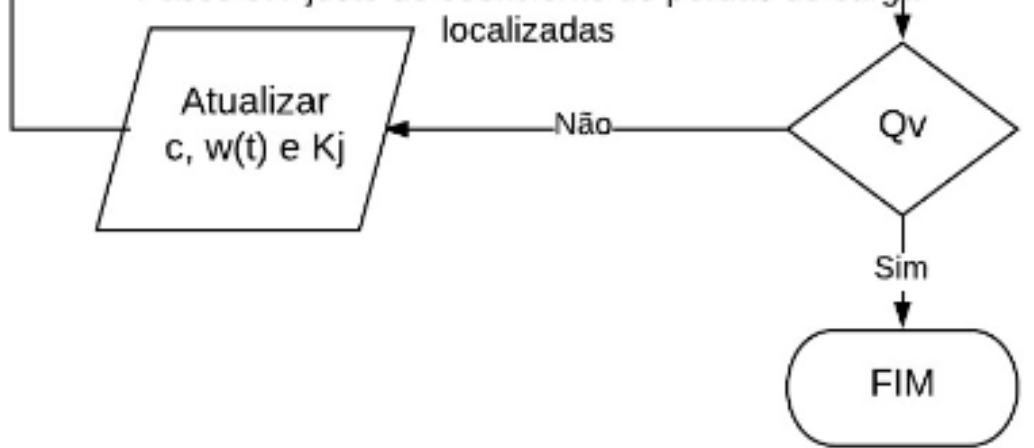

Fonte: Adaptado de Martínez-Solano, Iglesias-Rey e Arce (2017) 


\subsubsection{Validação da calibração}

Para a validação da calibração, foram utilizadas as seguintes métricas:

$$
\begin{aligned}
& \overline{E A}=\frac{\sum_{j=1}^{n_{p}}\left|p_{j}-p_{j}^{*}\right|}{n_{p}} \\
& \widetilde{E A}=\left|p_{j}-p_{j}^{*}\right|_{\left(n^{P} / 2\right)} \\
& \overline{E R}=\frac{\sum_{j=1}^{n_{p}}\left(\left|p_{j}-p_{j}^{*}\right| / p_{j}^{*}\right)}{n_{p}} \\
& \widetilde{E R}=\left(\left|p_{j}-p_{j}^{*}\right| / p_{j}^{*}\right)_{\left(n_{p} / 2\right)} \\
& M S E=\frac{\left(p_{j}-p_{j}^{*}\right)^{2}}{n_{p}}
\end{aligned}
$$

sendo $\overline{E A}$ o erro absoluto médio (m); $\widetilde{E A}$ o erro absoluto mediano (m); $\overline{E R}$ o erro relativo médio; $\widetilde{E R}$ o erro relativo mediano; $M S E$ o erro médio quadrático (Mean Squared Error) $\left(\mathrm{m}^{2}\right)$; $\mathrm{n}_{\mathrm{p}}$ é o número de dados existentes da variável $\mathrm{p}_{\mathrm{j}}$; e $\left(\mathrm{n}_{\mathrm{p}} / 2\right)$ representa a mediana do conjunto de dados indexada.

Foram construídos três gráficos, sendo um relacionando as pressões observada e as simuladas de todos os pontos monitorados durante todo o período utilizado na calibração, outro mostrando o erro absoluto acumulado e um terceiro mostrando o erro relativo acumulado. Para efeito de comparação, essas métricas também foram calculadas para os dados de carga de pressão simulados antes de iniciar o processo de calibração.

Além da construção dessas métricas para a validação, os resultados da calibração foram estendidos para um período de 144 horas em que foram realizadas medições de vazão e carga de pressão nos mesmos pontos utilizados na calibração. A curva de consumo deste modelo foi feita do mesmo modo que na seção 4.2.4 e as pressões horárias modeladas foram comparadas com as observadas. As mesmas métricas da calibração também foram calculadas para os dados de validação.

Como as vazões foram ajustadas durante o segundo passo da calibração, suas medidas não foram incluídas no cálculo dos erros, uma vez que a diferença entre as vazões simuladas e observadas eram desprezíveis. 


\subsection{Partição da Rede}

A rede foi particionada através de dois diferentes métodos: o método da maximização da modularidade (NEWMAN, 2004), chamado neste trabalho de "ModulMax" e o método de partição multinível "k-way" (KARYPIS; KUMAR, 1998a), chamado de "METIS". Ambas as metodologias utilizam a estrutura topológica da rede de abastecimento de água como dado de entrada.

\subsubsection{Características topológicas da rede de abastecimento de água}

A estrutura topológica de uma rede de abastecimento de água é dada através de um grafo sem direção $\mathrm{G}(\mathrm{V}, \mathrm{E})$, onde $V=\left\{v_{1}, v_{2}, \ldots, v_{n}\right\}$ é o conjunto de vértices (que representam nós e tanques); $E=\left\{e_{1}, e_{2}, \ldots, e_{m}\right\}$ é o conjunto de arestas (tubos, válvulas e bombas); $n=|V|$ é o número total de vértices; $m=|E|$ é o número total de arestas; $k_{i}$ é o grau de $v_{i}$, que é definido como o número de arestas ligados a $v_{i} ; A$ é a matriz de adjacência $n \times n\left(A_{i j}=1\right.$, se $v_{i}$ é adjacente a $v_{j}$, caso contrário $A_{i j}=0$ ). $P$ é o vetor de ponderação $n \times 1$, onde $P_{i}$ indica o peso que o vértice $v_{i}$ possui.

\subsubsection{Algoritmo "ModulMax"}

Com os valores da estrutura topológica da rede, realizou-se a partição da rede através do método de maximização da modularidade. Este algoritmo buscou maximizar a modularidade, dada pela equação ( 17 ). Por ser um algoritmo aglomerativo, ele iniciou supondo que cada vértice fosse uma comunidade, e então calculou qual junção de duas comunidades causaria o maior acréscimo (ou menor decréscimo) no índice de modularidade (IQ) da partição. Os passos do algoritmo utilizados foram:

a) Altera-se, aleatoriamente, a posição dos vértices na matriz A, mantendo a mesma estrutura topológica;

b) Inicialmente, cada vértice é considerado como um distrito;

c) A alteração da modularidade $\Delta I Q$ é calculada para todo par ij da matriz A aplicando-se a equação ( 18 );

d) A maior variação da modularidade $\Delta I Q$ da matriz A é encontrada, e seu índice $\left\{i^{*}, j^{*}\right\}$ é marcado;

e) Os vértices $i^{*}$ e $j^{*}$ são aglomerados em um único vértice novo, somando a linha $i^{*}$ com a linha $j^{*}$ e excluindo a linha e a coluna $i^{*}$ da matriz A;

f) Retorna-se ao passo c) até que a matriz A tenha somente uma linha.

As partições que dividiam a rede de 2 até 100 grupos foram salvas. No passo a) o algoritmo busca a melhor alteração de modularidade naquela iteração, sem se preocupar com a 
próxima. Desse modo, a ordem dos vértices na matriz de adjacência influencia o resultado final das partições, pois quando duas alterações de modularidade resultam em valores idênticos, o algoritmo aglomera o primeiro par que encontra. Portanto, o método foi executado 5 vezes com diferentes matrizes $\mathrm{A}_{0}$ e o resultado que possuiu a maior soma do índice de modularidade das 100 primeiras partições foi escolhido.

\subsubsection{Algoritmo METIS}

Este algoritmo, como descrito na seção 3.5, possui 3 fases: agrupamento, partição e refinamento.

a) Fase 1 - Agrupamento

Nesta fase, uma sequência de grafos $\left(\mathrm{A}_{0}, \mathrm{~A}_{1}, \mathrm{~A}_{2}, \ldots\right)$ é construída a partir do grafo original $\mathrm{A}_{0}$ utilizando a estratégia de Random Matching.

i. Inicialmente, todos os nós do grafo são considerados como não visitados;

ii. Seleciona-se aleatoriamente um nó i do grafo;

iii. Randomicamente, é verificada a existência de um nó j, ligado ao nó i, que ainda não tenha sido visitado;

iv. Caso exista este nó j, ele é aglomerado ao nó i e este novo nó é marcado como visitado;

v. Caso todos os nós, ligados ao nó i, tenham sido visitados, o nó i é então marcado como visitado;

vi. Até que todos os nós sejam visitados, o algoritmo retorna ao passo ii iterativamente.

Esta estratégia é repetida até que a redução do tamanho de dois grafos consecutivos seja maior que o fator de 0,8 . O cálculo dessa redução é feito através de razão entre o número de nós do grafo i pelo número de nós do grafo i-1.

\section{b) Fase 2 -Partição}

A partição do grafo agrupado foi feita através do algoritmo iterativo de Kernighan-Lin (KERNIGHAN; LIN, 1970). Este método dividiu a rede em $\mathrm{k}$ grupos de tamanhos os mais próximos possíveis, buscando minimizar o número de arestas entre grupos. O método inicia dividindo a rede em $\mathrm{k}$ grupos aleatórios, e então analisa o ganho de um vértice v, conectado ao vértice $u$, de outro grupo, passar de seu atual grupo para o outro através da equação:

$$
g_{v}=\sum_{(v, u) \in E \wedge P[v] \neq P[u]} w(v, u)-\sum_{(v, u) \in E \wedge P[v]=P[u]} w(v, u)
$$


sendo $\mathrm{w}(\mathrm{u}, \mathrm{v})$ o peso da aresta $(\mathrm{u}, \mathrm{v})$. Se $\mathrm{g}_{\mathrm{v}}$ é positivo, então mover o vértice $\mathrm{v}$ do grupo atual para outro grupo reduz o número de cortes da partição. Há, também, uma restrição quanto ao índice de balanço da partição, que pode permitir ou impedir uma troca de vértices. Neste trabalho, o índice de balanço máximo permitido foi de 1,5, calculado de acordo com a equação ( 21 ). O processo é repetido sucessivamente para todos os nós de borda até que nenhum ganho seja positivo.

c) Fase 3 -Refinamento

Obtida a partição inicial do grafo agrupado, a última fase do processo tem por objetivo refinar os resultados nos grafos maiores. Assim, o refinamento é feito após transformar o grafo $\mathrm{G}_{\mathrm{i}}$ para o grafo $\mathrm{G}_{\mathrm{i}-1}$, até retornar ao original. $\mathrm{O}$ algoritmo utilizado nessa fase foi o método de Refinamento Simplificado de Kernighan-Lin (KARYPIS; KUMAR, 1998a), que é semelhante à primeira iteração do método de Kerninghan-Lin tradicional. Ou seja, na fase de refinamento, a análise de troca de vértices entre grupos vizinhos ocorre uma vez para cada nó, em cada etapa do refinamento.

Nesta abordagem, os nós são ponderados de acordo com a demanda média, enquanto as tubulações permanecem sem pesos. $\mathrm{O}$ algoritmo foi executado para partições que dividiam a rede de 2 a 100 grupos. Para cada número de grupos, o processo foi repedido 200 vezes e a solução escolhida foi a que resultou em um menor número de arestas eliminadas.

\subsection{Comparação dos resultados}

As métricas utilizadas para comparar todas as 198 soluções obtidas pelos dois métodos descritos, o índice das métricas na seção 3.5 e os símbolos de suas representações são mostradas Tabela 7.

Tabela 7 - Métricas utilizadas para a comparação das partições

\begin{tabular}{l|c|c}
\hline \multicolumn{1}{c|}{ Métrica } & $\begin{array}{c}\text { Referência } \\
(\text { Seção 3.5) }\end{array}$ & Símbolo \\
\hline Índice de Modularidade & $\mathrm{g})$ & $\mathrm{IQ}$ \\
\hline Número de tubulações entre distritos & a) & $\mathrm{N}_{\mathrm{FEC}}$ \\
\hline Número de conexões do distrito mais conectado & b) & $\mathrm{N}_{\mathrm{P}}$ \\
\hline Índice de Balanço da Demanda & $\mathrm{e})$ & $\mathrm{I}_{\mathrm{B}}{ }^{\mathrm{D}}$ \\
\hline Índice de Balanço do Comprimento & $\mathrm{e})$ & $\mathrm{I}_{\mathrm{B}}{ }^{\mathrm{C}}$ \\
\hline
\end{tabular}

Foram plotados dois tipos de gráficos: os de linha, para comparar o desempenho das duas metodologias utilizadas em função do número de grupos da partição; e os de radar, que 
compararam os resultados das partições com 5, 10, 20, 30, 40, 50, 75 e 100 grupos entre as duas abordagens utilizadas.

\subsubsection{Seleção da melhor partição}

Como primeiro critério de seleção de partições factíveis para a rede de distribuição de água de Pederneiras, foram impostas as seguintes restrições:

a) Número máximo de distritos: 50

b) Comprimento máximo de tubulações de um distrito: $25 \mathrm{~km}$

c) Número máximo de tubulações cortadas em um único distrito: 20

d) Demanda média máxima de um distrito: 250 1/s

Criou-se, então, um subconjunto de partições que satisfizeram todas as restrições impostas acima, criando o Conjunto Restrito. Sobre esse subconjunto de partições factíveis foram selecionadas as soluções que se encontravam na frente Pareto (chamado de Conjunto Frente Pareto). Esse grupo foi analisado através da programação por compromisso multicritério (ZELENY; COCHRANE, 1973), levando em consideração todas as métricas elencadas na seção 4.4., a proximidade entre a solução avaliada e o ponto ideal e a distância entre essa solução e o ponto NADIR. O ideal de cada métrica foi tomado como o seu melhor resultado teórico, enquanto o NADIR foi calculado a partir do pior valor da métrica obtido por uma das soluções do Conjunto Restrito. O ponto ideal e NADIR de cada métrica podem ser observados na Tabela 8.

Tabela 8 - Pontos Ideal e NADIR de cada métrica utilizada para a seleção multicritério da melhor partição

\begin{tabular}{c|c|c}
\hline Métrica & Ideal & NADIR \\
\hline $\mathrm{IQ}$ & 1 & 0,91 \\
\hline $\mathrm{N}_{\mathrm{FEC}}$ & 0 & 151 \\
\hline $\mathrm{N}_{\mathrm{P}}$ & 0 & 20 \\
\hline $\mathrm{I}_{\mathrm{B}}{ }^{\mathrm{D}}$ & 1 & 2,55 \\
\hline $\mathrm{I}_{\mathrm{B}}{ }^{\mathrm{C}}$ & 1 & 3,77 \\
\hline
\end{tabular}

Com os valores Ideal e NADIR de cada métrica foram criados critérios normalizados de minimização através da equação:

$$
C A_{i, j}=\frac{\mid \text { Ideal }_{i}-M_{i, j} \mid}{\mid \text { Ideal }_{i}-N A D I R_{i} \mid}
$$


sendo $\mathrm{CA}_{\mathrm{i}, \mathrm{j}}$ o critério de avaliação da partição j para a métrica $\mathrm{i}$; Ideal $_{\mathrm{i}} \mathrm{o}$ ideal da métrica

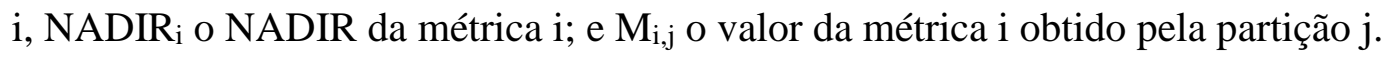

Deste modo, foram definidos cinco critérios que variavam de 0 a 1 e eram melhores quanto mais próximos estivessem de zero. Calculou-se então as soluções que pertenciam ao Conjunto Compromisso Ideal, através da equação ( 58 ):

$$
\operatorname{Min} F c c_{j}=\left[\sum_{i=1}^{n m}\left(C A_{i, j}\right)^{p d}\right]^{1 / p d} \quad \forall p d \in \mathbb{Z} / \mathrm{pd}>0
$$

sendo $\mathrm{Fcc}_{\mathrm{j}}$ a p-distância entre o ponto ideal e o ponto correspondente aos critérios de avaliação da solução j; e $\mathrm{CA}_{\mathrm{i}, \mathrm{j}}$ é o critério de avaliação da partição j para a métrica i; nm é o número de métricas utilizadas para selecionar a melhor partição. Nesta pesquisa, nm é igual a 5.

O método de programação por compromisso multicritério pode ser modificado, selecionando também as soluções que estiverem mais distantes do NADIR, como explicitado na equação ( 59 ), que deu origem ao Conjunto Compromisso NADIR (ZELENY, 2011):

$$
\text { Max Fnadir }=\left[\sum_{i=1}^{n m}\left(1-C A_{i, j}\right)^{p d}\right]^{1 / p d} \quad \forall p d \in \mathbb{Z} / \mathrm{pd}>0
$$

sendo Fnadir $_{j}$ a p-distância entre o ponto NADIR e o ponto correspondente aos critérios de avaliação da solução j.

Para cada pd, variando de 1 a infinito, foi selecionada a partição que apresentou a menor $\mathrm{Fcc}_{\mathrm{j}}$ para pertencer ao Conjunto Compromisso Ideal e a maior distância de Fnadirj para o Conjunto Compromisso NADIR. As soluções que pertenceram à interseção dos dois conjuntos foram selecionadas e empiricamente escolheu-se a melhor solução (Figura 10).

$\mathrm{Na}$ Figura 10, o Conjunto Inicial (C.I.) representa todas as soluções encontradas, sendo 99 realizadas pelo método de modularidade e outras 99 pelo método METIS. O Conjunto Restrito (C.R.) representa todas as soluções que satisfazem as restrições impostas no item 4.4. O Conjunto da Frente Pareto (C.F.P.) corresponde a todas as soluções do C.R. que pertencem à Frente Pareto, possuindo como funções objetivo as cinco métricas contidas na Tabela 7. O Conjunto Compromisso Ideal (C.C.I) representa todas as soluções que foram selecionadas como mais próximas ao Ideal pelo método de programação por compromisso Lp; O Conjunto Compromisso NADIR (C.C.N.) representa todas as soluções que foram selecionadas como mais distantes do NADIR pelo método de programação por compromisso Lp; O Conjunto Selecionado (C.S.), por fim, é contido por todas as soluções que estão na interseção de C.C.N. e C.C.I. 
Figura 10 - Processo realizado para a seleção da melhor partição da rede. C.I. Conjunto Inicial; C.R. Conjunto Restrito; C.F.P. Conjunto da Frente Pareto; C.C.I. Conjunto Compromisso Ideal; C.C.N. Conjunto Compromisso NADIR; C.S. Conjunto Selecionado.

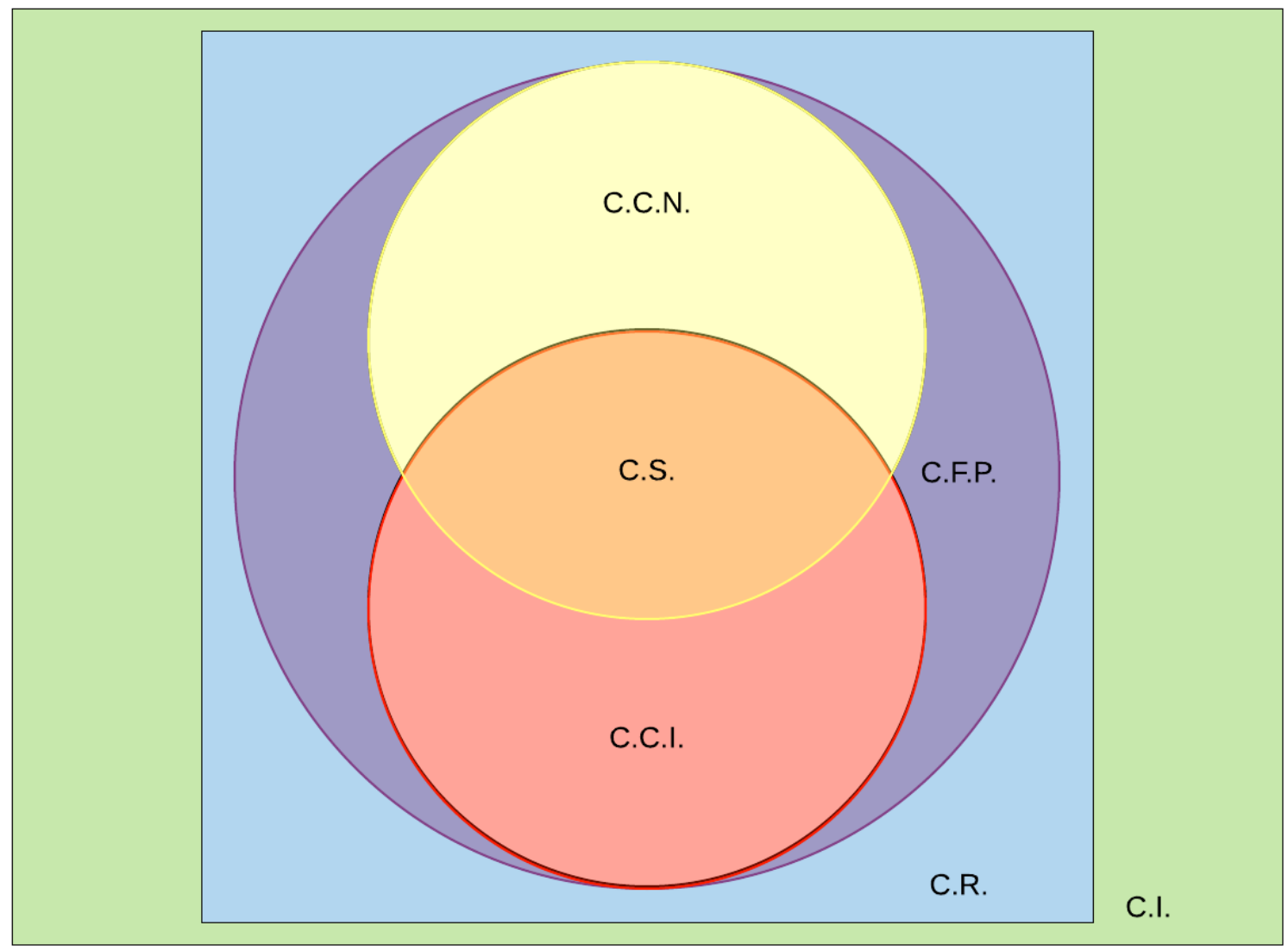

Fonte: Elaboração do autor

\subsection{Determinação do status das tubulações}

A seleção das tubulações que foram fechadas, as mantidas abertas e as que foram colocadas válvulas redutoras de pressão, foi feita com base em um método manual e iterativo. Primeiramente, todas as tubulações que ligam distritos foram fechadas. Os passos para selecionar quais tubulações deveriam ficar abertas foram:

a) Abriu-se todas as tubulações que foram consideradas tubulações "tronco" pelos gestores da rede.

b) A simulação do modelo foi então executada.

c) Analisou-se cada distrito separadamente, iniciando pelos distritos mais próximos dos reservatórios.

d) Observou-se se algum nó do distrito apresentou uma carga de pressão inferior a 15 mca no momento de maior consumo. Caso afirmativo, uma tubulação, à escolha dos gestores da rede, foi aberta. 
e) Quando todas os nós satisfizeram o critério mínimo de carga de pressão, passou-se a analisar o próximo distrito.

Com o modelo final, os gestores da rede, juntamente com o pesquisador, escolheram empiricamente algumas tubulações para inserir VRP's a fim de reduzir a carga de pressão dos nós da rede. 


\section{RESULTADOS E DISCUSSÃO}

\subsection{Modelagem hidráulica do setor Lacta}

Para a realização da modelagem hidráulica do Setor Lacta foi necessário fazer uma campanha de medição de cargas de pressão e vazão da rede. Para a seleção dos pontos de medição de carga de pressão a metodologia explicitada na seção 4.2.2 foi utilizada. A medição de vazão foi feita somente na saída do único reservatório que abastece o setor.

\subsubsection{Plano de Amostragem}

O plano de amostragem foi realizado utilizando a criação de soluções inteiras aleatórias, seleção por torneio, simples troca para o cruzamento, 500 gerações, 200 indivíduos na população, cada vetor solução com 20 posições e com mutação e cruzamento com probabilidades de $1 \%$ e $90 \%$, respectivamente.

A curva Pareto encontrada pode ser visualizada na Figura 11:

Figura 11 - Curva Pareto do plano de amostragem

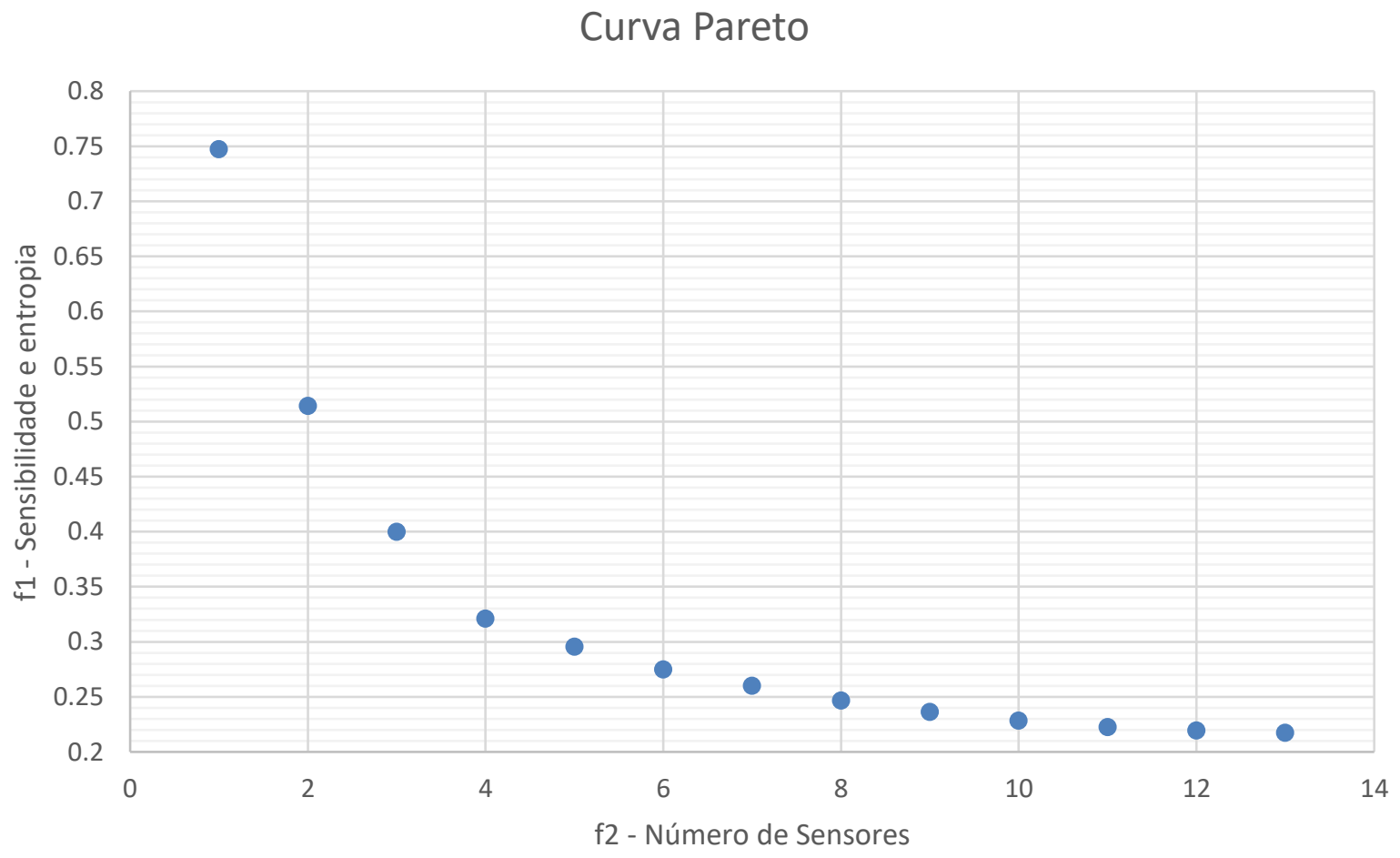

Fonte: Elaboração do autor

A sensibilidade de cada plano de amostragem da curva Pareto, assim como a melhora da sensibilidade causada pela inclusão de um novo sensor são mostradas na Tabela 9. 
Tabela 9 - Sensibilidade dos planos de amostragem da curva Pareto e o ganho de sensibilidade e entropia pela inclusão de um sensor

\begin{tabular}{c|c|c|c}
\hline $\begin{array}{c}\text { Número de } \\
\text { sensores } \\
(\mathbf{f 1})\end{array}$ & $\begin{array}{c}\text { Sensibilidade } \\
\text { e entropia } \\
(\mathbf{f 2})\end{array}$ & $\begin{array}{c}\text { Alteração de } \\
\mathbf{f 2}\end{array}$ & $\begin{array}{c}\text { Melhoria } \\
\text { Relativa (\%) }\end{array}$ \\
\hline 1 & 0,748 & - & - \\
\hline 2 & 0,514 & 0,233 & $31,2 \%$ \\
\hline 3 & 0,400 & 0,114 & $22,2 \%$ \\
\hline 4 & 0,321 & 0,079 & $19,7 \%$ \\
\hline 5 & 0,296 & 0,026 & $8,0 \%$ \\
\hline 6 & 0,275 & 0,021 & $7,0 \%$ \\
\hline 7 & 0,260 & 0,015 & $5,4 \%$ \\
\hline 8 & 0,247 & 0,013 & $5,1 \%$ \\
\hline 9 & 0,237 & 0,010 & $4,1 \%$ \\
\hline 10 & 0,229 & 0,008 & $3,4 \%$ \\
\hline 11 & 0,223 & 0,006 & $2,5 \%$ \\
\hline 12 & 0,220 & 0,003 & $1,5 \%$ \\
\hline 13 & 0,218 & 0,002 & $0,9 \%$ \\
\hline
\end{tabular}

Fonte: Elaboração do autor

Neste estudo foi utilizado o plano de amostragem com 9 sensores. A escolha do número de sensores foi devido à quantidade de sensores disponíveis, mas pode-se perceber pelos valores da Tabela 9 que a aquisição de novos aparelhos não acarretaria em uma melhora significativa na sensibilidade. Além disso, 9 sensores satisfizeram as recomendações sugeridas pelo Water Research Center (WATER RESEARCH CENTRE, 1989) e pelo American Engineering Computer Application Committee (ECAC, 1999), segundo as Tabela 1 e Tabela 2. A primeira sugere que para uma cidade com menos de 30.000 habitantes, o número de sensores esteja entre 20 e 40. No entanto, como o setor a ser calibrado abastece uma população de aproximadamente 9000 pessoas, 9 sensores podem ser suficientes para a calibração. O órgão americano, por sua vez, indica o número de sensores em função do nível de detalhamento desejado e do número de nós do modelo. Como o modelo a ser calibrado possui 242 nós, 9 pontos de monitoramento cobrem 3,7\% dos nós, classificando o nível de detalhamento do projeto entre baixo e moderado. Como para projetos de operação do sistema o nível de detalhamento desejado pode ser baixo, a utilização de 9 sensores satisfez a sugestão deste órgão. 
A Figura 12 apresenta a localização dos 9 nós selecionados pelo plano de amostragem para a instalação dos sensores de carga de pressão.

\subsubsection{Campanha de medição}

Os aparelhos que medem a carga de pressão foram instalados em residências próximas aos pontos selecionados pelo plano de amostragem (Figura 12). Como existiu a necessidade de autorização dos proprietários das residências para a instalação do aparelho e também foi necessária a existência de uma saída de água conectada diretamente à rede de abastecimento, muitas vezes não foi possível instalar o transdutor de pressão com datalogger exatamente sobre o nó selecionado. No entanto, buscou-se instalar os aparelhos o mais próximo possível destes pontos. A Figura 12 mostra a localização da instalação de cada aparelho: 
Figura 12 - Localização dos pontos definidos no plano de amostragem (pontos verdes) e da instalação dos medidores de carga de pressão (pontos vermelhos)

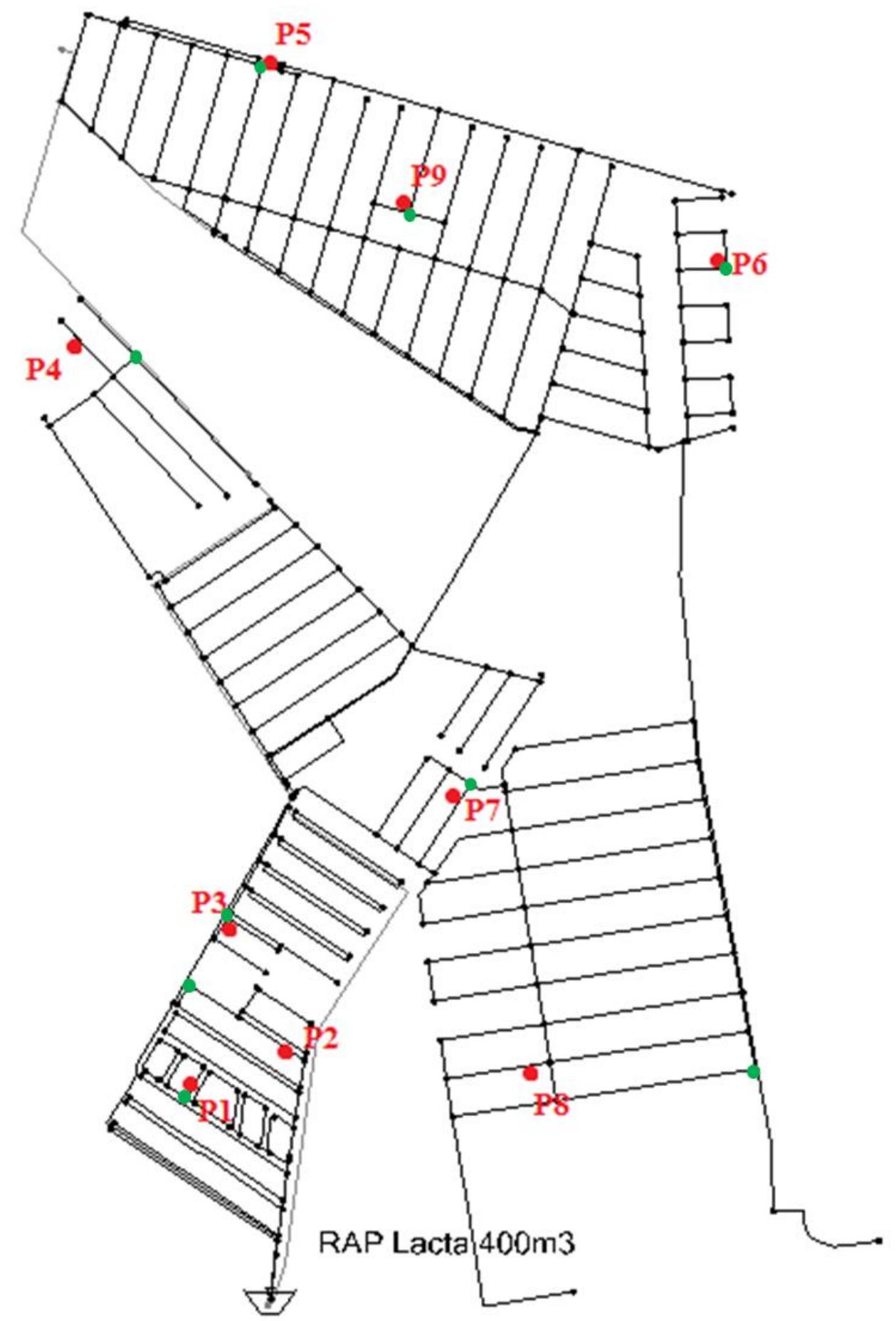

Fonte: Elaboração do autor

As Figura 13,Figura 14 e Figura 15 ilustram alguns dataloggers instalados no setor, enquanto a Figura 16 mostra a instalação do medidor de vazão. Nas Figura 17 eFigura 18 são apresentados os dados de carga de pressão e vazão coletados, respectivamente. 
Figura 13 - Local de instalação do data logger P2 para a campanha de medição do Setor Lacta

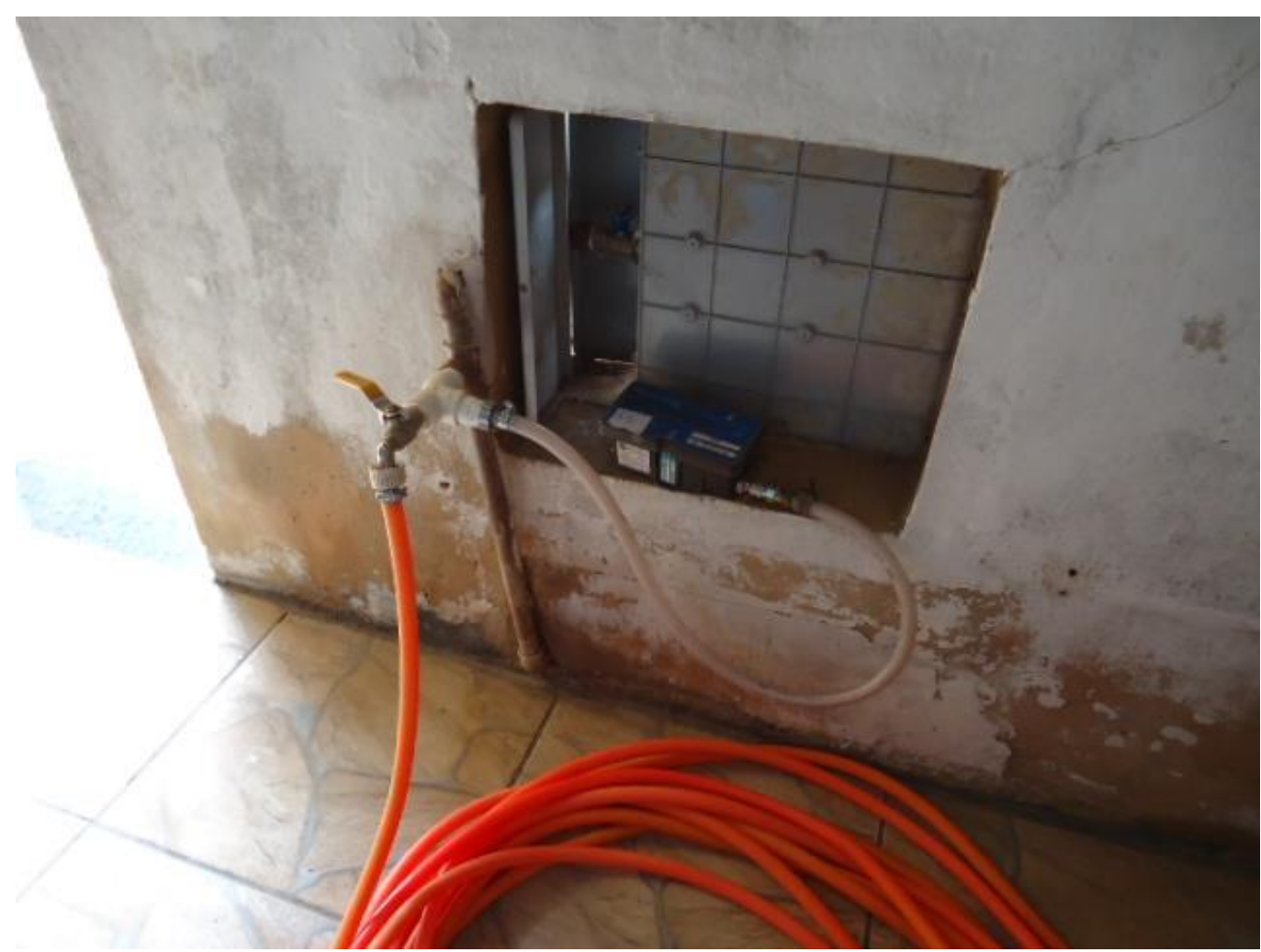

Fonte: Elaboração do Autor

Figura 14 - Local de instalação do data logger P5 para a campanha de medição do Setor Lacta

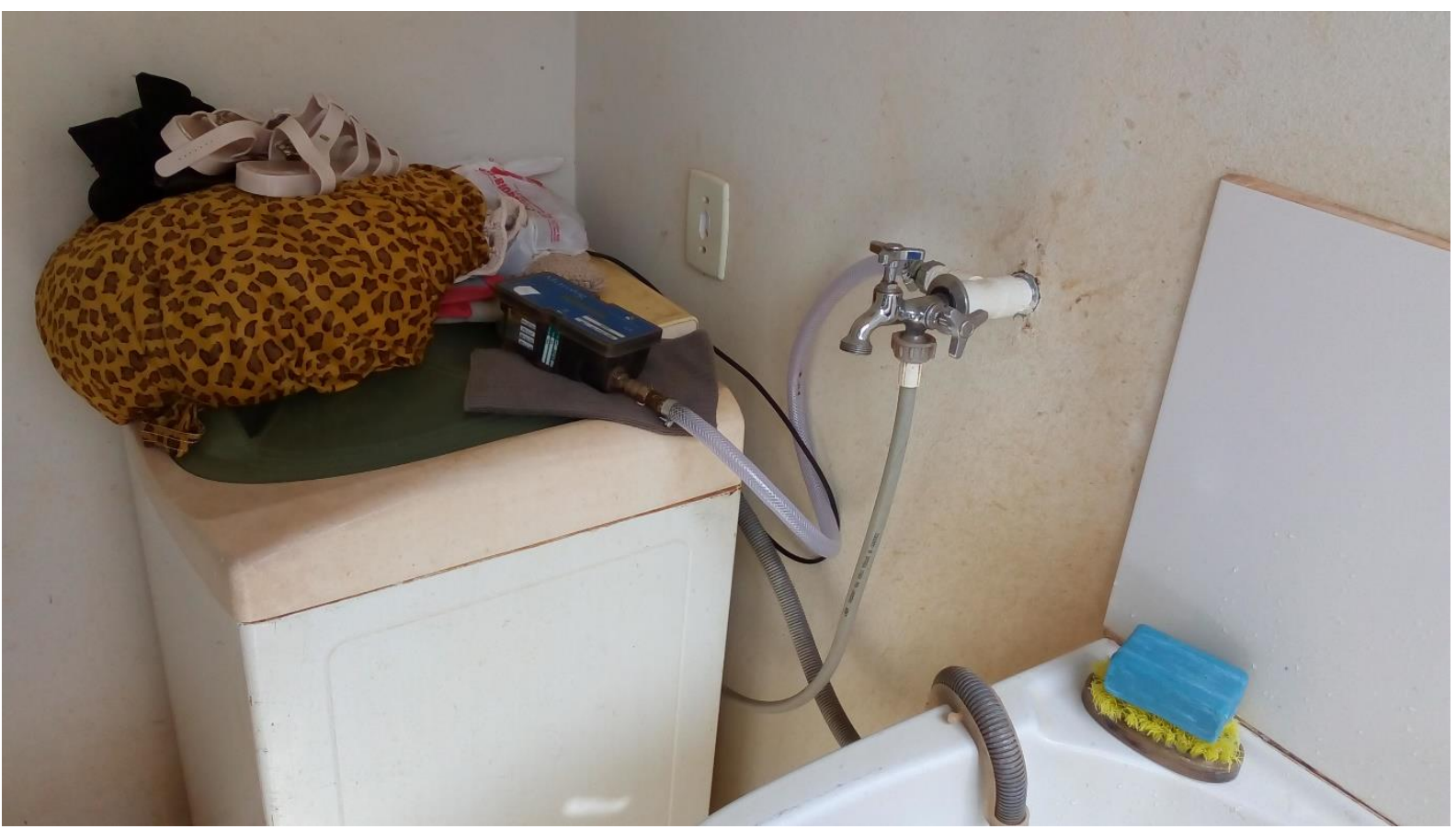

Fonte: Elaboração do Autor 
Figura 15 - Local de instalação do data logger P6 para a campanha de medição do Setor Lacta

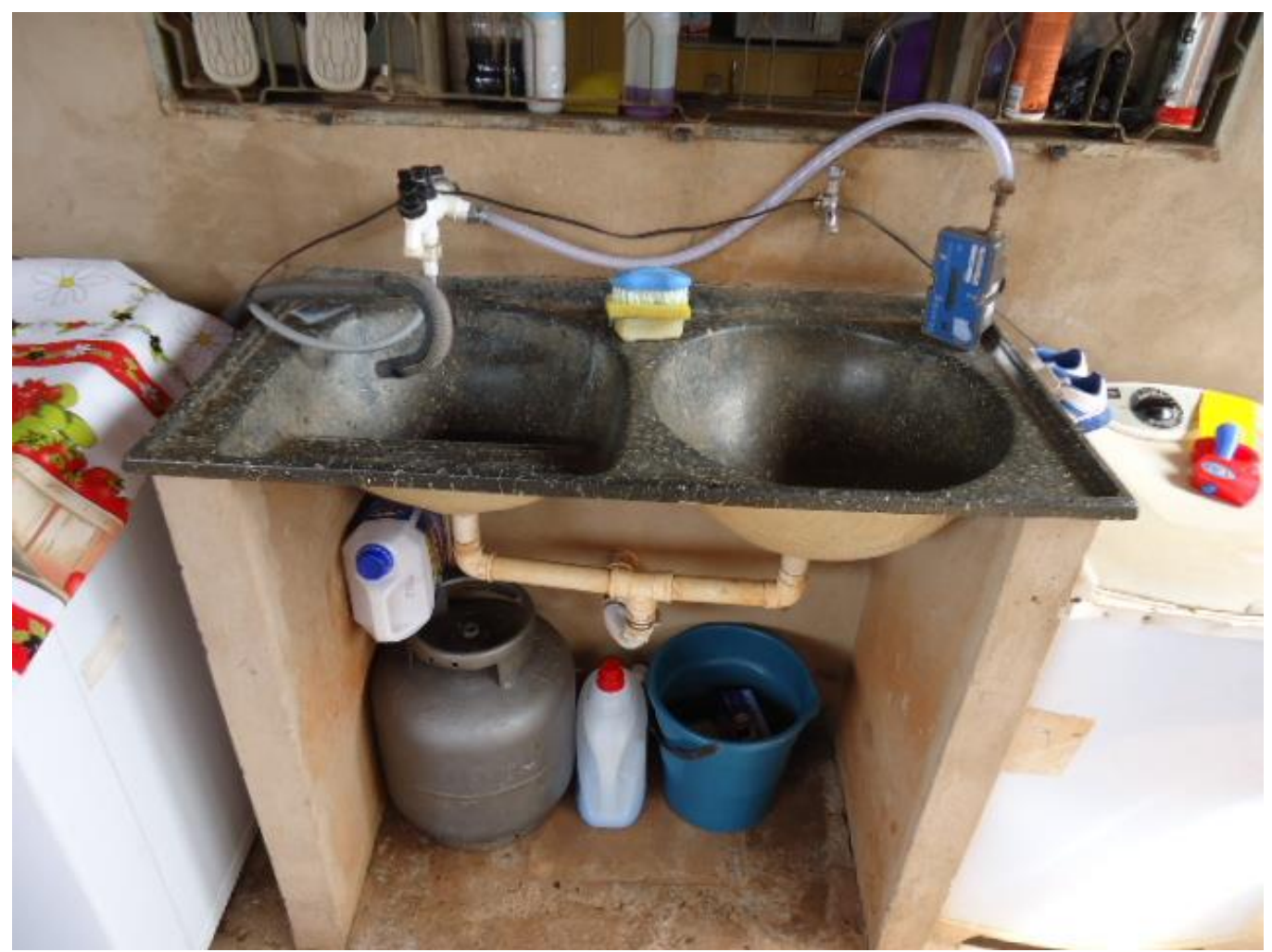

Fonte: Elaboração do Autor

Figura 16 - Instalação do medidor de vazão na saída do reservatório Lacta

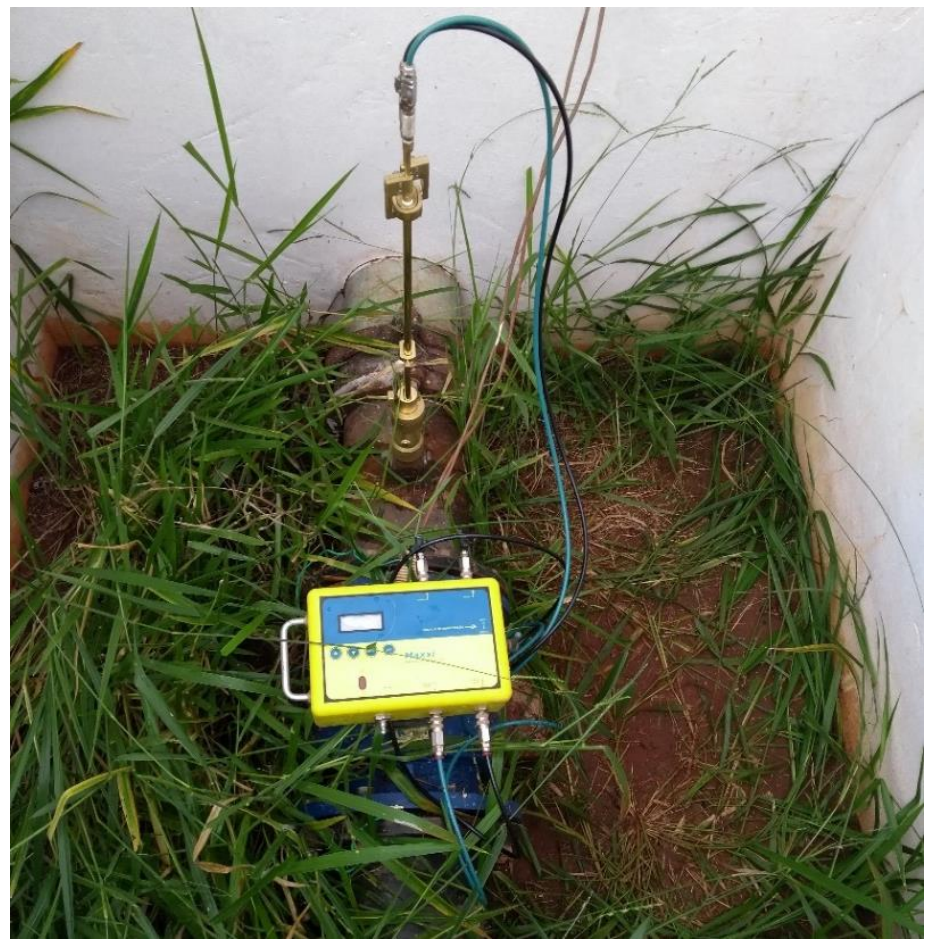

Fonte: Elaboração do Autor 
Figura 17 - Dados de carga de pressão dinâmica(mca) coletados durante a campanha de medição.

Cargas de Pressão (mca)

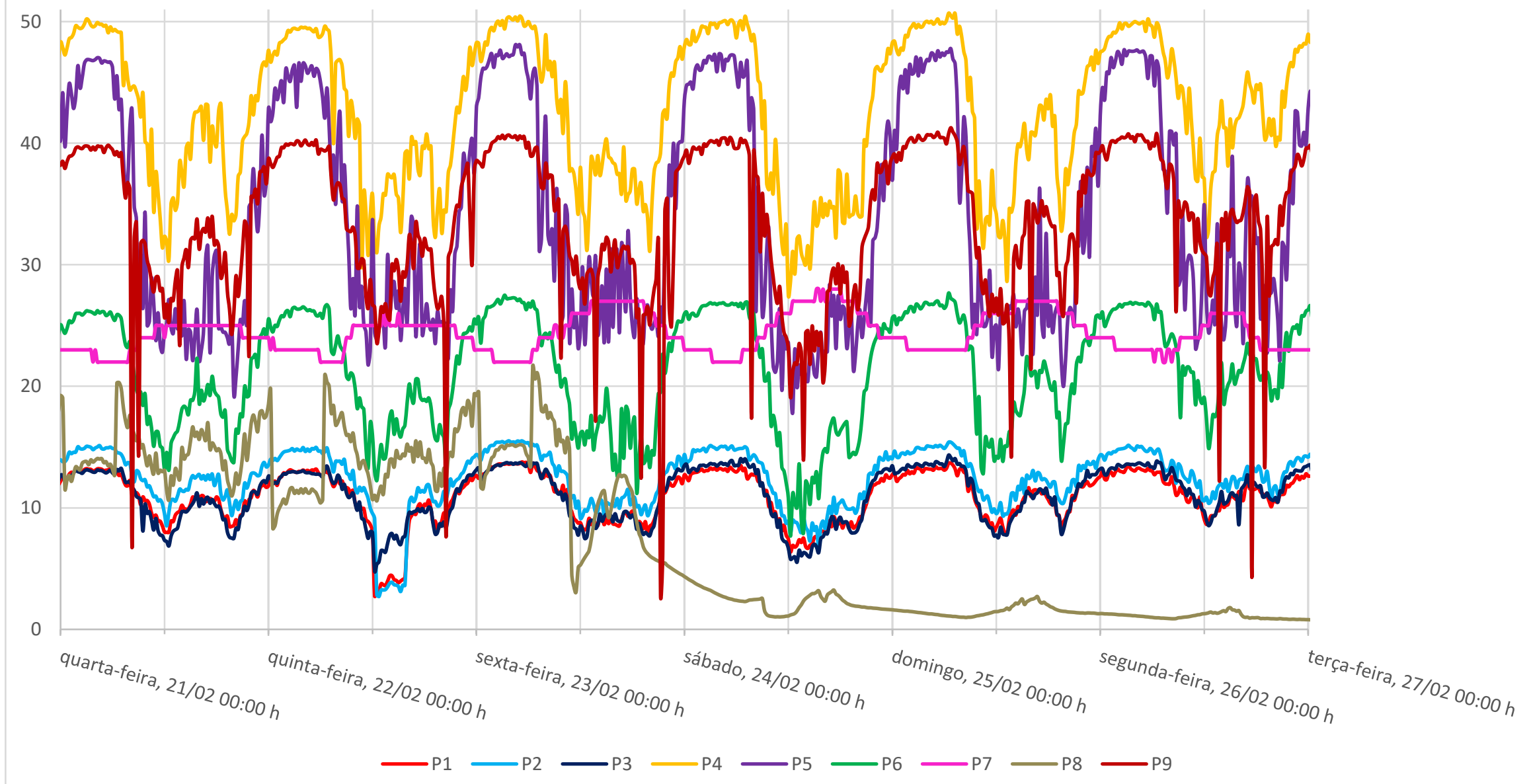

Fonte: Elaboração do Autor 
Figura 18 - Dados de vazão com intervalos de leitura de 1 minuto, coletados na saída do reservatório que abastece o setor Lacta durante a campanha de medição, com uma curva de média móvel utilizando um período de 60 medições.

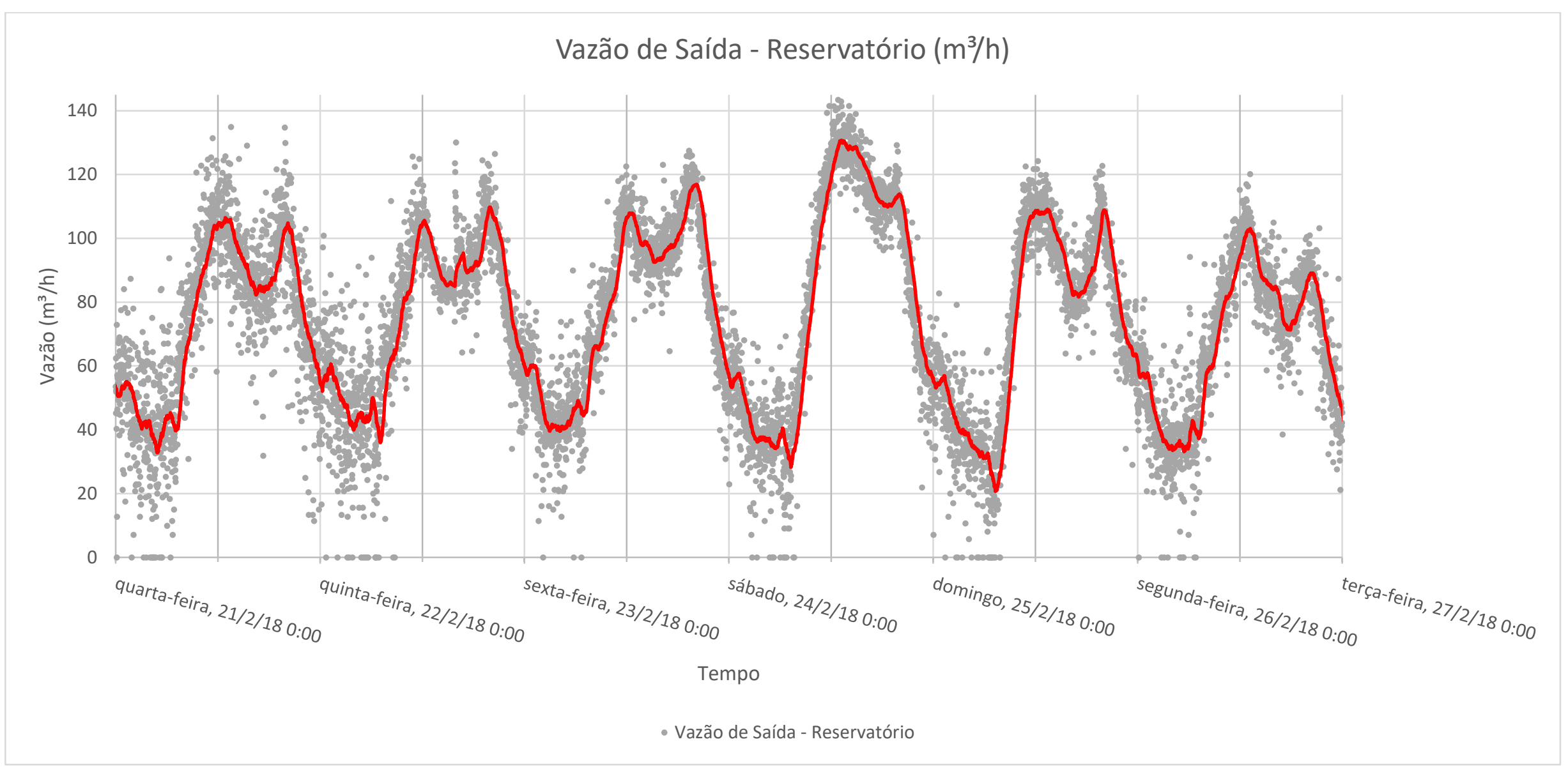

Fonte: Elaboração do Auto 
Observou-se um comportamento inesperado no monitoramento dos pontos $\mathrm{P} 7$ e P8. O ponto P7 revelou uma inversão da curva de carga de pressão esperada, apresentando pressões mais altas durante o dia e mais baixas durante a noite. Atribuiu-se esse comportamento a um erro de leitura do aparelho e, portanto, os dados coletados por ele foram descartados para a calibração. O ponto $\mathrm{P} 8$, por sua vez, apresentou uma queda brusca de carga de pressão todos os dias, entre às 0:00h e 5:00h. Além disso, a carga de pressão neste ponto tornou-se muito baixa a partir da metade do dia 23/02/18. Após uma apresentação e discussão com os responsáveis pelo funcionamento da rede de abastecimento de água de Pederneiras, chegou-se à conclusão de que o ponto P8 era, na realidade, abastecido por outro reservatório do município, sendo uma área isolada por válvulas, e que, portanto, a rede atual do setor Lacta era diferente desta construída como modelo preliminar. Descobriu-se, também, que as válvulas redutoras de pressão instaladas no sistema estavam travadas em uma posição fixa e desconhecida durante a campanha de medição. A constatação foi feita com base nas altas pressões medidas nos pontos P5, P6 e P9. Portanto, existiram duas perdas de cargas localizadas devido às válvulas redutoras de pressão que foram calibradas. Além disso, foi detectada, também, a existência de uma tubulação adicional no sistema, que tinha como função aumentar a carga de pressão na área próxima ao ponto P3. A Figura 19 mostra a localização desta tubulação, cuja existência foi confirmada após verificação em campo.

Figura 19 - Localização da tubulação encontrada na rede após verificação da modelagem preliminar

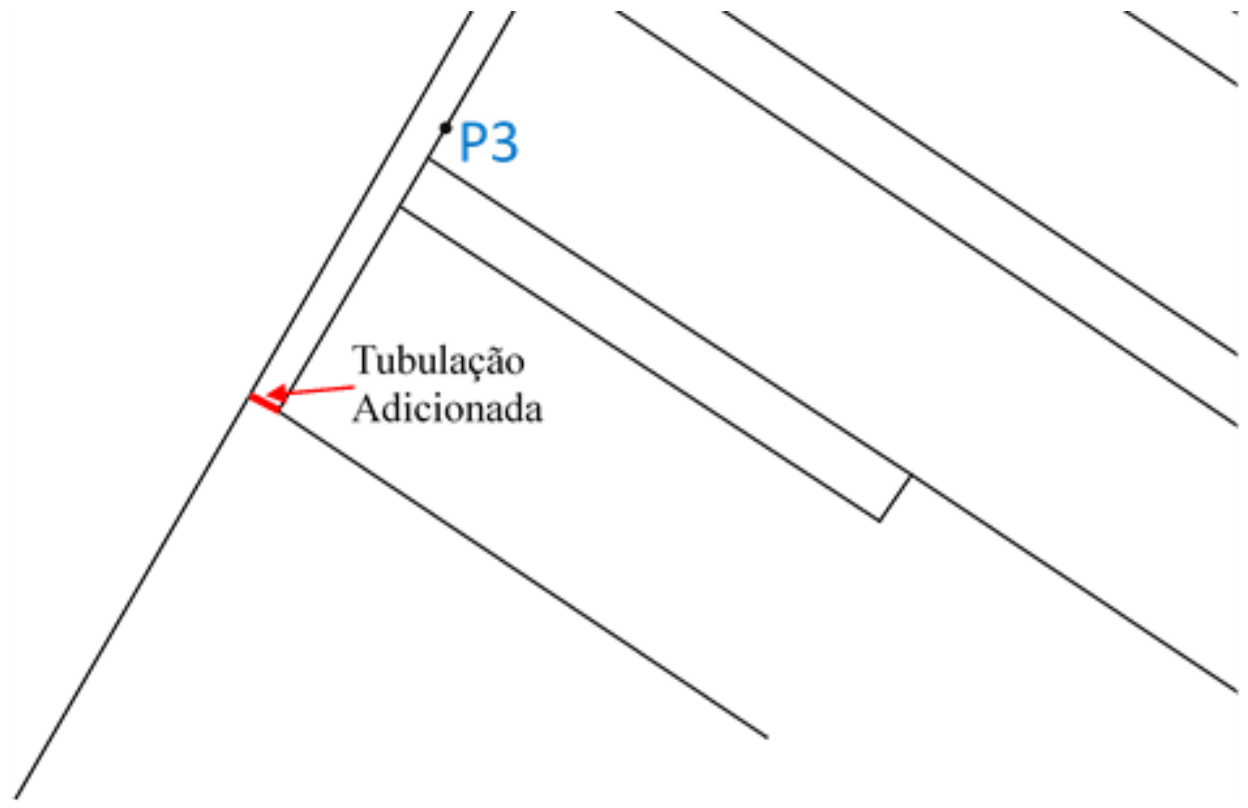

Fonte: Elaboração do Autor

Observou-se, também, uma queda brusca de carga de pressão em todos os pontos do setor no dia 22/02/2018, das 12:00h às 15:00h. Essa queda de carga de pressão, possivelmente, 
ocorreu por uma falha da bomba que abastece parte do setor. Dessa forma, após a análise dos dados recebidos e de discussões com os responsáveis pela operação da rede, o modelo preliminar do setor Lacta foi redesenhado, como mostrado na Figura 20.

Figura 20 - Nova configuração do Setor Lacta

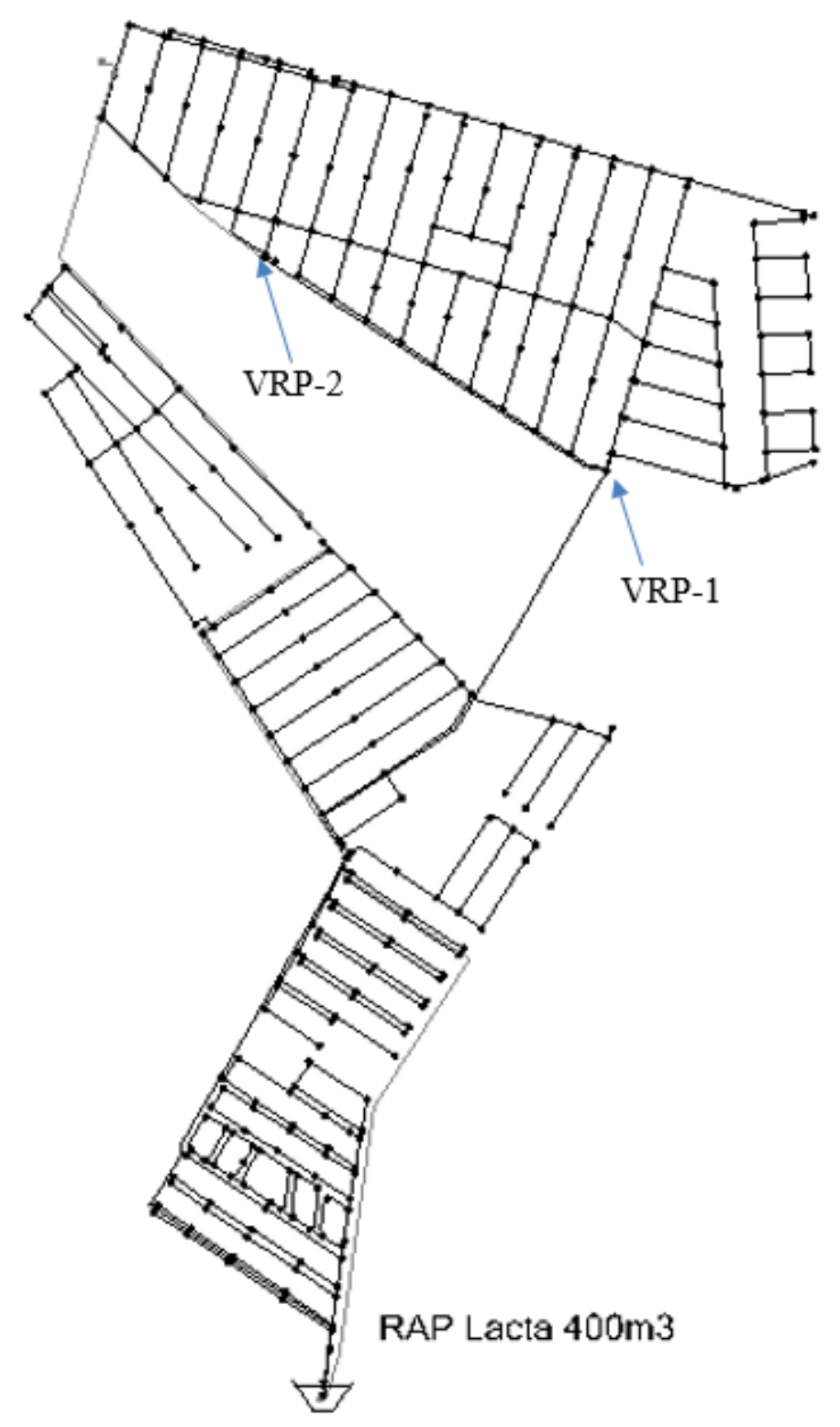

Fonte: Elaboração do Autor

\subsubsection{Tratamento dos dados coletados}

Para os dados de vazão, que foram coletados a cada minuto, foram feitas as médias dos valores de cada hora, resultando assim em vazões médias horárias, como mostrado na Figura 21. O mesmo foi feito com os dados de carga de pressão, que foram coletados a cada 15 minutos. O medidor do nível do reservatório apresentou falhas no dia 20/02/2018 e, portanto, os dados deste dia foram descartados. O período em que todos os dados necessários foram coletados 
inicia no dia 21/02/2018 às 00:00h e acaba no dia 26/02/2018 às 23:59h. A Figura 22 mostra 0 nível de água do reservatório que abastece o setor. Com os dados de consumo faturado mensal do Setor Lacta foi possível iniciar o processo de calibração preliminar do modelo. 
Figura 21 - Dados médios horários dos pontos de carga de pressão medidos e da vazão de saída do reservatório que abastece o Setor Lacta.

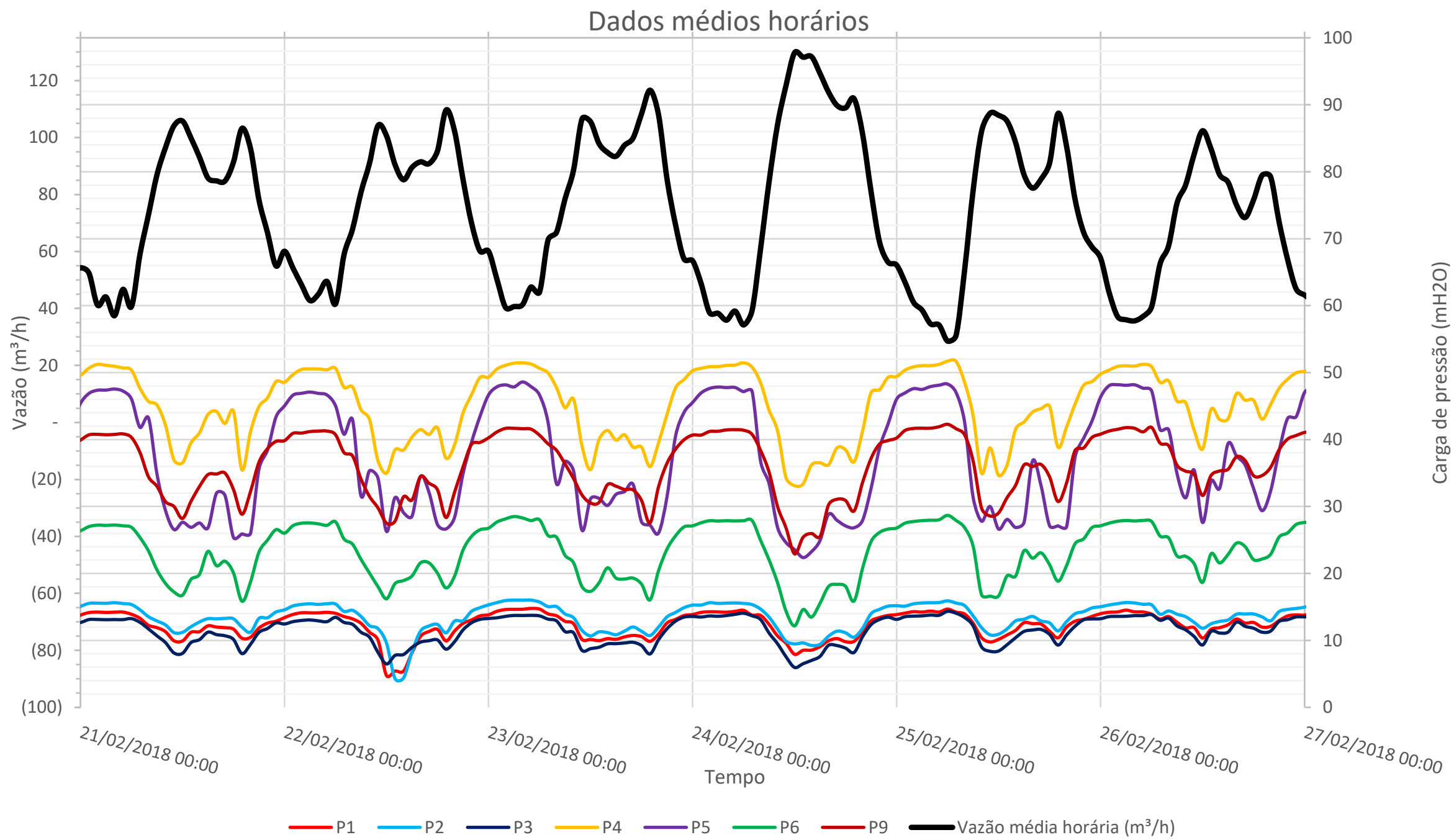

Fonte: Elaboração do Autor 
Figura 22 - Nível de água no reservatório que abastece o setor Lacta

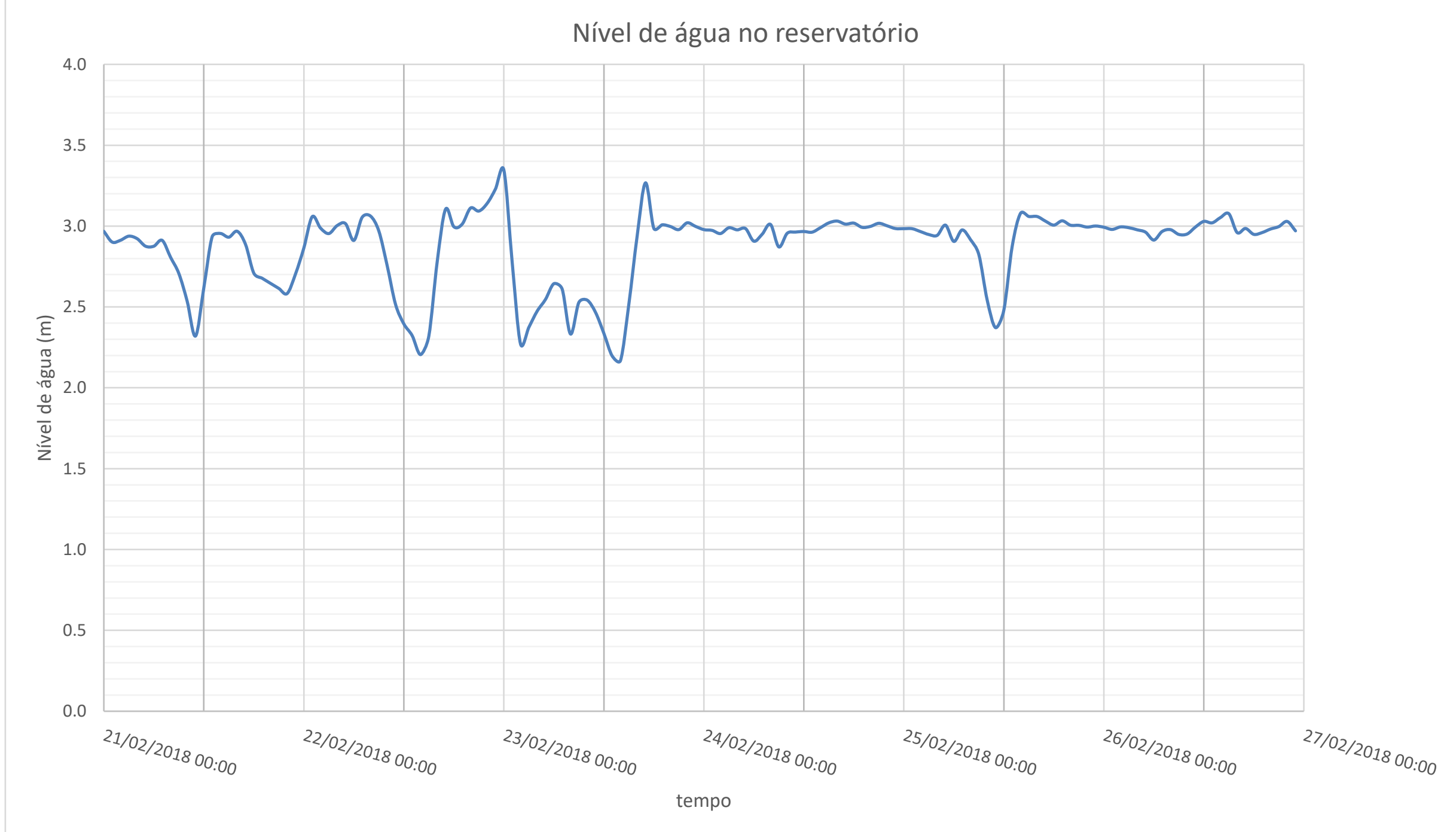

Fonte: Elaboração do Autor 


\subsubsection{Calibração do modelo}

Para a realização da calibração, foram utilizados os dados dos dias 21/02/2018 e do dia 23/02/2018, quarta e sexta-feira, totalizando 48 horas. Decidiu-se não utilizar os dados do dia 22/02/2018 por este apresentar uma queda brusca de carga de pressão entre 12:00h e 15:00h. Essa queda brusca foi considerada como um problema atípico ocorrido na rede, possivelmente devido a uma falha na bomba que pressuriza a área de coroa do sistema. Os dias 24/02/2018 e 25/02/2018 foram um sábado e um domingo e, portanto, apresentaram uma curva de consumo diferente. Estes dias foram, no entanto, utilizados para realizar a validação da calibração realizada.

O modelo preliminar incluiu uma curva de demanda igual a curva adimensional da vazão de saída do reservatório, coeficiente de vazamento igual a zero e rugosidade absoluta de todas as tubulações igual a 0,01 mm. Como todas as tubulações da rede são de PVC e este material não apresenta uma variação de rugosidade muito grande, foi estipulado que as rugosidades absolutas das tubulações não seriam calibradas. Ao invés delas, foram calibradas as perdas de carga localizadas das duas válvulas redutoras de pressão 1 e 2 , indicadas na Figura 20. As perdas de carga localizadas foram calibradas através da utilização de tubulações fictícias, em que a variável de decisão foi a rugosidade absoluta destas tubulações. A Tabela 1 mostra as características das tubulações fictícias de cada uma das VRP's.

Tabela 10 - Características das tubulações fictícias utilizadas para calibrar as perdas de carga localizadas dos acessórios da rede

\begin{tabular}{l|c|c}
\hline Acessório & Diâmetro (mm) & Comprimento (m) \\
\hline VRP - 1 & 100 & 75 \\
\hline VRP - & 50 & 50 \\
\hline
\end{tabular}

Fonte: Elaboração do Autor

As características iniciais do modelo hidráulico preliminar, que foi utilizado para o processo da calibração, encontram-se na Tabela 11.

Tabela 11 - Valor iniciais das variáveis do modelo a serem calibradas

\begin{tabular}{|c|c|}
\hline Elemento & Valor Inicial \\
\hline $\begin{array}{l}\text { Rugosidade absoluta das tubulações fictícias } \\
\text { que simulam as perdas de carga localizadas } \\
\text { (ع) }\end{array}$ & $1 \mathrm{~mm}$ \\
\hline Coeficiente de Vazamento (c) & $0 \mathrm{~L} / \mathrm{s} \cdot \mathrm{m}^{1,18}$ \\
\hline Curva de Consumo Adimensional & $\begin{array}{l}\text { Igual à curva da vazão da saída do } \\
\text { reservatório }\end{array}$ \\
\hline
\end{tabular}


Com o modelo hidráulico preliminar, iniciou-se o processo de calibração da rede. Os limites mínimo e máximo da rugosidade absoluta das tubulações fictícias para a calibração das perdas de carga localizadas das VRP's foram de 1 a $10 \mathrm{~mm}$, com um incremento de 0,01 mm. Foram necessárias apenas três iterações para encontrar uma solução final. O critério de parada foi atingido, pois nas iterações 3 e 4 o coeficiente de vazamento encontrado foi o mesmo, considerando 2 algarismos significativos. A Tabela 12 resume os resultados encontrados em cada uma das iterações:

Tabela 12 - Resultados das iterações do processo de calibração do setor Lacta

\begin{tabular}{c|c|c|c|c|c}
\hline \multirow{2}{*}{ Iteração } & $\begin{array}{c}\text { Coef. de } \\
\text { vazamento } \\
(\mathbf{c})-\end{array}$ & \multicolumn{2}{|c|}{$\begin{array}{c}\text { Coef. de perda de carga } \\
\text { localizada }(\boldsymbol{\varepsilon}-\mathbf{K}) *\end{array}$} & \multicolumn{2}{|c}{ Aptidão } \\
\cline { 3 - 6 } & $\mathbf{L / ( \mathbf { s m } ^ { \wedge } \mathbf { 1 , 1 8 } )}$ & $\mathbf{V R P - 1}$ & $\mathbf{V R P - 2}$ & $\begin{array}{c}\text { Eq. ( 10 } \\
)_{* *}\end{array}$ & Eq. ( 9 )*** \\
\hline 0 & 0 & 0 & 0 & 389,12 & 15,280 \\
\hline 1 & 0,00051 & $2,28-38,8$ & $7,27-127,2$ & 10,19 & 0,591 \\
\hline 2 & 0,00054 & $1,83-35,7$ & $6,11-114,1$ & 9,84 & 0,565 \\
\hline 3 & 0,00053 & $1,68-34,7$ & $6,67-120,7$ & 9,61 & 0,547 \\
\hline 4 & 0,00053 & - & - & - & - \\
\hline
\end{tabular}

* A calibração foi feita alterando o valor da rugosidade absoluta $\varepsilon$. A conversão deste valor para coeficiente de perda de carga localizada (K) foi feita de acordo com a equação ( 46 ).

** Equação utilizada para a calibração, utilizando Pppf =0,30m e Qppf =2,27 m³/h.

*** Equação usualmente utilizada como função objetivo de problemas de calibração. Esta equação não foi utilizada no processo de calibração, sendo calculada somente como parâmetro de comparação.

Fonte: Elaboração do Autor

A Figura 23 mostra a correlação entre as cargas de pressão medidas e simuladas com o modelo hidráulico inicial, enquanto a Figura 24 apresenta esta correlação depois do processo de calibração. A Tabela 13 mostra a melhora do modelo após a calibração através de cinco métricas. Nota-se que o erro médio quadrático do modelo antes da calibração era de 33,42 $\mathrm{m}^{2}$ e foi reduzido para 1,03 $\mathrm{m}^{2}$ após o processo de calibração.

Tabela 13 - Métricas calculadas para o modelo antes e após o processo de calibração

\begin{tabular}{l|l|c|c}
\multicolumn{2}{c|}{ Métrica } & $\begin{array}{c}\text { Antes da } \\
\text { calibração }\end{array}$ & $\begin{array}{c}\text { Após a } \\
\text { calibração }\end{array}$ \\
\cline { 2 - 5 } Erro Absoluto Médio & $\overline{E A}(\mathrm{~m})$ & 4,05 & 0,74 \\
\hline Erro Absoluto Mediano & $\widetilde{E A}(\mathrm{~m})$ & 2,56 & 0,55 \\
\hline Erro Relativo Médio & $\widetilde{E R}(\%)$ & $16,9 \%$ & $3,2 \%$ \\
\hline Erro Relativo Mediano & $\widetilde{E R}(\%)$ & $13,1 \%$ & $2,5 \%$ \\
\hline Erro Médio Quadrático & $\mathrm{MSE}\left(\mathrm{m}^{2}\right)$ & 33,42 & 1,03 \\
\hline
\end{tabular}

Fonte: Elaboração do Autor 
Na Figura 25 pode-se observar a porcentagem acumulada dos erros absolutos da calibração, enquanto na Figura 26 é possível averiguar a porcentagem acumulada dos erros relativos da calibração.

Figura 23 - Relação entre as cargas de pressões observadas e simuladas antes do processo de calibração

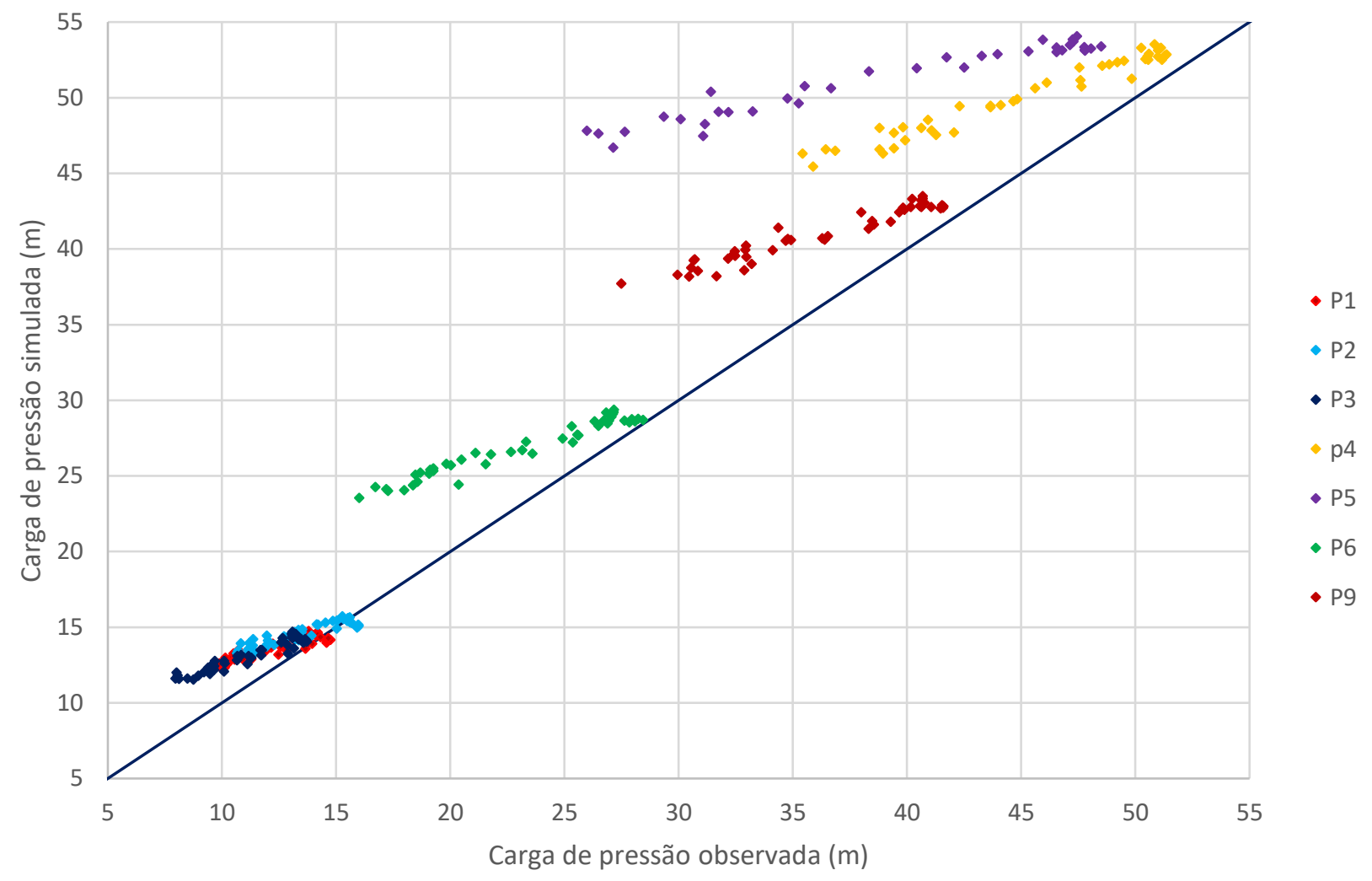

Fonte: Elaboração do Autor 
Figura 24 - Relação entre as cargas de pressões observadas e simuladas após o processo de calibração

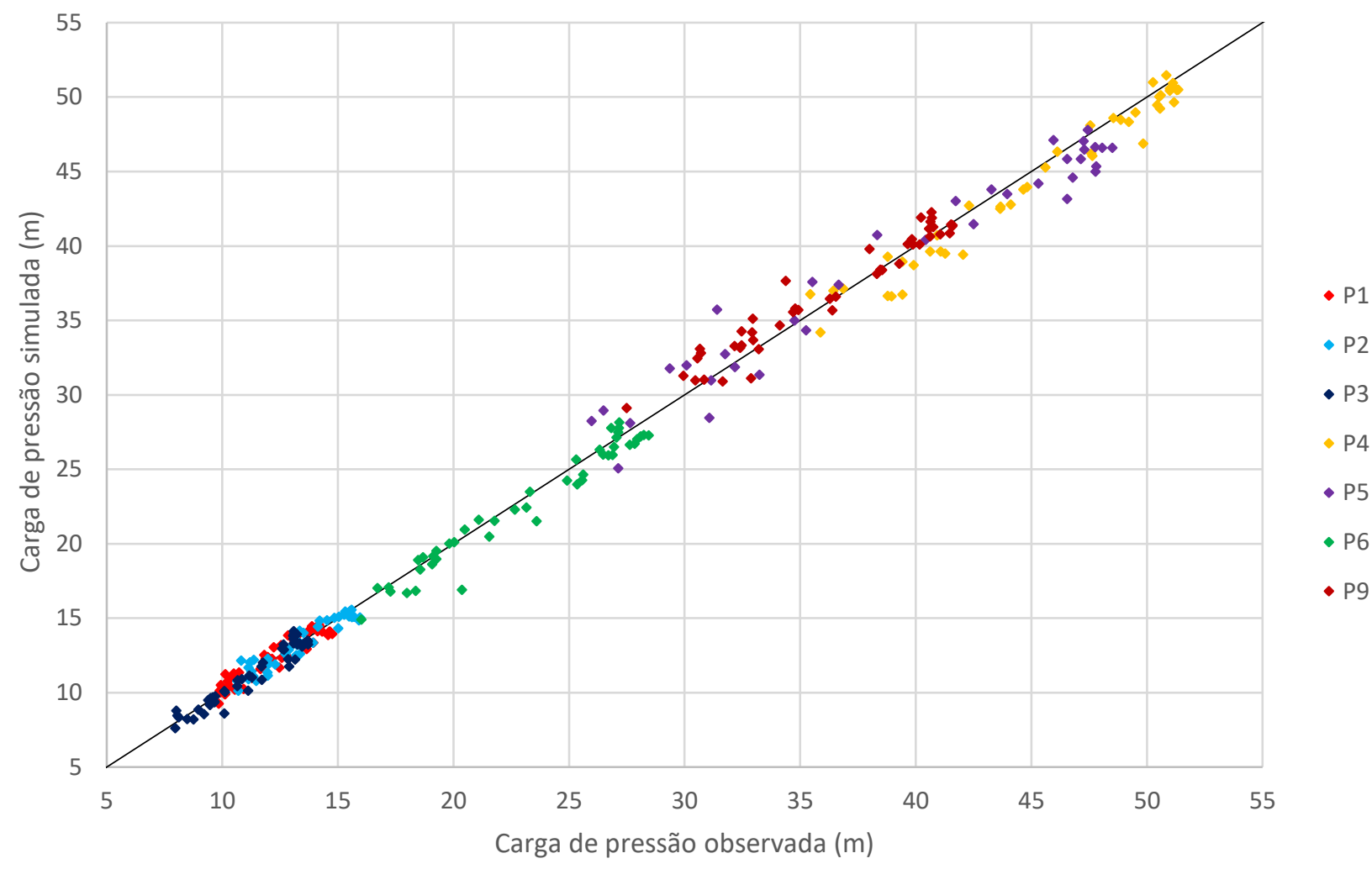

Fonte: Elaboração do Autor 
Figura 25 - Erro absoluto entre as cargas de pressões observadas e simuladas após a calibração do Setor Lacta

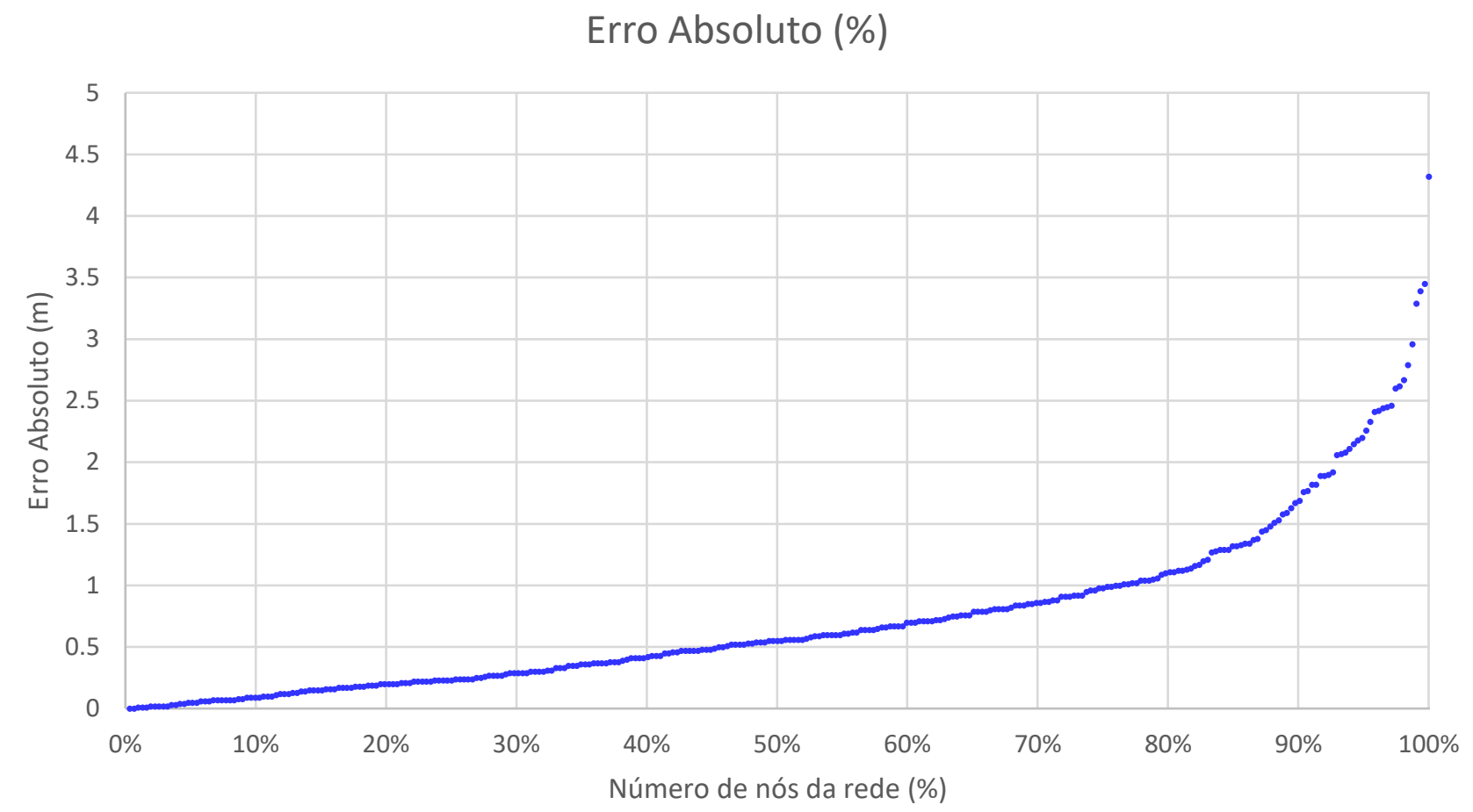

Fonte: Elaboração do Autor

Figura 26 - Erro relativo entre as cargas de pressões observadas e simuladas após a calibração do Setor Lacta

Erro Relativo (\%)

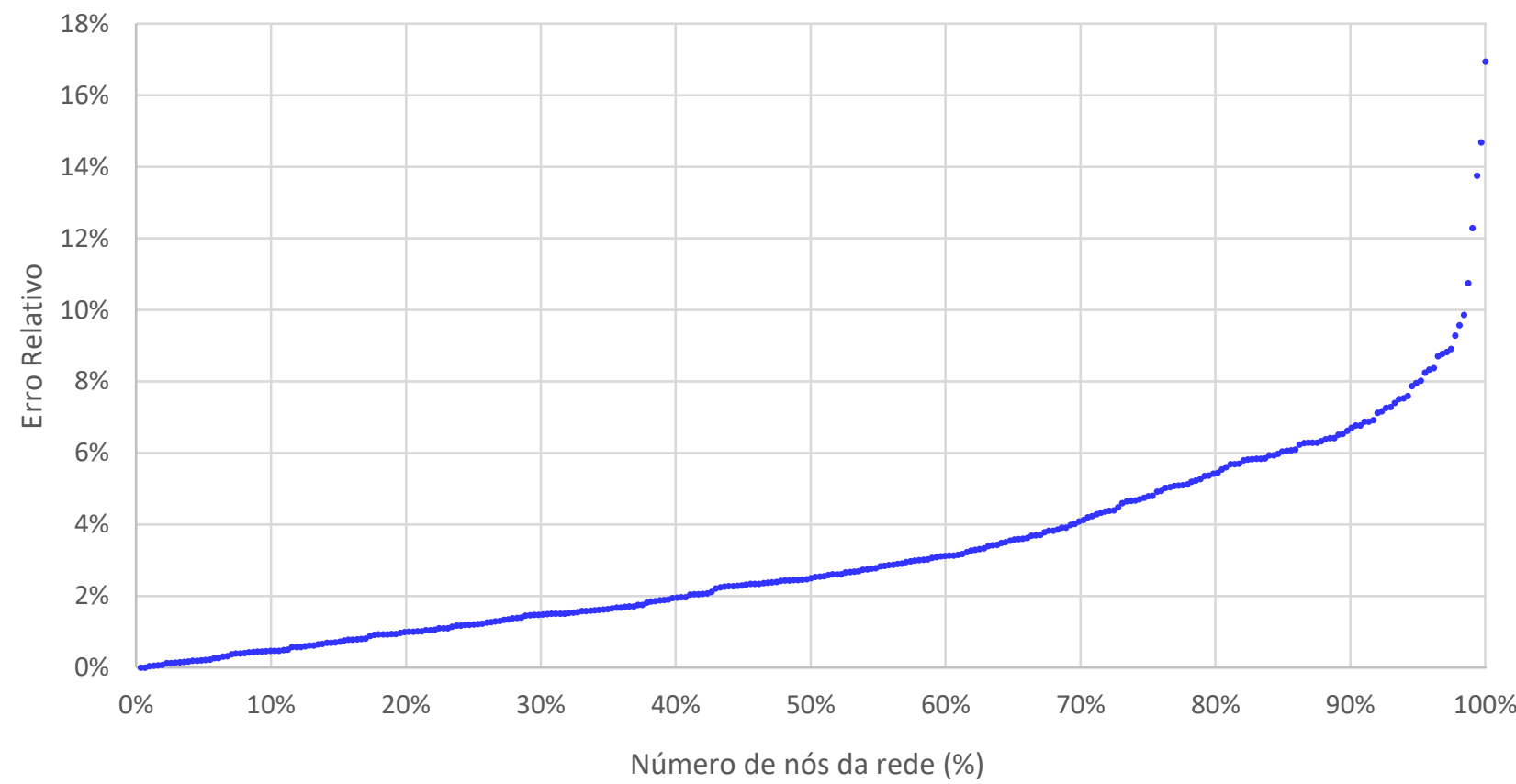

Fonte: Elaboração do Autor 
Os pontos com maiores erros, tanto da Figura 25quanto da Figura 26, pertencem ao nó P5. Esses erros, mais altos em comparação aos demais, são justificados pela localização do nó, que se encontra no final da rede, em um local onde a vazão da tubulação é menor e, portanto, o consumo pontual das residências próximas ao P5 interfere de maneira mais significativa na carga de pressão.

Observou-se, a partir da Figura 25, que 46\% das pressões simuladas possuem um erro menor que $0,5 \mathrm{~m}, 76 \%$ têm um erro menor que $1,0 \mathrm{~m}$ e $93 \%$ possuem um erro menor que $2 \mathrm{~m}$. Na Figura 26, pode-se observar o erro relativo da calibração. Percebeu-se que $76 \%$ dos pontos apresentaram um erro relativo menor que $5 \%$, enquanto somente $1,6 \%$, ou 5 pontos, tiveram um erro relativo maior que $10 \%$. Por ser uma calibração com modelo estendido de $48 \mathrm{~h}$ e devido às imprecisões de cota topográfica, à aproximação da distribuição de demanda e ao desprezo das perdas de carga localizada, pode-se concluir que a calibração foi satisfatória.

Com os resultados da calibração, descritos na Tabela 12, foi construído um modelo para validação, com seis dias de duração. Com ele foi possível comparar os resultados simulados com os dados de vazão e carga de pressão coletados entre os dias 21/02/2018, às 00:00h, e dia 27/02/2018, às 00:00h. Foi construída uma curva de consumo para cada hora simulada, da mesma forma que foi feita na calibração, igualando a vazão média horária simulada com a observada.

A Figura 27 mostra a relação entre as pressões medidas e simuladas para todos os dias de validação para o ponto P1. Essa verificação pode ser visualizada para os outros pontos no Apêndice A, onde também é possível observar a relação horária entre o volume de água referente ao consumo real e ao vazamento na rede. O modelo indicou uma perda de água por vazamento na ordem de $33 \%$ do total consumido no setor, e a porcentagem de vazamento por hora pode ser observada também no Apêndice A. 
Figura 27 - Validação do modelo hidráulico do Setor Lacta - pressões observadas (pontos) e simuladas (linha) do ponto P1

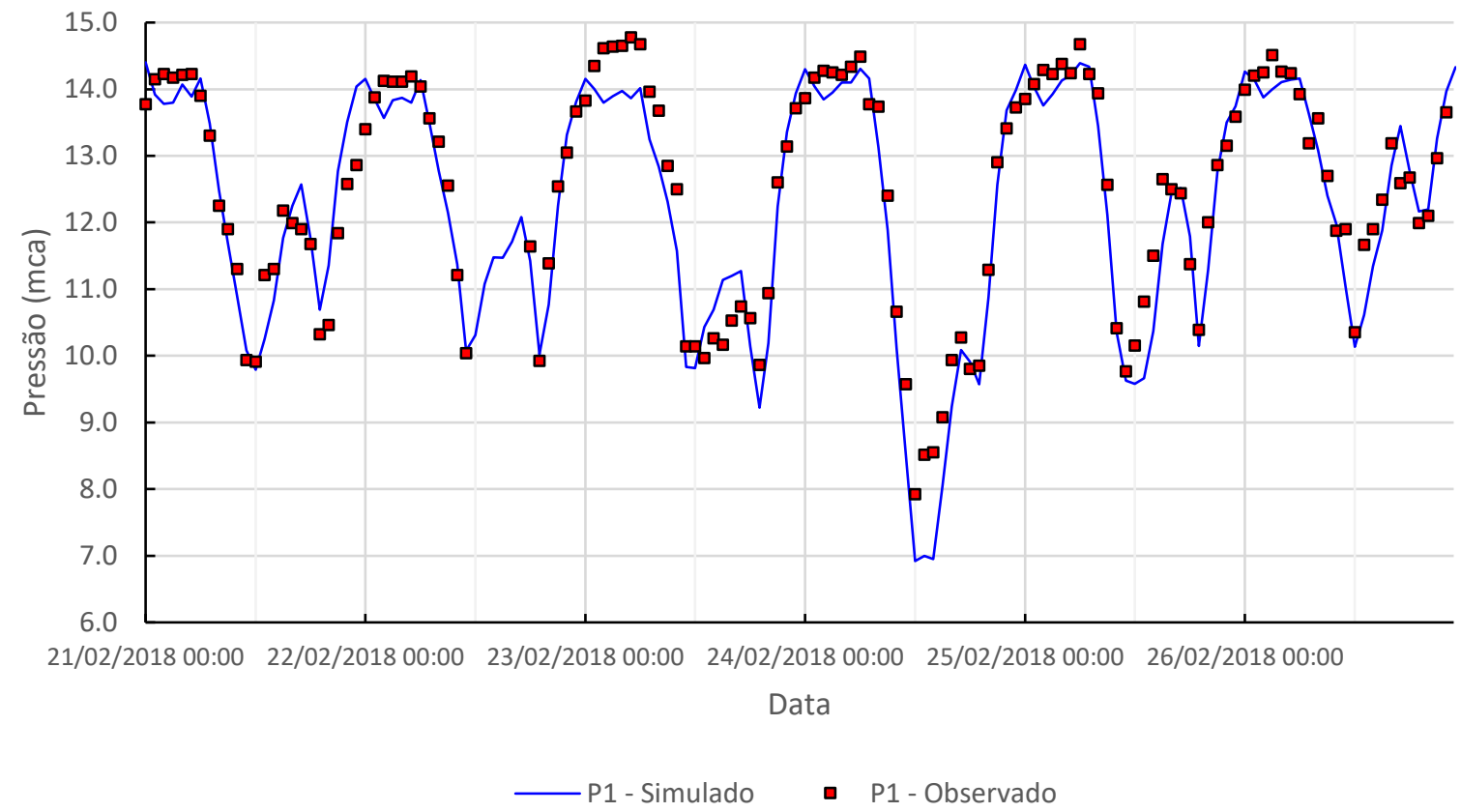

Fonte: Elaboração do autor

A Figura 28 mostra a comparação entre as pressões observadas e simuladas durante todo o período de validação. Percebe-se um resultado divergem mais no Ponto P5. Isso ocorre devido à localização da medição ter ocorrido no final da rede, onde a vazão é menor e, portanto, o modelo pode apresentar resultados piores. A Tabela 14 mostra os resultados das métricas calculadas para o período de validação. Percebeu-se que os valores das métricas não apresentaram grande alteração em relação às métricas da calibração, indicando que a validação do modelo foi satisfatória.

Tabela 14 - Métricas calculadas para o modelo para o período de calibração e validação

\begin{tabular}{l|c|c|c}
\hline \multicolumn{1}{c|}{ Métrica } & $\begin{array}{c}\text { Período de } \\
\text { Calibração }\end{array}$ & $\begin{array}{c}\text { Período de } \\
\text { Validação }\end{array}$ & Alteração \\
\hline Erro Absoluto Médio & $0,74 \mathrm{~m}$ & $0,93 \mathrm{~m}$ & $25,7 \%$ \\
\hline Erro Absoluto Mediano & $0,55 \mathrm{~m}$ & $0,54 \mathrm{~m}$ & $-1,8 \%$ \\
\hline Erro Relativo Médio & $3,2 \%$ & $4,0 \%$ & $25,0 \%$ \\
\hline Erro Relativo Mediano & $2,5 \%$ & $2,6 \%$ & $4,0 \%$ \\
\hline Erro Médio Quadrático & $1,03 \mathrm{~m}^{2}$ & $2,26 \mathrm{~m}^{2}$ & $122,3 \%$ \\
\hline Fonte: Elaboração do Autor
\end{tabular}

Fonte: Elaboração do Autor 
Figura 28 - Comparação entre as pressões observadas e simuladas durante todo o período de validação

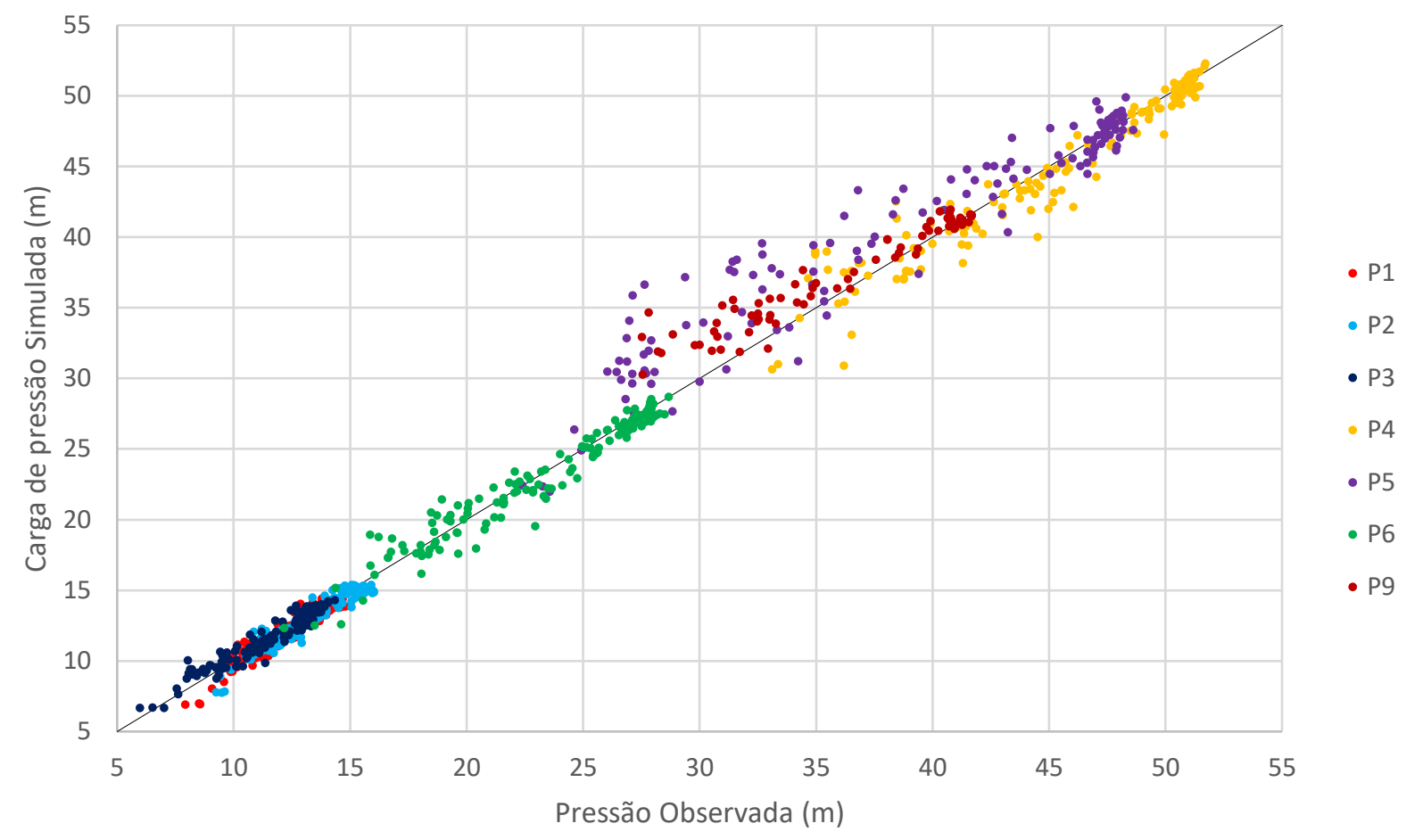

Fonte: Elaboração do Autor

As curvas de consumo utilizadas em cada dia da validação são mostradas na Figura 29.

Figura 29 - Curvas adimensionais de consumo para todos os dias usados na validação da calibração do Setor Lacta

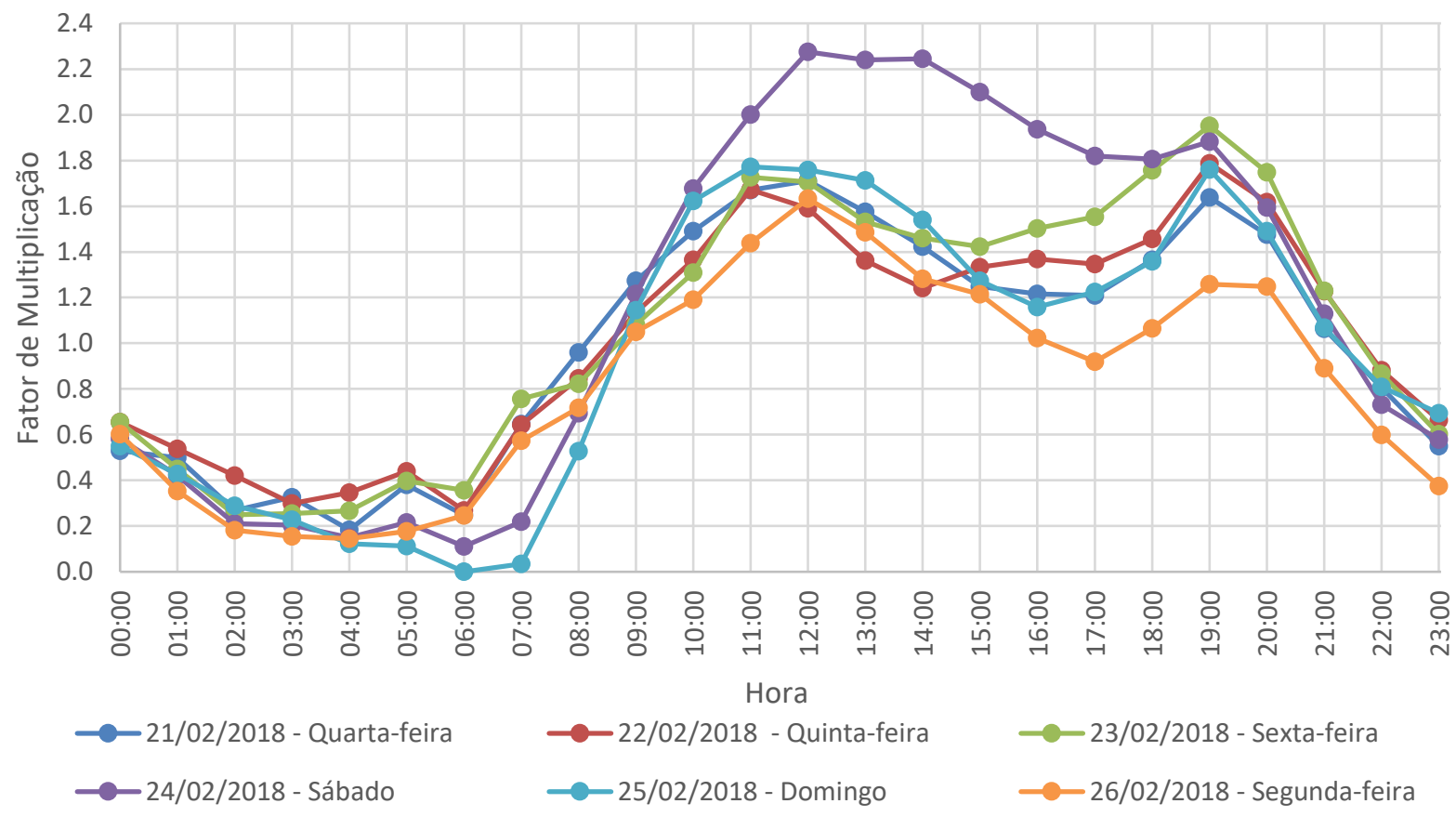

Fonte: Elaboração do Autor 
Observou-se que as curvas de sábado e domingo apresentaram um consumo menor pela manhã (entre as 5:00h e as 7:00h) e a curva de sábado apresentou um consumo maior durante a tarde. As outras curvas tiveram um comportamento semelhante, exceto pela curva de segundafeira, que apresentou um consumo menor durante a noite. Para encontrar uma curva de consumo típica do setor, foi feita a média dos fatores de multiplicação de todas as curvas, exceto as curvas de sábado e domingo, por apresentarem um comportamento diferenciado. Essa curva típica é apresentada na Figura 30.

Figura 30 - Curva adimensional típica de consumo nos dias da semana - Setor Lacta

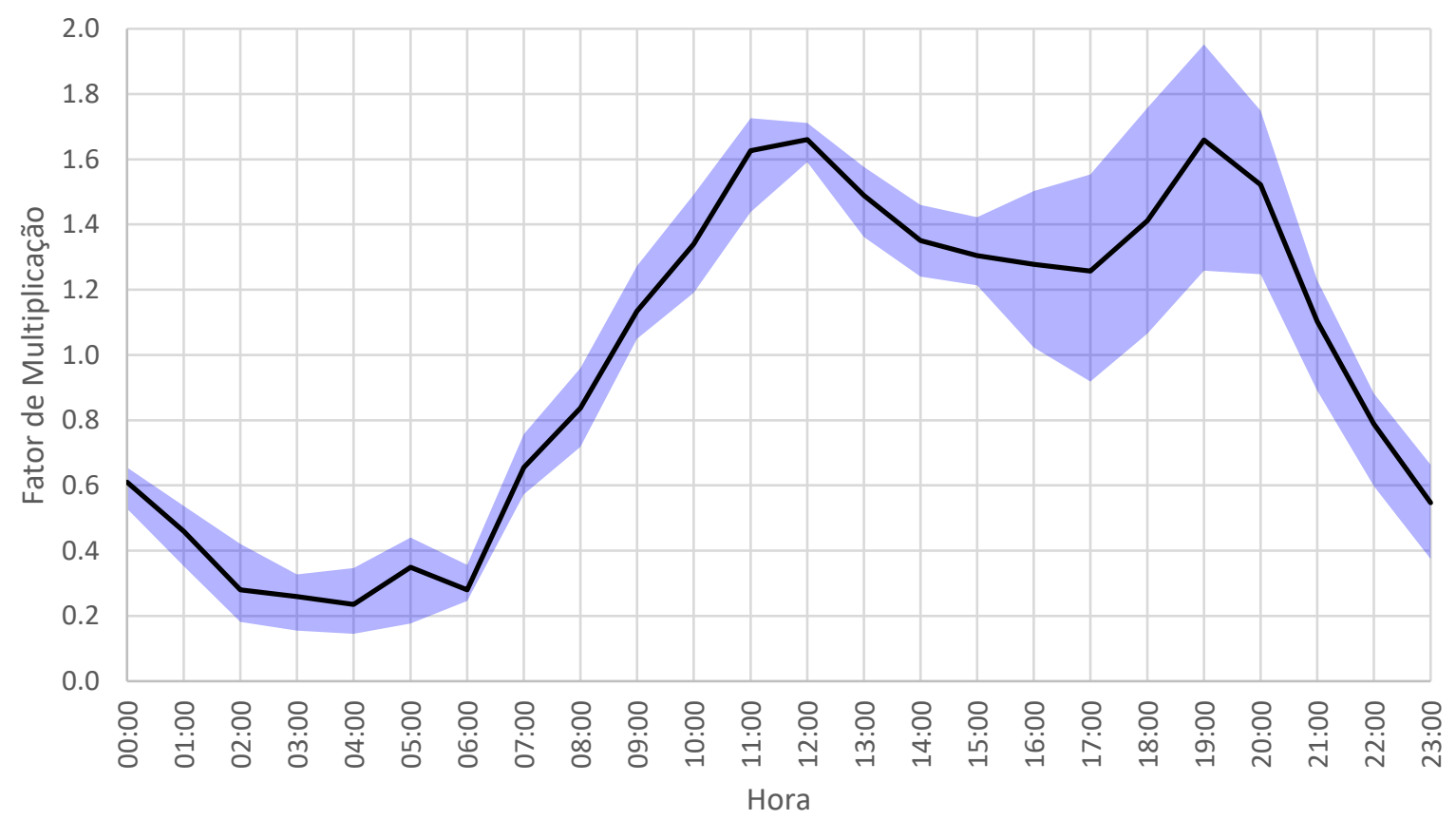

Faixa de fatores de multiplicação — Curva típica (média)

Fonte: Elaboração do Autor

Com a curva adimensional típica de consumo nos dias da semana do Setor Lacta e o coeficiente de vazamento e as rugosidades que simulam as perdas de cargas localizadas encontradas na calibração, pode-se construir o modelo hidráulico definitivo do Setor Lacta e, na próxima etapa, estender os resultados para o restante da cidade.

\subsection{Construção do modelo hidráulico final de Pederneiras}

Para a construção do modelo hidráulico final de Pederneiras foi incluída a curva de consumo típica de $24 \mathrm{~h}$ encontrada, assim como o coeficiente de vazamento igual a 0,00053 $\mathrm{L} /\left(\mathrm{s} \cdot \mathrm{m}^{1,18}\right)$ em todos os nós da rede. Possivelmente o coeficiente de vazamento é maior em regiões com tubulações mais antigas, como no centro. No entanto, para simplificar o processo 
de modelagem, o coeficiente de vazamento e a curva típica de consumo utilizadas foram as mesmas para toda a rede. O consumo nodal do modelo refere-se ao consumo faturado medido verificado no mês de abril de 2018. Com esses dados, juntamente com as informações das características físicas da rede fornecidas pela SABESP-Pederneiras, foi construído o modelo hidráulico. Esse modelo é atualmente separado em 10 setores, os quais são mostrados na Figura 31.

Figura 31 - Modelo hidráulico final de Pederneiras com as indicações dos setores da rede de abastecimento da cidade

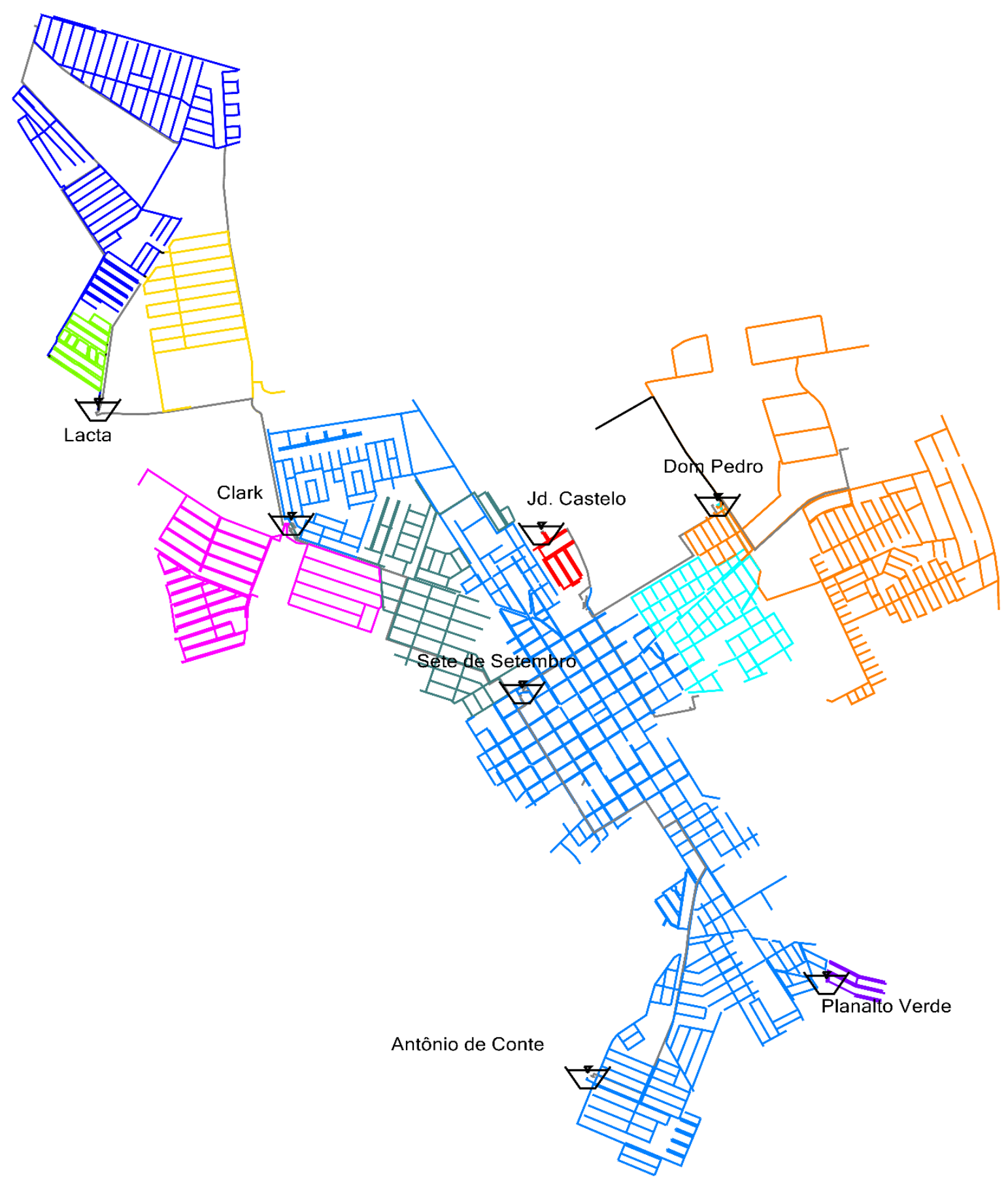

Fonte: Elaboração do Autor 
Na Tabela 15 é apresentado o nome dado a cada um dos setores, o reservatório de abastecimento de cada um deles, a forma como o setor é abastecido e o comprimento total das tubulações pertencentes a cada um.

Tabela 15 - Informações dos setores da rede de abastecimento de água de Pederneiras

\begin{tabular}{l|l|l|l|c}
\hline \multicolumn{1}{c|}{ Nome } & Cor & $\begin{array}{c}\text { Reservatório de } \\
\text { abastecimento }\end{array}$ & \multicolumn{1}{|c|}{$\begin{array}{c}\text { Tipo de } \\
\text { Pressurização }\end{array}$} & $\begin{array}{c}\text { Comprimento da } \\
\text { tubulação (m) }\end{array}$ \\
\hline \multirow{2}{*}{ Centro } & & Antônio Conte & Bomba & \multirow{2}{*}{88952} \\
\cline { 2 - 3 } & & Clark & Bomba & \\
\cline { 2 - 4 } & Sete de Setembro & Gravidade & 19882 \\
\hline Clark Zona Alta & Clark & Bomba & 15059 \\
\hline Clark Zona Baixa & Clark & Gravidade & 8502 \\
\hline Clark/Colina & Clark & Bomba & 29553 \\
\hline Dom Pedro Zona Alta & & Dom Pedro & Bomba & 11731 \\
\hline Dom Pedro Zona Baixa & & Dom Pedro & Gravidade & 2377 \\
\hline Jd. Castelo & & Jd. Castelo & Bomba & 4635 \\
\hline Lacta Zona Alta & & Lacta & Bomba & 28512 \\
\hline Lacta Zona Baixa & & Lacta & Gravidade & 2043 \\
\hline Planalto Verde & Planalto Verde & Gravidade & \\
\hline
\end{tabular}

Fonte: Elaboração do Autor

Os setores Planalto Verde e Jd. Castelo são relativamente pequenos e fisicamente isolados do restante da rede, e por isso não foram considerados no processo de partição da rede. As métricas calculadas para a partição atual da rede são mostradas na Tabela 16. Com o modelo estendido construído, as metodologias propostas para a partição da rede foram realizadas.

Tabela 16 - Métricas da partição inicial da rede de abastecimento de água de Pederneiras

\begin{tabular}{c|c|c|c|c}
\hline IQ & $\mathbf{N}_{\text {FEC }}$ & $\mathbf{N}_{\mathbf{P}}$ & $\mathbf{I}_{\mathbf{B}} \mathbf{D}$ & $\mathbf{I}_{\mathbf{B}}^{\mathbf{C}}$ \\
\hline 0,73 & 13 & 6 & 3,91 & 3,48 \\
\hline
\end{tabular}

Fonte: Elaboração do Autor

\subsection{Partição da rede}

Os resultados das partições de ambos os métodos ModulMax e METIS podem ser visualizados no Apêndice B. As FigurasFigura 32 a Figura 36 apresentam as métricas das soluções encontradas. Nota-se que os resultados de cada metodologia ocorreram da maneira esperada, uma vez que o método ModulMax teve um desempenho melhor no índice de modularidade enquanto o METIS se destacou no índice de balanço da demanda, sendo essas as métricas utilizadas como função objetivo correspondentes a cada metodologia. 
Analisando os resultados, observou-se, também, que o método ModulMax resulta em partições menos balanceadas em relação à demanda, mas com um número baixo de tubulações conectando distritos. O método METIS retorna partições com características opostas, sendo mais balanceadas, porém com um número maior de tubulações entre distritos.

Figura 32 - Índice de Modularidade das partições geradas pelos métodos ModulMax e METIS Índice de Modularidade - IQ

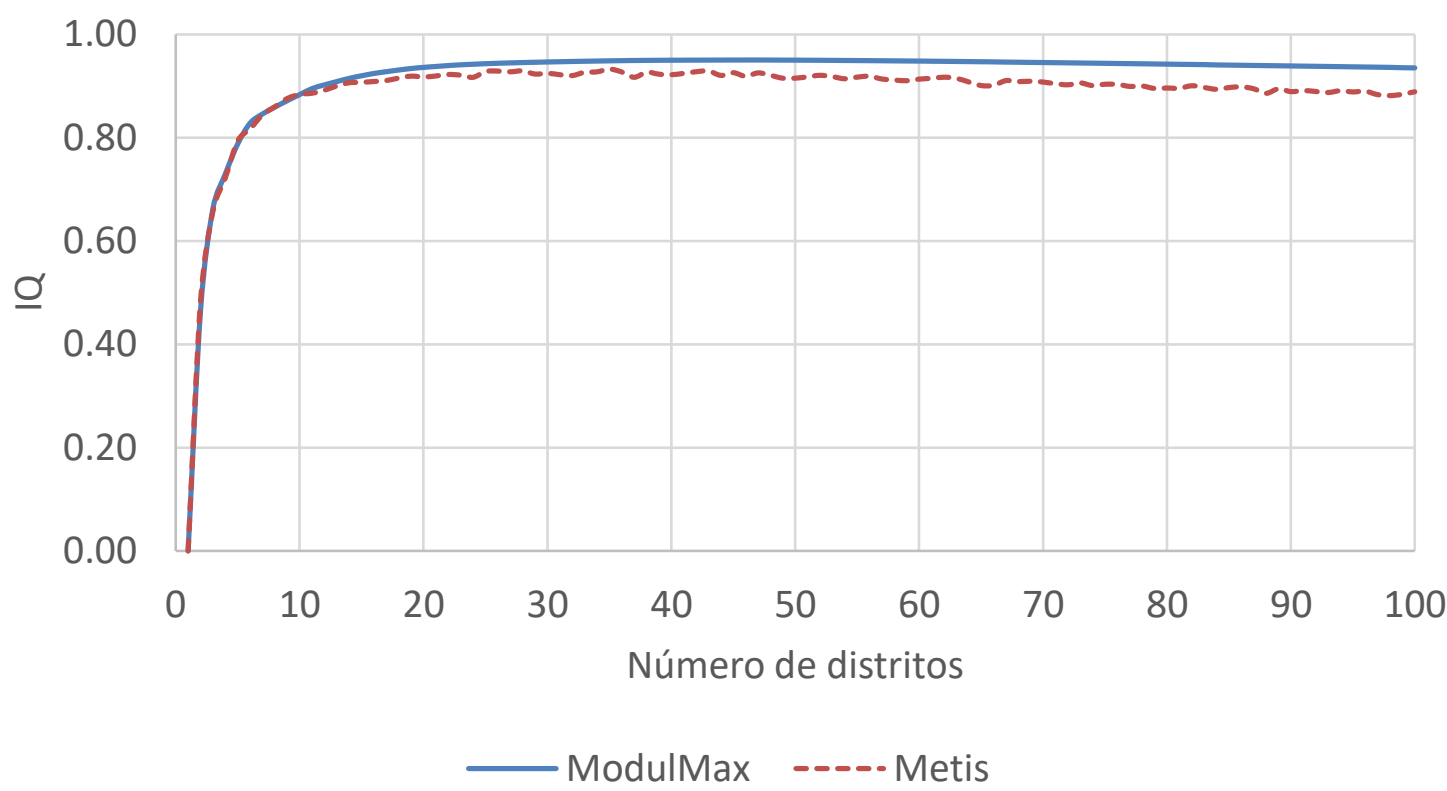

Fonte: Elaboração do Autor

Figura 33 - Número de tubulações entre distritos das partições geradas pelos métodos ModulMax e METIS

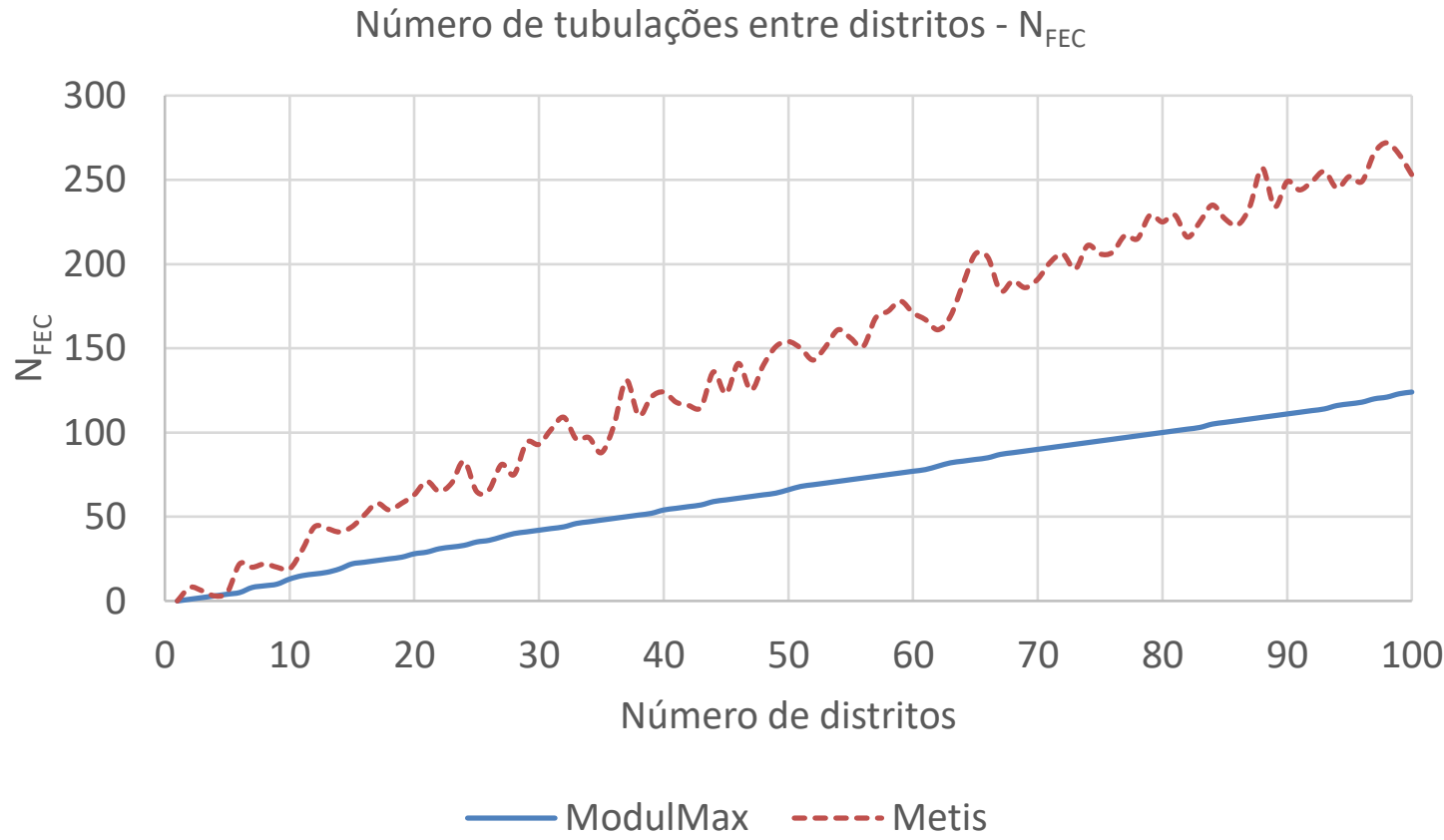

Fonte: Elaboração do Autor 
Figura 34 - Número de conexões do distrito mais conectado das partições geradas pelos métodos ModulMax e METIS

Númeto máximo de conexões do distrito mais conectado- $\mathrm{N}_{\mathrm{P}}$

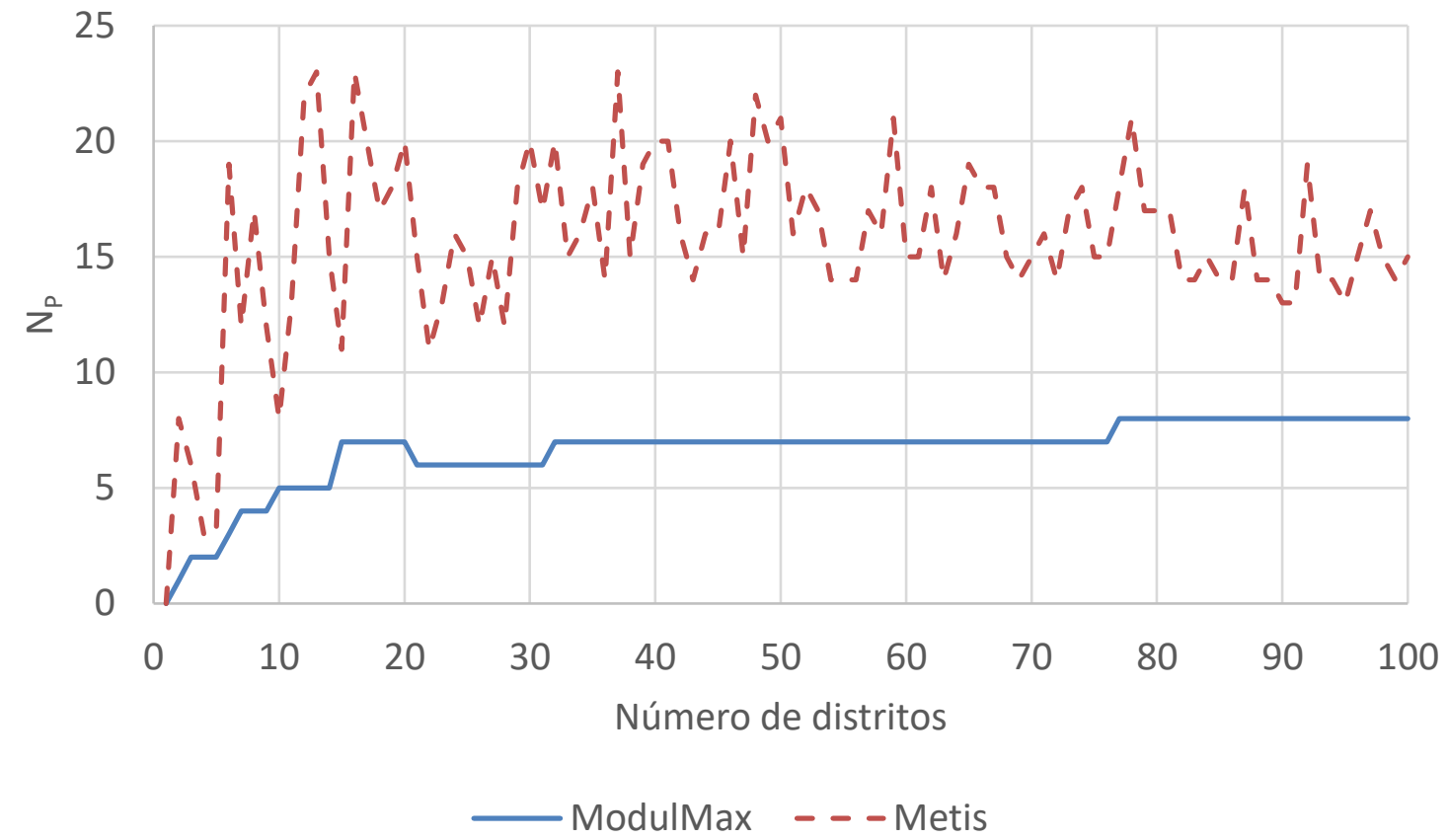

Fonte: Elaboração do Autor

Figura 35 - Índice de balanço da demanda das partições geradas pelos métodos ModulMax e METIS Índice de balanço da demanda $-I_{B}{ }^{D}$

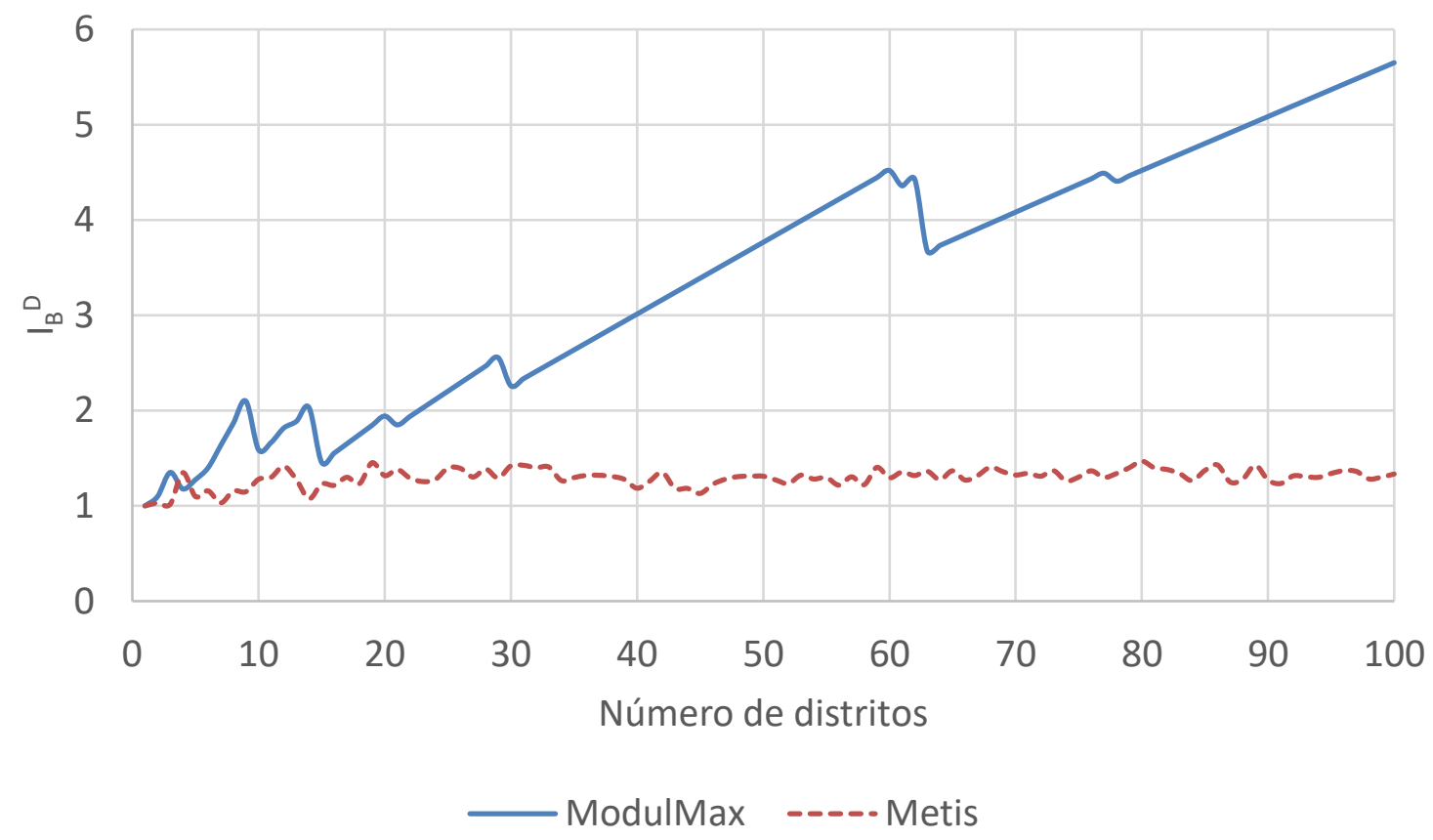

Fonte: Elaboração do Autor 
Figura 36 - Índice de balanço do comprimento das partições geradas pelos métodos ModulMax e METIS

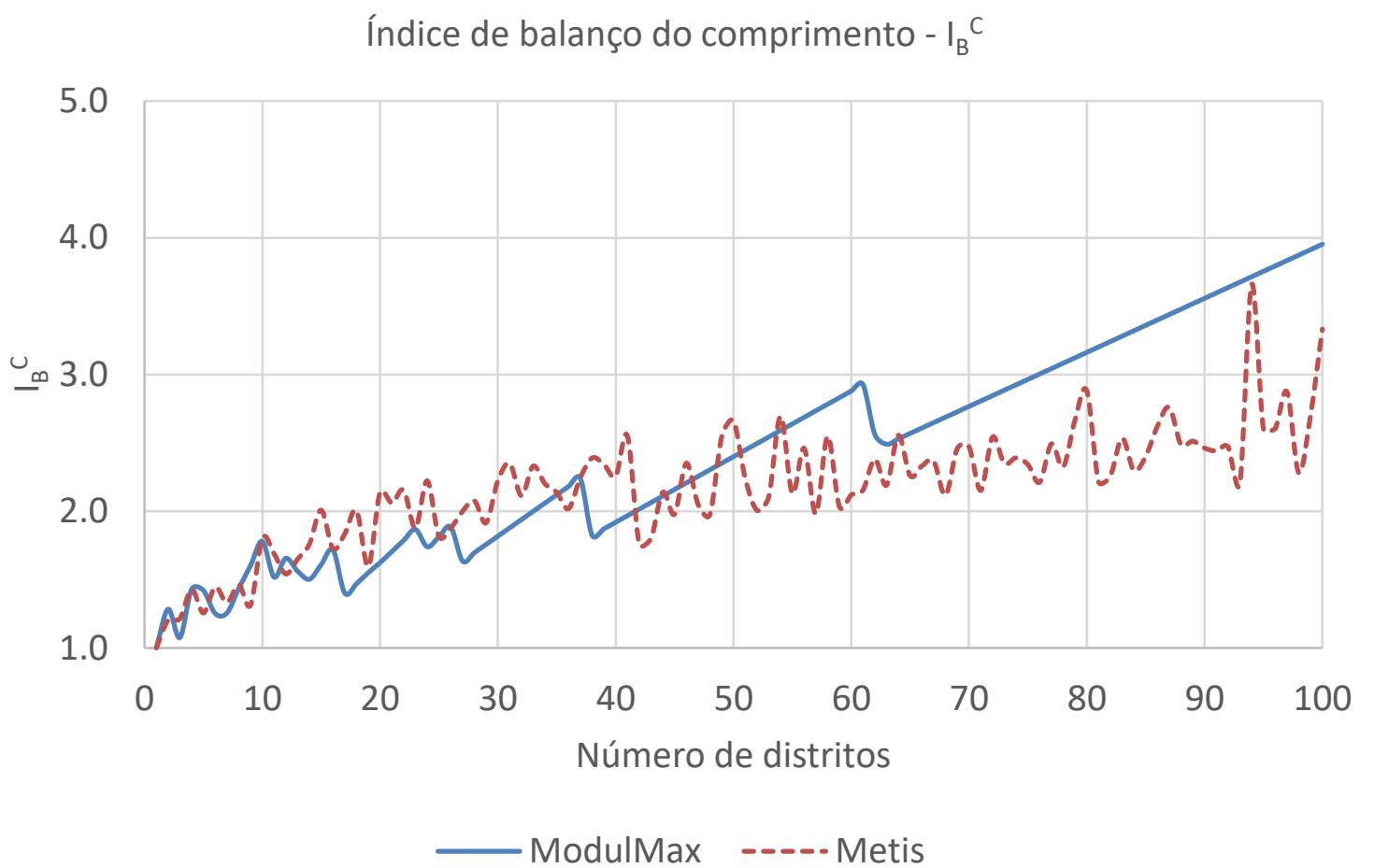

Fonte: Elaboração do Autor

A Figura 37 mostra a comparação das métricas calculadas para os dois métodos quando se particiona a rede em 5, 10, 20, 30, 40, 50, 75 ou 100 distritos. Foi possível constatar que quanto maior o número de distritos, maior é a diferença de resultados entre as duas metodologias, cada qual se aproximando mais da métrica que a orienta. Foi observado, também, que as partições com menor número de distritos, entre 5 e 30, apresentaram resultados melhores quando comparadas com as partições em muitos distritos.

Quanto ao índice de modularidade IQ (Figura 32), verificou-se que, embora seja a métrica diretamente otimizada pelo ModulMax, ambas as metodologias apresentaram resultados similares, com ModulMax ligeiramente melhor. NFEC (Figura 33) mostrou índices bem parecidos para divisões em poucos distritos, mas percebeu-se um resultado pior pela metodologia de METIS quando o número de distritos aumentou. O mesmo comportamento aconteceu com $\mathrm{N}_{\mathrm{p}}$ (Figura 34), e com uma intensidade ainda maior, sendo essa a métrica com maior diferença entre as metodologias. $\mathrm{I}_{\mathrm{B}}{ }^{\mathrm{C}}$ (Figura 35) foi a métrica mais instável na comparação de metodologias, como pode ser visualizado na Figura 36. No entanto, em geral, o método METIS apresentou melhores resultados de $\mathrm{I}_{\mathrm{B}}{ }^{\mathrm{C}}$ para soluções com até 40 partições, e a partir disso, ModulMax passou a apresentar melhores resultados. Finalmente, ao analisar $\mathrm{I}_{\mathrm{B}}{ }^{\mathrm{D}}$ (Figura 36), observou-se uma clara superioridade do método METIS, que restringiu esse índice durante o processo de partição. 
Quando as comparações foram feitas em relação ao número de partições, percebeu-se que aquelas que possuiam até dez distritos tiveram um resultado próximo para ambas as metodologias, embora a ModulMax apresentasse um resultado ligeiramente melhor para $\mathrm{Np}$ e a METIS para $I_{B}{ }^{D}$. A partir de 20 partições, observou-se uma diferença mais significativa entre os resultados.

Figura 37 - Comparação das métricas dos métodos ModulMax e METIS para partições de 5, 10, 20, 30, 40, 50,75 e 100 distritos. Todas as métricas foram normalizadas de 0 a 1 , sendo 10 máximo valor obtido para uma partição e 0 o menor.

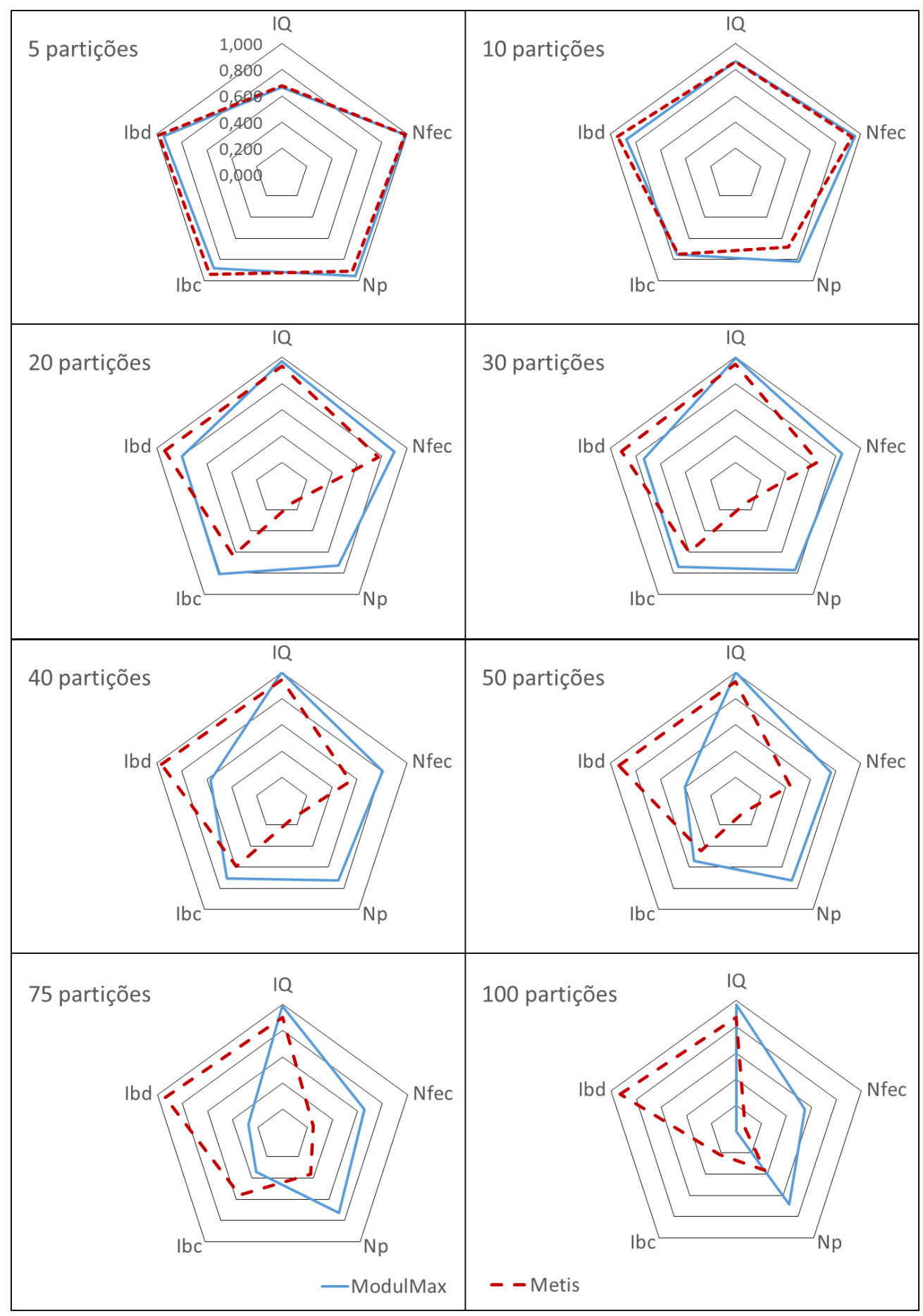

Fonte: Elaboração do Autor 


\subsection{Seleção da melhor partição}

O Conjunto inicial possui 198 soluções e pode ser visualizado no Apêndice B. Já o Conjunto Restrito e o Conjunto Frente Pareto possuem, respectivamente, 52 e 32 soluções e podem ser observados no Apêndice $\mathrm{C}$, onde também é possível analisar os resultados dos cálculos para encontrar os elementos pertencentes ao C.C.I. e C.C.N, que possuem 2 e 3 soluções, respectivamente. As soluções pertencentes ao Conjunto Compromisso Ideal, Conjunto Compromisso NADIR e Conjunto Selecionado podem ser observadas na Figura 43. O nome da solução foi adotado como o nome do método utilizado seguido por uma vírgula e pelo número de distritos em que a rede foi dividida. Atenta-se para o fato de que, nesta etapa do projeto, as métricas foram normalizadas segundo a equação ( 57 ), e, portanto, foram alteradas para serem métricas de minimização.

As restrições utilizadas para a criação do Conjunto Restrito, explicitadas na seção 4.4.1, podem ser observadas nas Figura 38 a Figura 40, exceto a restrição de máximo número de partições.

Figura 38 - Comprimento da tubulação do distrito mais extenso e limite imposto na seção 4.4.1

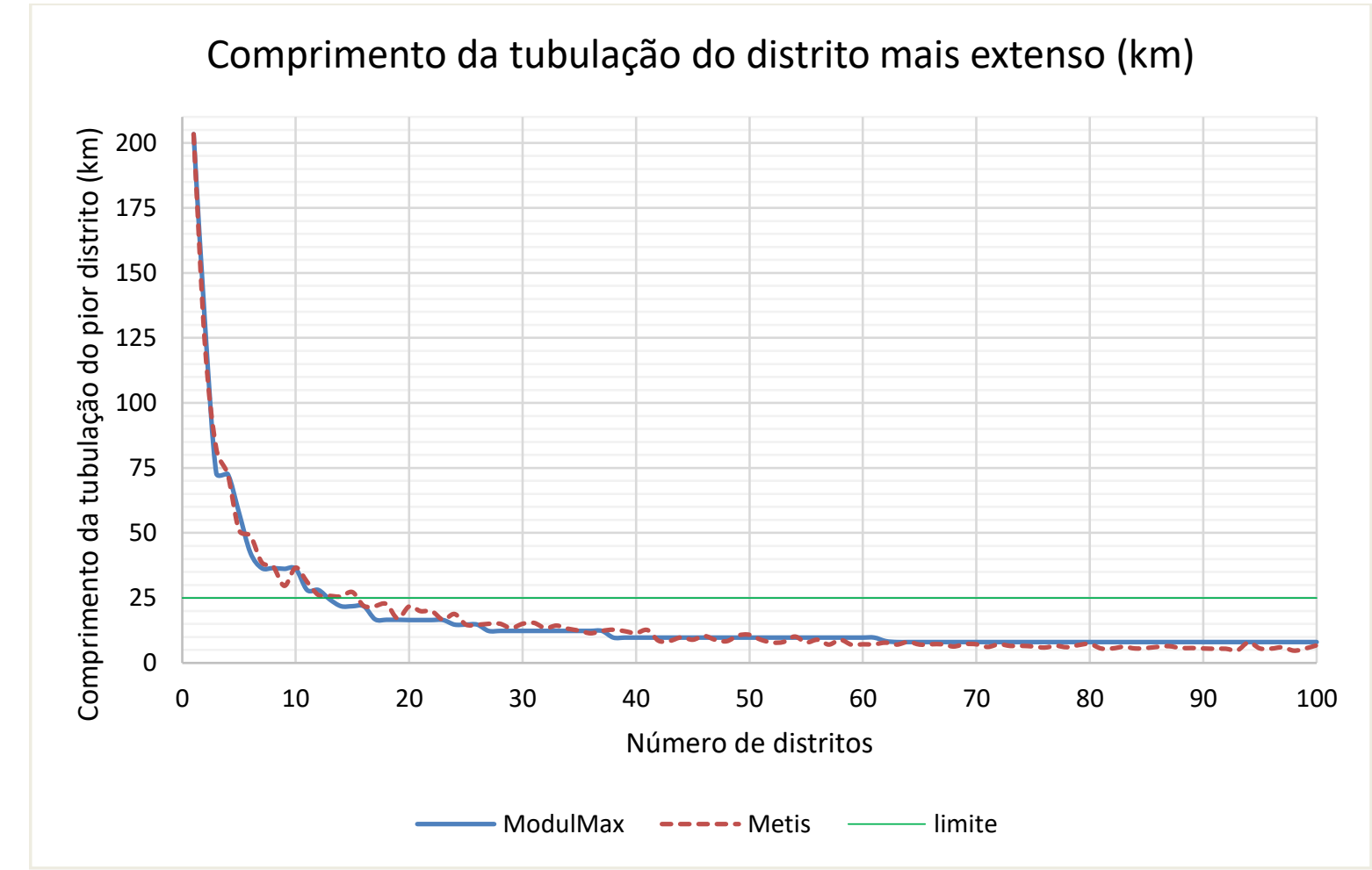

Fonte: Elaboração do Autor

A restrição quanto ao comprimento da tubulação do maior distrito excluiu as partições com menos de 13 distritos do método ModulMax e aquelas com menos de 16 distritos do METIS. Nota-se que essa restrição não teve influência para a construção do Conjunto Restrito, uma vez que a restrição quanto a demanda média máxima excluiu todas as soluções delimitadas 
por essa restrição. Observa-se também que, devido ao comportamento semelhante dos dois métodos quanto ao comprimento de tubulação do distrito mais extenso, o número de partições restringidas de ambos os métodos é semelhante.

Figura 39 - Número de conexões do distrito mais conectado e limite imposto pela seção 4.4.1

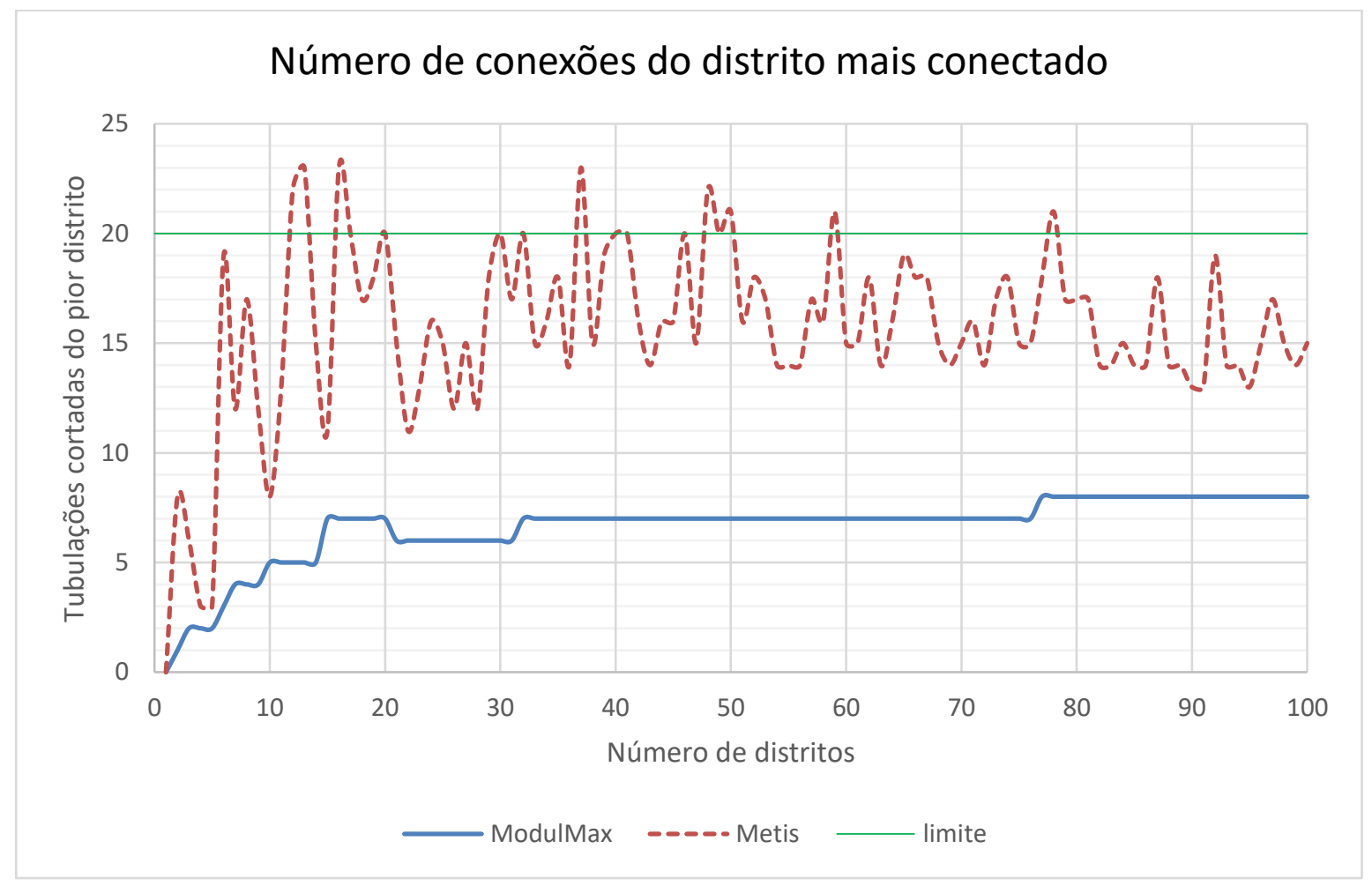

Fonte: Elaboração do Autor

A restrição quanto ao número de conexões do distrito mais conectado excluiu apenas 8 soluções, sendo todas pertencentes ao método METIS. Nota-se que essa restrição excluiu soluções distantes umas das outras e com altos número de grupos, como a solução METIS com 78 partições, por exemplo. Observa-se o bom desempenho das soluções ModulMax nessa restrição, apresentando no máximo 8 conexões entre distritos de um único distrito. 
Figura 40 - Demanda média máxima e limite imposto pela seção 4.4.1

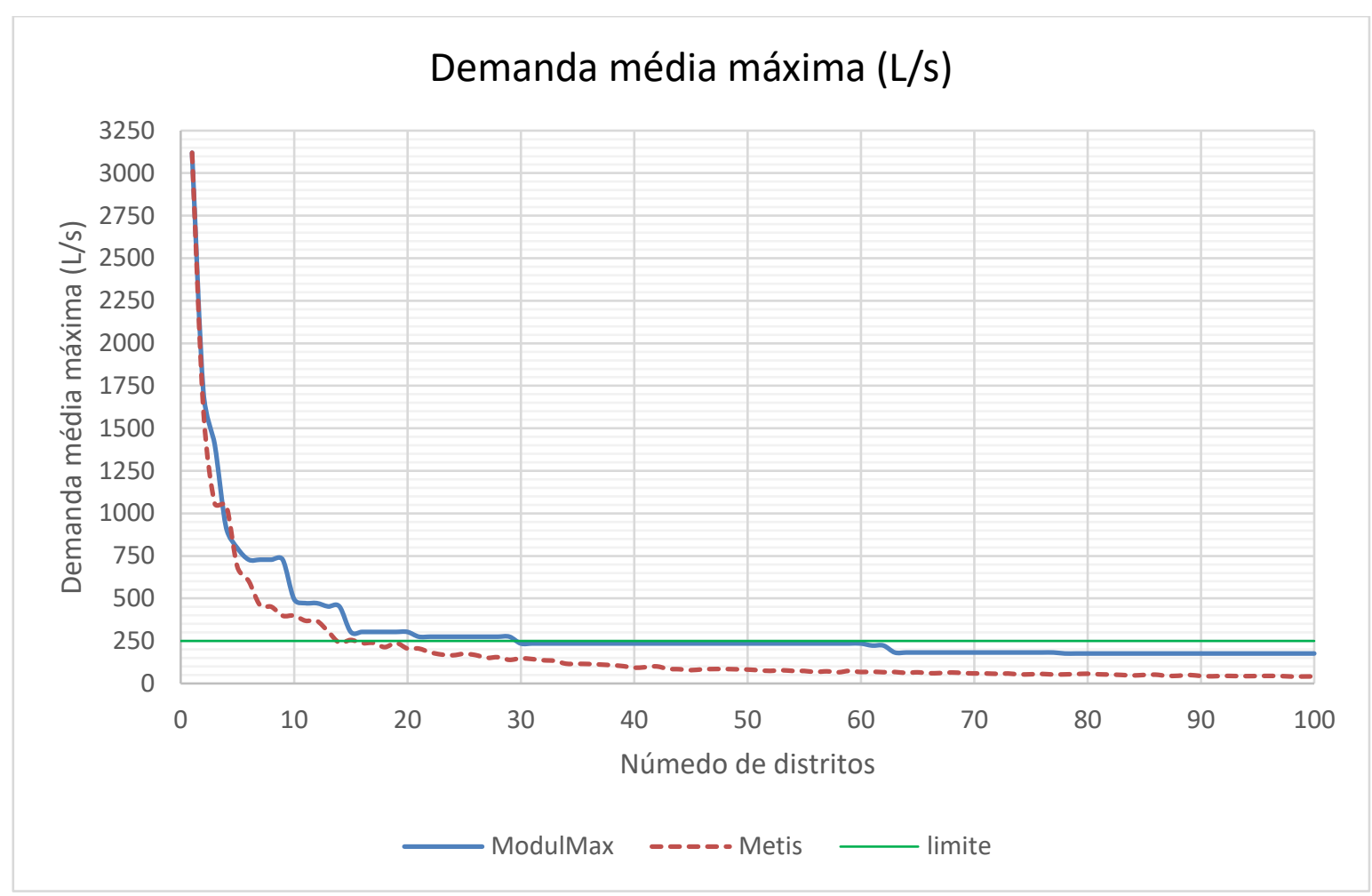

Fonte: Elaboração do Autor

A restrição relativa à demanda média máxima, por fim, excluiu todas as partições com menos de 30 distritos do ModulMax e com menos de 18 distritos do METIS. Essa restrição excluiu mais soluções ModulMax, uma vez que o índice de balanço dessa metodologia é pior quando comparado com a METIS.

Analisando o Conjunto Restrito resultante, notou-se que o método METIS possui soluções com menor número de partições e um número maior de tubulações cortadas, enquanto o método ModulMax proporciona partições com características opostas.

A Figura 43 apresenta a comparação duas a duas das métricas normalizadas para todas as soluções contidas no Conjunto Pareto, destacando a solução de 30 partições obtida através do método ModulMax, a qual foi escolhida como melhor partição, como demonstrado posteriormente.

De maneira geral, percebeu-se que as soluções ModulMax, por serem obtidas de maneira iterativa e dependente entre elas, apresentaram resultados mais próximos entre si, formando linhas bem definidas. Já o método METIS, por cada partição ter sido gerada através de um processo independente, resultou em soluções mais espalhadas nos gráficos.

Quando se comparou IQ e $\mathrm{N}_{\mathrm{FEC}}$, uma clara vantagem foi observada nas soluções ModulMax, como esperado, uma vez que essa metodologia usou IQ como função objetivo e sua principal vantagem foi gerar baixo $\mathrm{N}_{\mathrm{FEC}}$. O mesmo ocorreu quando se comparou IQ e $\mathrm{N}_{\mathrm{P}}$, 
pelas mesmas razões. Quando se comparou IQ e $\mathrm{I}_{\mathrm{B}}{ }^{\mathrm{c}}$, no entanto, não foi possível observar um destaque claro para nenhuma das metodologias. Percebeu-se que as soluções ModulMax apresentaram um desempenho melhor em IQ, mas o desempenho de algumas soluções METIS foram melhores sob $\mathrm{I}_{\mathrm{B}}{ }^{\mathrm{C}}$. A última comparação de $\mathrm{IQ}$, que foi feita com $\mathrm{I}_{\mathrm{B}}{ }^{\mathrm{D}}$, demonstrou uma clara diferença entre as metodologias, uma vez que as métricas foram usadas diretamente durante o processo de partição de ambas as metodologias, sendo a primeira utilizada na ModulMax e a segunda na METIS.

A comparação de $\mathrm{N}_{\mathrm{FEC}}$ com $\mathrm{N}_{\mathrm{P}}$ mostrou que as soluções ModulMax foram melhores sob este aspecto. Já quando a comparação ocorreu entre $\mathrm{N}_{\mathrm{FEC}}$ e $\mathrm{I}_{\mathrm{B}}{ }^{\mathrm{C}}$, não houve uma metodologia que se destacasse, uma vez que a frente Pareto correspondente à essas duas métricas tenha uma solução de cada metodologia. A comparação de $\mathrm{N}_{F E C}$ e $\mathrm{I}_{B}{ }^{\mathrm{D}}$ identificou uma clara diferença entre as metodologias.

Comparando $\mathrm{N}_{P}$ e $\mathrm{I}_{\mathrm{B}}{ }^{\mathrm{C}}$ concluiu-se que as soluções ModulMax apresentaram soluções mais balanceadas, enquanto as soluções METIS tiveram resultados ruins para $\mathrm{N}_{P}$ e satisfatórios para a outra métrica. A comparação de $\mathrm{N}_{P}$ e $\mathrm{I}_{B}{ }^{\mathrm{D}}$ apontou uma grande diferença entre as metodologias, não apresentando um desempenho melhor para nenhuma delas. Finalmente, a comparação entre $\mathrm{I}_{\mathrm{B}}{ }^{\mathrm{C}}$ e $\mathrm{I}_{\mathrm{B}}^{\mathrm{D}}$ mostrou, como esperado, uma superioridade das soluções METIS, uma vez que esse método utilizou o índice de balanço da demanda em seu processo de partição e o índice de balanço de comprimento possui resultados parecidos entre os métodos.

Na Tabela 17 é apresentada a melhor solução de cada comparação explicitada na Figura 41, utilizando como critério de escolha aquela partição que possui a menor distância euclidiana da origem.

Tabela 17 - Soluções com menor distância euclidiana da origem dos gráficos que relacionam as métricas duas a duas. Na diagonal da tabela, estão as soluções que possuem o menor valor da métrica

\begin{tabular}{c|l|c|c|c|c}
\hline Métrica & \multicolumn{1}{|c|}{$\mathbf{N}_{\mathrm{FEC}}$} & $\mathbf{I Q}$ & $\mathbf{N}_{\mathbf{P}}$ & $\mathbf{I}_{\mathbf{B}}{ }^{\mathbf{C}}$ & $\mathbf{I}_{\mathbf{B}}{ }^{\mathbf{D}}$ \\
\hline $\mathbf{N}_{\mathrm{FEC}}$ & ModulMax,30 & - & - & - & - \\
\hline $\mathbf{I Q}$ & ModulMax,36 & ModulMax, 44 & - & - & - \\
\hline $\mathbf{N}_{\mathbf{P}}$ & ModulMax, 30 & ModulMax, 44 & ModulMax, 30 e 31 & - & - \\
\hline $\mathbf{I}_{\mathbf{B}}{ }^{\mathbf{C}}$ & METIS, 19 & ModulMax, 38 & ModulMax, 30 & METIS, 20 & - \\
\hline $\mathbf{I}_{\mathbf{B}}{ }^{\mathbf{D}}$ & METIS, 18 & ModulMax, 30 & ModulMax, 30 & METIS, 19 & METIS, 45 \\
\hline
\end{tabular}

Fonte: Elaboração do Autor

Analisando a Tabela 17, percebeu-se que as soluções ModulMax dominaram as métricas $\mathrm{N}_{\mathrm{FEC}}, \mathrm{N}_{P}$ e IQ, enquanto as soluções METIS prevaleceram sob $\mathrm{I}_{\mathrm{B}}{ }^{\mathrm{C}}$ e $\mathrm{I}_{\mathrm{B}}{ }^{\mathrm{D}}$. As partições explicitadas nesta tabela podem ser visualizadas no Apêndice D. 
Figura 41 - Gráficos de frequência e correlação das cinco métricas normalizadas de todas as soluções contidas no Conjunto Pareto, utilizadas para a seleção da melhor partição

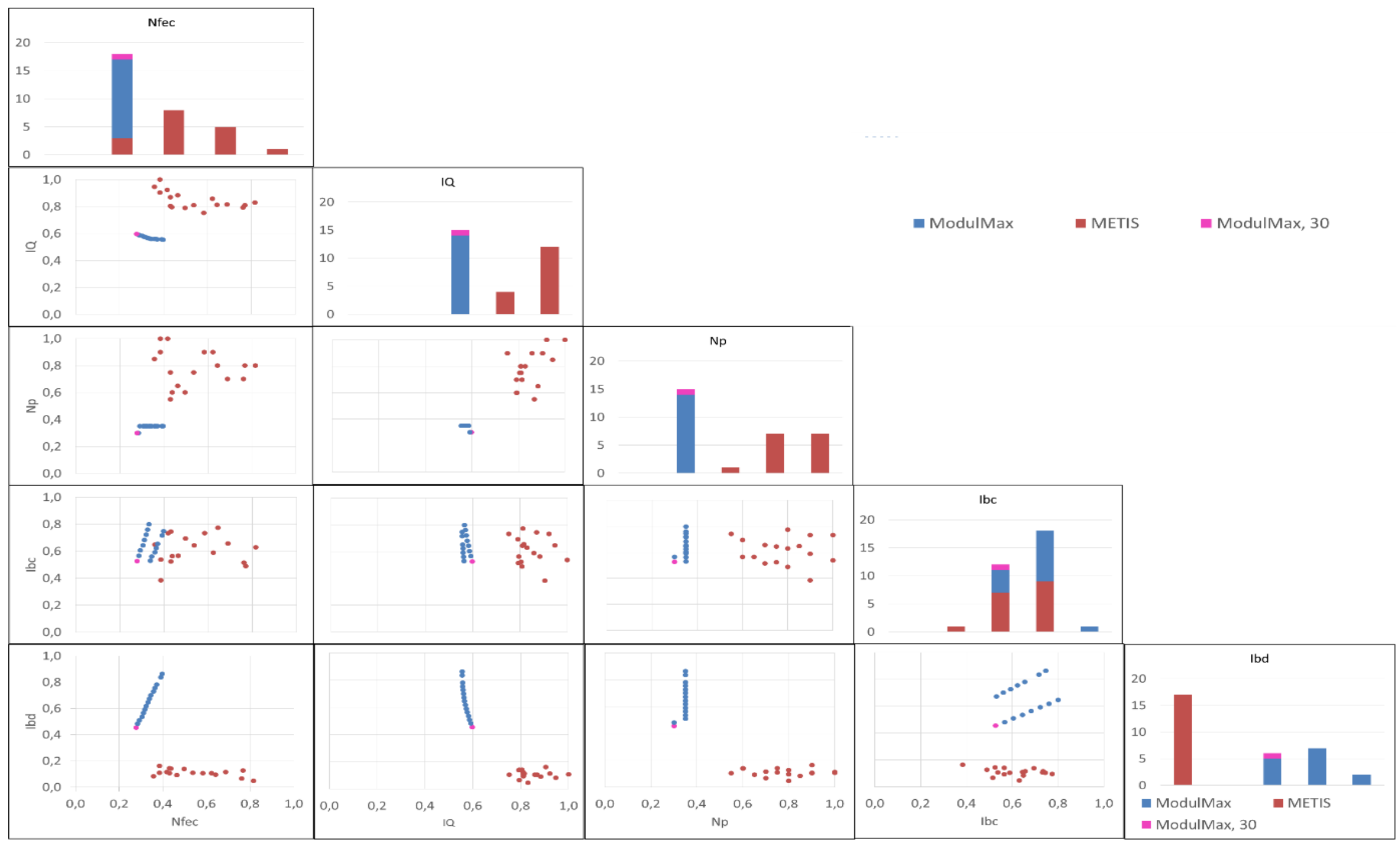

Fonte: Elaboração do Autor 
Na Figura 43, o Conjunto Inicial (C.I.) representa todas as soluções encontradas, sendo 99 realizadas pelo método de modularidade e outras 99 pelo método METIS. O Conjunto Restrito (C.R.), com 52 elementos, representa todas as soluções que satisfazem as restrições impostas no item 4.4. O Conjunto da Frente Pareto (C.F.P.), com 32 soluções, corresponde a todas as soluções do C.R. que pertencem à Frente Pareto, possuindo como funções objetivo as cinco métricas contidas na Tabela 7. O Conjunto Compromisso Ideal (C.C.I), com apenas dois elementos, representa todas as soluções que foram selecionadas como mais próximas ao Ideal pelo método de programação por compromisso Lp. O Conjunto Compromisso NADIR (C.C.N.), com 3 elementos, representa todas as soluções que foram selecionadas como mais distantes do NADIR pelo método de programação por compromisso Lp. O Conjunto Selecionado (C.S.), por fim, é constituído apenas pela única solução que pertence à intersecção entre o C.C.I. e o C.C.N.

A solução METIS com 18 partições é apresentada na Figura 42, apenas para demonstrar o resultado típico das soluções advindas das partições utilizando essa metodologia. Observouse que os distritos obtidos são mais homogêneos, como a metodologia propõe, mas, no entanto, o número de conexões entre distritos é muito alto, o que causaria dificuldades para gerenciá-los de maneira independente. 
Figura 42 - Partição da Rede de Abastecimento de Água de Perderneiras em 18 distritos, utilizando o método METIS

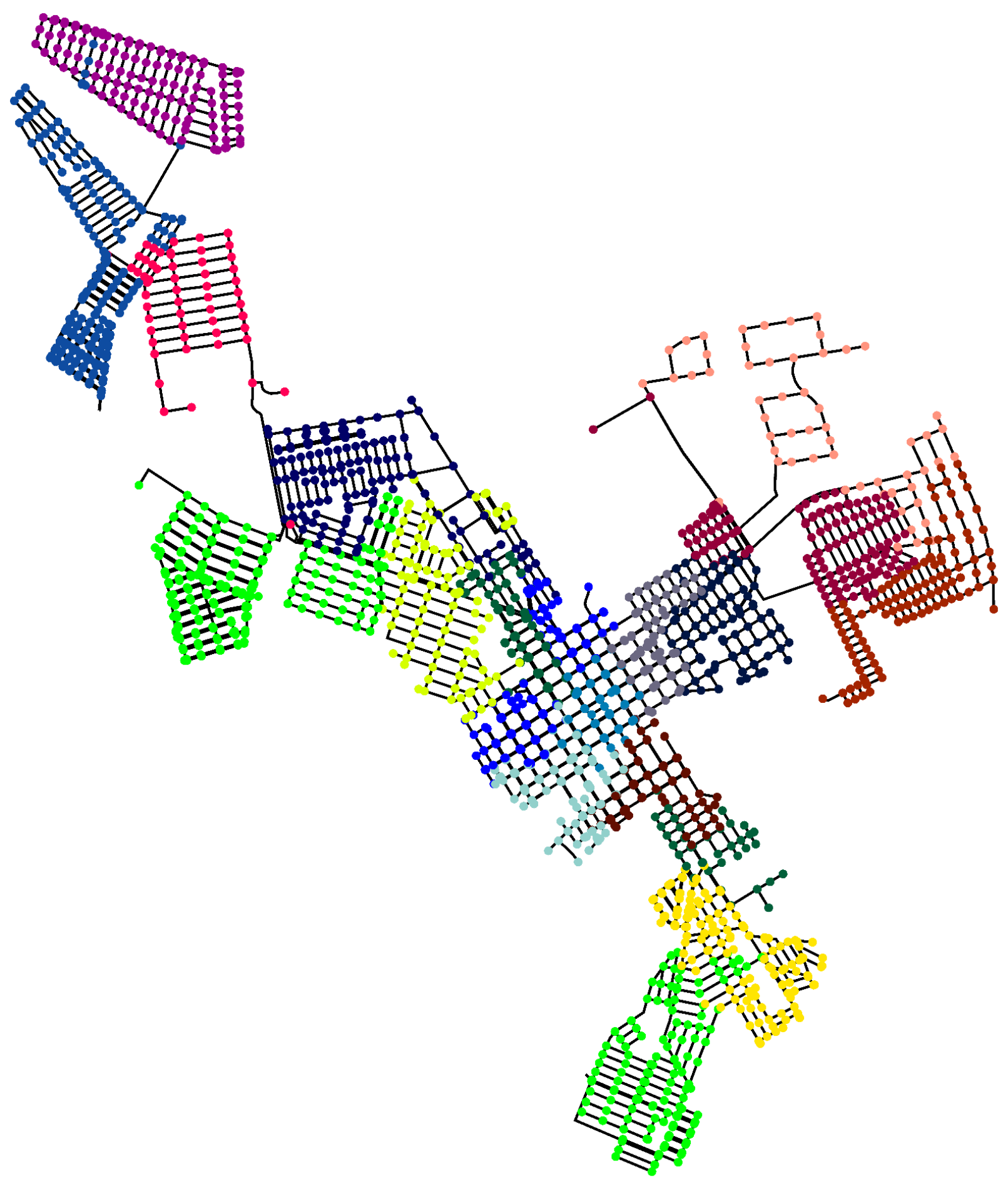

Fonte: Elaboração do autor

Notou-se que apenas a solução que divide a rede em 30 distritos segundo o método ModulMax pertence ao Conjunto Selecionado e, portanto, ela foi escolhida para particionar o sistema de distribuição de água do município de Pederneiras. 
Figura 43 - Conjunto de soluções em cada etapa do processo realizado para a seleção da melhor partição da rede.

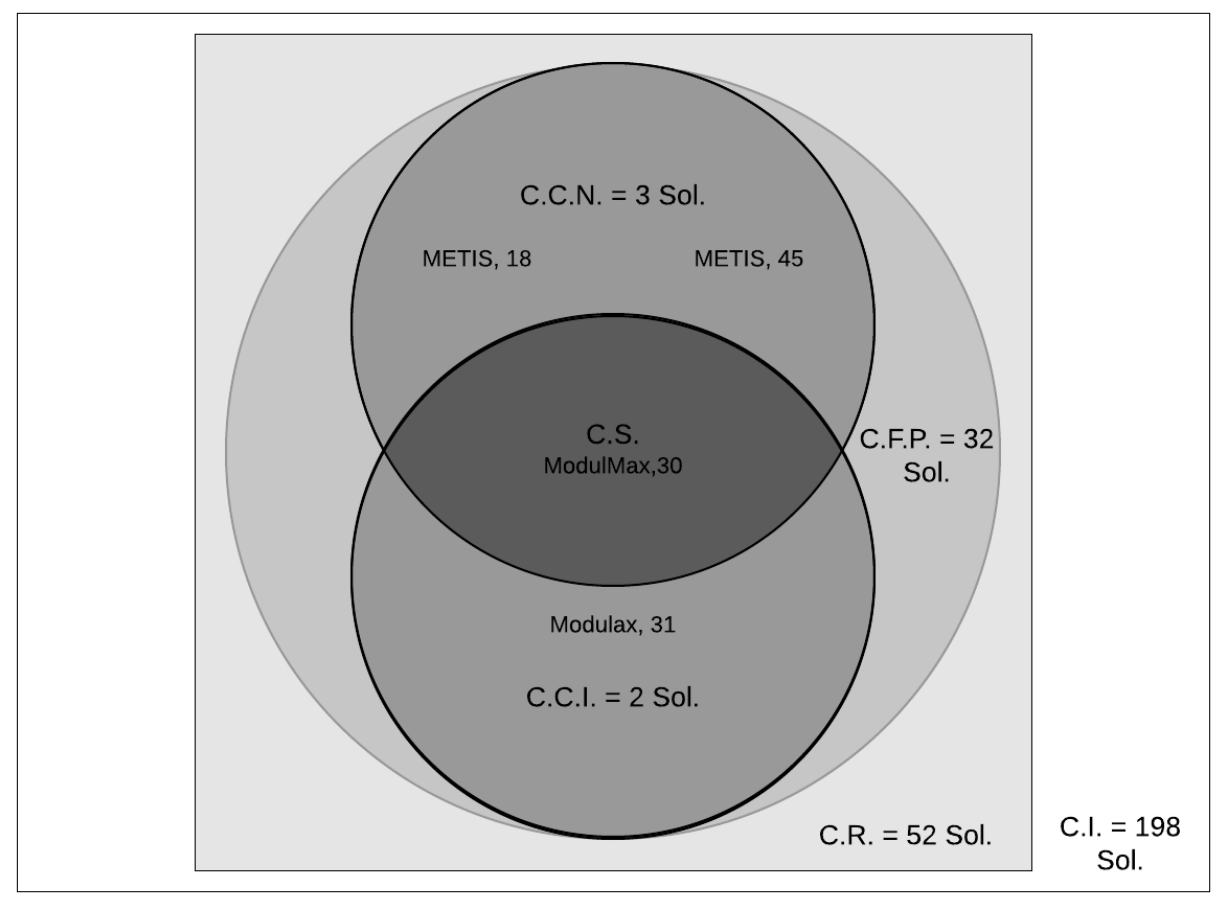

Fonte: Elaboração do Autor

A partição MoldulMax,30 é apresentada na Figura 44. Outras partições obtidas neste trabalho podem ser visualizadas no Apêndice D. A Tabela 18 explicita as características da solução escolhida. 
Figura 44 - Partição da Rede de Abastecimento de Água de Perderneiras em 30 distritos, utilizando o método ModulMax

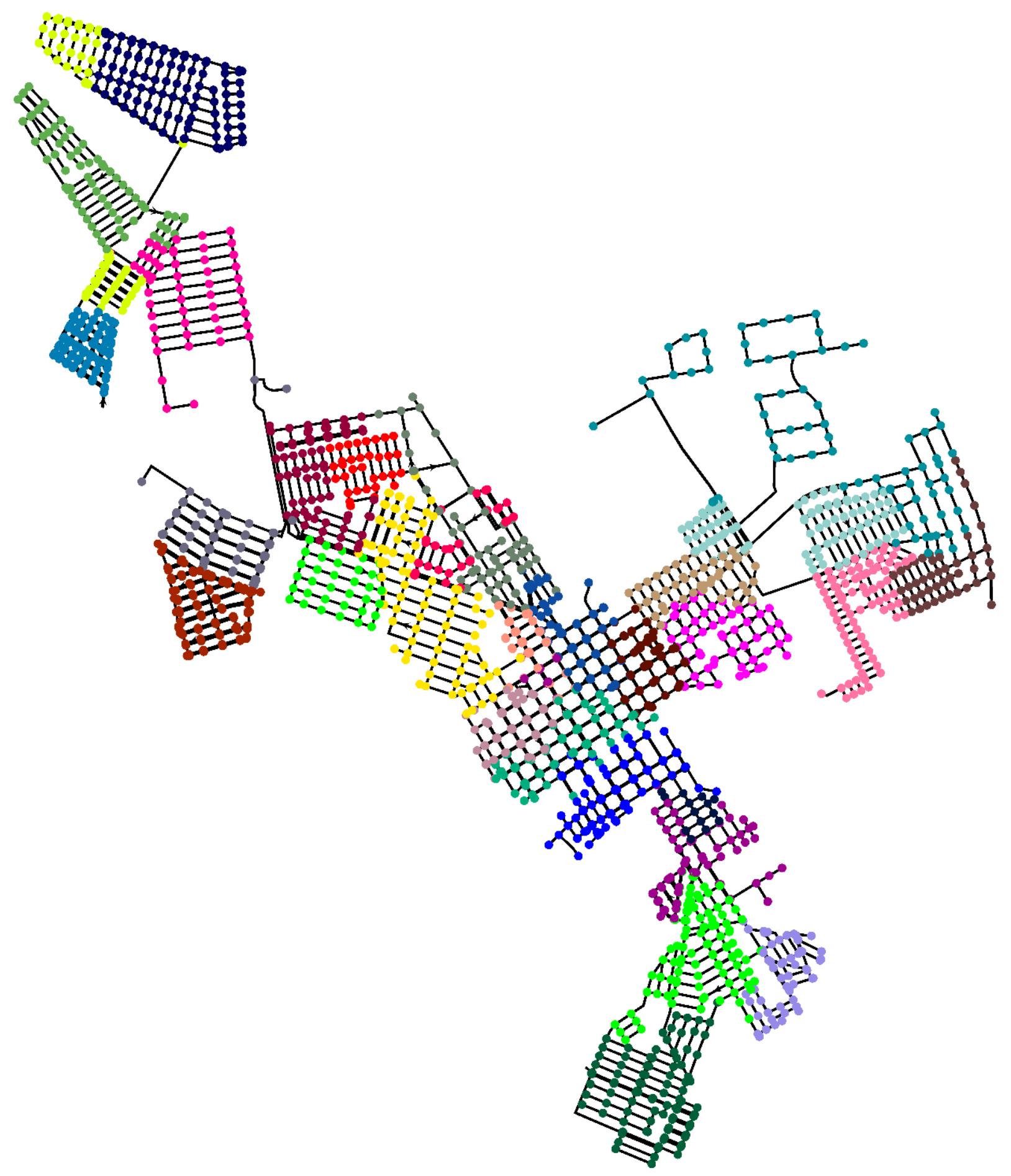

Fonte: Elaboração do Autor 
Tabela 18 - Indicadores da partição da rede de abastecimento de água de Pederneiras em 30 distritos através do método ModulMax

\begin{tabular}{c|c|c|c|c|c|c}
\hline IQ & $\mathbf{N}_{\mathbf{F E C}}$ & $\mathbf{N}_{\mathbf{P}}$ & $\mathbf{I}_{\mathbf{B}} \mathbf{D}$ & $\mathbf{I}_{\mathbf{B}} \mathbf{C}$ & $\begin{array}{c}\text { Comprimento de } \\
\text { tubulação do distrito mais } \\
\text { extenso (km) }\end{array}$ & $\begin{array}{c}\text { Demanda média diária } \\
\text { do distrito com maior } \\
\text { consumo (L/s) }\end{array}$ \\
\hline 0,95 & 42 & 6 & 2,26 & 1,82 & 12,3 & 235 \\
\hline
\end{tabular}

Fonte: Elaboração do Autor

A Figura 45 indica a localização das tubulações que interligam os 30 distritos da rede, sendo que as tubulações em vermelho foram fechadas após a partição e as tubulações em verde permaneceram abertas. Para decidir quais tubulações seriam fechadas, o modelo construído na seção 5.2 foi utilizado. A metodologia empírica explicitada na seção 4.5 foi utilizada. Das 42 tubulações que interligam os 30 distritos, 30 tiveram que permanecer abertas e 12 delas foram selecionadas para serem fechadas. Foi decidido incluir seis válvulas redutoras de pressão no modelo final, reduzindo a alta carga de pressão em algumas partes da rede. O problema de baixa carga de pressão em algumas áreas não foi resolvido, mas a subdivisão da rede em distritos menores facilitou a compreensão e análise da mesma. O modelo apontou que a colocação dessas seis VRP's reduziria a demanda total da rede em 8,4 \%. Essa estimativa foi feita comparandose o consumo total da rede antes e depois da inclusão das válvulas. Como a parcela do consumo nodal referente à vazamentos é calculada em função da pressão no nó, a diminuição desta causa também uma diminuição do consumo. A Tabela 19 explicita o status de todas as tubulações que ligam diferentes distritos, além de indicar em quais distritos foram incluídas VRP's.

Tabela 19 - Indicação dos status de todas as tubulações que ligam os distritos, indicando também em quais distritos foram incluídas VRP's. A cor da segunda coluna se refere às cores mostradas na Figura 44

\begin{tabular}{c|c|c|c|c|c}
\hline Distrito & Cor & $\begin{array}{c}\text { Número de } \\
\text { tubulações } \\
\text { abertas }\end{array}$ & $\begin{array}{c}\text { Número de } \\
\text { tubulações } \\
\text { fechadas }\end{array}$ & $\begin{array}{c}\text { Total de } \\
\text { tubulações }\end{array}$ & VRP \\
\hline 1 & & 1 & 0 & 1 & 0 \\
\hline 2 & & 1 & 1 & 2 & 1 \\
\hline 3 & & 3 & 2 & 5 & 1 \\
\hline 4 & 2 & 0 & 2 & 0 \\
\hline 5 & & 4 & 1 & 5 & 0 \\
\hline 6 & 2 & 2 & 4 & 1 \\
\hline 7 & 3 & 0 & 3 & 0 \\
\hline 8 & & 1 & 1 & 2 & 0 \\
\hline 9 & & 3 & 2 & 5 & 0 \\
\hline 10 & & 3 & 0 & 3 & 0 \\
\hline 11 & & 2 & 1 & 3 & 0 \\
\hline 12 & & 1 & 0 & 1 & 0 \\
\hline
\end{tabular}




\begin{tabular}{c|c|c|c|c|c}
\hline Distrito & Cor & $\begin{array}{c}\text { Número de } \\
\text { tubulações } \\
\text { abertas }\end{array}$ & $\begin{array}{c}\text { Número de } \\
\text { tubulações } \\
\text { fechadas }\end{array}$ & $\begin{array}{c}\text { Total de } \\
\text { tubulações }\end{array}$ & VRP \\
\hline 13 & & 1 & 0 & 1 & 0 \\
\hline 14 & & 2 & 1 & 3 & 0 \\
\hline 15 & & 1 & 2 & 3 & 0 \\
\hline 16 & & 5 & 0 & 5 & 0 \\
\hline 17 & & 3 & 1 & 4 & 0 \\
\hline 18 & & 1 & 0 & 1 & 0 \\
\hline 19 & & 3 & 0 & 3 & 0 \\
\hline 20 & & 4 & 2 & 6 & 0 \\
\hline 21 & & 1 & 0 & 1 & 0 \\
\hline 22 & & 2 & 2 & 4 & 2 \\
\hline 23 & & 2 & 2 & 4 & 1 \\
\hline 24 & & 1 & 0 & 1 & 0 \\
\hline 25 & & 2 & 0 & 2 & 0 \\
\hline 26 & & 1 & 1 & 2 & 0 \\
\hline 27 & & 1 & 1 & 2 & 1 \\
\hline 28 & & 1 & 1 & 2 & 1 \\
\hline 29 & & 2 & 0 & 2 & 0 \\
\hline 30 & & 1 & 1 & 2 & \\
\hline
\end{tabular}

Fonte: Elaboração do Autor 
Figura 45 -Indicação das 42 tubulações que ligam diferentes distritos da rede de abastecimento de água de Pederneiras.

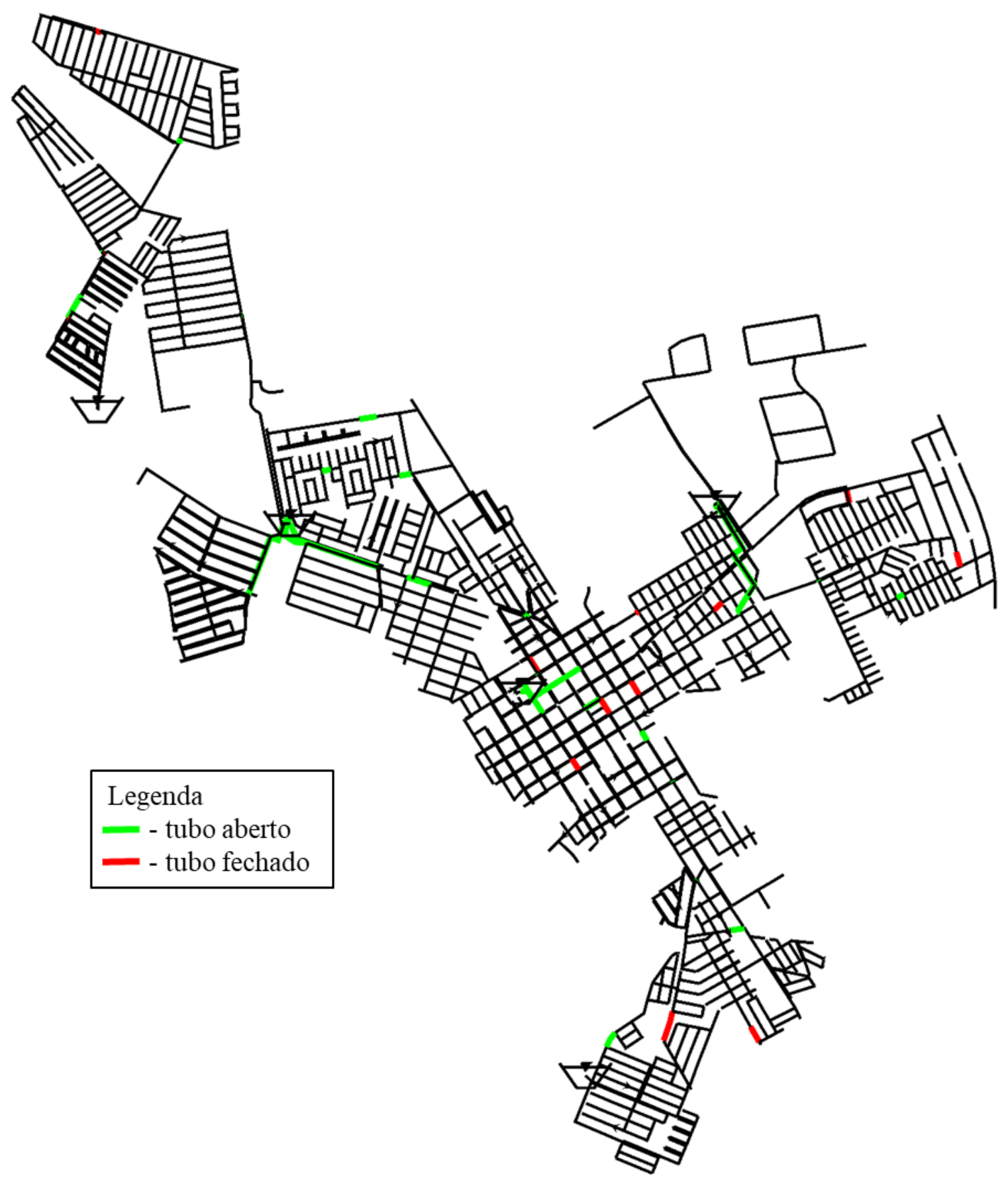

Fonte: Elaboração do Autor

A Figura 46 demonstra como o processo de partição trouxe essa facilidade de compreensão e análise. Nota-se que ao analisar a imagem a) da figura, é difícil compreender onde ocorrem as ligações dos nós e quais são os agrupamentos existentes nessa parte da rede. Ao analisar a imagem b) dessa mesma figura, constata-se que a análise da rede se tornou um processo mais simples, pois sabe-se exatamente quais são os agrupamentos existentes na rede 
e quais são as tubulações que os ligam. As Figura 47 eFigura 48 mostram a distribuição de carga de pressão da rede de abastecimento de água de Pederneiras às 4:00h (hora de menor consumo) antes e depois da partição e inclusão das válvulas redutoras de pressão, respectivamente. Pode-se perceber que as cores nos nós e destaque das tubulações que interligam os distritos facilitam o entendimento sobre a rede e assim a proposição de intervenções sobre a mesma torna-se mais trivial. Cabe ressaltar que essas análises foram meramente acadêmicas e não devem ser utilizadas como parâmetro para alterações reais na rede, uma vez que o modelo final realizado na seção 5.2 é fictício.

Figura 46 -Visualização dos distritos de uma parte da rede de abastecimento de água no município de Pederneiras antes (a) e depois (b) de realizar-se a partição. As cores significam o agrupamento por distrito, o que facilita a análise da rede por partes.

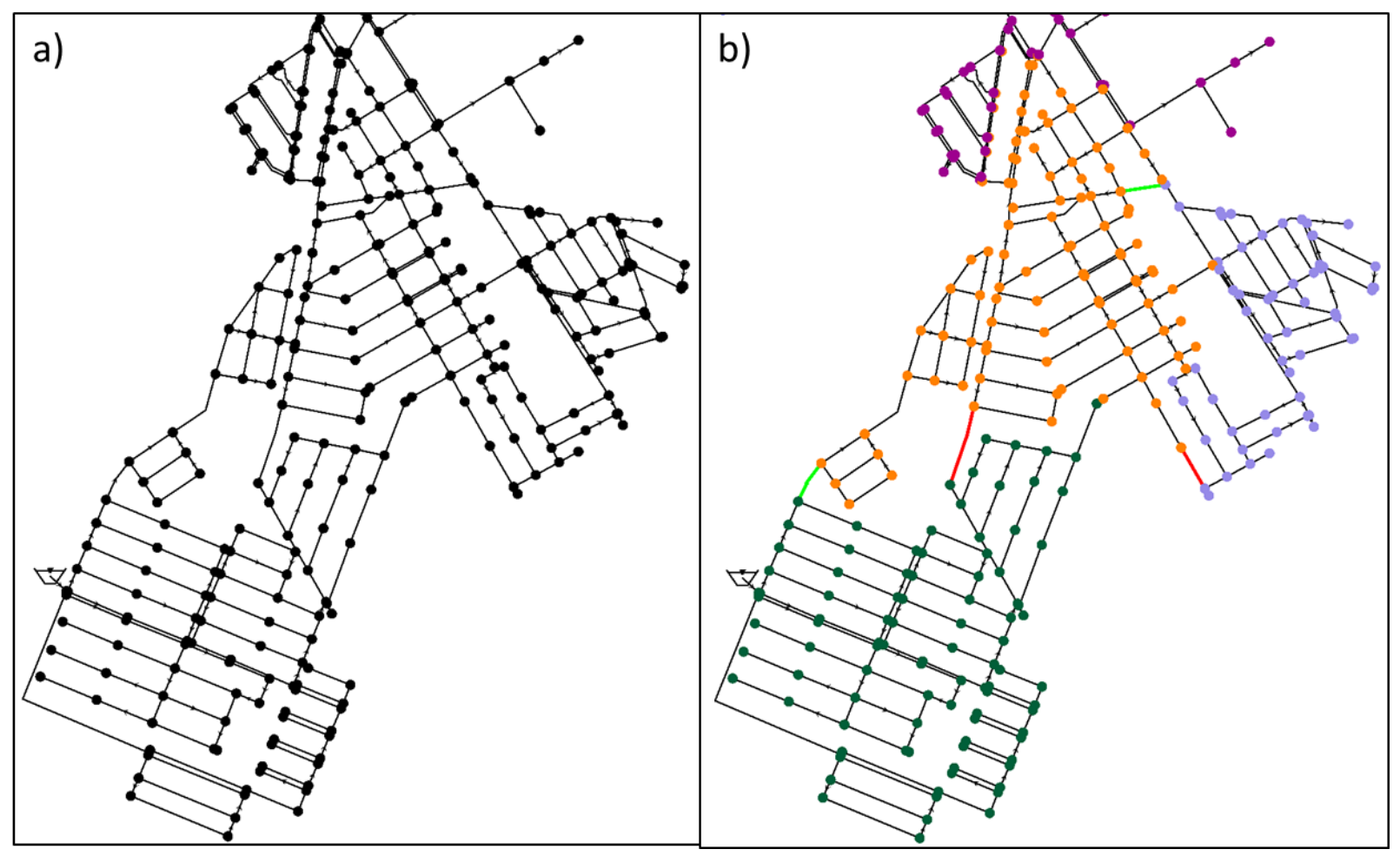

Fonte: Elaboração do Autor 
Figura 47 - Distribuição de pressões no modelo hidráulico de Pederneiras às 4:00 h antes da partição proposta e inclusão de válvulas

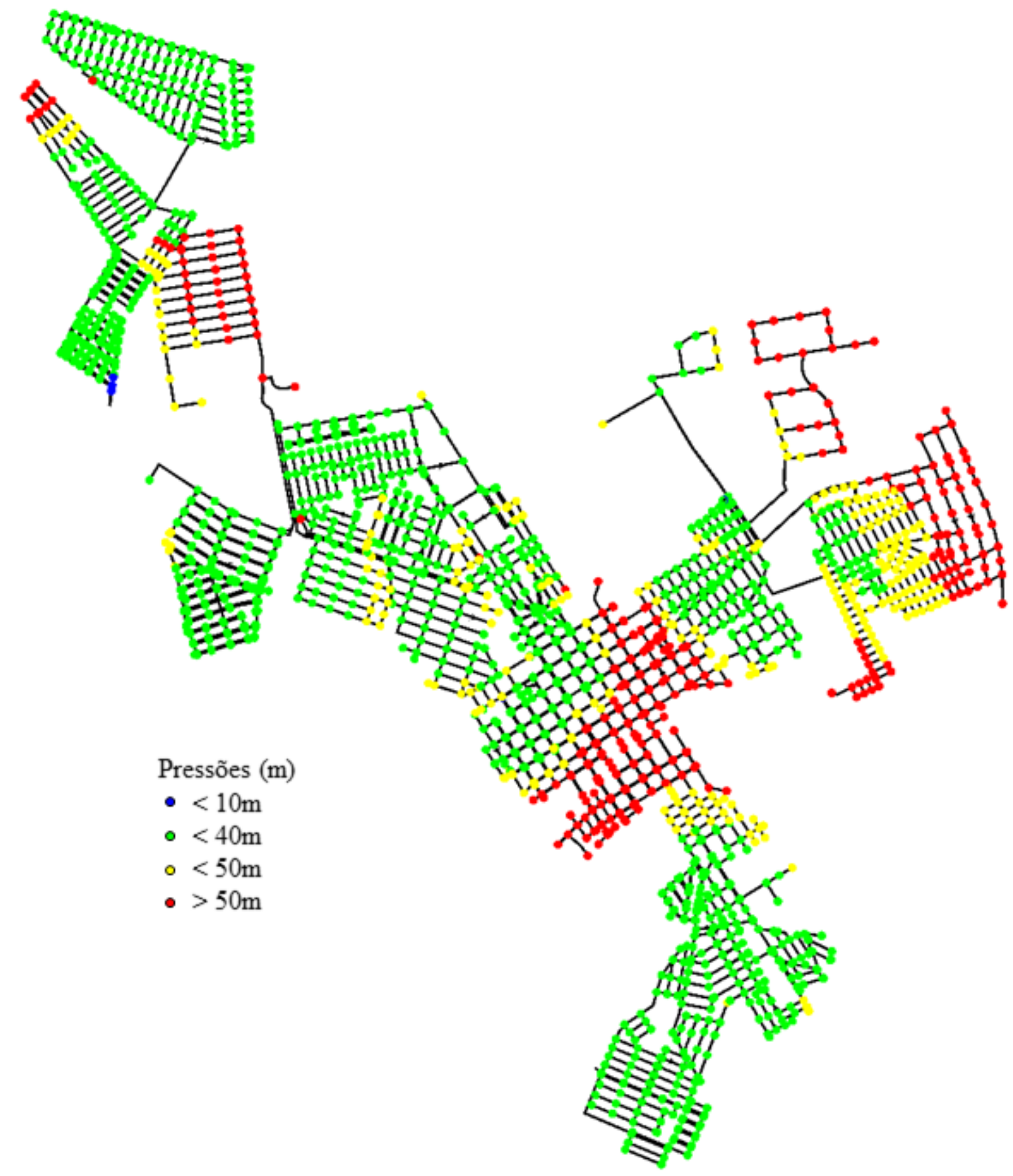

Fonte: Elaboração do Autor 
Figura 48 - Distribuição das pressões no modelo hidráulica de Pederneiras às 4:00h após a partição proposta e inclusão de válvulas

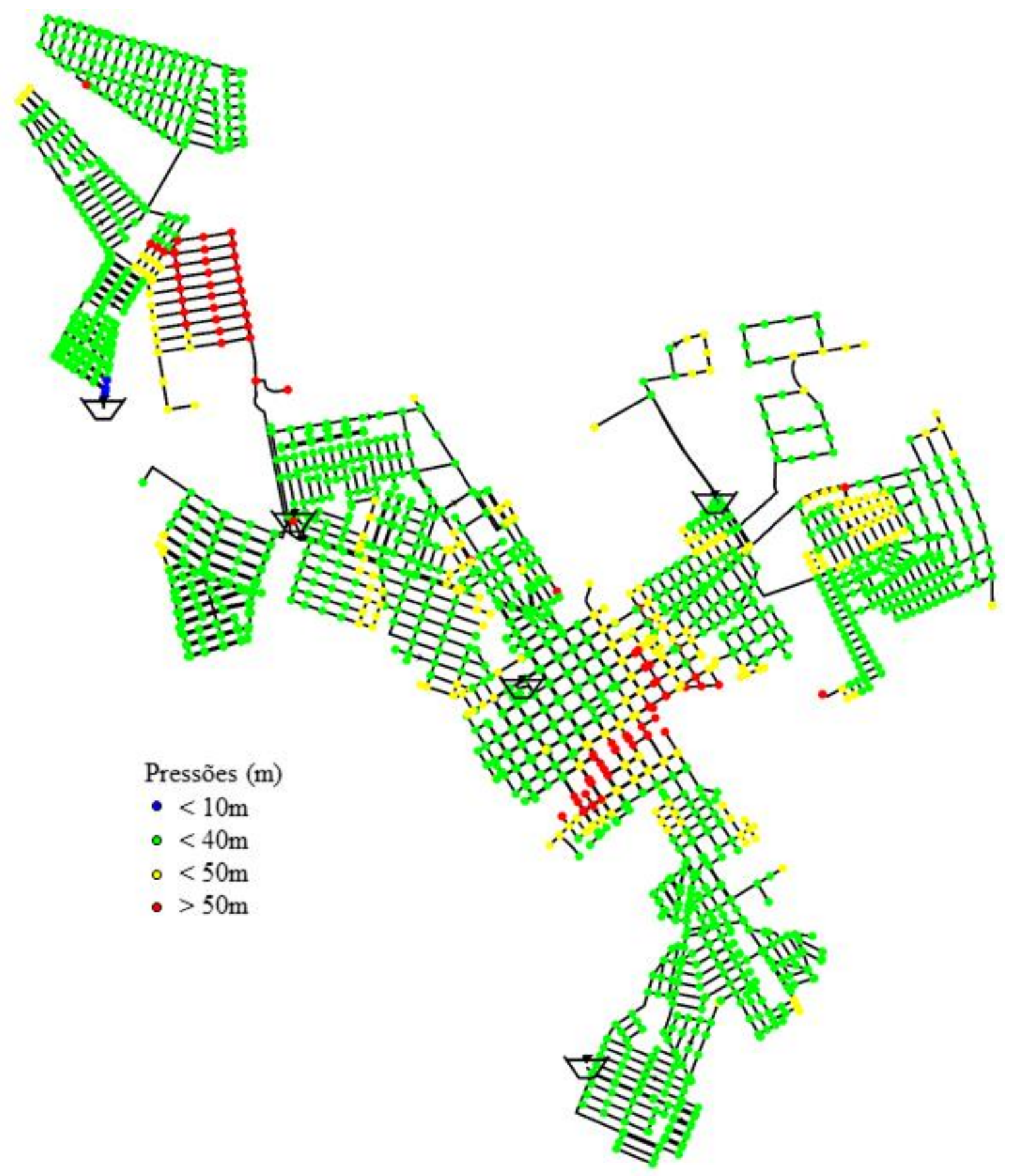

Fonte: Elaboração do Autor

Observa-se que as pressões tiveram uma redução significativa após a inclusão das válvulas redutoras de pressão. As áreas mais afetadas foram a região do reservatório 7 de setembro e do Dom Pedro. A região com excesso de carga de pressão do Setor Lacta é abastecida por uma bomba que pode ser substituída por uma outra de menor potência ou então adicionar a ela um inversor de frequência. 


\section{CONCLUSÃO}

A presente pesquisa teve como objetivo sistematizar, através de um estudo de caso, os passos necessários para o processo de partição de redes de abastecimento de água, além de comparar dois métodos bastante utilizados para tal fim. O primeiro passo consistiu em criar um modelo preliminar da rede em um software de modelagem hidráulica, seguida da realização do plano de amostragem e medição das pressões e vazões em campo. Nessa etapa, percebeu-se a grande dificuldade de obter o cadastro físico da rede atualizado, uma vez que foram encontradas algumas inconsistências quanto à localização de tubulações, status de válvulas, curva da bomba, entre outros.

Após o ajuste desse cadastro, realizou-se a calibração de uma parte da rede da cidade para o perído de monitoramento, que ocorreu entre os dias 21 e 27 de fevereiro de 2018. Com essa parcela da rede calibrada, uma extensão dos dados criou um modelo final fictício de toda a rede, o qual foi utilizado para o processo de partição.

Dois métodos foram utilizados para o particionamento da rede, um chamado de ModulMax (NEWMAN, 2004), que tem como principal vantagem a maximização do índice de modularidade e minimização do número de conexões entre distritos, e outro chamado METIS (KARYPIS; KUMAR, 2013), que busca a partição da rede em distritos de tamanhos homogêneos. A vantagem de se ter distritos de tamanhos semelhantes é que um número menor de partições seria necessário para se ter distritos gerenciáveis.

A rede foi particionada segundo os dois métodos em soluções de 2 a 100 distritos. Uma metodologia foi proposta para selecionar, dentre as 198 soluções encontradas, aquela que seria mais adequada para ser implantada. Essa metodologia leva em consideração cinco métricas, sendo elas o índice de modularidade, número de conexões entre distritos, número de conexões do distrito mais conectado, índice de balanço do comprimento e índice de balanço da demanda. Com essas métricas, foi utilizada a metodologia de programação por compromisso multicritério. O trabalho levou à conclusão que a divisão da rede em 30 distritos através do método ModulMax foi a melhor solução do conjunto.

Com essa solução, um método empírico baseado nas pressões da rede e nos diâmetros das tubulações foi utilizado para decidir quais tubulações deveriam permanecer abertas ou deveriam ser fechadas e em quais seriam instaladas válvulas redutoras de pressão.

Assim, conclui-se que a proposta do trabalho de sistematizar os passos necessários para a realização de uma partição de rede de abastecimento de água foi satisfatoriamente alcançada, assim como a proposição de uma metodologia para selecionar uma partição. 
Sobre as fragilidades do trabalho, pode-se citar a extrapolação dos dados relativos à curva de demanda, rugosidades e coeficiente de vazamento, que foram estendidos do Setor Lacta para todo a cidade sem a devida verificação. Ressalta-se também a desconsideração de índices hidráulicos da rede, como a carga de pressão nodal, durante o processo de partição, avaliação e seleção das soluções encontradas de ambos os métodos.

Para trabalhos futuros, recomenda-se que sejam investigadas outras metodologias, em especial aquelas que utilizam a abordagem de agrupamento espectral, além de investigar os resultados dos métodos empregados nesse projeto utilizando diferentes pesos para os vértices e arestas. O processo de partição poderia também ser aplicado em outras redes de abastecimento de água, a fim de verificar sua eficácia. Outras métricas poderiam ser investigadas e utilizadas para o processo de seleção da melhor solução. Um estudo mais aprofundado sobre o status final das tubulações que ligam diferentes distritos e sobre a inclusão de válvulas redutoras de pressão também pode ser feito. 


\section{REFERÊNCIAS BIBLIOGRÁFICAS}

ABE, N. Proposição de Calibração de Redes de Sistemas de Abastecimento de água através de Método Híbrido. [s.1.] Universidade de São Paulo, 2014.

ABRAHAM, E.; STOIANOV, I. Efficient preconditioned iterative methods for hydraulic simulation of large scale water distribution networks. Procedia Engineering. Anais...2015

ALVISI, S.; FRANCHINI, M. Pipe roughness calibration in water distribution systems using grey numbers. Journal of Hydroinformatics, v. 12, n. 4, p. 424, 2010.

ALVISI, S.; FRANCHINI, M. A procedure for the design of district metered areas in water distribution systems. Procedia Engineering. Anais...2014

APAYDIN, Ö. Automated Calibration of Water Distribution Networks. [s.l.] MIDDLE EAST TECHNICAL UNIVERSITY, 2013.

BEHZADIAN, K. et al. A comparative study of stochastic and deterministic sampling design for model calibration. World Environmental and Water Resources Congress 2008: Ahupua'a - Proceedings of the World Environmental and Water Resources Congress 2008, v. 316, n. 1998, p. 1-11, 2008.

BHAVE, P. R. Calibrating Water Distribution Network Models. Journal of Environmental Engineering, v. 114, n. 3, p. 575-592, 1988.

BILAC, R. P. R.; ALVES, A. DE M. Crescimento urbano nas áreas de preservação permanente (APPs): um estudo de caso do leito do rio Apodi/Mossoró na zona urbana de Pau dos Ferros-RN. Revista Geotemas, v. 4, n. 2, p. 79-95, 2015.

BLACK, P. E. Dictionary of Algorithms and Data Structures. U.S. National Institute of Standards and Technology, 2006.

BRASIL. Plano Nacional de Saneamento Básico - PLANSAB. Ministério das Cidades. Secretaria Nacional de Saneamento Ambiental Plano Nacional de Saneamento Básico, p. 173, 2013.

BRASIL. Sistema Nacional de Informações sobre Saneamento - SNIS. Disponível em: <http://www.snis.gov.br/diagnostico-agua-e-esgotos/diagnostico-ae-2017>. Acesso em: 16 jun. 2019.

BRASSEL, K. E.; REIF, D. A Procedure to Generate Thiessen Polygons. Geographical Analysis, v. 11, n. 3, p. 289-303, 1979.

BUI, T. N.; JONES, C. A heuristic for reducing fill-in in sparse matrix factorization. [s.l: s.n.]. 
CHEUNG, P. B. Análise de reabilitação de redes de distribuição de água para abastecimento via algoritmos genéticos multiobjetivo. Análise de reabilitação de redes de distribuição de água para abastecimento via algoritmos genéticos multiobjetivo, 2004.

CIAPONI, C.; MURARI, E.; TODESCHINI, S. Modularity-Based Procedure for Partitioning Water Distribution Systems into Independent Districts. Water Resources Management, 2016.

CLAUSET, A.; NEWMAN, M. E. J.; MOORE, C. Finding community structure in very large networks. Physical Review E - Statistical Physics, Plasmas, Fluids, and Related Interdisciplinary Topics, 2004.

COEllo COEllo, C. A. Statistics of the EMOO Repository. Disponível em: <http://delta.cs.cinvestav.mx/ ccoello/EMOO/>. Acesso em: 30 jan. 2018.

COEllo COELlo, C. A.; LECHUGA, M. S. MOPSO: A proposal for multiple objective particle swarm optimization. Proceedings of the 2002 Congress on Evolutionary Computation, CEC 2002. Anais...2002

CORne, D. W.; KNOWleS, J. D.; OATES, M. J. The Pareto Envelope-based Selection Algorithm for Multiobjective Optimization. Proceedings of the Parallel Problem Solving from Nature VI Conference. Anais...2000

DATTA, R. S. N.; SRIDHARAN, K. Parameter Estimation in Water-Distribution Systems by Least Squares. Journal of Water Resources Planning and Management, v. 120, n. 4, p. 405-422, 1994.

DE SCHAETZEN, W. Optimal calibration and sampling design for hydraulic network models. [s.1.] University of Exeter, 2000.

DE SCHAETZEN, W. B. .; WALTERS, G. ,; SAVIC, D. . Optimal sampling design for model calibration using shortest path, genetic and entropy algorithms. Urban Water, v. 2, n. 2, p. 141-152, 2000.

DEB, K. Multi-Objective Optimization Using Evolutionary AlgorithmsJohn Wiley \& sons, LTD, 2001. Disponível em: <https://books.google.co.in/books/about/Multi_Objective_Optimization_Using_Evolu.html?i $\mathrm{d}=\mathrm{OSTn} 4 \mathrm{GSy} 2 \mathrm{uQC} \&$ pgis=1\%5Cnhttps://books.google.com/books?id=OSTn4GSy2uQC\&pg is $=1>$

DEB, K. et al. A fast and elitist multiobjective genetic algorithm: NSGA-II. IEEE Transactions on Evolutionary Computation, v. 6, n. 2, p. 182-197, 2002.

DI NARDO, A. et al. An Automated Tool for Smart Water Network Partitioning. Water Resources Management, v. 27, n. 13, p. 4493-4508, 2013. 
DI NARDO, A. et al. Water Network Sectorization Based on Graph Theory and Energy Performance Indices. Journal of Water Resources Planning and Management, 2014a.

DI NARDO, A. et al. SWANP: software for automatic Smart WAter Network Partitioning. 7th Intl. Congress on Env. Modelling and Software. Anais...2014b

DI NARDO, A. et al. Divide and conquer partitioning techniques for smart water networks. Procedia Engineering. Anais...2014c

DI NARDO, A. et al. Performance indices for water network partitioning and sectorization. Water Science and Technology: Water Supply, v. 15, n. 3, p. 499-509, 2015.

DI NARDO, A. et al. Water Distribution Network Clustering: Graph Partitioning or Spectral Algorithms? International Workshop on Complex Networks and their Applications. Anais...2017

DI NARDO, A. et al. Performance of partitioned water distribution networks under spatial-temporal variability of water demand. Environmental Modelling and Software, v. 101, p. 128-136, 2018.

DI NARDO, A.; DI NATALE, M.; SANTONASTASO, G. F. A comparison between different techniques for water network sectorization. Water Science \& Technology: Water Supply, v. 14, n. 6, p. 961, 2014.

DIAO, K.; ZHOU, Y.; RAUCH, W. Automated Creation of District Metered Area Boundaries in Water Distribution Systems. Journal of Water Resources Planning and Management, v. 139, n. 2, p. 184-190, 2013.

DINI, M.; TABESH, M. A New Method for Simultaneous Calibration of Demand Pattern and Hazen-Williams Coefficients in Water Distribution Systems. Water Resources Management, v. 28, n. 7, p. 2021-2034, 2014.

DORIGO, M.; MANIEZZO, V.; COLORNI, A. Ant system: optimization by a colony of cooperating agents. IEEE Transactions on Systems, Man, and Cybernetics, Part B (Cybernetics), v. 26, n. 1, p. 29-41, 1996.

EBERHART, R.; KENNEDY, J. A new optimizer using particle swarm theory. Micro Machine and Human Science, 1995. MHS'95., Proceedings of the Sixth International Symposium on. Anais...1995

ECAC, A. Calibration Guidelines for Water Distribution System Modeling. Proc. AWWA Information Management and Technology Conf., New Orleans. Anais...1999

ELIADES, D. G. et al. EPANET-MATLAB Toolkit: An Open-Source Software for Interfacing EPANET with MATLAB. Proc. 14th International Conference on Computing and Control for the Water Industry (CCWI). Anais...The Netherlands: nov. 2016 
FARLEY, M. Leakage management and control. A best practice training manual, 2001.

FERRARI, G.; BECCIU, G.; OTHERS. Hybrid graph partitioning approach for dividing a water distribution network into district metered areas. WDSA 2012: 14th Water Distribution Systems Analysis Conference, 24-27 September 2012 in Adelaide, South Australia. Anais...2012

FIDUCCIA, C. M.; MATTHEYSES, R. M. A linear-time heuristic for improving network partitions. Proceedings - Design Automation Conference. Anais...1982

FIORINI MOROSINI, A. et al. Identification of measurement points for calibration of water distribution network models. 16th Water Distribution System Analysis Conference, WDSA2014 - Urban Water Hydroinformatics and Strategic Planning. Anais...2014

FONSECA, C. M.; FLEMING, P. J. Genetic Algorithms for Multiobjective Optimization: Formulation, Discussion and Generalization. Icga, v. 93, n. July, p. 416-423, 1993.

FORMIGA, K. T. M.; CHAUDHRY, F. H. Modelos de análise hidráulica de redes de distribuição de água considerando demanda dirigida pela pressão e vazamentos. Engenharia Sanitaria e Ambiental, v. 13, n. 2, p. 153-162, 2008.

FORTUNATO, S. Community detection in graphsPhysics Reports, 2010.

GAMBOA-MEDINA, M. M.; REIS, L. F. R. Sampling Design for Leak Detection in Water Distribution Networks. Procedia Engineering, v. 186, p. 460-469, 2017.

GAMBOA MEDINA, M. M. Detecção de vazamentos e alterações em redes de distribuição de água para abastecimento, durante a operação, usando sinais de pressão. [s.1.] Universidade de São Paulo, 2017.

GAO, T. Roughness and Demand Estimation in Water Distribution Networks Using Head Loss Adjustment. Journal of Water Resources Planning and Management, v. 143, n. 12, p. $4017070,2017$.

GERMANOPOULOS, G. A technical note on the inclusion of pressure dependent demand and leakage terms in water supply network models. Civil Engineering Systems, v. 2, n. 3, p. 171-179, 1985.

GIRVAN, M.; NEWMAN, M. E. J. Community structure in social and biological networks. Proceedings of the National Academy of Sciences, v. 99, n. 12, p. 7821-7826, 2002.

GIUSTOLISI, O.; RIDOLFI, L. New Modularity-Based Approach to Segmentation of Water Distribution Networks. Journal of Hydraulic Engineering, v. 140, n. 10, p. 04014049 , 
2014.

GOLDBERG, D. E. Genetic Algorithms in Search, Optimization, and Machine Learning. [s.l: s.n.]. v. Addison-We

GRAYMAN, W.; MURRAY, R.; SAVIC, D. Effects of Redesign of Water Systems for Security and Water Quality Factors. World Environmental and Water Resources Congress 2009, v. 41036, n. 2009, p. 504-514, 2009.

GREYVENSTEIN, B.; VAN ZYL, J. E. An experimental investigation into the pressure - Leakage relationship of some failed water pipes. Journal of Water Supply: Research and Technology - AQUA, v. 56, n. 2, p. 117-124, 2007.

GÜNTER, S.; BUNKE, H. Validation indices for graph clustering. Pattern Recognition Letters, v. 24, n. 8, p. 1107-1113, 2003.

HAJEBI, S. et al. Multi-agent simulation to support water distribution network partitioning. 2013.

HAJEBI, S. et al. Water distribution network sectorisation using structural graph partitioning and multi-objective optimization. Procedia Engineering. Anais...2014

HAN, R.; LIU, J. Spectral Clustering and Genetic Algorithm for Design of District Metered Areas in Water Distribution Systems. Procedia Engineering. Anais...2017

HARTIGAN, A.; WONG, M. A. A K-Means Clustering Algorithm. Journal of the Royal Statistical Society, 1979.

HASTIE, T.; TIBSHIRANI, R.; FRIEDMAN, J. Unsupervised learning. In: The elements of statistical learning. [s.1.] Springer, 2009. p. 485-585.

HENDRICKSON, B.; LELAND, R. A multilevel algorithm for partitioning graphs. Proceedings of the 1995 ACM/IEEE conference on Supercomputing (CDROM) Supercomputing '95. Anais...1995

HERRERA, M. et al. An approach to water supply clusters by semi-supervised learning. International Environmental Modelling and Software Society (iEMSs). Modelling for Environment's Sake, Fifth Biennial Meeting, 2010.

HUTTON, C. J. et al. Dealing with Uncertainty in Water Distribution System Models : A Framework for Real-Time Modeling and Data Assimilation. water Resources Planning and Management, v. 169, n. February, p. 169-183, 2014.

IBGE. IBGE. Disponível em: <http://www.ibge.gov.br/apps/populacao/projecao/>. JOWITT, P. W.; XU, C. Optimal Valve Control in Water-Distribution Networks. Journal of Water Resources Planning and Management, v. 116, n. 4, p. 455-472, 1990.

KAPELAN, Z. S.; SAVIC, D. A.; WALTERS, G. A. Multiobjective Sampling Design 
for Water Distribution Model Calibration. Journal of Water Resources Planning and Management, v. 129, n. 6, p. 466-479, 2003.

KAPELAN, Z. S.; SAVIC, D. A.; WALTERS, G. A. Multiobjective design of water distribution systems under uncertainty. Water Resources Research, v. 41, n. 11, p. 1-15, 2005a.

KAPELAN, Z. S.; SAVIC, D. A.; WALTERS, G. A. Optimal Sampling Design Methodologies for Water Distribution Model Calibration. Journal of Hydraulic Engineering, v. 131, n. 3, p. 190-200, 2005b.

KAPELAN, Z. S.; SAVIC, D. A.; WALTERS, G. A. Calibration of Water Distribution Hydraulic Models Using a Bayesian-Type Procedure. Journal of Hydraulic Engineering, v. 133, n. 8, p. 927-936, 2007.

KARYPIS, G.; KUMAR, V. Analysis of multilevel graph partitioning. Proceedings of the 1995 ACM/IEEE conference on Supercomputing (CDROM). Anais...1995

KARYPIS, G.; KUMAR, V. Multilevelk-way Partitioning Scheme for Irregular Graphs. Journal of Parallel and Distributed Computing, 1998a.

KARYPIS, G.; KUMAR, V. A Fast and High Quality Multilevel Scheme for Partitioning Irregular Graphs. SIAM Journal on Scientific Computing, 1998b.

KARYPIS, G.; KUMAR, V. METIS* A Software Package for Partitioning Unstructured Graphs, Partitioning Meshes , and Computing Fill-Reducing Orderings of Sparse Matrices. Manual, 2013.

KERNIGHAN, B. W.; LIN, S. An Efficient Heuristic Procedure for Partitioning Graphs. Bell System Technical Journal, 1970.

KITA, H. et al. Multi-objective optimization by means of the thermodynamical genetic algorithm. Lecture Notes in Computer Science (including subseries Lecture Notes in Artificial Intelligence and Lecture Notes in Bioinformatics). Anais...1996

KNOWLES, J. D.; CORNE, D. W. Approximating the Nondominated Front Using the Pareto Archived Evolution Strategy. Evolutionary Computation, v. 8, n. 2, p. 149-172, 2000.

KOPPEL, T.; VASSILJEV, A. Calibration of a model of an operational water distribution system containing pipes of different age. Advances in Engineering Software, v. 40, n. 8, p. 659-664, 2009.

LAMBERT, A.; HIRNER, W. Losses from Water Supply Systems: Astandard Terminology and Recommended Performance Measures. [s.1.] IWA, 2000.

LANSEY, K. E. et al. Calibration Assessment and Data Collection for Water Distribution Networks. Journal of Hydraulic Engineering, v. 127, n. 4, p. 270-279, 2001. 
LIU, H. et al. Comparing topological partitioning methods for district metered areas in the water distribution network. Water (Switzerland), 2018.

LTD WATER INDUSTRY RESEARCH. A manual of DMA practiceUK Water Industry Research London, , 1999.

MACQUEEN, J. Some Methods for classification and Analysis of Multivariate Observations. 5th Berkeley Symposium on Mathematical Statistics and Probability 1967. Anais...1967

MAKAREMI, Y.; HAGHIGHI, A.; GHAFOURI, H. R. Optimization of Pump Scheduling Program in Water Supply Systems Using a Self-Adaptive NSGA-II; a Review of Theory to Real Application. Water Resources Management, v. 31, n. 4, p. 1283-1304, 2017.

MARTÍNEZ-SOLANO, F. J.; IGLESIAS-REY, P. L.; ARCE, S. X. M. Simultaneous Calibration of Leakages, Demands and Losses from Measurements. Application to the Guayaquil Network (Ecuador). Procedia Engineering. Anais...2017

MIETTINEN, K. “Concepts,” Nonlinear MultiObjective Optimization. [s.l: s.n.].

MORRISON, J.; TOOMS, S.; ROGERS, D. District Metered Areas: Guidance Notes. International Water Association Water Loss Task ..., p. 100, 2007.

MUHAMMED, K. et al. Optimal Rehabilitation of Water Distribution Systems Using a Cluster-Based Technique. Journal of Water Resources Planning and Management, v. 143, n. 7, p. $04017022,2017$.

NBR, A. 12218--Projeto de rede de distribuição de água para abastecimento público. Associação Brasileira de normas Técnicas--ABNT. Rio de Janeiro, 2017.

NELDER, J. A.; MEAD, R. A Simplex Method for Function Minimization. The Computer Journal, v. 7, n. 4, p. 308-313, 1965.

NEWMAN, M. E. J. Fast algorithm for detecting community structure in networks. Physical Review E - Statistical Physics, Plasmas, Fluids, and Related Interdisciplinary Topics, 2004.

NEWMAN, M. E. J.; GIRVAN, M. Finding and evaluating community structure in networks. Physical Review E - Statistical, Nonlinear, and Soft Matter Physics, 2004.

NOVÁK, P.; NEUMANN, P.; MACAS, J. Graph-based clustering and characterization of repetitive sequences in next-generation sequencing data. BMC Bioinformatics, 2010.

ORMSBEE, L. AND WOOD, D. Explicit Pipe Network Calibration. Journal of Water Resources Planning and Management, v. 112, n. 2, p. 166-182, 1986.

OSTFELD, A. et al. The Battle of the Water Sensor Networks (BWSN): A Design Challenge for Engineers and Algorithms. Journal of Water Resources Planning and 
Management, 2008.

OSYCZKA, A.; KUNDU, S. A modified distance method for multicriteria optimization, using genetic algorithms. Computers \& Industrial Engineering, v. 30, n. 4, p. 871-882, 1996.

PARETO, V. Course of Political EconomyLausanne, , 1896.

PERELMAN, L.; OSTFELD, A. Topological clustering for water distribution systems analysis. Environmental Modelling and Software, v. 26, n. 7, p. 969-972, 2011.

POHL, I. Bidirectional and heuristic search in path problems. [s.l: s.n.].

PONS, P.; LATAPY, M. Computing communities in large networks using random walks. Lecture Notes in Computer Science (including subseries Lecture Notes in Artificial Intelligence and Lecture Notes in Bioinformatics). Anais...2005

PORTO, R. M. Hidráulica Básica--Quarta Edição. Editora USP Projeto REENGE, São Paulo, Brasil, 2006.

RAHAL, C. M. et al. Parameter tuning for simulation models of water distribution networks. Proceedings of the Institution of Civil Engineers, v. 69, n. 3, p. 751-762, 1980.

REED, P. M. et al. Evolutionary multiobjective optimization in water resources: The past, present, and future. Advances in water resources, v. 51, p. 438-456, 2013.

REGO, A. A. DE C. Integração de Ferramentas SIG para a Optimização de Sistema Adutor com Recurso ao EPANET. 2007.

REYNOLDS, O. XXIX. An experimental investigation of the circumstances which determine whether the motion of water shall he direct or sinuous, and of the law of resistance in parallel channels. Philosophical Transactions of the Royal Society of London, v. 174, p. 935-982, 1883.

RIGHETTO, A. M. Calibração de modelo hidráulico de rede de distribuição de água. Revista Brasileira de Recursos H\{\’i\}dricos, v. 6, n. 3, p. 33-44, 2001.

ROSSMAN, L. A. EPANET 2: users manual. Cincinnati US Environmental Protection Agency National Risk Management Research Laboratory, v. 38, n. September, p. 200, 2000.

RUDOLPH, G. Convergence of evolutionary algorithms in general search spaces. Proceedings of IEEE International Conference on Evolutionary Computation. Anais...1996

SALOMONS, E.; SKULOVICH, O.; OSTFELD, A. Battle of Water Networks DMAs: Multistage Design Approach. Journal of Water Resources Planning and Management, v. 143, n. 10, p. 04017059, 2017.

SAVIC, D. A.; KAPELAN, Z. S.; JONKERGOUW, P. M. R. Quo vadis water distribution model calibration?Urban Water Journal, 2009. 
SCHAFFER, J. D. Multiple objective optimization with vector evaluated genetic algorithms. The 1st international Conference on Genetic Algorithms, n. JANUARY 1985, p. 93-100, 1985.

SCHÖLKOPF, B.; SMOLA, A. J. Learning with kernels. Journal of the Electrochemical Society, 2002.

SCHUETZ, P.; CAFLISCH, A. Efficient modularity optimization by multistep greedy algorithm and vertex mover refinement. Physical Review E - Statistical, Nonlinear, and Soft Matter Physics, 2008.

SELA PERELMAN, L. et al. Automated sub-zoning of water distribution systems. Environmental Modelling and Software, 2015.

SEMPEWO, J.; PATHIRANA, A.; VAIRAVAMOORTHY, K. Spatial Analysis Tool for Development of Leakage Control Zones from the Analogy of Distributed Computing. Water Distribution Systems Analysis 2008, 2009.

SHAMIR, U. Y.; HOWARD, C. D. D. Water distribution systems analysis. Journal of the Hydraulics Division, v. 94, n. 1, p. 219-234, 1968.

SIMONE, A. et al. A Proposal of Optimal Sampling Design Using Infrastructure Modularity. Procedia Engineering. Anais...2017

SOARES, A. K. Calibração de modelos de redes de distribuição de água para abastecimento considerando vazamentos e demandas dirigidas pela pressão. [s.l.] Universidade de São Paulo, 2003.

SOARES, A. K. et al. Aplicação de modelo dirigido pela pressão na estimativa de parâmetros de redes de distribuição de água. XXIV Iberian Latin-American Computational Methods in Engineering, Anais Eletronicos, 2003.

SRINIVAS, N.; DEB, K. Muiltiobj ective Optimization Using Nondominated Sorting in Genetic Algorithms. Evolutionary Computation, v. 2, n. 3, p. 221--248, 1995.

STADLER, W. A survey of multicriteria optimization or the vector maximum problem, part I: 1776-1960. Journal of Optimization Theory and Applications, v. 29, n. 1, p. 1-52, 1979.

SWAMEE, P. K. Design of a submarine oil pipeline. Journal of transportation Engineering, v. 119, n. 1, p. 159-170, 1993.

TANYIMBOH, T.; TAHAR, B.; TEMPLEMAN, A. Pressure-driven modelling of water distribution systems. Compute, v. 1, n. 1988, p. 255-261, 2003.

TARJAN, R. Depth-First Search and Linear Graph Algorithms. SIAM Journal on Computing, 1972. 
TECHNOLOG. Metrolog Datalogger - Installation and Operating Manual. [s.l: s.n.]. Disponível em: <http://www.imbemacontrols.nl/ /media/Productmedia/ImbemaControls-Belgium/Documenten-Controls/Manual_Metrolog.pdf $>$.

THE MATHWORKS INC. MATLAB (R2015a)The MathWorks Inc., 2015. Disponível em: $<$ http://scholar.google.com/scholar?hl=en\&btnG=Search\&q=intitle:MATLAB+The+Languag e+of+Technical+Computing\#0>

TODINI, E.; PILATI, S. Gradient Algorithm for the Analysis of Pipe Networks. In: Computer Applications in Water Supply. Volume 1: Systems Analysis and Simulation. [s.l: s.n.]. p. 20.

TSUTIYA, M. T. Abastecimento de água. [s.1.] Departamento de Engenharia Hidráulica e Sanitária da Escola Politécnica da Universidade de São Paulo, 2004.

TZATCHKOV, V.; ALCOCER-YAMANAKA, V.; BOURGUETT ORTÍZ, V. Graph Theory Based Algorithms for Water Distribution Network Sectorization Projects. Water Distribution Systems Analysis (WDSA). Anais...2006

VAIRAVAMOORTHY, K.; LUMBERS, J. Leakage Reduction in Water Distribution Systems: Optimal Valve Control. Journal of Hydraulic Engineering, v. 124, n. 11, p. 1146$1154,1998$.

VAN ROSSUM, G. Python Programming Language. USENIX Annual Technical Conference. Anais...2007

WALSKI, T. M. Technique for Calibrating Network Models. Journal of Water Resources Planning and Management, v. 109, n. 4, p. 360-372, 1983.

WALSKI, T. M. Case Study: Pipe Network Model Calibration Issues. Journal of Water Resources Planning and Management, ASCE, v. 112, n. 2, p. 238-249, 1986.

WALSKI, T.; WU, Z.; HARTELL, W. Performance of automated calibration for water distribution systems. In: Critical Transitions in Water and Environmental Resources Management. [s.1: s.n.]. p. 1-10.

WATER AUTHORITIES ASSOCIATION; CENTRE, W. R. Leakage control policy and practice. Technical working group on waste of waterWRc Group London, , 1985.

WATER RESEARCH CENTRE. Network analysis a code a practice. [s.l.] WRC, 1989.

WATERGEMS, B. V8i User's Guide.(2009). Bentley WaterGEMS V8i User's Guide. Bentley Pres, 2009.

WU, J. et al. A comparative study of Monte Carlo simple genetic algorithm and noisy 
genetic algorithm for cost-effective sampling network design under uncertainty. Advances in Water Resources, v. 29, n. 6, p. 899-911, 2006.

WU, Z. Y. et al. Calibrating water distribution model via genetic algorithms. Proc. AWWA IMTech, Kansas City, Mo, 2002.

WU, Z. Y. et al. Method and system for automatic water distribution model calibrationGoogle Patents, , 2008.

YU, G.; POWELL, R. S. Optimal design of meter placement in water distribution systems. International Journal of Systems Science, v. 25, n. 12, p. 2155-2166, 1994.

ZELENY, M. Multiple Criteria Decision Making (MCDM): From Paradigm Lost to Paradigm Regained? Journal of Multi-Criteria Decision Analysis, 2011.

ZELENY, M.; COCHRANE, J. L. Multiple criteria decision making. [s.l.] University of South Carolina Press, 1973.

ZHANG, Q. et al. Automatic Partitioning of Water Distribution Networks Using Multiscale Community Detection and Multiobjective Optimization. Journal of Water Resources Planning and Management, v. 143, n. 9, p. 4017057, 2017.

ZHOU, A. et al. Multiobjective evolutionary algorithms: A survey of the state of the art. Swarm and Evolutionary Computation, v. 1, n. 1, p. 32-49, 2011.

ZHU, Z. et al. Scalable community discovery of large networks. Proceedings - The 9th International Conference on Web-Age Information Management, WAIM 2008. Anais...2008

ZITZLER, E.; THIELE, L. An Evolutionary Algorithm for Multiobjective Optimization : The Strength Pareto Approach. TIK-Report, n. 43, p. 43, 1998. 
APÊNDICE A 
Relação entre as pressões simuladas e observadas de todos os pontos de medição durante todo o período de validação, que se inicia às 0:00h do dia 21/02/2018 (quarta-feira) e acaba às 23:00h do dia 26/02/2018 (segunda-feira).

Figura 49 - Validação do modelo hidráulico do Setor Lacta - pressões observadas (pontos) e simuladas (linha) do ponto $\mathbf{P 1}$

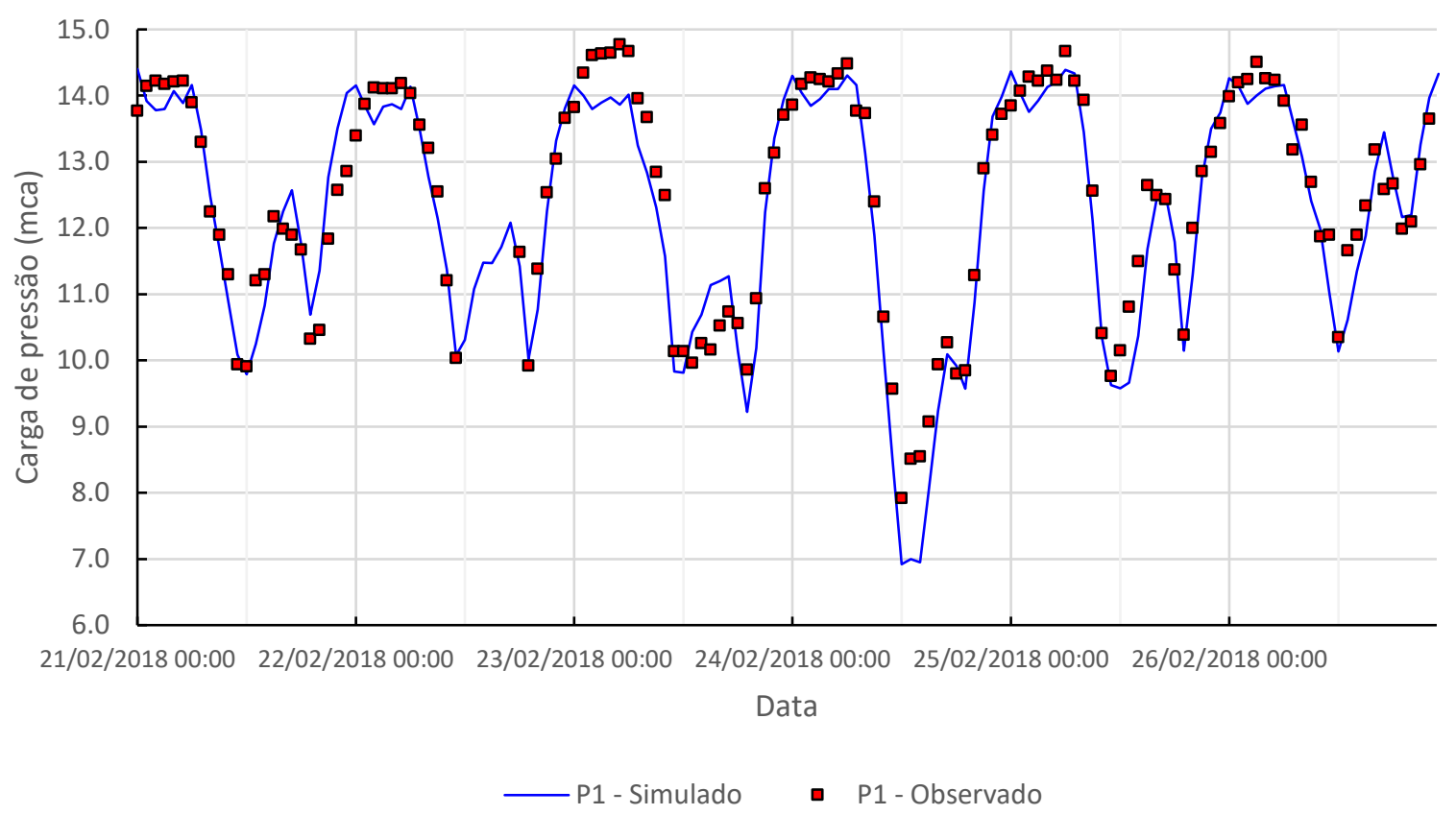

Figura 50 - Validação do modelo hidráulico do Setor Lacta - pressões observadas (pontos) e simuladas (linha) do ponto $\mathbf{P 2}$

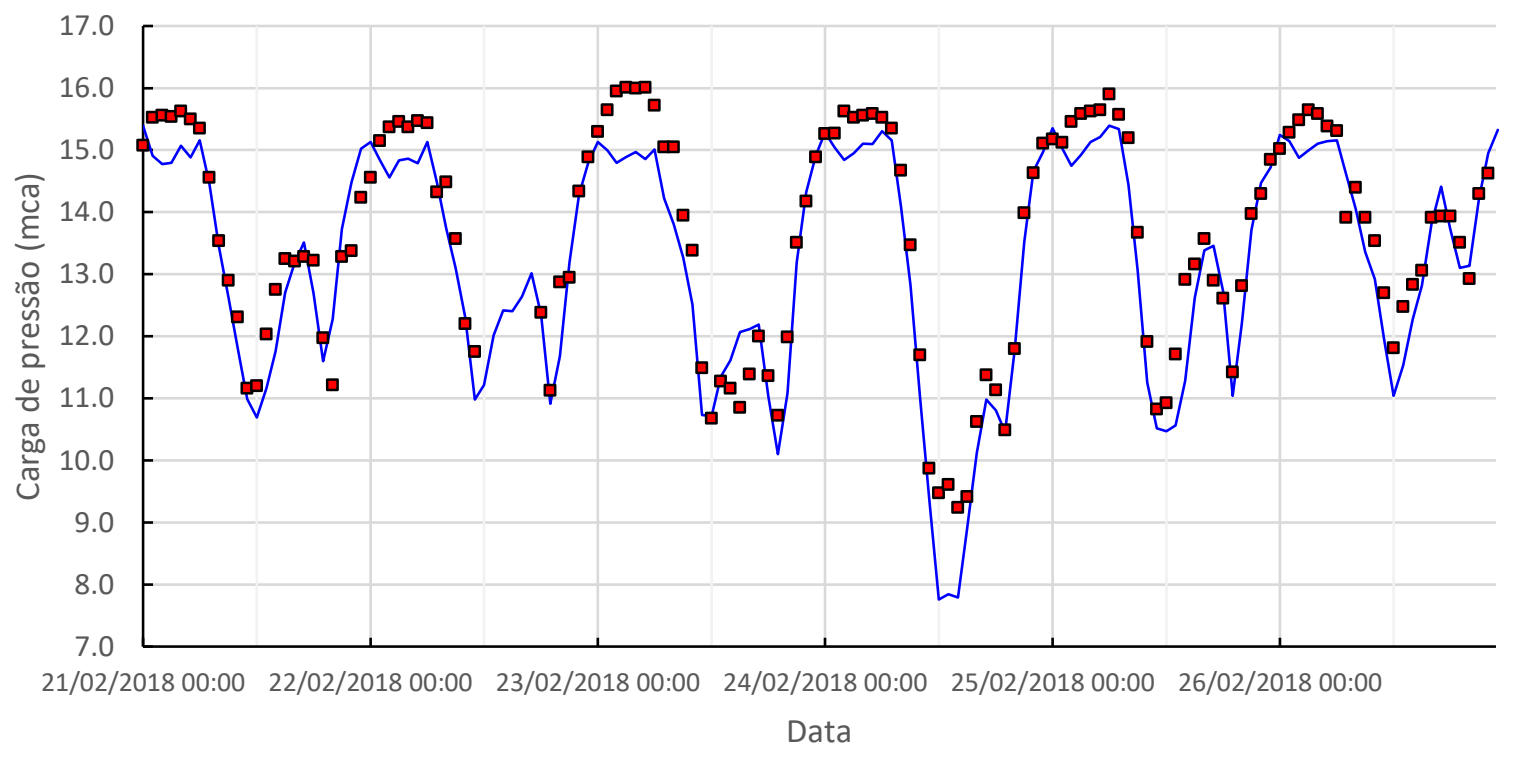


Figura 51 - Validação do modelo hidráulico do Setor Lacta - pressões observadas (pontos) e simuladas (linha) do ponto $\mathbf{P 3}$

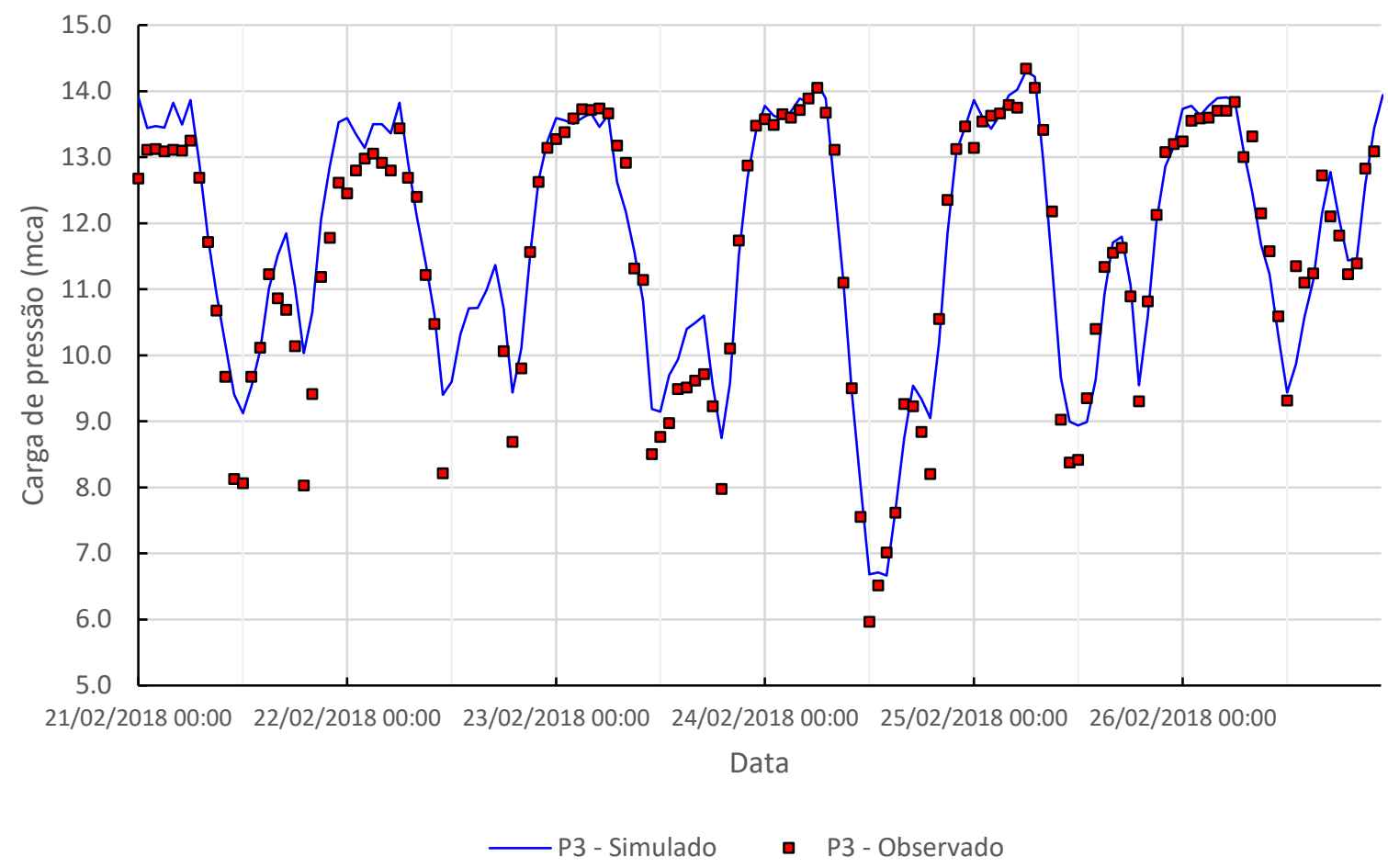

Figura 52 - Validação do modelo hidráulico do Setor Lacta - pressões observadas (pontos) e simuladas (linha) do ponto $\mathbf{P 4}$

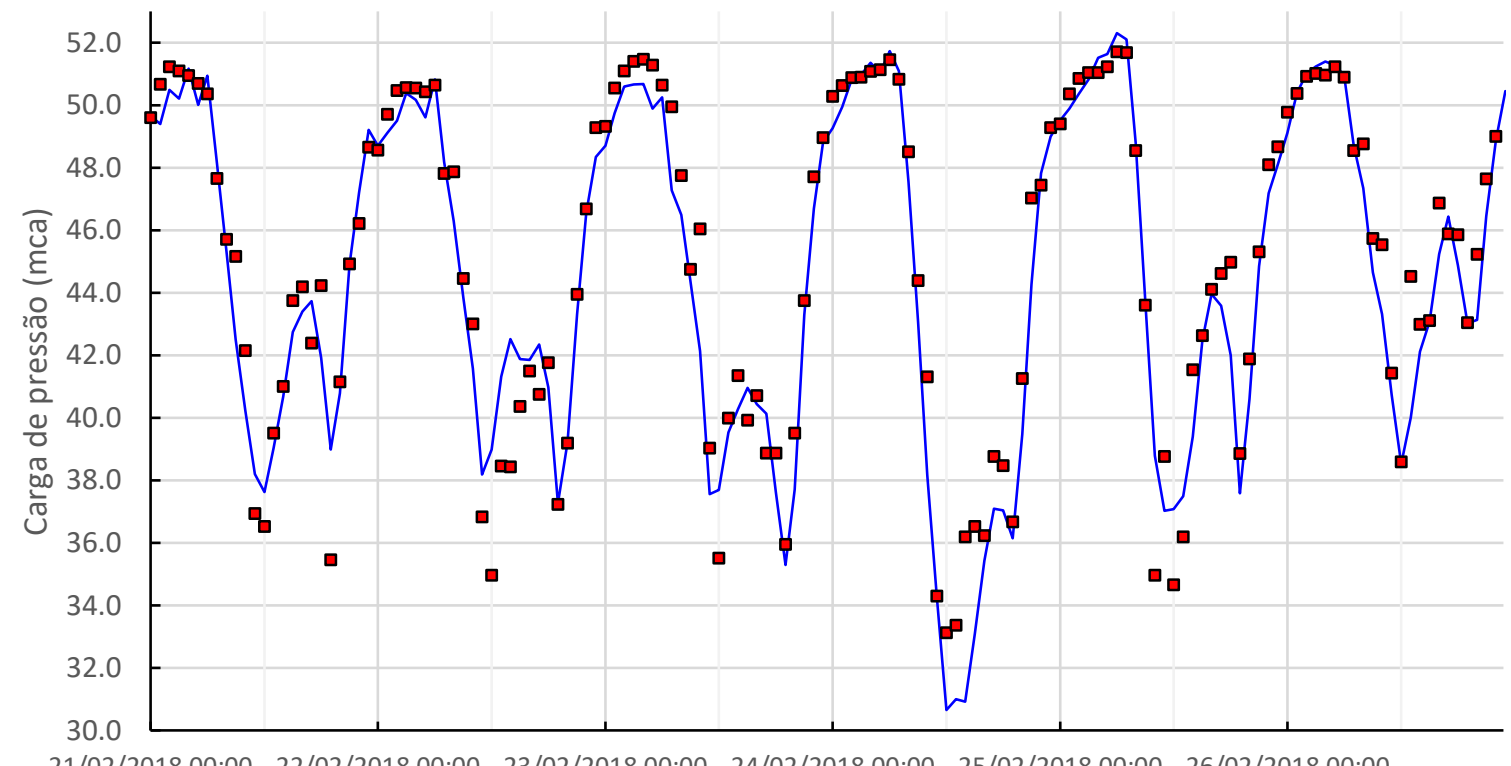

21/02/2018 00:00 22/02/2018 00:00 23/02/2018 00:00 24/02/2018 00:00 25/02/2018 00:00 26/02/2018 00:00

Data 
Figura 53 - Validação do modelo hidráulico do Setor Lacta - pressões observadas (pontos) e simuladas (linha) do ponto P5

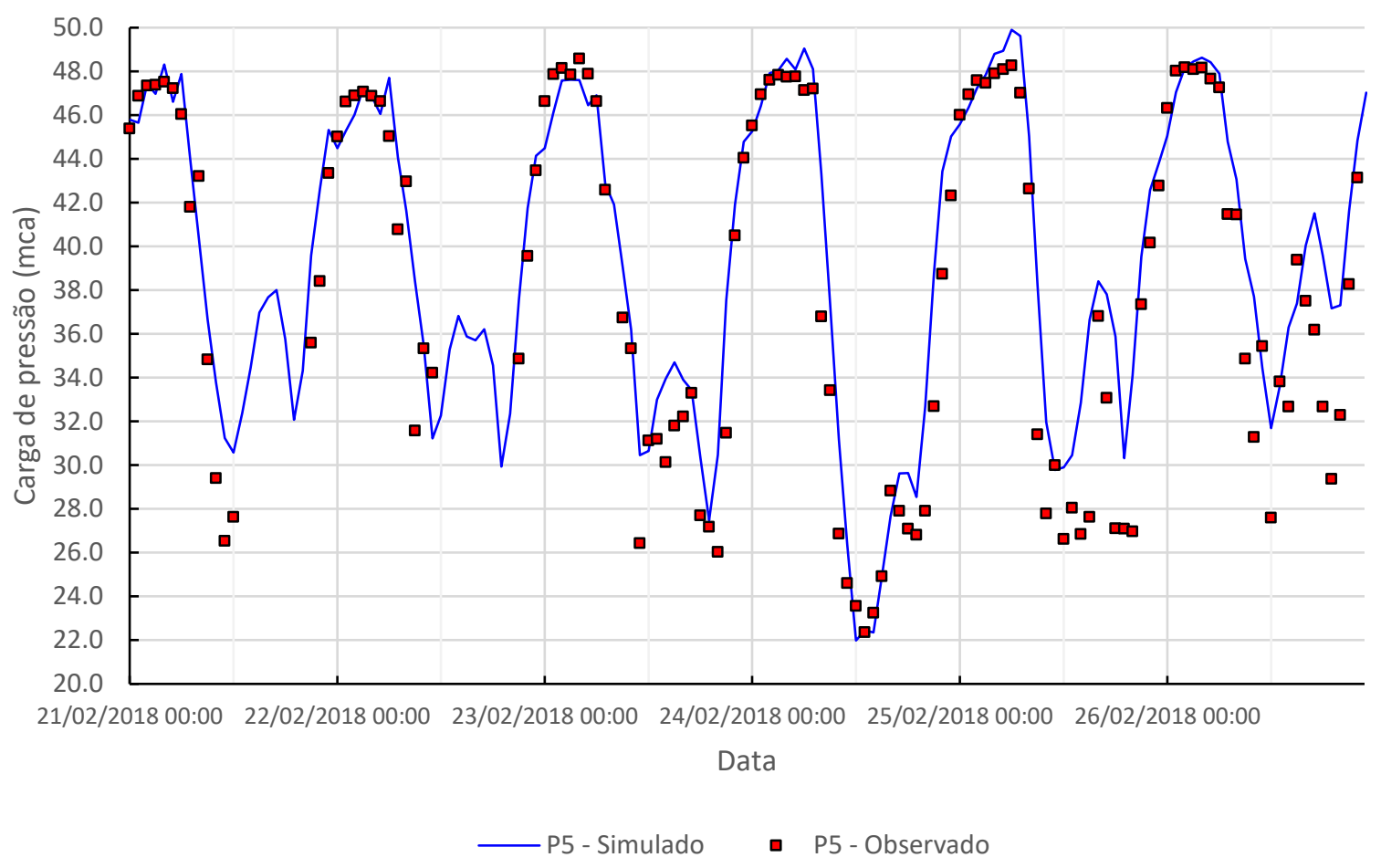

Figura 54 - Validação do modelo hidráulico do Setor Lacta - pressões observadas (pontos) e simuladas (linha) do ponto P6

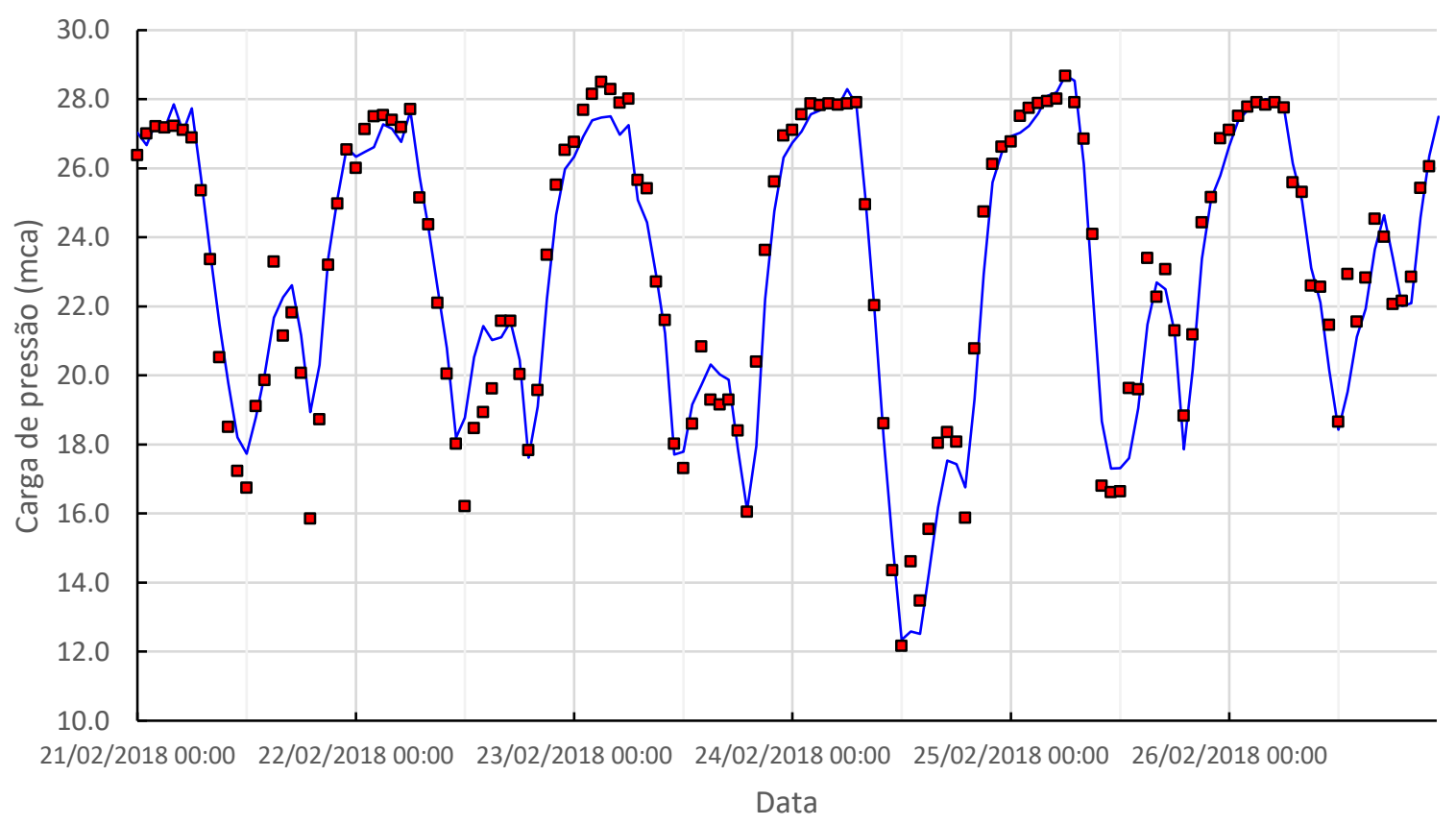

— P6 - Simulado a P6-Observado 
Figura 55 - Validação do modelo hidráulico do Setor Lacta - pressões observadas (pontos) e simuladas (linha) do ponto $\mathbf{P 9}$

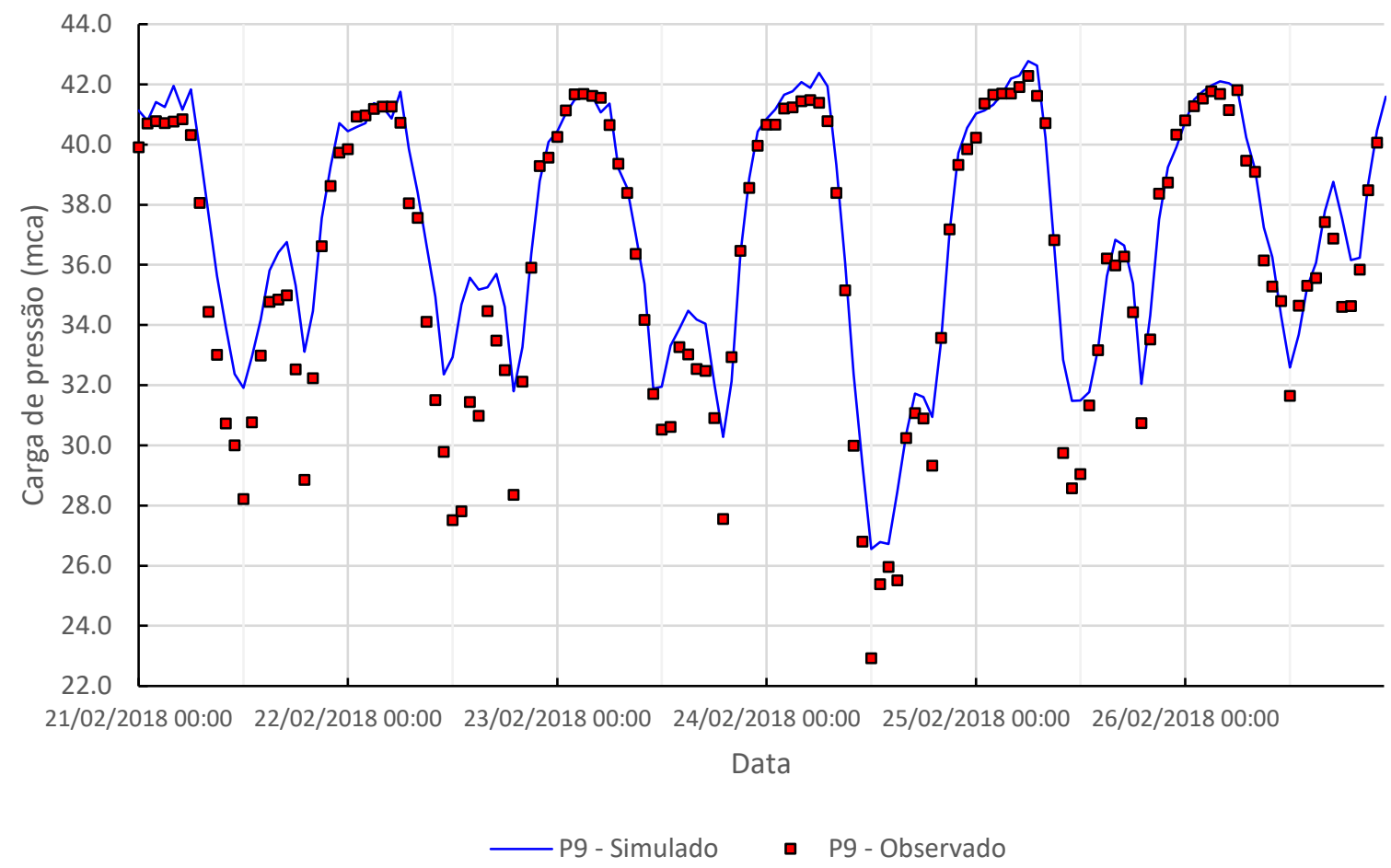

Figura 56 - Vazões referentes ao consumo total e ao vazamento durante todo o período de validação da calibração do setor Lacta

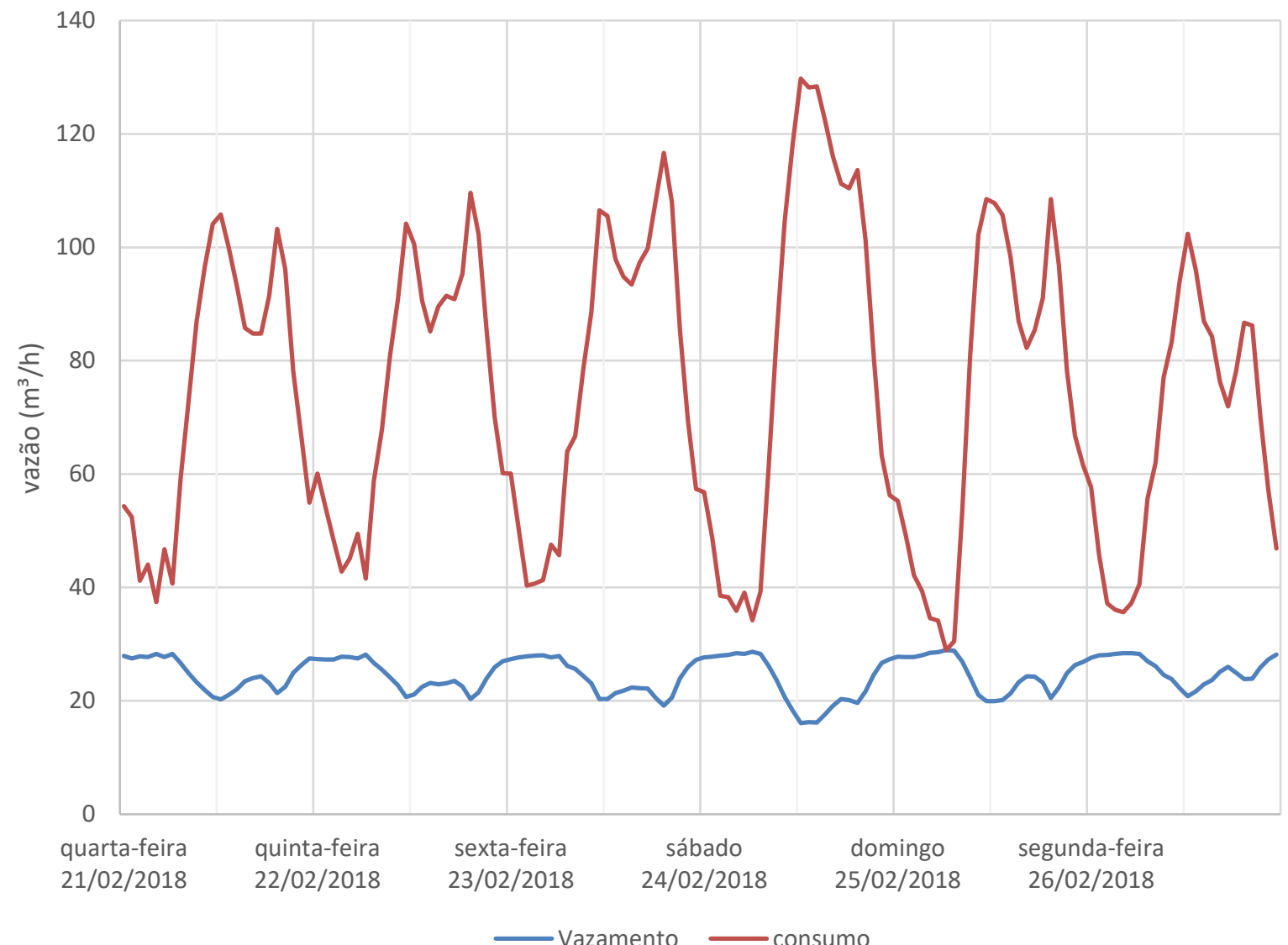


Figura 57 - Porcentagem do consumo total relativo a vazamentos durante todo o período de validação da calibração do setor Lacta

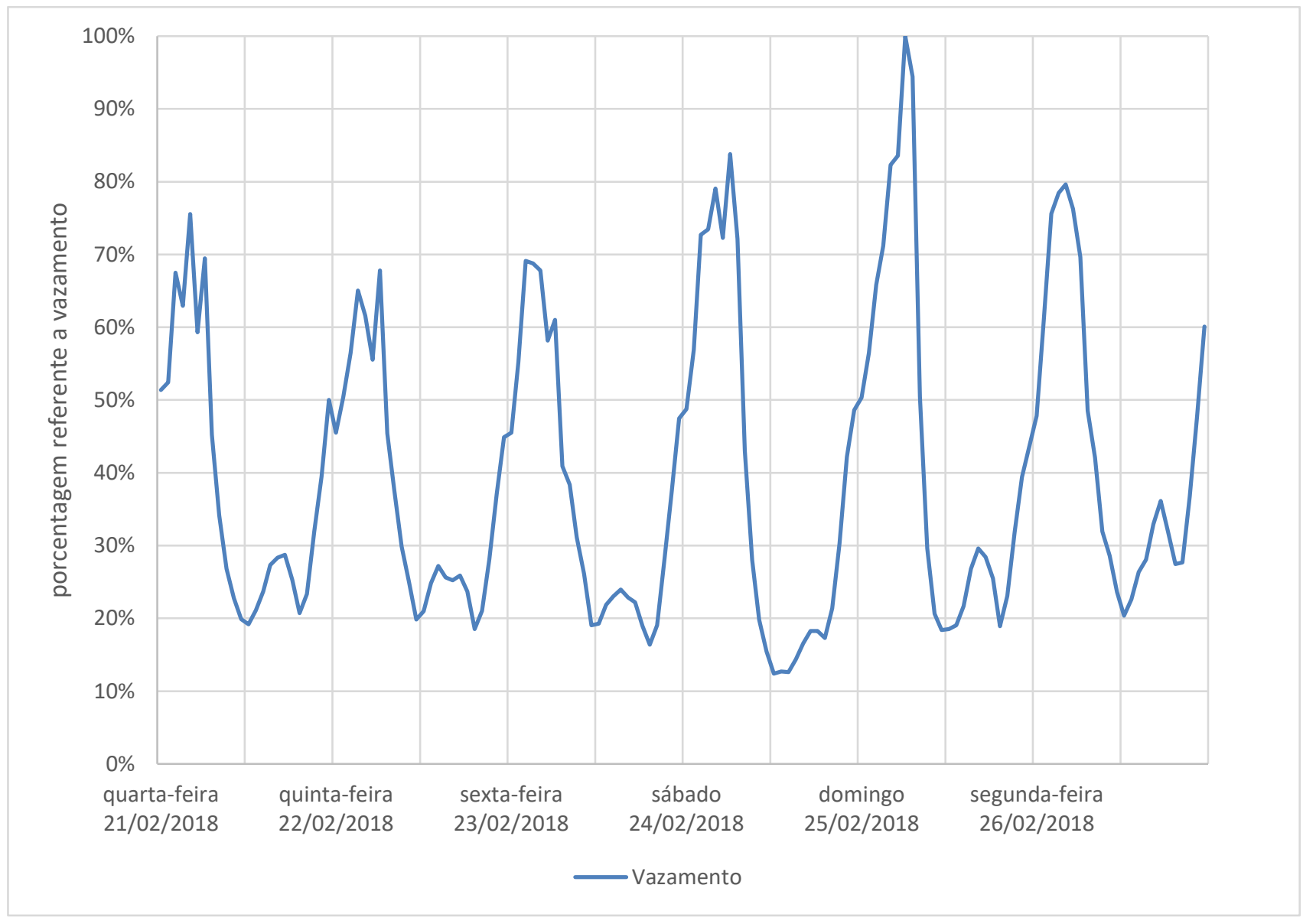


APÊNDICE B 
Tabela 20 - Resultados das partições dos métodos ModulMax e METIS, com os valores das métricas utilizadas para avaliar as soluções encontradas

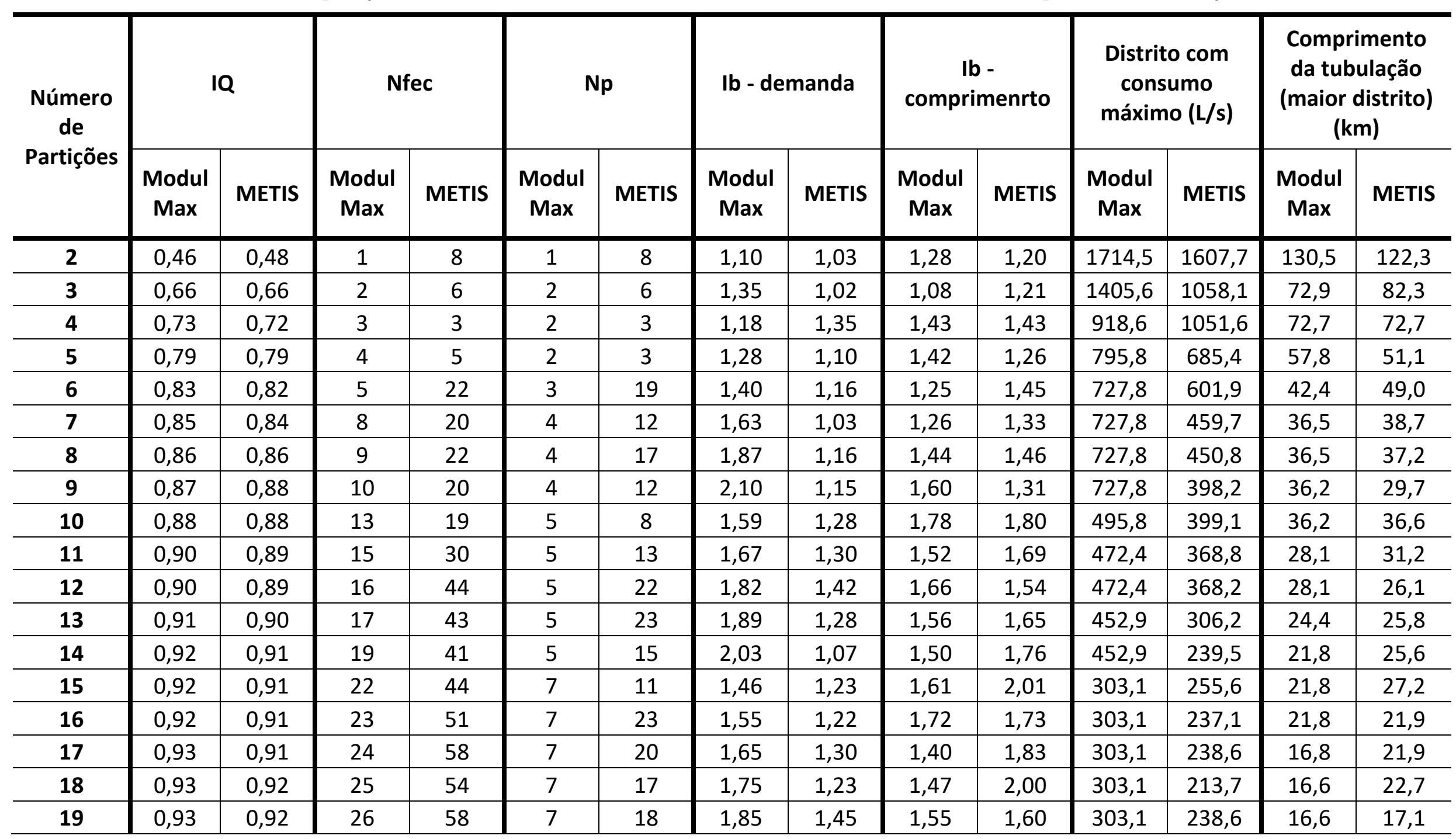




\begin{tabular}{|c|c|c|c|c|c|c|c|c|c|c|c|c|c|c|}
\hline \multirow{2}{*}{$\begin{array}{l}\text { Número } \\
\text { de } \\
\text { Partições }\end{array}$} & \multicolumn{2}{|c|}{ IQ } & \multicolumn{2}{|c|}{ Nfec } & \multicolumn{2}{|c|}{$\mathrm{Np}$} & \multicolumn{2}{|c|}{ Ib - demanda } & \multicolumn{2}{|c|}{$\begin{array}{c}\text { lb - } \\
\text { comprimenrto }\end{array}$} & \multicolumn{2}{|c|}{$\begin{array}{l}\text { Distrito com } \\
\text { consumo } \\
\text { máximo (L/s) }\end{array}$} & \multicolumn{2}{|c|}{$\begin{array}{c}\text { Comprimento } \\
\text { da tubulação } \\
\text { (maior distrito) } \\
\text { (km) }\end{array}$} \\
\hline & $\begin{array}{l}\text { Modul } \\
\text { Max }\end{array}$ & METIS & $\begin{array}{l}\text { Modul } \\
\text { Max }\end{array}$ & METIS & $\begin{array}{l}\text { Modul } \\
\text { Max }\end{array}$ & METIS & $\begin{array}{l}\text { Modul } \\
\text { Max }\end{array}$ & METIS & $\begin{array}{l}\text { Modul } \\
\text { Max }\end{array}$ & METIS & $\begin{array}{l}\text { Modul } \\
\text { Max }\end{array}$ & METIS & $\begin{array}{l}\text { Modul } \\
\text { Max }\end{array}$ & METIS \\
\hline 22 & 0,94 & 0,92 & 31 & 65 & 6 & 11 & 1,94 & 1,29 & 1,79 & 2,15 & 274,9 & 183,2 & 16,5 & 19,9 \\
\hline 23 & 0,94 & 0,92 & 32 & 70 & 6 & 13 & 2,03 & 1,26 & 1,87 & 1,88 & 274,9 & 170,3 & 16,5 & 16,6 \\
\hline 24 & 0,94 & 0,92 & 33 & 83 & 6 & 16 & 2,11 & 1,28 & 1,74 & 2,22 & 274,9 & 165,8 & 14,7 & 18,8 \\
\hline 25 & 0,94 & 0,93 & 35 & 65 & 6 & 15 & 2,20 & 1,40 & 1,81 & 1,81 & 274,9 & 174,3 & 14,7 & 14,8 \\
\hline 26 & 0,94 & 0,93 & 36 & 66 & 6 & 12 & 2,29 & 1,39 & 1,88 & 1,88 & 274,9 & 167,2 & 14,7 & 14,7 \\
\hline 31 & 0,95 & 0,92 & 43 & 102 & 6 & 17 & 2,34 & 1,43 & 1,88 & 2,35 & 235,0 & 143,5 & 12,3 & 15,4 \\
\hline 32 & 0,95 & 0,92 & 44 & 109 & 7 & 20 & 2,41 & 1,40 & 1,94 & 2,11 & 235,0 & 136,6 & 12,3 & 13,4 \\
\hline 33 & 0,95 & 0,93 & 46 & 96 & 7 & 15 & 2,49 & 1,41 & 2,00 & 2,33 & 235,0 & 133,1 & 12,3 & 14,4 \\
\hline 34 & 0,95 & 0,93 & 47 & 97 & 7 & 16 & 2,56 & 1,27 & 2,06 & 2,20 & 235,0 & 116,2 & 12,3 & 13,2 \\
\hline 35 & 0,95 & 0,93 & 48 & 88 & 7 & 18 & 2,64 & 1,30 & 2,12 & 2,14 & 235,0 & 115,6 & 12,3 & 12,4 \\
\hline 36 & 0,95 & 0,93 & 49 & 104 & 7 & 14 & 2,71 & 1,32 & 2,18 & 2,02 & 235,0 & 114,5 & 12,3 & 11,4 \\
\hline 37 & 0,95 & 0,92 & 50 & 131 & 7 & 23 & 2,79 & 1,32 & 2,24 & 2,24 & 235,0 & 111,4 & 12,3 & 12,3 \\
\hline 38 & 0,95 & 0,93 & 51 & 110 & 7 & 15 & 2,86 & 1,31 & 1,82 & 2,39 & 235,0 & 107,5 & 9,8 & 12,8 \\
\hline 39 & 0,95 & 0,92 & 52 & 121 & 7 & 19 & 2,94 & 1,28 & 1,87 & 2,34 & 235,0 & 102,2 & 9,8 & 12,2 \\
\hline 40 & 0,95 & 0,92 & 54 & 124 & 7 & 20 & 3,01 & 1,19 & 1,92 & 2,26 & 235,0 & 92,5 & 9,8 & 11,5 \\
\hline
\end{tabular}




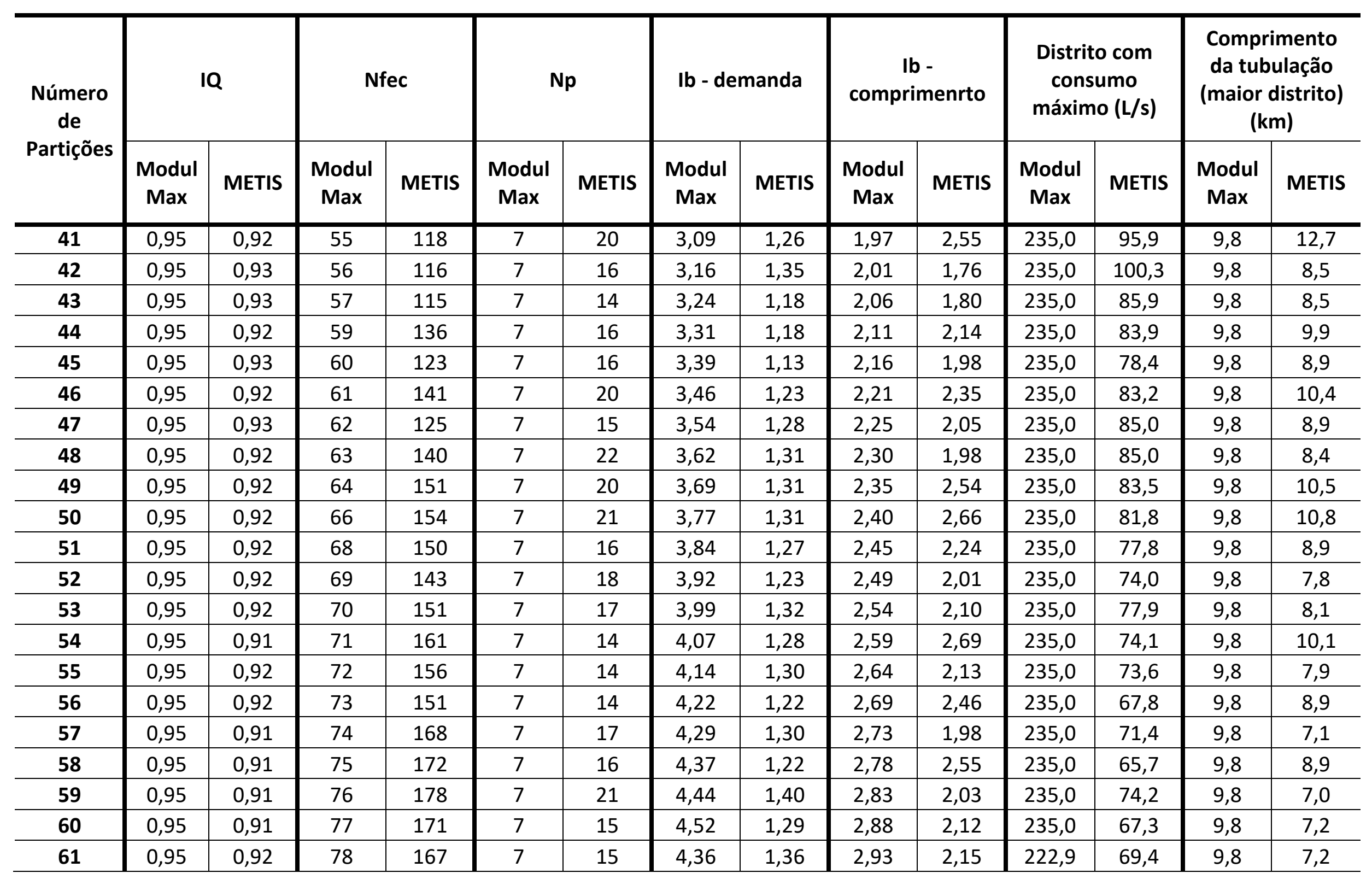




\begin{tabular}{|c|c|c|c|c|c|c|c|c|c|c|c|c|c|c|}
\hline \multirow{2}{*}{$\begin{array}{l}\text { Número } \\
\text { de } \\
\text { Partições }\end{array}$} & \multicolumn{2}{|c|}{ IQ } & \multicolumn{2}{|c|}{ Nfec } & \multicolumn{2}{|c|}{$\mathrm{Np}$} & \multicolumn{2}{|c|}{ Ib - demanda } & \multicolumn{2}{|c|}{$\begin{array}{c}\text { lb - } \\
\text { comprimenrto }\end{array}$} & \multicolumn{2}{|c|}{$\begin{array}{l}\text { Distrito com } \\
\text { consumo } \\
\text { máximo (L/s) }\end{array}$} & \multicolumn{2}{|c|}{$\begin{array}{c}\text { Comprimento } \\
\text { da tubulação } \\
\text { (maior distrito) } \\
\text { (km) }\end{array}$} \\
\hline & $\begin{array}{l}\text { Modul } \\
\text { Max }\end{array}$ & METIS & $\begin{array}{l}\text { Modul } \\
\text { Max }\end{array}$ & METIS & $\begin{array}{l}\text { Modul } \\
\text { Max }\end{array}$ & METIS & $\begin{array}{l}\text { Modul } \\
\text { Max }\end{array}$ & METIS & $\begin{array}{l}\text { Modul } \\
\text { Max }\end{array}$ & METIS & $\begin{array}{l}\text { Modul } \\
\text { Max }\end{array}$ & METIS & $\begin{array}{l}\text { Modul } \\
\text { Max }\end{array}$ & METIS \\
\hline 64 & 0,95 & 0,91 & 83 & 188 & 7 & 16 & 3,73 & 1,27 & 2,53 & 2,56 & 182,0 & 62,1 & 8,0 & 8,1 \\
\hline 65 & 0,95 & 0,90 & 84 & 206 & 7 & 19 & 3,79 & 1,37 & 2,57 & 2,26 & 182,0 & 65,7 & 8,0 & 7,1 \\
\hline 66 & 0,95 & 0,90 & 85 & 204 & 7 & 18 & 3,85 & 1,27 & 2,61 & 2,33 & 182,0 & 60,1 & 8,0 & 7,2 \\
\hline 67 & 0,95 & 0,91 & 87 & 184 & 7 & 18 & 3,91 & 1,32 & 2,65 & 2,37 & 182,0 & 61,4 & 8,0 & 7,2 \\
\hline 68 & 0,95 & 0,91 & 88 & 190 & 7 & 15 & 3,97 & 1,41 & 2,69 & 2,12 & 182,0 & 64,5 & 8,0 & 6,3 \\
\hline 73 & 0,94 & 0,91 & 93 & 197 & 7 & 17 & 4,26 & 1,37 & 2,88 & 2,35 & 182,0 & 58,5 & 8,0 & 6,5 \\
\hline 74 & 0,94 & 0,90 & 94 & 211 & 7 & 18 & 4,32 & 1,26 & 2,92 & 2,39 & 182,0 & 53,2 & 8,0 & 6,6 \\
\hline 75 & 0,94 & 0,90 & 95 & 206 & 7 & 15 & 4,37 & 1,30 & 2,96 & 2,34 & 182,0 & 54,2 & 8,0 & 6,3 \\
\hline 76 & 0,94 & 0,90 & 96 & 207 & 7 & 15 & 4,43 & 1,37 & 3,00 & 2,21 & 182,0 & 56,1 & 8,0 & 5,9 \\
\hline 77 & 0,94 & 0,90 & 97 & 217 & 8 & 18 & 4,49 & 1,30 & 3,04 & 2,49 & 182,0 & 52,6 & 8,0 & 6,6 \\
\hline 78 & 0,94 & 0,90 & 98 & 215 & 8 & 21 & 4,41 & 1,34 & 3,08 & 2,32 & 176,3 & 53,6 & 8,0 & 6,1 \\
\hline 79 & 0,94 & 0,90 & 99 & 229 & 8 & 17 & 4,46 & 1,40 & 3,12 & 2,67 & 176,3 & 55,3 & 8,0 & 6,9 \\
\hline 80 & 0,94 & 0,90 & 100 & 225 & 8 & 17 & 4,52 & 1,47 & 3,16 & 2,88 & 176,3 & 57,3 & 8,0 & 7,3 \\
\hline 81 & 0,94 & 0,90 & 101 & 229 & 8 & 17 & 4,58 & 1,40 & 3,20 & 2,22 & 176,3 & 53,9 & 8,0 & 5,6 \\
\hline 82 & 0,94 & 0,90 & 102 & 216 & 8 & 14 & 4,63 & 1,38 & 3,24 & 2,26 & 176,3 & 52,6 & 8,0 & 5,6 \\
\hline
\end{tabular}




\begin{tabular}{|c|c|c|c|c|c|c|c|c|c|c|c|c|c|c|}
\hline \multirow{2}{*}{$\begin{array}{l}\text { Número } \\
\text { de } \\
\text { Partições }\end{array}$} & \multicolumn{2}{|c|}{ IQ } & \multicolumn{2}{|c|}{ Nfec } & \multicolumn{2}{|c|}{ Np } & \multicolumn{2}{|c|}{ Ib - demanda } & \multicolumn{2}{|c|}{$\begin{array}{c}\text { lb - } \\
\text { comprimenrto }\end{array}$} & \multicolumn{2}{|c|}{$\begin{array}{l}\text { Distrito com } \\
\text { consumo } \\
\text { máximo (L/s) }\end{array}$} & \multicolumn{2}{|c|}{$\begin{array}{c}\text { Comprimento } \\
\text { da tubulação } \\
\text { (maior distrito) } \\
\text { (km) }\end{array}$} \\
\hline & $\begin{array}{l}\text { Modul } \\
\text { Max }\end{array}$ & METIS & $\begin{array}{l}\text { Modul } \\
\text { Max }\end{array}$ & METIS & $\begin{array}{l}\text { Modul } \\
\text { Max }\end{array}$ & METIS & $\begin{array}{l}\text { Modul } \\
\text { Max }\end{array}$ & METIS & $\begin{array}{l}\text { Modul } \\
\text { Max }\end{array}$ & METIS & $\begin{array}{l}\text { Modul } \\
\text { Max }\end{array}$ & METIS & $\begin{array}{l}\text { Modul } \\
\text { Max }\end{array}$ & METIS \\
\hline 85 & 0,94 & 0,90 & 106 & 227 & 8 & 14 & 4,80 & 1,37 & 3,36 & 2,40 & 176,3 & 50,4 & 8,0 & 5,7 \\
\hline 86 & 0,94 & 0,90 & 107 & 223 & 8 & 14 & 4,86 & 1,43 & 3,40 & 2,62 & 176,3 & 51,8 & 8,0 & 6,2 \\
\hline 87 & 0,94 & 0,89 & 108 & 234 & 8 & 18 & 4,92 & 1,25 & 3,44 & 2,76 & 176,3 & 44,8 & 8,0 & 6,4 \\
\hline 88 & 0,94 & 0,89 & 109 & 257 & 8 & 14 & 4,97 & 1,28 & 3,48 & 2,49 & 176,3 & 45,4 & 8,0 & 5,7 \\
\hline 89 & 0,94 & 0,89 & 110 & 234 & 8 & 14 & 5,03 & 1,43 & 3,52 & 2,51 & 176,3 & 50,0 & 8,0 & 5,7 \\
\hline 94 & 0,94 & 0,89 & 116 & 245 & 8 & 14 & 5,31 & 1,30 & 3,71 & 3,66 & 176,3 & 43,1 & 8,0 & 7,9 \\
\hline 95 & 0,94 & 0,89 & 117 & 252 & 8 & 13 & 5,37 & 1,34 & 3,75 & 2,60 & 176,3 & 44,0 & 8,0 & 5,6 \\
\hline 96 & 0,94 & 0,89 & 118 & 249 & 8 & 15 & 5,42 & 1,37 & 3,79 & 2,61 & 176,3 & 44,5 & 8,0 & 5,5 \\
\hline 97 & 0,94 & 0,88 & 120 & 266 & 8 & 17 & 5,48 & 1,36 & 3,83 & 2,87 & 176,3 & 43,8 & 8,0 & 6,0 \\
\hline 98 & 0,94 & 0,88 & 121 & 272 & 8 & 15 & 5,54 & 1,28 & 3,87 & 2,28 & 176,3 & 40,8 & 8,0 & 4,7 \\
\hline 99 & 0,94 & 0,88 & 123 & 265 & 8 & 14 & 5,59 & 1,30 & 3,91 & 2,70 & 176,3 & 41,0 & 8,0 & 5,6 \\
\hline 100 & 0,94 & 0,89 & 124 & 253 & 8 & 15 & 5,65 & 1,33 & 3,95 & 3,33 & 176,3 & 41,6 & 8,0 & 6,8 \\
\hline
\end{tabular}


APÊNDICE C 
Figura 58 - Soluções pertencentes ao Conjunto Restrito e ao Conjunto Pareto, com indicação de suas métricas e suas métricas normalizadas

\begin{tabular}{|c|c|c|c|c|c|c|c|c|c|c|c|}
\hline \multirow{2}{*}{$\begin{array}{l}\text { Conjunto } \\
\text { Restrito }\end{array}$} & \multicolumn{5}{|c|}{ Métricas } & \multicolumn{5}{|c|}{ Métricas normalizadas } & \multirow{2}{*}{$\begin{array}{c}\text { Conjunto } \\
\text { Pareto }\end{array}$} \\
\hline & $\mathbf{N}_{\mathrm{FEC}}$ & IQ & $\mathbf{N}_{\mathbf{p}}$ & $I_{B}{ }^{C}$ & $I_{B}{ }^{D}$ & $\mathbf{N}_{\mathrm{FEC}}$ & IQ & $\mathbf{N}_{\mathrm{p}}$ & $I_{B}{ }^{C}$ & $I_{B}{ }^{D}$ & \\
\hline Modul3,30 & 42 & 0,95 & 6 & 1,82 & 2,26 & 0,278 & 0,598 & 0,300 & 0,527 & 0,455 & Sim \\
\hline Modul3,31 & 43 & 0,95 & 6 & 1,88 & 2,34 & 0,285 & 0,592 & 0,300 & 0,566 & 0,483 & Sim \\
\hline Modul3,32 & 44 & 0,95 & 7 & 1,94 & 2,41 & 0,291 & 0,586 & 0,350 & 0,605 & 0,510 & Sim \\
\hline Modul3,33 & 46 & 0,95 & 7 & 2,00 & 2,49 & 0,305 & 0,582 & 0,350 & 0,644 & 0,537 & Sim \\
\hline Modul3,34 & 47 & 0,95 & 7 & 2,06 & 2,56 & 0,311 & 0,577 & 0,350 & 0,683 & 0,564 & Sim \\
\hline Modul3,35 & 48 & 0,95 & 7 & 2,12 & 2,64 & 0,318 & 0,573 & 0,350 & 0,722 & 0,592 & Sim \\
\hline Modul3,36 & 49 & 0,95 & 7 & 2,18 & 2,71 & 0,325 & 0,569 & 0,350 & 0,761 & 0,619 & Sim \\
\hline Modul3,37 & 50 & 0,95 & 7 & 2,24 & 2,79 & 0,331 & 0,565 & 0,350 & 0,800 & 0,646 & Sim \\
\hline Modul3,38 & 51 & 0,95 & 7 & 1,82 & 2,86 & 0,338 & 0,563 & 0,350 & 0,531 & 0,673 & $\mathrm{im}$ \\
\hline Modul3,39 & 52 & 0,95 & 7 & 1,87 & 2,94 & 0,344 & 0,561 & 0,350 & 0,561 & 0,700 & Sim \\
\hline Modul3,40 & 54 & 0,95 & 7 & 1,92 & 3,01 & 0,358 & 0,559 & 0,350 & 0,592 & 0,728 & Sim \\
\hline Modul3,41 & 55 & 0,95 & 7 & 1,97 & 3,09 & 0,364 & 0,558 & 0,350 & 0,623 & 0,755 & Sim \\
\hline Modul3,42 & 56 & 0,95 & 7 & 2,01 & 3,16 & 0,371 & 0,557 & 0,350 & 0,654 & 0,782 & Sim \\
\hline Modul3,43 & 57 & 0,95 & 7 & 2,06 & 3,24 & 0,377 & 0,557 & 0,350 & 0,685 & 0,809 & Não \\
\hline Modul3,44 & 59 & 0,95 & 7 & 2,11 & 3,31 & 0,391 & 0,556 & 0,350 & 0,716 & 0,837 & $\mathrm{im}$ \\
\hline Modul3,45 & 60 & 0,95 & 7 & 2,16 & 3,39 & 0,397 & 0,555 & 0,350 & 0,747 & 0,864 & Sim \\
\hline Modul3,46 & 61 & 0,95 & 7 & 2,21 & 3,46 & 0,404 & 0,555 & 0,350 & 0,778 & 0,891 & Não \\
\hline Modul3,47 & 62 & 0,95 & 7 & 2,25 & 3,54 & 0,411 & 0,555 & 0,350 & 0,809 & 0,918 & \\
\hline Modul3,48 & 63 & 0,95 & 7 & 2,30 & 3,62 & 0,417 & 0,556 & 0,350 & 0,840 & 0,946 & Não \\
\hline Modul3,49 & 64 & 0,95 & 7 & 2,35 & 3,69 & 0,424 & 0,557 & 0,350 & 0,871 & 0,973 & Não \\
\hline Modul3,50 & 66 & 0,95 & 7 & 2,40 & 3,77 & 0,437 & 0,558 & 0,350 & 0,902 & 1,000 & 10 \\
\hline METIS,17 & 58 & 0,91 & 20 & 1,83 & 1,30 & 0,384 & 1,000 & 1,000 & 0,538 & 0,108 & Sim \\
\hline METIS,18 & 54 & 0,92 & 17 & 2,00 & 1,23 & 0,358 & 0,946 & 0,850 & 0,648 & 0,084 & Sim \\
\hline METIS,19 & 58 & 0,92 & 18 & 1,60 & 1,45 & 0,384 & 0,905 & 0,900 & 0,384 & 0,164 & Sim \\
\hline METIS,20 & 63 & 0,92 & 20 & 2,14 & 1,32 & 0,417 & 0,922 & 1,000 & 0,734 & 0,115 & Sim \\
\hline METIS,21 & 71 & 0,92 & 15 & 2,06 & 1,38 & 0,470 & 0,902 & 0,750 & 0,682 & 0,138 & Não \\
\hline METIS,22 & 65 & 0,92 & 11 & 2,15 & 1,29 & 0,430 & 0,869 & 0,550 & 0,744 & 0,105 & $\mathrm{im}$ \\
\hline METIS,23 & 70 & 0,92 & 13 & 1,88 & 1,26 & 0,464 & 0,884 & 0,650 & 0,565 & 0,092 & Sim \\
\hline METIS,24 & 83 & 0,92 & 16 & 2,22 & 1,28 & 0,550 & 0,930 & 0,800 & 0,788 & 0,099 & Não \\
\hline METIS,25 & 65 & 0,93 & 15 & 1,81 & 1,40 & 0,430 & 0,805 & 0,750 & 0,525 & 0,143 & Sim \\
\hline METIS,26 & 66 & 0,93 & 12 & 1,88 & 1,39 & 0,437 & 0,795 & 0,600 & 0,565 & 0,142 & Sim \\
\hline METIS,27 & 81 & 0,93 & 15 & 2,00 & 1,30 & 0,536 & 0,811 & 0,750 & 0,644 & 0,110 & Sim \\
\hline METIS,28 & 75 & 0,93 & 12 & 2,08 & 1,39 & 0,497 & 0,791 & 0,600 & 0,694 & 0,140 & Sim \\
\hline METIS,29 & 94 & 0,92 & 18 & 1,91 & 1,29 & 0,623 & 0,859 & 0,900 & 0,590 & 0,106 & Sim \\
\hline METIS,30 & 93 & 0,92 & 20 & 2,22 & 1,42 & 0,616 & 0,843 & 1,000 & 0,788 & 0,152 & Não \\
\hline METIS,31 & 102 & 0,92 & 17 & 2,35 & 1,43 & 0,675 & 0,874 & 0,850 & 0,870 & 0,154 & Não \\
\hline METIS,32 & 109 & 0,92 & 20 & 2,11 & 1,40 & 0,722 & 0,893 & 1,000 & 0,717 & 0,145 & Não \\
\hline METIS,33 & 96 & 0,93 & 15 & 2,33 & 1,41 & 0,636 & 0,822 & 0,750 & 0,858 & 0,147 & Não \\
\hline
\end{tabular}




\begin{tabular}{l|c|c|c|c|c|c|c|c|c|c|c}
\hline METIS,34 & 97 & 0,93 & 16 & 2,20 & 1,27 & 0,642 & 0,812 & 0,800 & 0,774 & 0,096 & Sim \\
\hline METIS,35 & 88 & 0,93 & 18 & 2,14 & 1,30 & 0,583 & 0,752 & 0,900 & 0,733 & 0,107 & Sim \\
\hline METIS,36 & 104 & 0,93 & 14 & 2,02 & 1,32 & 0,689 & 0,815 & 0,700 & 0,657 & 0,116 & Sim \\
\hline METIS,38 & 110 & 0,93 & 15 & 2,39 & 1,31 & 0,728 & 0,821 & 0,750 & 0,896 & 0,112 & Não \\
\hline METIS,39 & 121 & 0,92 & 19 & 2,34 & 1,28 & 0,801 & 0,862 & 0,950 & 0,866 & 0,101 & Não \\
\hline METIS,40 & 124 & 0,92 & 20 & 2,26 & 1,19 & 0,821 & 0,874 & 1,000 & 0,809 & 0,067 & Não \\
\hline METIS,41 & 118 & 0,92 & 20 & 2,55 & 1,26 & 0,781 & 0,843 & 1,000 & 1,000 & 0,094 & Não \\
\hline METIS,42 & 116 & 0,93 & 16 & 1,76 & 1,35 & 0,768 & 0,809 & 0,800 & 0,489 & 0,127 & Sim \\
\hline METIS,43 & 115 & 0,93 & 14 & 1,80 & 1,18 & 0,762 & 0,793 & 0,700 & 0,516 & 0,066 & Sim \\
\hline METIS,44 & 136 & 0,92 & 16 & 2,14 & 1,18 & 0,901 & 0,889 & 0,800 & 0,734 & 0,066 & Não \\
\hline METIS,45 & 123 & 0,93 & 16 & 1,98 & 1,13 & 0,815 & 0,830 & 0,800 & 0,630 & 0,047 & Sim \\
\hline METIS,46 & 141 & 0,92 & 20 & 2,35 & 1,23 & 0,934 & 0,908 & 1,000 & 0,871 & 0,082 & Não \\
\hline METIS,47 & 125 & 0,93 & 15 & 2,05 & 1,28 & 0,828 & 0,835 & 0,750 & 0,677 & 0,101 & Não \\
\hline METIS,49 & 151 & 0,92 & 20 & 2,54 & 1,31 & 1,000 & 0,950 & 1,000 & 0,993 & 0,112 & Não \\
\hline AS
\end{tabular}

As soluções pertencentes ao conjunto pareto são aquelas que pertencem à frente pareto, utilizando como funções objetivo as cinco métricas normalizadas mostradas na tabela. 
APÊNDICE D 
Ilustração das soluções com 5, 10, 20, 30, 40 e 50 partições de ambas as metodologias, além das soluções encontradas na Tabela 17.

Figura 59 - Partição da rede de abastecimento de água de Pederneiras em 5 distritos, através do método METIS

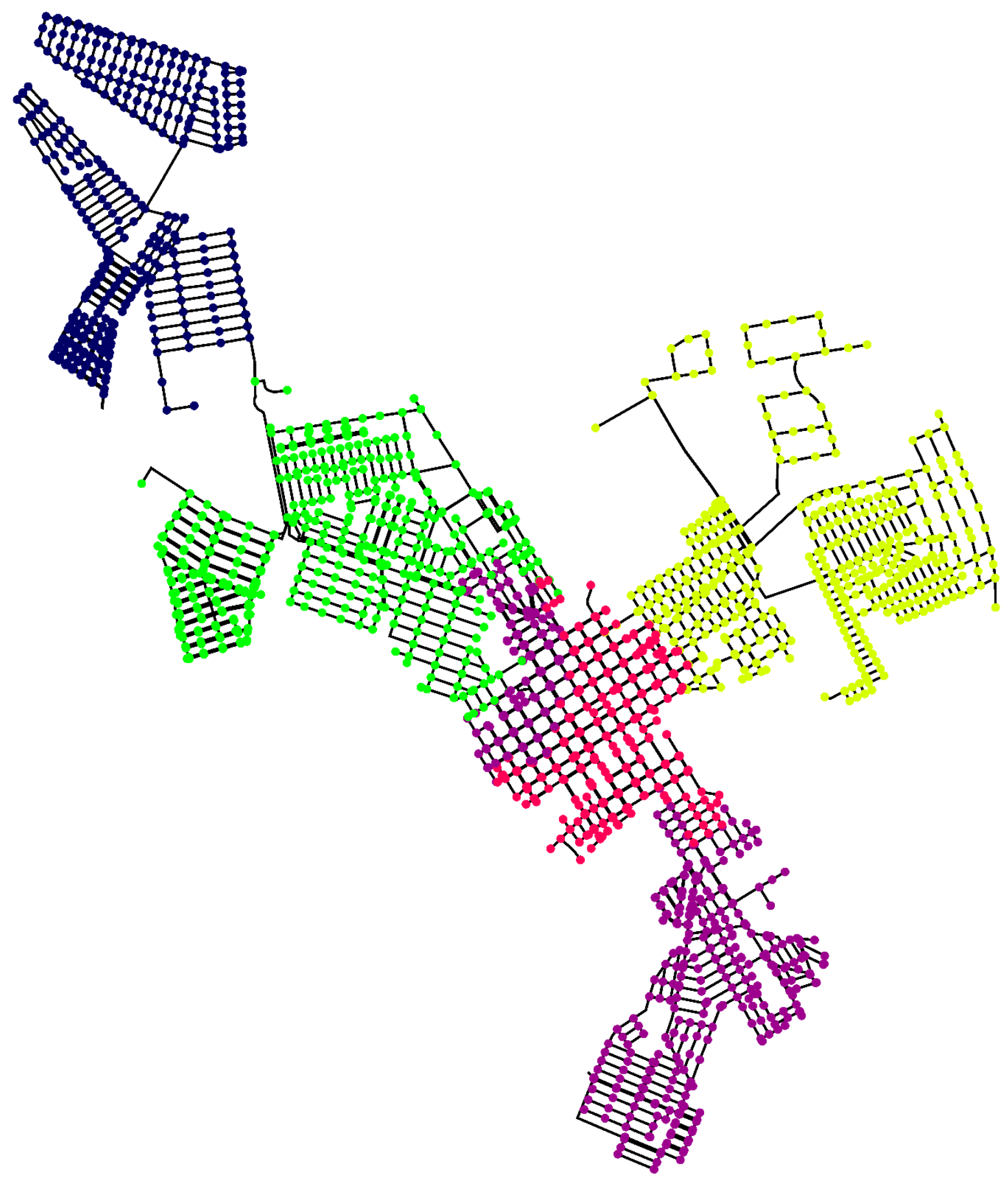

Fonte: Elaboração do Autor 
Figura 60Partição da rede de abastecimento de água de Pederneiras em 5 distritos, através do método ModulMax

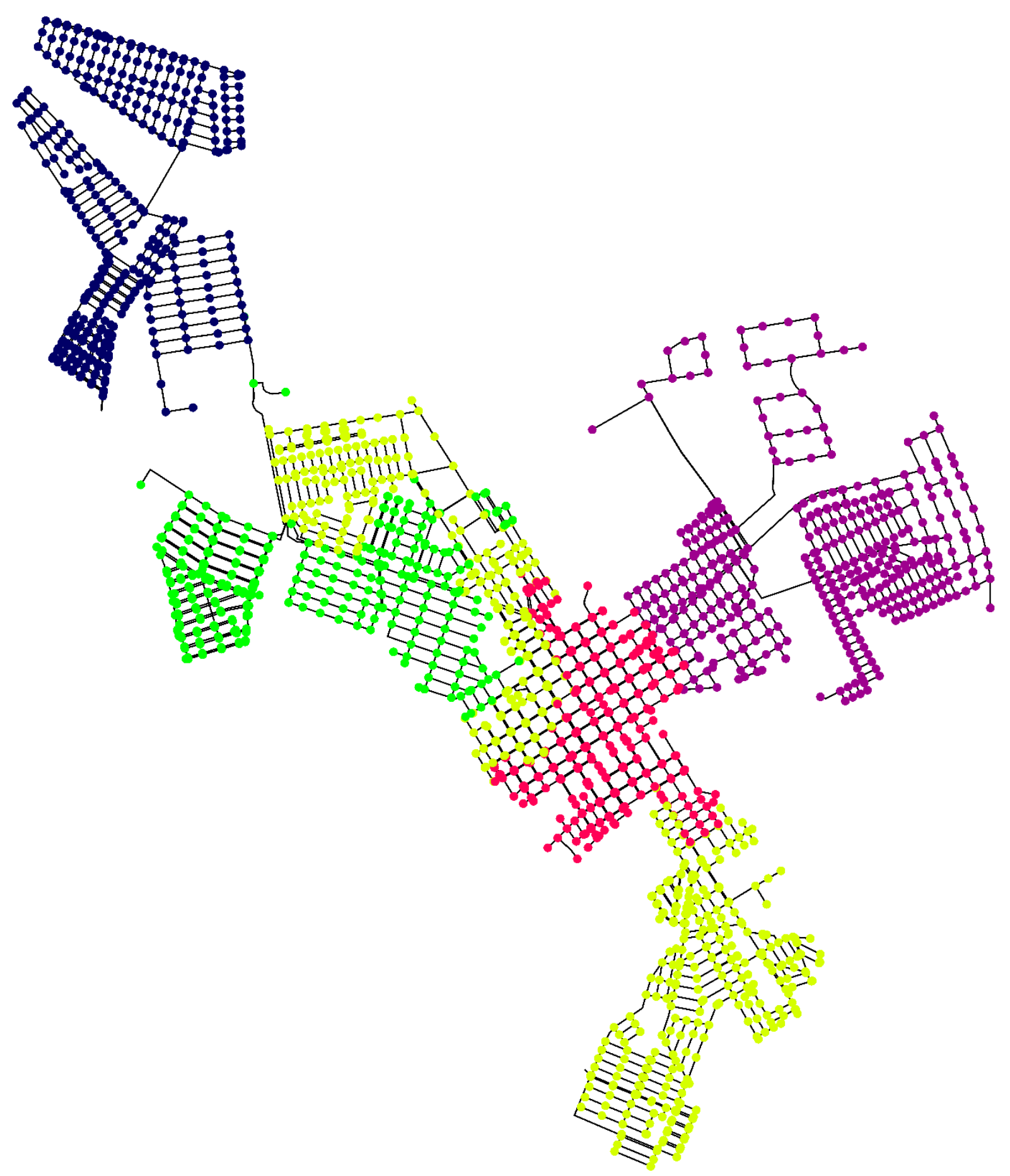

Fonte: Elaboração do Autor 
Figura 61 - Partição da rede de abastecimento de água de Pederneiras em 10 distritos, através do método METIS

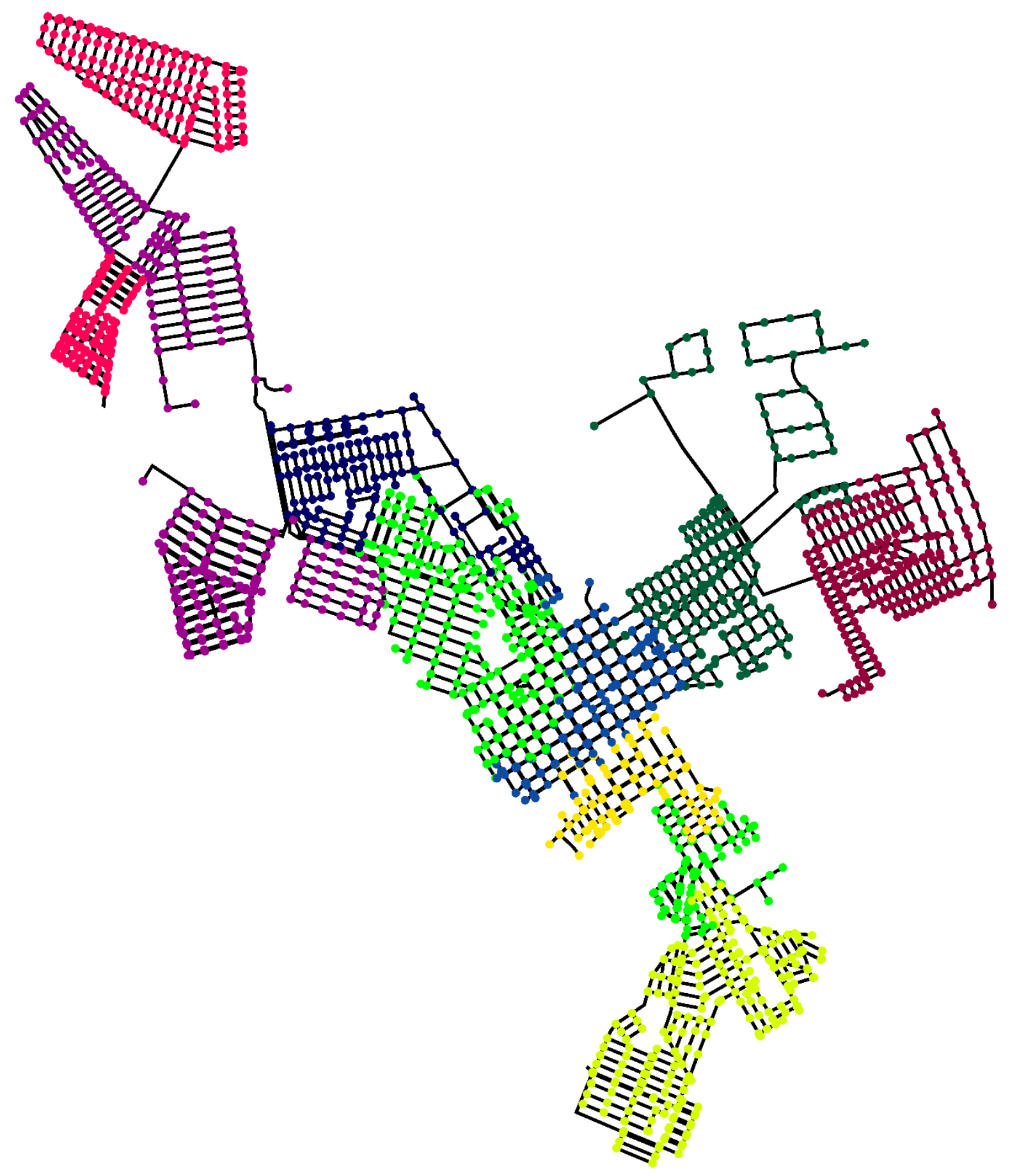

Fonte: Elaboração do Autor 
Figura 62 - Partição da rede de abastecimento de água de Pederneiras em 10 distritos, através do método ModulMax

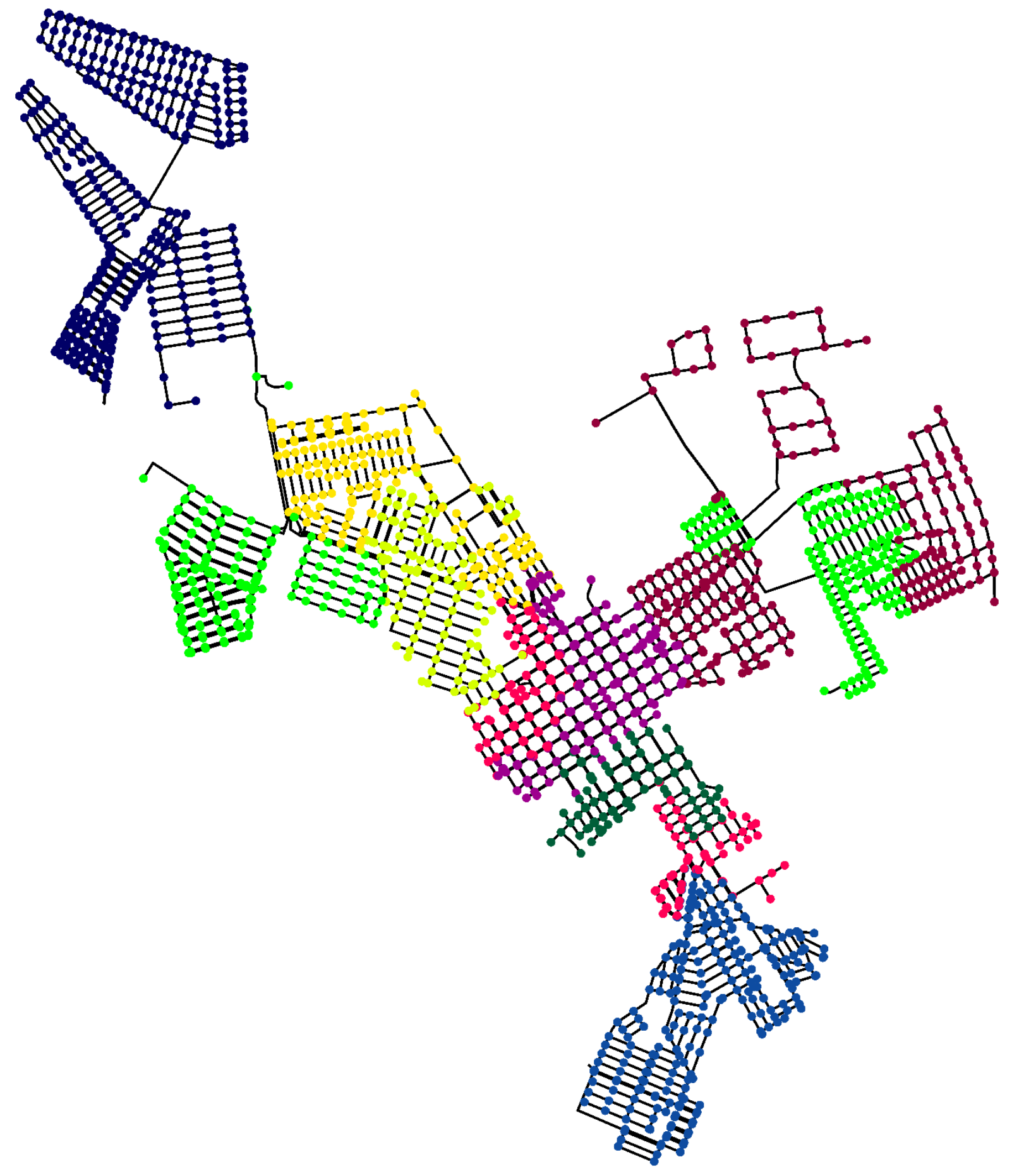

Fonte: Elaboração do Autor 
Figura 63 - Partição da rede de abastecimento de água de Pederneiras em 20 distritos, através do método METIS

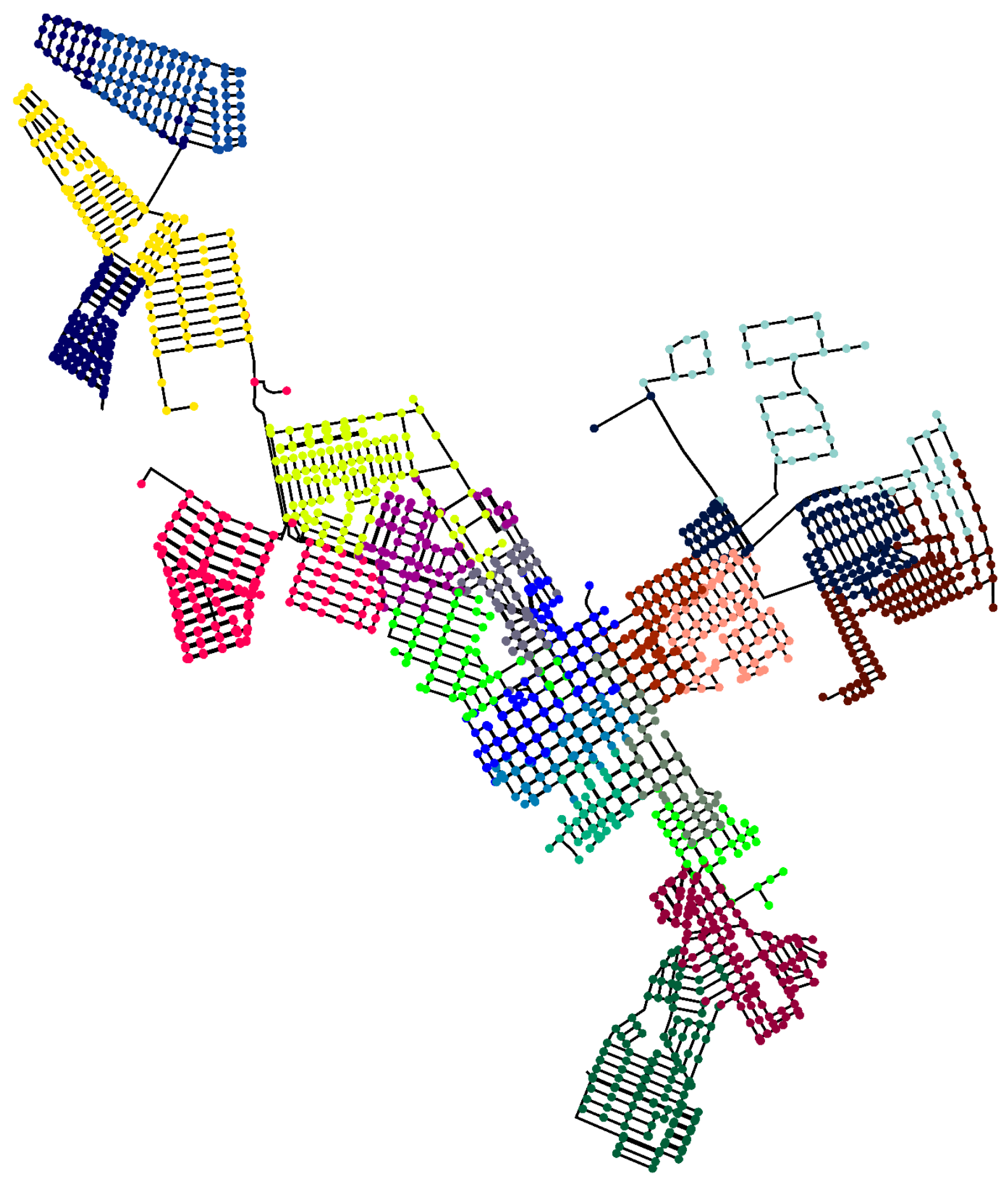

Fonte: Elaboração do Autor 
Figura 64 - Partição da rede de abastecimento de água de Pederneiras em 20 distritos, através do método ModulMax

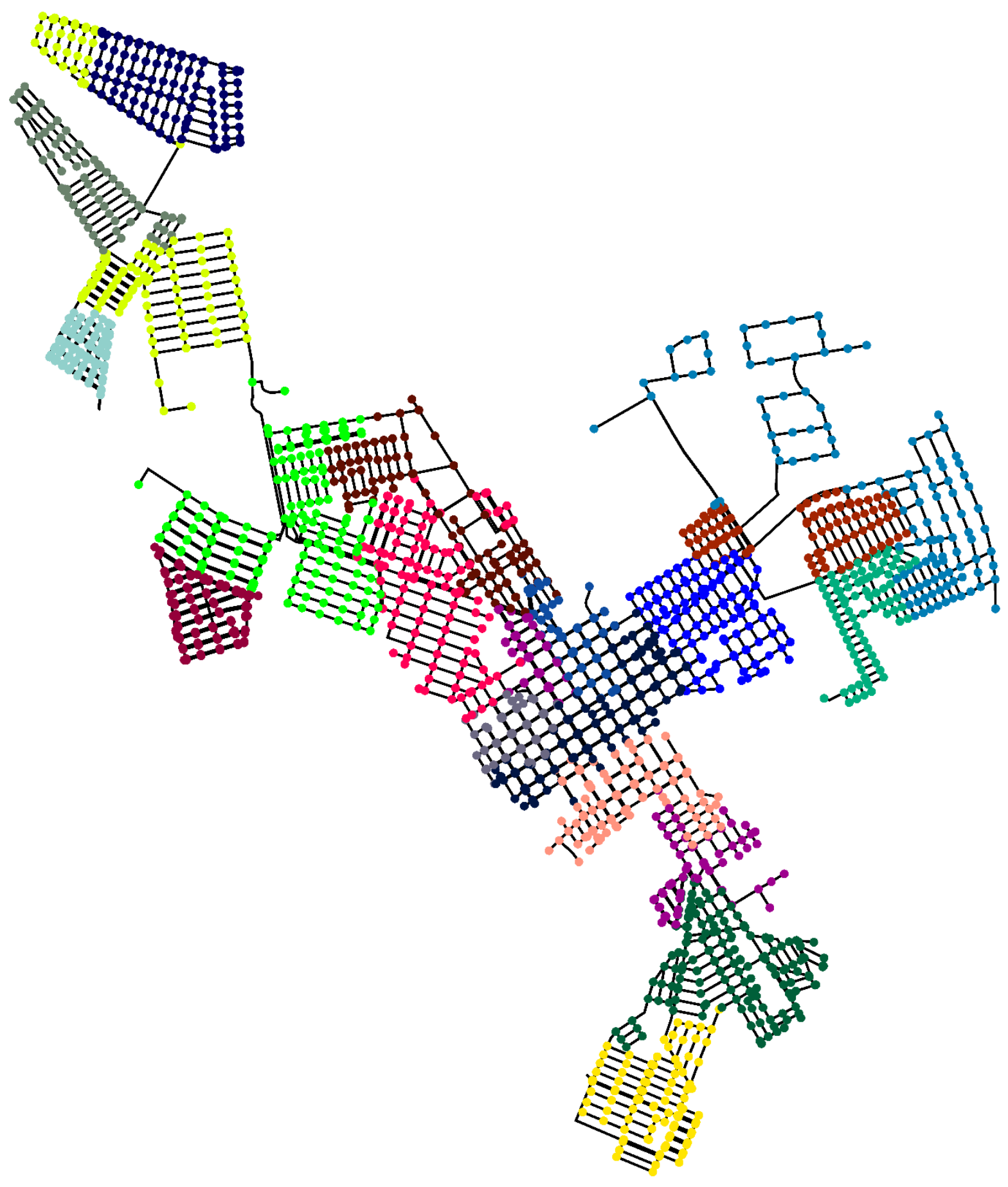

Fonte: Elaboração do Autor 
Figura 65 - Partição da rede de abastecimento de água de Pederneiras em 30 distritos, através do método METIS

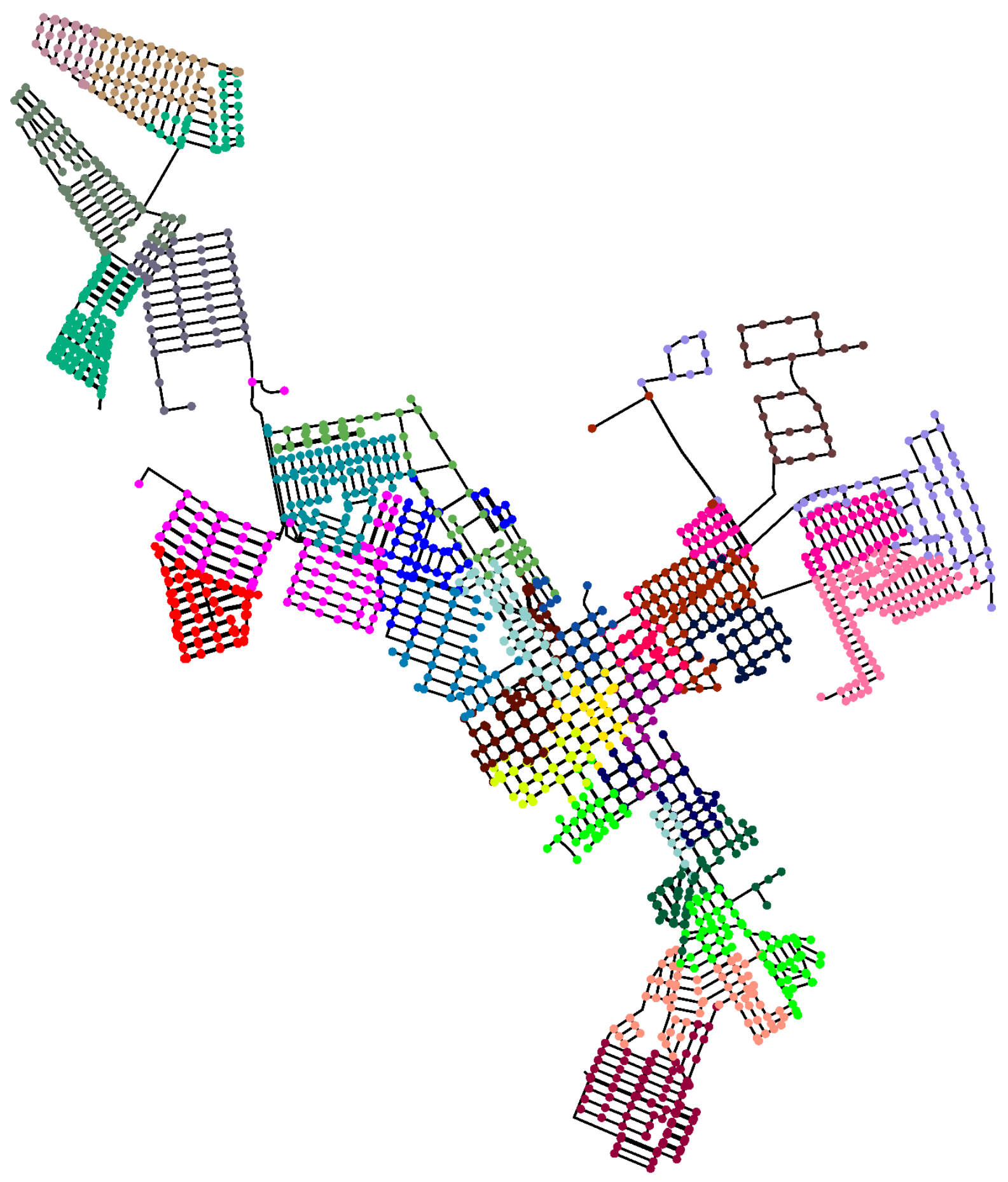

Fonte: Elaboração do Autor 
Figura 66 - Partição da rede de abastecimento de água de Pederneiras em 30 distritos, através do método ModulMax

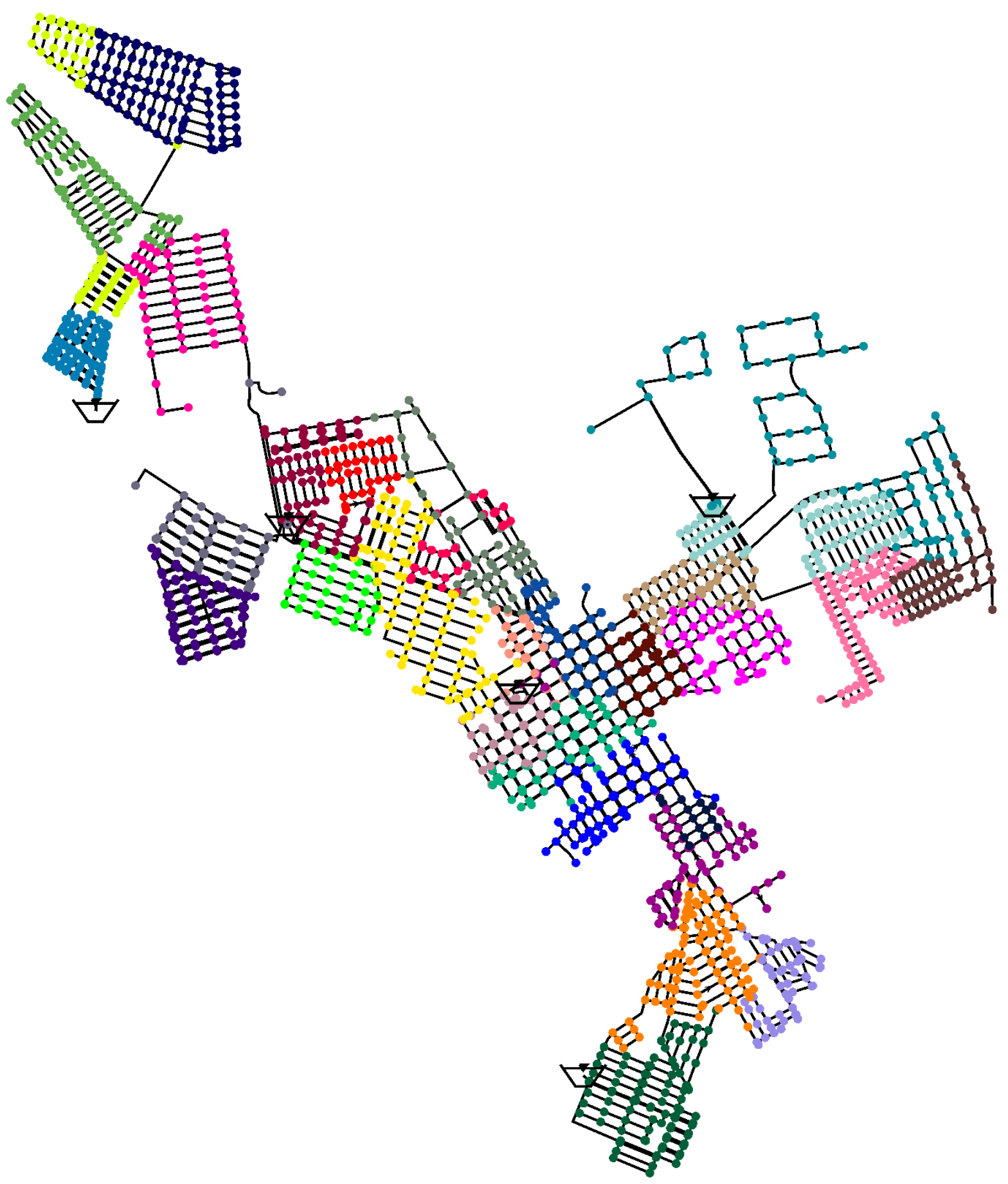

Fonte: Elaboração do Autor 
Figura 67 - Partição da rede de abastecimento de água de Pederneiras em 40 distritos, através do método METIS

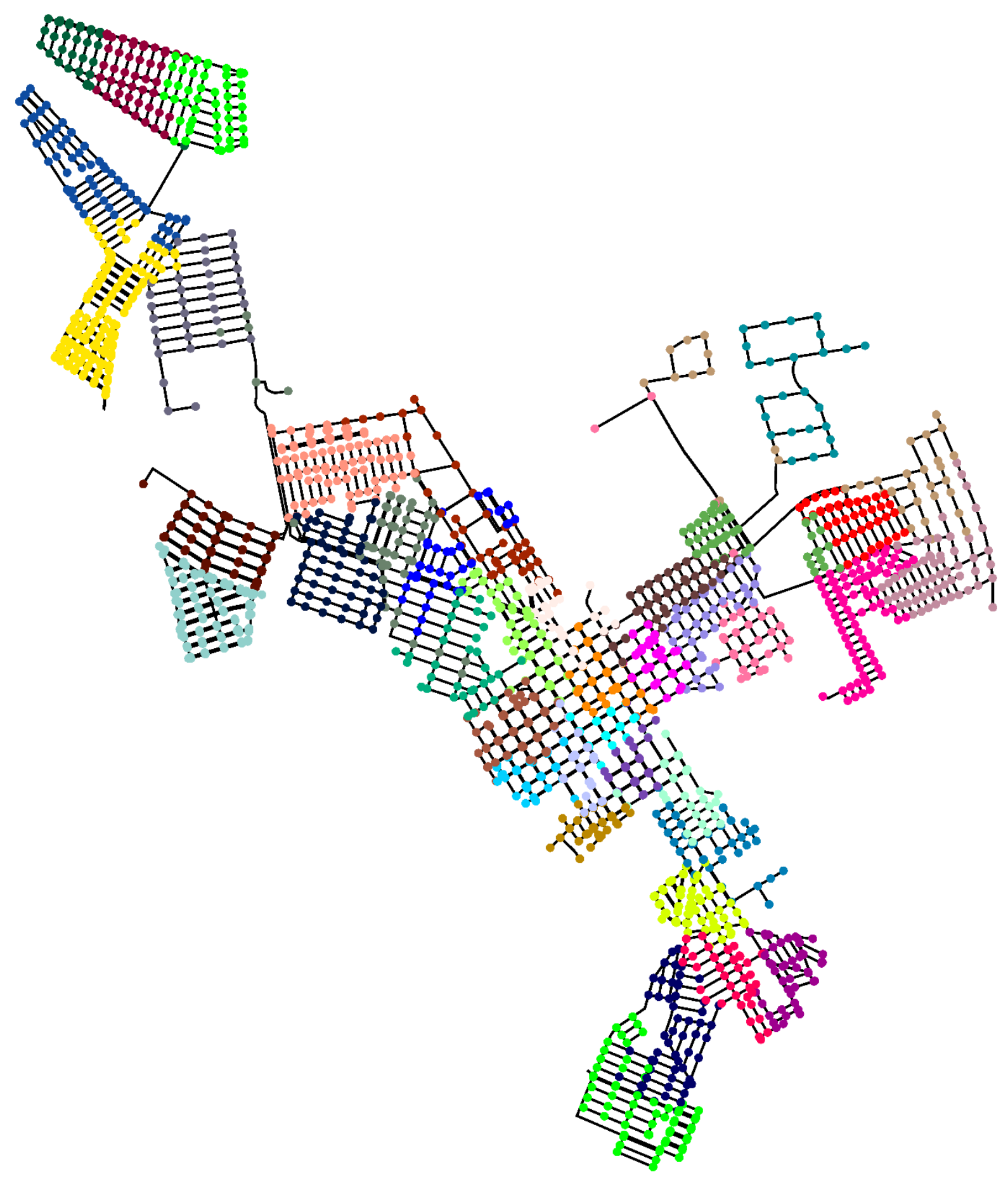

Fonte: Elaboração do Autor 
Figura 68 - Partição da rede de abastecimento de água de Pederneiras em 40 distritos, através do método ModulMax

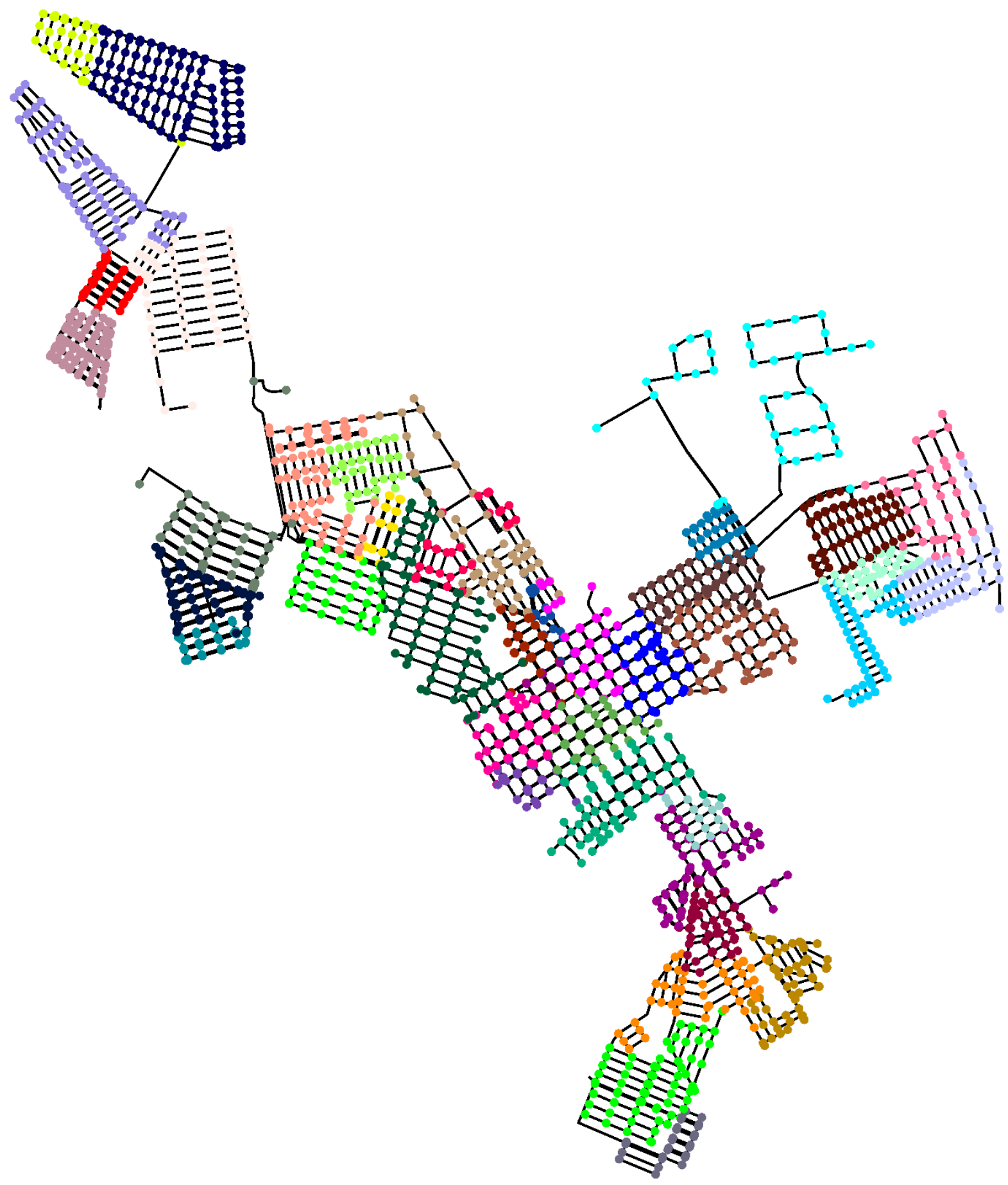

Fonte: Elaboração do Autor 
Figura 69 - Partição da rede de abastecimento de água de Pederneiras em 50 distritos, através do método METIS

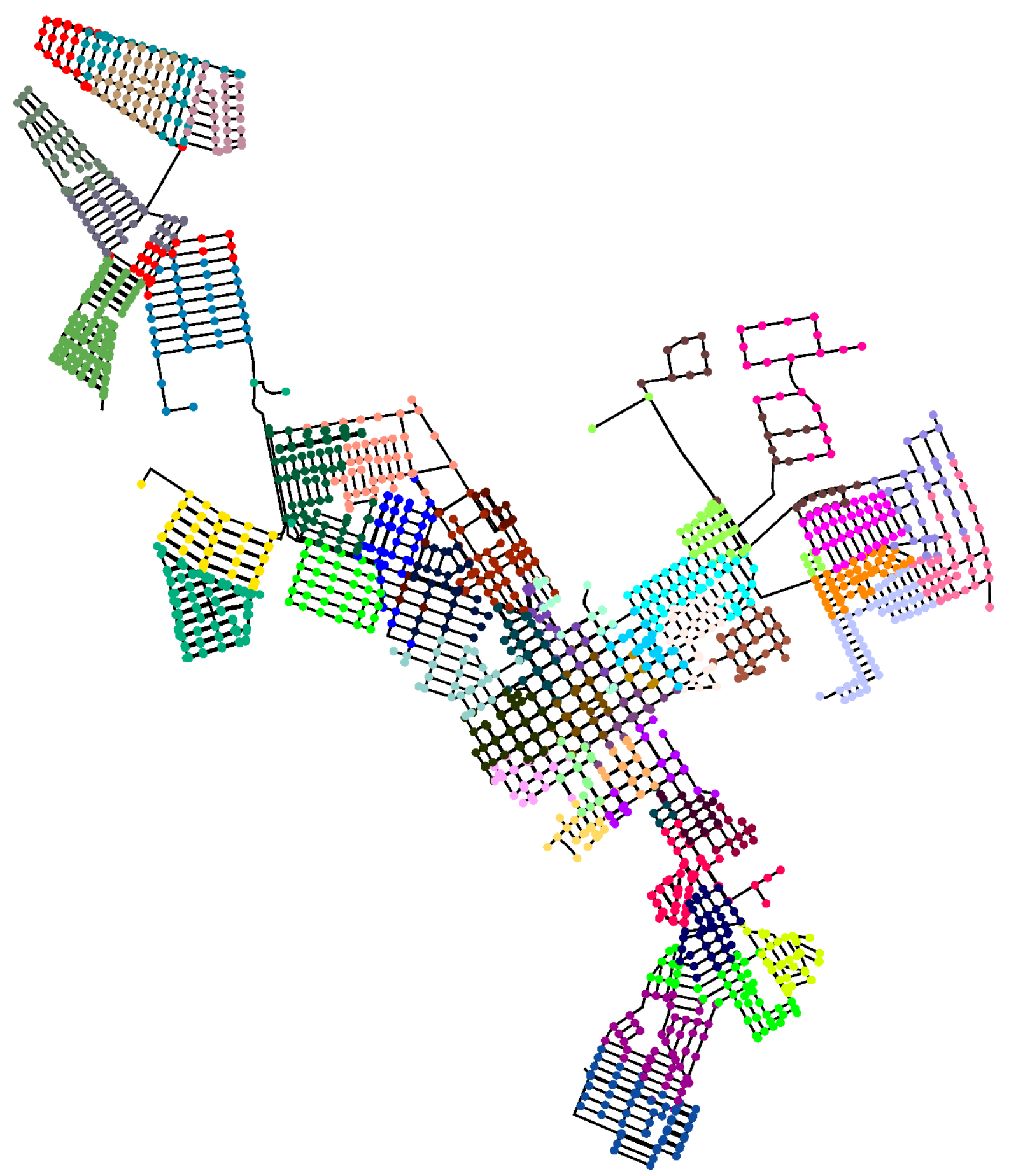

Fonte: Elaboração do Autor 
Figura 70 - Partição da rede de abastecimento de água de Pederneiras em 50 distritos, através do método ModulMax

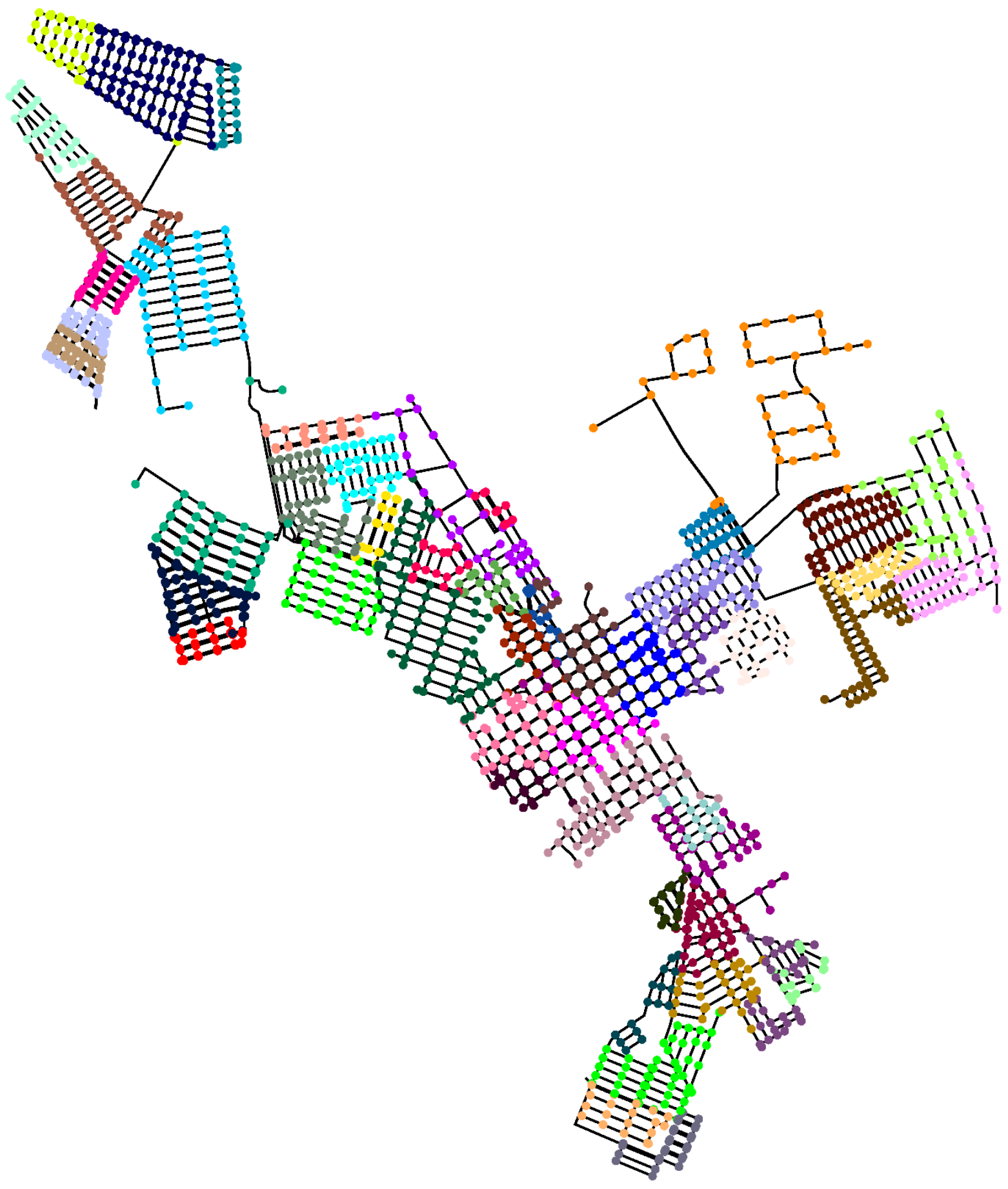

Fonte: Elaboração do Autor 
Figura 71 - Partição da rede de abastecimento de água de Pederneiras em 18 distritos, através do método METIS

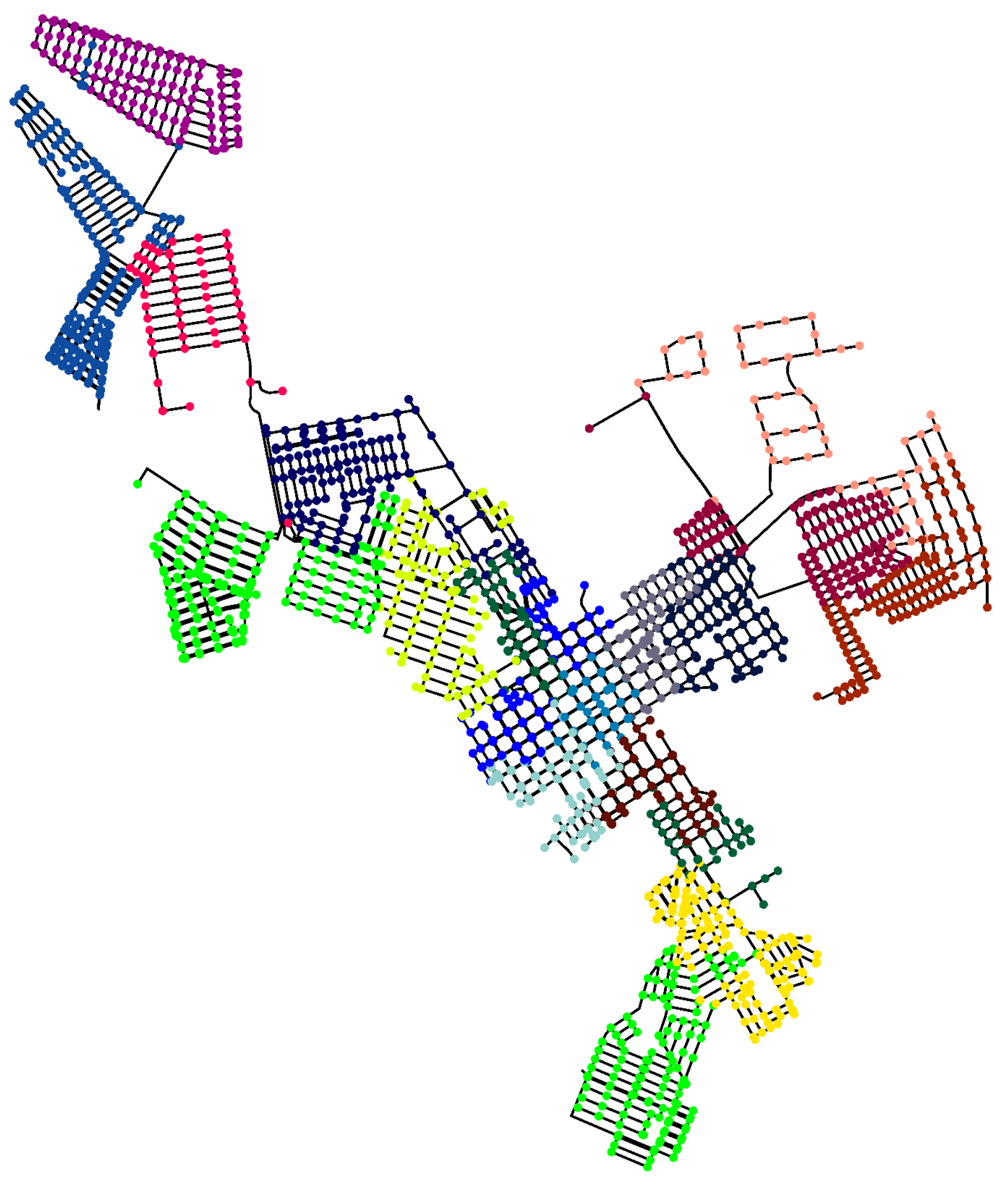

Fonte: Elaboração do Autor 
Figura 72 - Partição da rede de abastecimento de água de Pederneiras em 19 distritos, através do método METIS

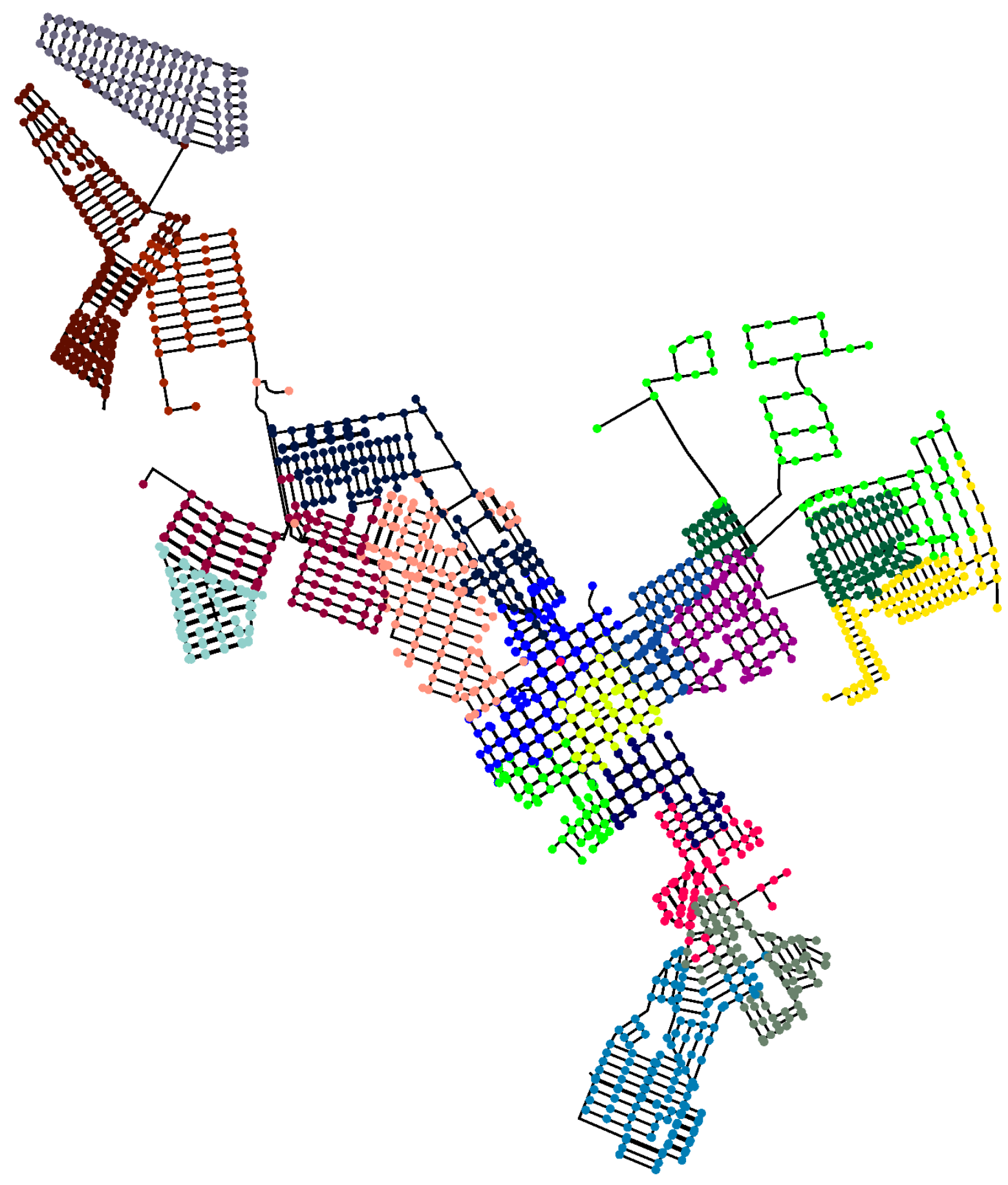

Fonte: Elaboração do Autor 
Figura 73 - Partição da rede de abastecimento de água de Pederneiras em 45 distritos, através do método METIS

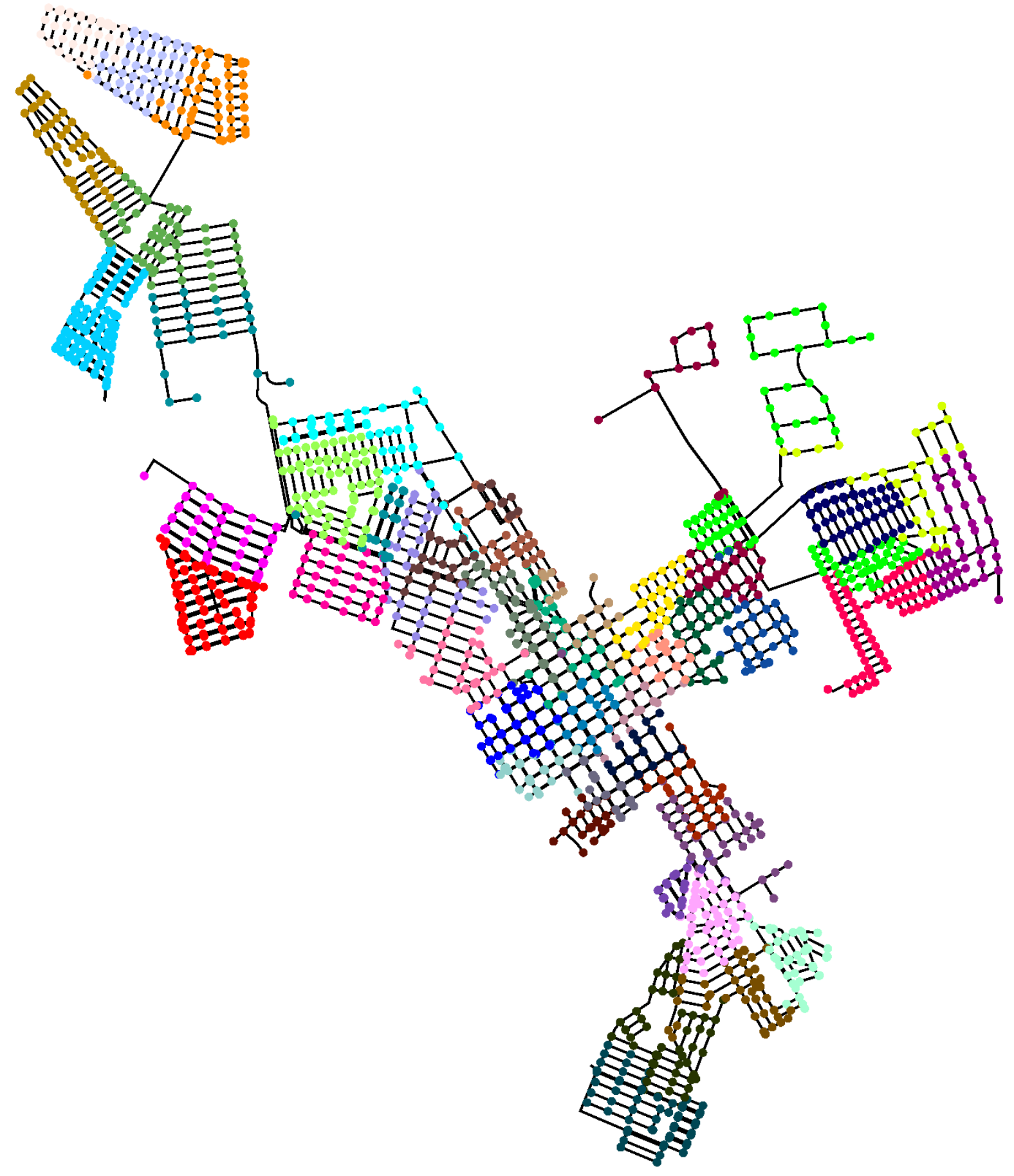

Fonte: Elaboração do Autor 
Figura 74 - Partição da rede de abastecimento de água de Pederneiras em 31 distritos, através do método ModulMax

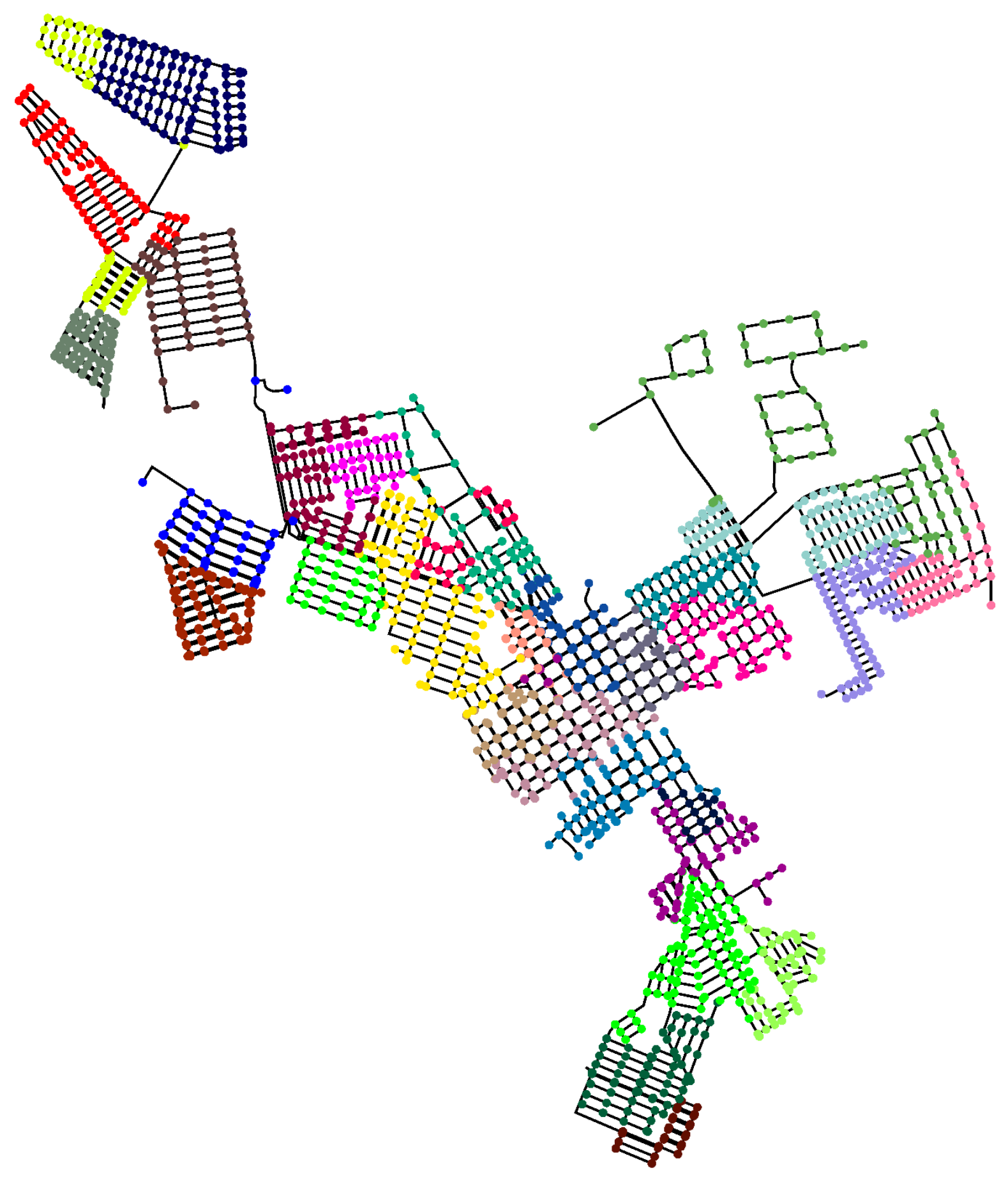

Fonte: Elaboração do Autor 
Figura 75 - Partição da rede de abastecimento de água de Pederneiras em 36 distritos, através do método ModulMax

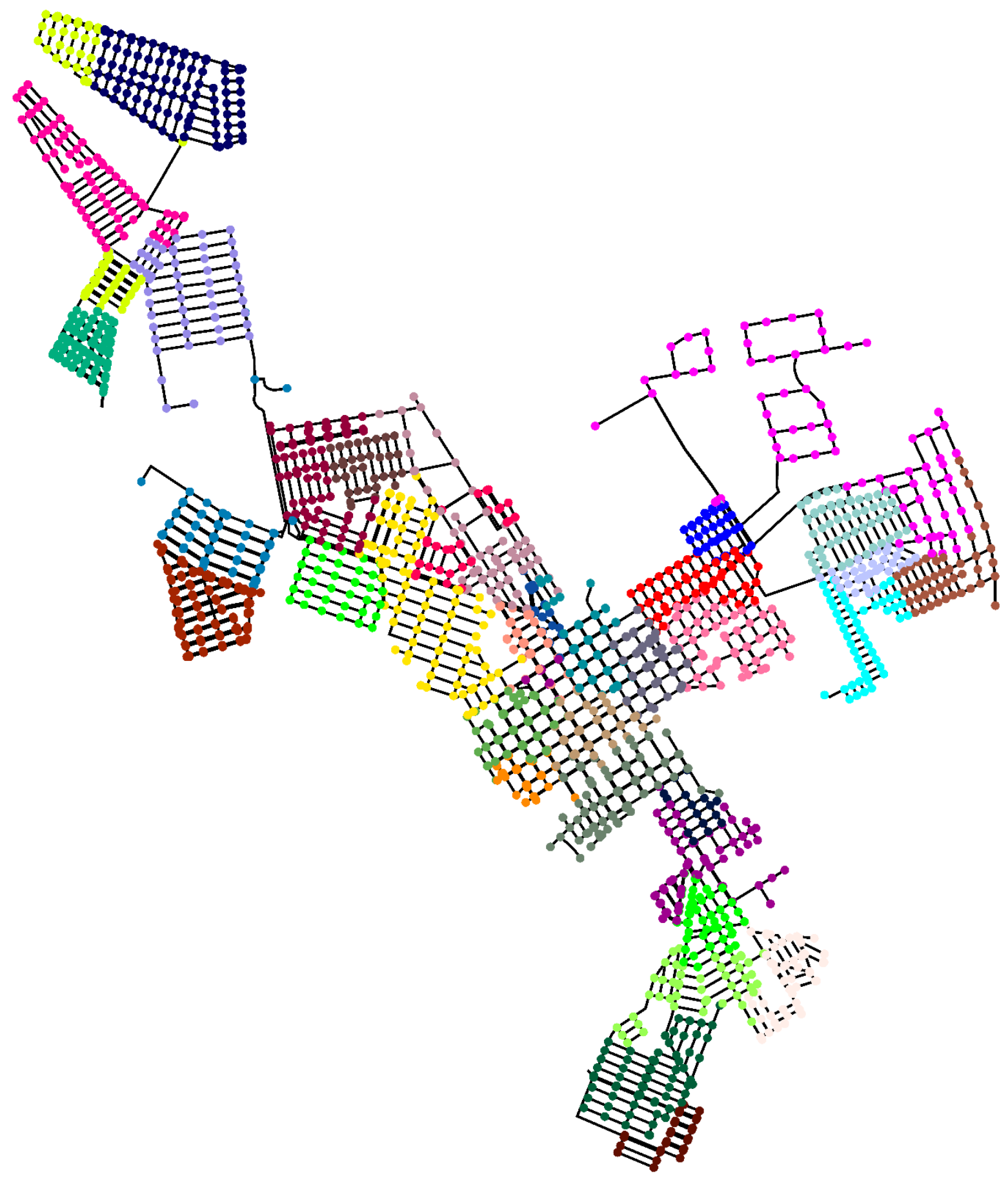

Fonte: Elaboração do Autor 
Figura 76 - Partição da rede de abastecimento de água de Pederneiras em 38 distritos, através do método ModulMax

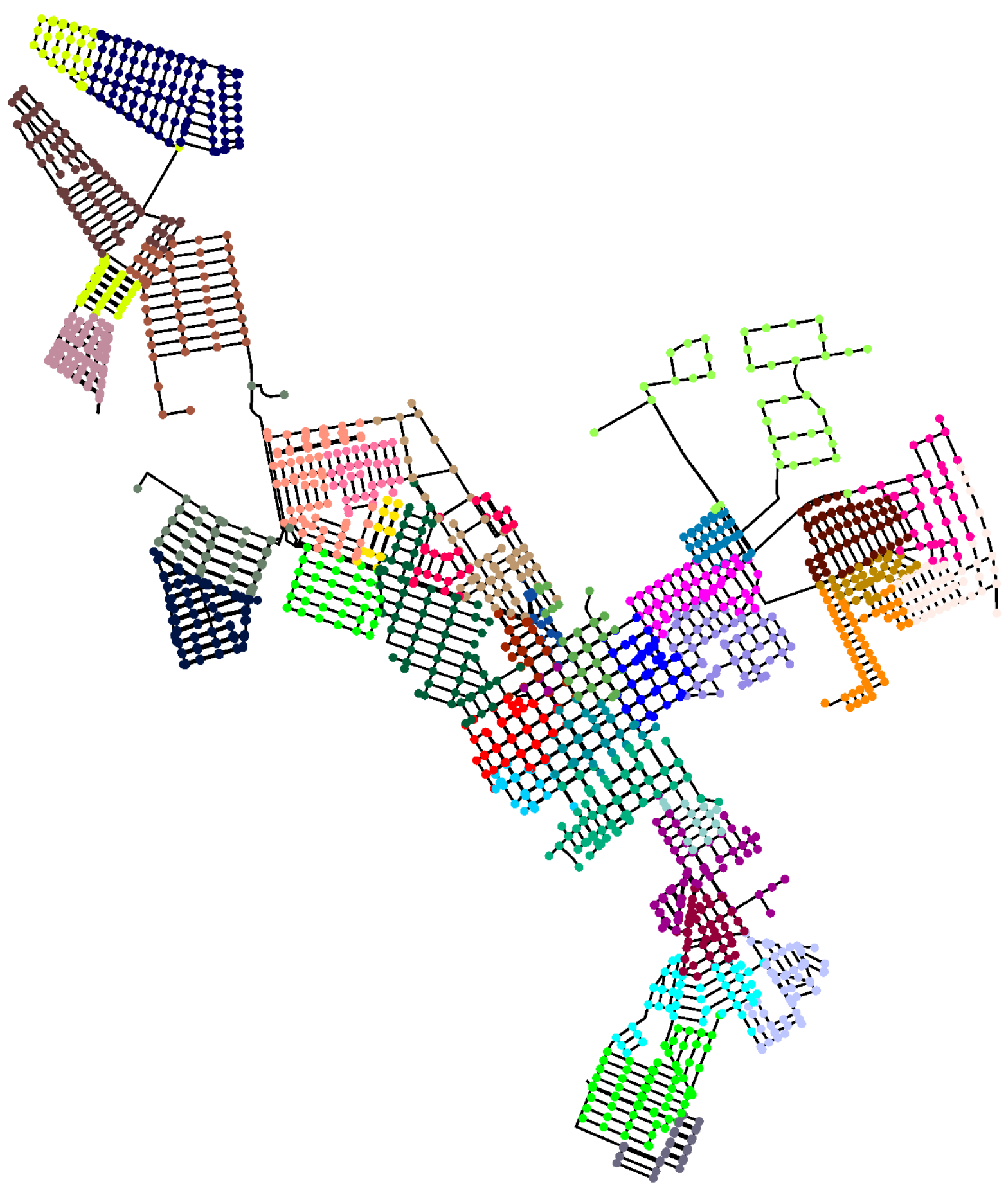

Fonte: Elaboração do Autor 
Figura 77 - Partição da rede de abastecimento de água de Pederneiras em 44 distritos, através do método ModulMax

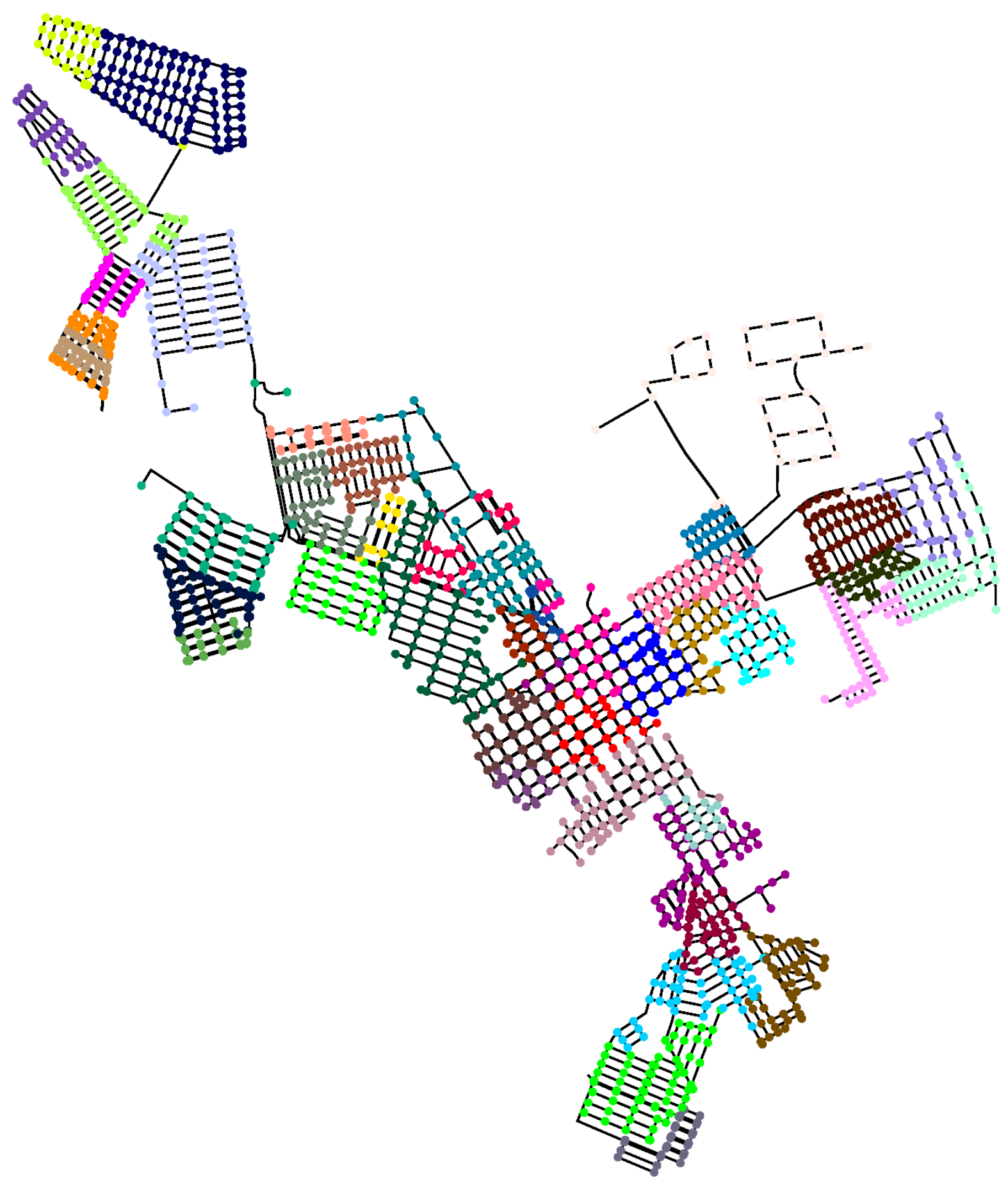

Fonte: Elaboração do Autor 
APÊNDICE E 
Figura 78 - Pressões na rede de abastecimento de água de Pederneiras às 13:00h após a partição proposta e inclusão de VRP's.

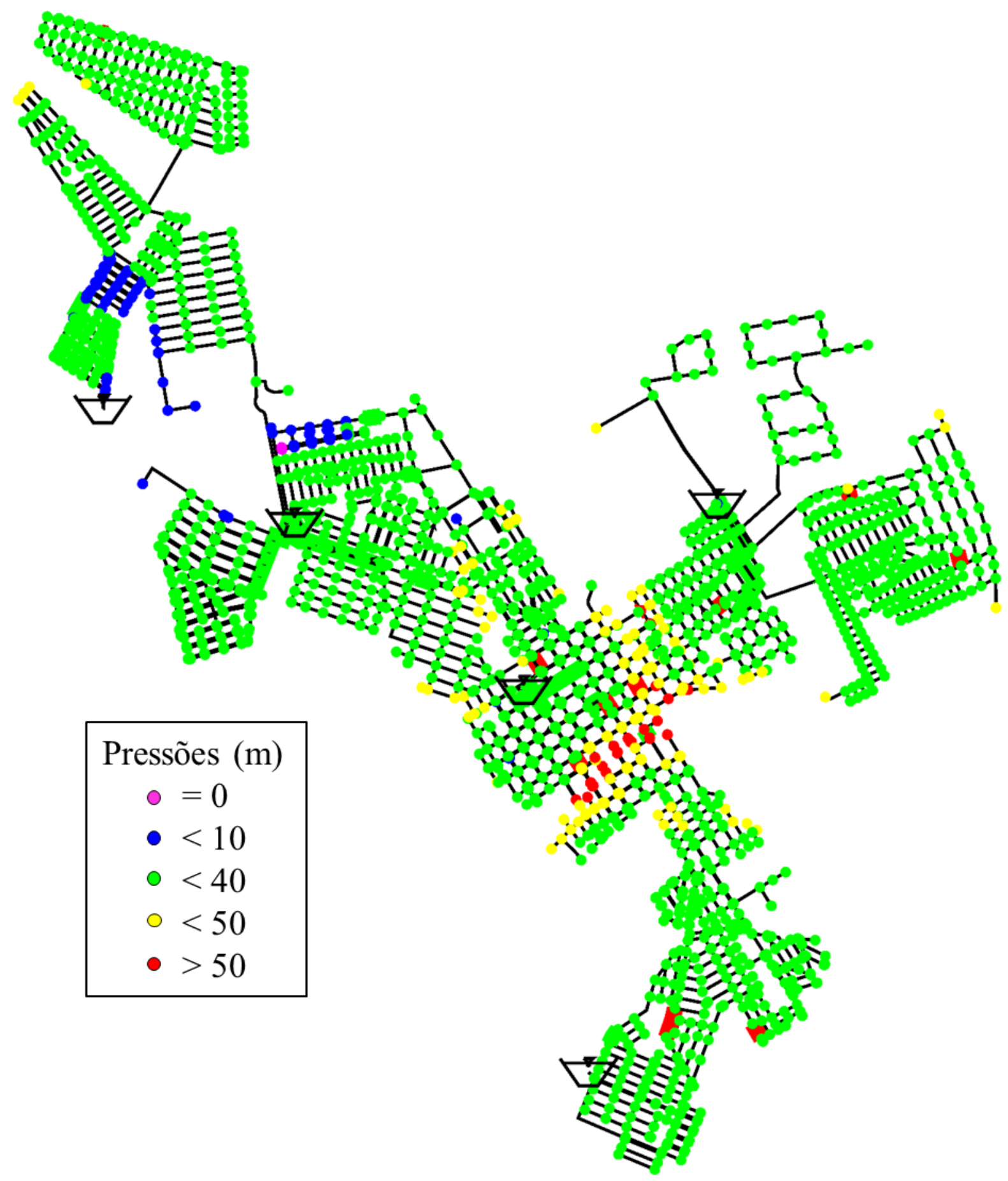


Figura 79 - Pressões na rede de abastecimento de água de Pederneiras às 13:00h antes da partição proposta e inclusão de VRP's.

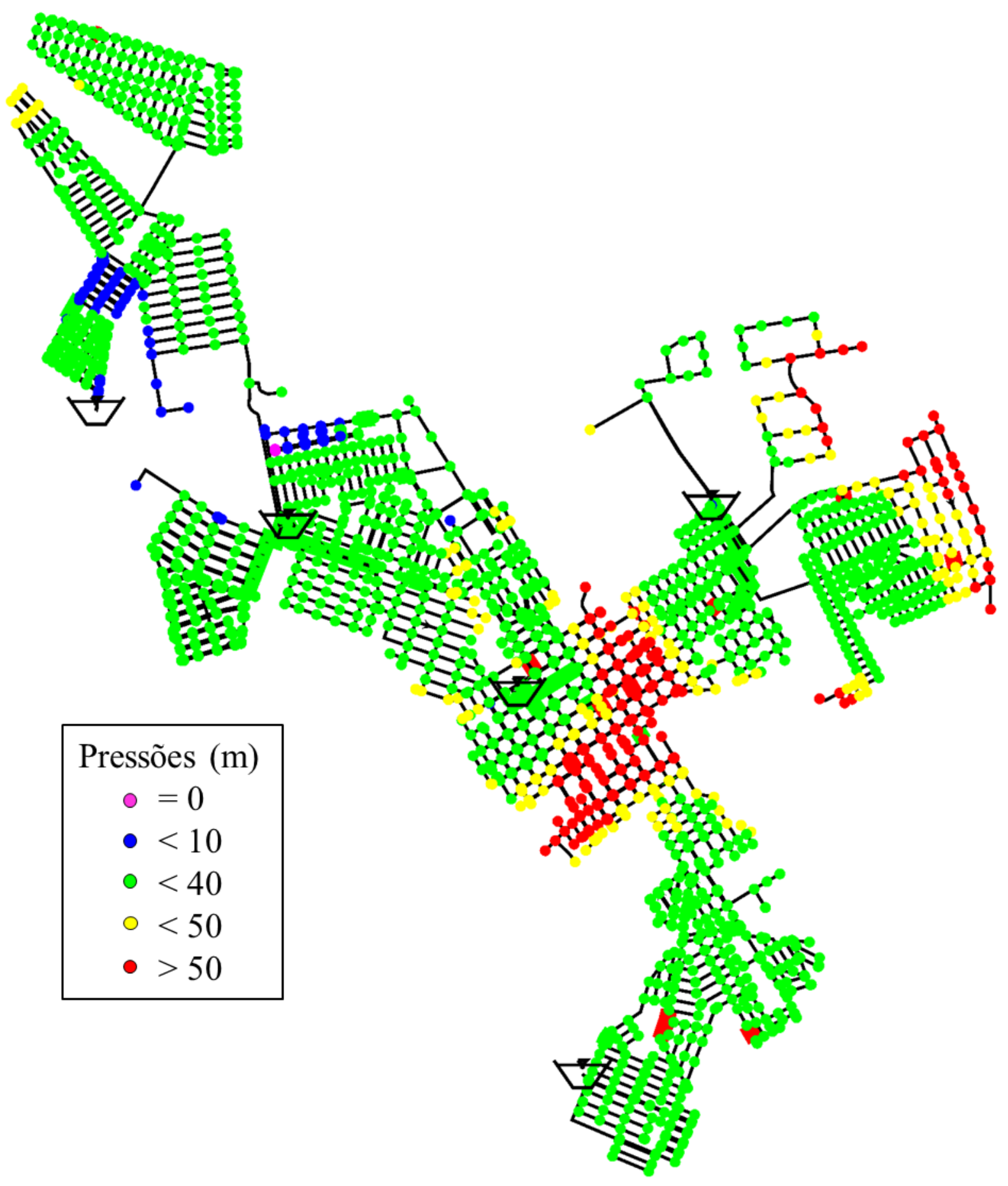

